\title{
Why Teachers Trust School Leaders
}

\section{by}

\section{Catherine Victoria Handford}

\author{
A thesis submitted in conformity with the requirements \\ for the degree of Doctor of Education \\ Graduate Department of Theory and Policy Studies in Education \\ Ontario Institute for Studies in Education \\ University of Toronto
}




\section{Why Teachers Trust School Leaders \\ Doctor of Education, 2011 \\ Victoria Handford \\ Department of Theory and Policy Studies in Education \\ University of Toronto \\ Abstract}

Research indicates trust in schools significantly relates to student achievement and trust in school leaders significantly relates to trust in schools. This study expands on the existing research by identifying behaviours principals display and teachers identify that correspond to antecedent conditions of trust, as identified in the research literature. Principal understandings are compared to teacher articulated thoughts in order to identify if shared understandings and interpretations of events are a component of trust in schools. Seventeen survey questions about trust were asked in 138 schools. Three high trust and three low trust schools were identified via deviation from the grand mean. Interview data related to a broad spectrum of school structures and daily events was gathered at the six identified schools from a randomly selected group of teachers and each school's principal. The interview data was coded using antecedent conditions of trust as the organizational units for analysis. Supporting previous research, this thesis finds teacher data identified the antecedent conditions that are described most frequently by teachers as being Competence, Consistency and Reliability, Openness and Respect. Principal data identified the antecedent conditions of trust as being similar, not identical. There are relevant differences described in elements within the antecedents between teachers and school leaders. Overall, the results confirm the findings of Bryk and Schneider and Tschannen-Moran, while adding detail to the understanding of what matters in trust when in-school educators reflect on issues of organizational life. 


\section{Acknowledgements}

Many people have supported me along my doctoral journey. While naming each and every person that has offered encouragement and conversation about the topic of trust is not possible, I have appreciated your willingness to engage with me and to support me. Individuals I want to be recognize for their role in detailed conversations, editing, and proofreading include: Dr. Darrin Griffiths, Patti Haskell, Dr. David Johnson Sue Leeder, Dr. John Nash, Michael Saver, Deb Warner, Rev. Dr. David Winsor, Betty Ann Wolder and the Honourable Justice Theo Wolder.

My thesis committee offered detailed critique which refined my thinking and helped me better articulate the topic. Thank you to Dr. Steve Anderson, Dr. Scott Bauer and Dr. Blair Mascall.

My thesis supervisor, Dr. Ken Leithwood, has listened far more than he ever imagined would be necessary, both in email and in person. His guidance, his priority setting, his refinement of thinking and his encouragement to "say it but never overstate it" were invaluable. Thank you, Ken.

Finally, thank you to my family. My sons, Andrew, Eric and Colin, have lived this journey. You incorporated this thesis into every aspect of your lives: hockey games, swim meets, improv events, concerts and school events, vacation and Christmas morning. I am fortunate to have such wonderful young men (children, in my heart) in my life. And to my husband, Dan: you made it all work. Thank you. 


\section{Table of Contents}

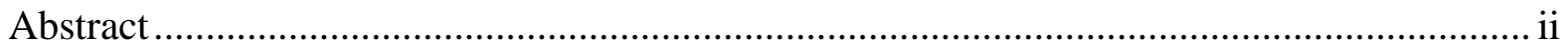

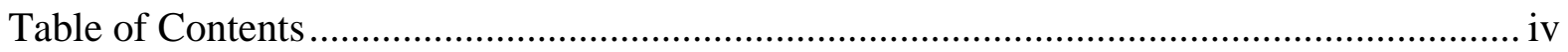

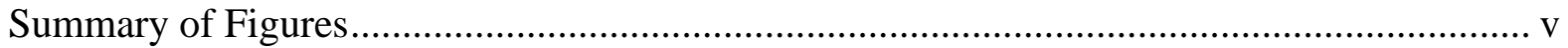

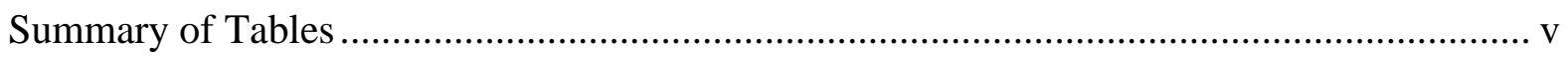

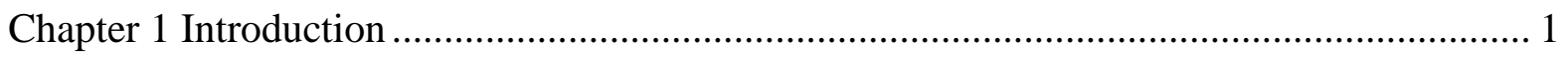

Chapter 2 Review of Research Literature and Framework.............................................. 12

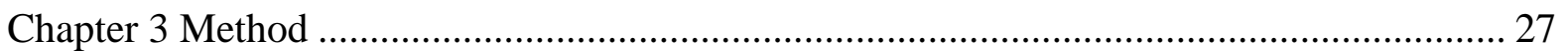

Chapter 4 Results: Benevolence, Caring and Competence............................................... 43

Chapter 5 Results: Consistency and Reliability, Fairness, Forgiveness, Honesty ................. 86

Chapter 6 Results: Integrity, Loyalty, Openness ......................................................... 120

Chapter 7 Results: Personal Regard for Others, Respect, Vulnerability ............................ 150

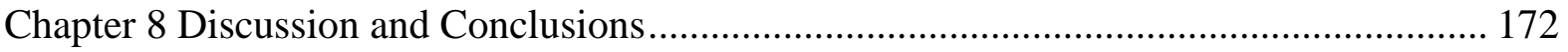

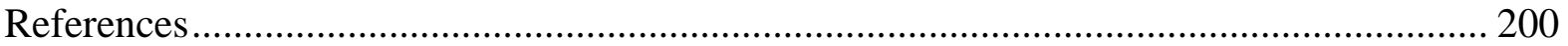

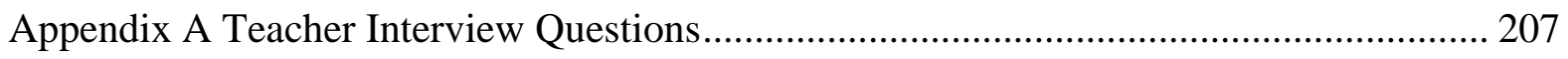

Appendix B Principal Interview Questions ............................................................... 208

Appendix C Data Verification: Comparison................................................................... 209 


\section{Summary of Figures}

Figure 1: A summary of antecedents of trust and their sources........................................ 14

Figure 2: A hierarchy of need as school leaders establish trust with teachers..................... 193

\section{Summary of Tables}

Table 1 Characteristics of research about antecedents giving rise to perceptions of leader

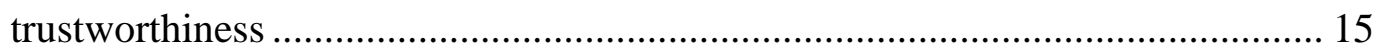

Table 2 Teacher Trust-in Leader-Score ................................................................... 29

Table 3 School Information Sometimes Associated with Trust in Schools..................... 41

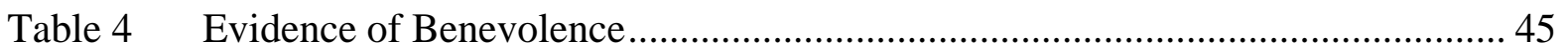

Table 5 Summary Comparison of High Trust and Low Trust: Benevolence .................. 54

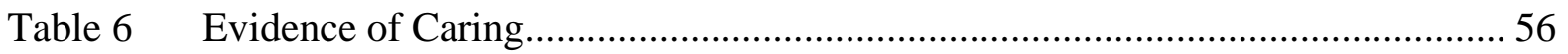

Table 7 Summary Comparison of High Trust and Low Trust: Caring .......................... 60

Table 8 Evidence of Competence .......................................................................... 61

Table 9 Summary Comparison of High Trust and Low Trust: Competence ................... 84

Table 10 Evidence of Consistency and Reliability .................................................. 87

Table 11 Summary Comparison of High Trust and Low Trust: Consistency/ Reliability 100

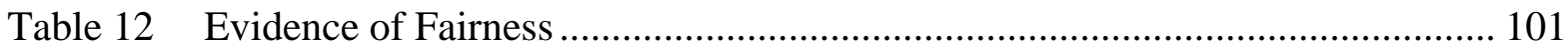

Table 13 Summary Comparison of High Trust and Low Trust: Fairness....................... 109

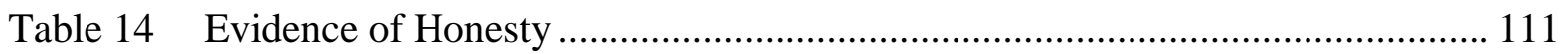

Table 15 Summary Comparison of High Trust and Low Trust: Honesty....................... 119

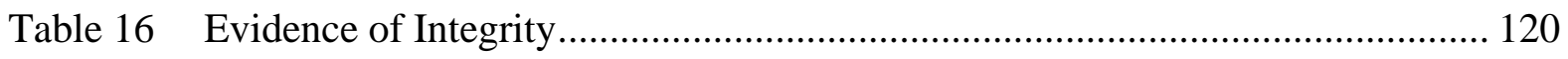

Table 17 Summary Comparison of High Trust and Low Trust: Integrity ...................... 128

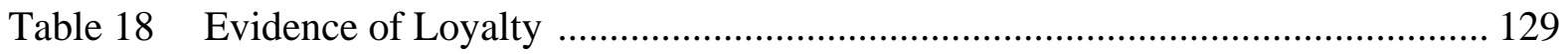

Table 19 Summary Comparison of High Trust and Low Trust: Loyalty ....................... 135

Table 20 Evidence of Openness .................................................................................. 136

Table 21 Summary Comparison of High Trust and Low Trust: Openness ..................... 149

Table 22 Evidence of Personal Regard for Others .................................................... 151

Table 23 Summary Comparison of High/Low Trust: Personal Regard for Others .......... 156

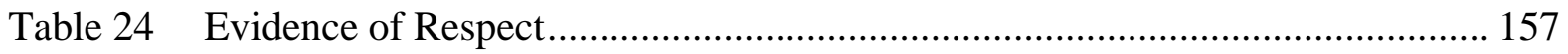


Table 25 Summary Comparison of High Trust and Low Trust: Respect ...................... 165

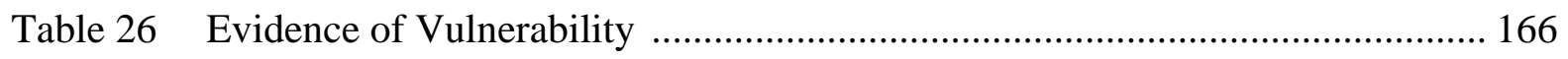

Table 27 Summary Comparison of High Trust and Low Trust: Vulnerability................ 171

Table 28 Summary Comparison of Overall Totals of Teacher Thought Units and Antecedents of Trust ............................................................................. 173

Table 29 Summary Comparison of Overall Totals of Principal Thought Units and

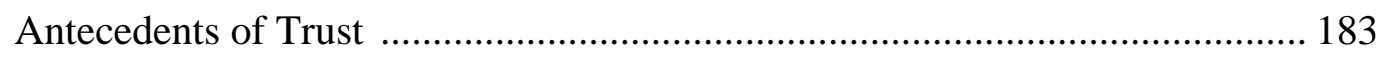

Table 30 Side by Side, All Teachers, All Principals .................................................. 189

Table 31 Comparison of Schools One and Six Totals of Teacher Thought Units ........... 191 


\section{Dedication}

To my mother, Frances Mark Handford, who instilled in me a love of learning and an understanding that perseverance is never optional. It's all in the living.

To Dr. Carson Mark, my uncle, a theoretical physicist in New Mexico, who displayed a love of learning, of achievement, of life - from Suwannee River to nuclear non-proliferation. He was never definitive about what was most significant. It's all in the living.

To Dr. Clifford Madsen, a professor at Florida State University, who pushed and pushed and pushed. And finally, I believed. It's all in the living. 


\section{Chapter 1 Introduction}

The overriding goal of this study is to determine what accounts for the degree of trust that teachers have in their principals.

In particular, the study will seek to answer the following questions:

1. To what extent do teachers identify influences on their trust in principals when they are engaged in conversation about their school and educational practices;

2. Which elements of leader trust do teachers identify most frequently and what leader behaviours do they associate with the elements; and

3. To what extent do principals and teachers hold similar views on the sources (or antecedents) of trust in principals?

\section{Background}

\section{The meaning of trust}

Definitions of trust vary and the research literature struggles to define it. The word trust is derived from the German word trost, a word that suggests comfort. Synonyms listed include certainty, belief and faith, suggesting instinctive, unquestioning belief, and reliance upon something, as well as an assurance of victory (Random House Dictionary, 1987, p. 2031). The assurance of victory, if, in fact, people somehow determine that to trust means they will in one form or another "win," is the heart of the problem with trust. Outside of sports or the awarding of contracts, people rarely experience pure wins, but because trust is partly defined by winning, distrust, in the face of "losing," is easily established. Trust has been defined as the “accepted vulnerability to another's possible but not expected ill will” (Baier, 1994, p. 99). Shaw defines trust as "a belief that those on whom we depend will meet our expectations of them” (1997, p. 21).

Hosmer defines trust as "the reliance ... on a voluntarily accepted duty on the part of another ... to recognize and protect the exchange” (1995, p. 393). Hosmer further views trust as “one party’s optimistic expectation of the behavior of another when the party must make a decision about how to act under conditions of vulnerability and dependence” (Ellis, Shockley, \& Zabalek, 2001, p. 383). Similar definitions include "the willingness of a party to be vulnerable to the actions of another party based on the expectation that the other party will perform an action important to the trustor, irrespective of the ability to monitor or control that 
other party” (Mayer, Davis and Schoorman, 1995, p. 712) and “confident positive expectations regarding another's conduct” (Lewicki, McAllister and Bies, 1998, p. 439).

Robinson integrates several authors' definitions and defines trust in terms of what one person's responsibilities are to the one who is trusting, saying trust is

one's expectations or beliefs about the likelihood that another's future actions will be beneficial, or at least not detrimental, to one's interests ... As a social construct, trust lies at the heart of relationships and contracts, influencing each party's behaviour toward the other ... as a general positive attitude toward another social entity, trust acts as a guideline, influencing one's interpretation of social behaviours within a relationship (Robinson, 1996, p. 576).

Luhmann states

Trust, then, is the generalized expectation that the other will handle his freedom, his disturbing potential for diverse action, in keeping with his personality - or, rather, in keeping with the personality which he has presented and made socially visible. He who stands by what he has allowed to be known about himself, whether consciously or unconsciously, is worthy of trust” (Luhmann, 1979, p.39).

Perhaps Gambetta provides the simplest definition. He states “trust is the individual's belief that the subject of trust will behave in a favorable manner to the individual, or at least in a manner that will not be harmful to the individual” (1988, p.238).

\section{The Roots of Trust}

Trust is complex. Flores and Solomon say "Trust is structurally a lot like love, even if it is also (obviously) different” (Flores et al., 1998, p. 217). Most of us acknowledge a physiological component to falling in love, even if it does not explain the entire love experience. Some evidence shows that trusting someone may involve, in part, a component of a physiological response. Perhaps there is something that happens that begins the process of evolving a trusting relationship. "The trust hormone, it seems, is also the mind-reading hormone... a sniff of oxytocin, which underpins social attachment among animals, also turns out to improve men's ability to read other people’s emotions” (Globe and Mail, March 28, 2007). Kosfeld et al. demonstrate neuropeptides, of which oxytocin is one, administered through a nasal spray, caused an increase in social attachment and affiliation, which in turn increased the benefits resulting from social interaction. They show "oxytocin specifically affects an individual's willingness to accept social risks arising through interpersonal interactions. These results concur with animal research suggesting an essential role for oxytocin as a biological basis of prosocial approach behaviour.” (2005, p. 673). While there 
may very well be a physiological component to trust, most of us would find this an unlikely expression of the total experience of trust.

\section{Why Trust is Important in Schools}

Trust in leaders is important in schools for a number of reasons. First, high trust among school staff, including trust in the leader, affects test scores. Research indicates that schools with a high-trust factor are three times as likely to increase test scores as schools that do not have high-trust ratios (Bryk, Schneider, 2002, p.111). Specifically, Bryk and Schneider found that schools with high relational trust improved reading scores by 8 percent and math scores by 20 percent over five years (ibid, p. 40).

Second, teacher morale has been strongly associated with higher student achievement (Black, 2001). Hoy et al. indicate that morale, “the sense of trust, confidence, enthusiasm and friendliness among teachers," is one of the seven features of a "healthy" school (1992, p. 183).

Third, trust is an "enabler of change.” Deborah Meier, a principal and researcher, who rebuilt the environment at a middle school on the brink of closure in Harlem, noted the importance of trust in her work. Her efforts included the typical "turn-around” targets, including setting high academic performance targets, engaging the community in the school life, making sure students and families see themselves reflected in the school curriculum and environment, developing specific instructional strategies that are employed throughout the school. Meier believes that building trust among everyone in the school was a central component of the success of her school in Harlem (2002).

Additionally, the standard to which teachers are accountable is set extremely high, and permeates their lives, not just their jobs. While it may not be reasonable, it is not then surprising that teachers expect school leaders, who have been selected and appointed, at least in part because of their exemplary practice as teachers, to be role models of trust for all to whom they are responsible and accountable. This expectation can be the beginning of great and productive working relationships or the disillusionment of scores of hard-working teachers. The expectation, the regulation, and the demands placed on all the stakeholders create vulnerability, and, therefore, the need for trust.

Chester Barnard, an American utilities executive, who was not an academic, wrote about topics such as authority based on his experiences as an employee with American Telephone and Telegraph from 1909, and as chief executive officer at New Jersey Bell 
Telephone Company from 1927. He, identified authority as a quality that was determined by what followers were willing to grant rather than by rank in an organization. He wrote that authority rested on the acceptance or consent of subordinates and is a relationship (Smith, 1975, p. 22).

Barnard knew his thoughts ran counter to those of others with similar experience and were "contradictory to legalistic conceptions and even opposed to the common sense and experience of some. Yet to his way of thinking, it was the only theory that explained the facts as he experienced them” (ibid, p. 23). In his book The Functions of the Executive, Barnard (1938) was particularly concerned with induced cooperation and internal structures in organizations, and “efficacious adaptations to changing circumstances” (Williamson, 1996, p. 31). Barnard and Talcott Parsons corresponded frequently from the early 1930s until Parson's death in 1961.

An industry was born. Leadership models have been developed, marketed, applied, and discarded only to be repackaged with small adjustments or perhaps a new name. Most leadership models have some valuable attributes and explain components of why an organization works or doesn't.

The transformational leadership model, however, has endured. There are some statements that are always components of a transformational model including setting direction, encouraging people to develop and apply their skills in ways that improve the organization and strong management skills. "Transformational leadership is defined in terms of the leader's effect on followers: they feel trust, admiration, loyalty, and respect toward the leader, and they are motivated to do more than they originally expected to do.” (Yukl, 1998, p. 325). Yukl goes on to indicate that Burns, a key author in the transformational leadership literature, described transformation leadership as a process in which "leaders and followers raise one another to higher levels of morality and motivation” (p. 324). Dirks and Ferrin found that trust in the leader had very high correlations with transformational leadership (2002, p. 623), and suggest that trust and transformational leadership may overlap because the behavioural description items in both cases are similar, as indicated in the leadership scale used by Bass in 1985. In an earlier study Dirks found that trust in teammates did not affect team performance, but trust in leadership did make a difference to performance (Dirks, 2000, p. 1009). 
Adaptability is part of relationships and organizations that remain effective (Heifetz and Linsky, 2002, p. 14). Economists explain change in organizational behaviour as involving an initial shift from "optimal” to "sub-optimal” in order to incorporate the change. This explanation rests on the presumption that all behaviour is "optimal," given the variables. The shift to sub-optimal, which is a part of change, is inefficient, disruptive and unsettling; however, if the desired change results in a more "optimal” behaviour, the change may be worth the discomfort. If a follower feels trust in a leader, the shift between the current optimal to sub-optimal behaviour will happen more smoothly, and optimal behaviour will return with minimal disruption. Setting aside trust, with a transformational leader, much of the ground work for adaptation will have been done. Add trust, and the ability to switch directions, no matter how frustrating, is going to happen more easily and with less time spent sub-optimal time. This organizational and personal adaptability is sometimes described, in part, when trust is described as a "lubricant."

Leadership seems to make a difference in organizations. Trust in the leader affects the difference the leader is able to make. Results indicate that trust in leaders' matters to organizational effectiveness, including to student achievement. With the exception of Williamson (1985) most research indicates that trust is a core component of leadership, healthy work environments, effective dyadic relationships, profit, and student achievement. In transformational leadership, trust in leaders is essential for increasing organizational citizenship behaviours, as it mediates the relationship between the dyad, providing the vehicle upon which a transformational leadership model rides (Podsakoff et al. 1990, p.135). Others have also found significant positive effects of trust on organizational citizenship behaviours (Konovsky and Pugh, 1994, McAllister, 1995, Robinson, 1996).

One reason that trust is important in schools is it may serve as a "lubricant" for most interactions (Fukuyama, 1995; Luhmann, 1979), allowing less time to be spent on details, planning and attending to messages, and more time to be spent on actions that will elicit the desired improvement. "Trust functions as a lubricant of organizational functioning; without it, the school is likely to experience the overheated friction of conflict as well as a lack of progress toward its admirable goals.” (Tschannen-Moran, 2004, p. xi). Sergiovanni, referencing Putnam, describes both social capital and relational trust as "the DNA of community” (Sergiovanni, 2005, p. 90; Putnam, 2000). 
Our willingness to trust is determined by an ever-increasing and multidimensional set of pre-conditions. Our own psychological makeup and our internal states, which may be affected by early childhood experiences, also affect our ability and willingness to trust. Erikson identified trust as the first stage of growth all humans must travel through to develop effective coping and interpersonal skills. Failure to develop the ability to trust at the very earliest stages of life (birth to eighteen months) will result, according to Erikson, in the inability to resolve other issues as they arise, an inability to move successfully through the remaining developmental stages. If bonding and establishment of trust does not occur early there will be an impact on all future relationships.

While Erikson may have most explicitly isolated the importance of trust in human development, other psychologists identify the ability to trust, to bond, and to predict outcomes as being critical for psychological growth and well being. Piaget, Freud, and Jung are a few prominent names who identify early bonding as of paramount importance, also linking early experiences to personality development. It is thought that trusting people have a component of being able to trust in their personality structure. "We know, from our own experience as well as from scientific research, that readiness to show trust is dependent on the systemic structure of personality as measured, for example, with the F Scale” (Luhmann, 1979, p.5).

Trust has a component of predictability and reliability. In x situation, the individual always, over time, does y. The other approves of y and/or his/her interests are encapsulated within y which moderates the relationship, therefore, the individual becomes trustworthy. If this were the total of trust behaviourists would be able to mould each of us into trustworthy living by simply employing a strong enough set of rewards contingent on ever closer approximation of the desired behaviour, in this case, trust behaviour. However,

Trust is founded on the motivation attributed to behaviour. Conduct on the experience of which trust depends must appear as an expression and reaffirmation of the personality. However, only such actions as are treated institutionally as 'free' are imputed to the personality." (ibid, p.41).

The key word is motivation. Behaviourists would insist that as long as a person behaves in a trustworthy manner it matters not what her motivation for doing so is. Life experience, however, seems to indicate more is at play in trust than simply behaviour. If a person believes that the other is behaving in a trustworthy manner and attributes this behaviour to a set of beliefs that ascribe things such as "virtue, understanding of other, value 
of other" as the motivation and later discovers that the person acted in a trustworthy manner for personal advancement, or other less lofty motives, there will be "hell to pay."

Another approach to trust is evident in the work of Georg Simmel, which posits that trust ultimately involves a "leap of faith" (Mollering, 2001). Trust is a core element of many major religions, including both Christianity and Judaism. Some scholars consider trust to be more an element of the Hebrew Scriptures and faith more a characteristic of the Christian scriptures (Richardson, 1958, p. 19; Richardson, 1964, p. 75). ${ }^{1}$ There may be an important difference between faith and trust. Luhmann, in discussing system trust and its role in stabilizing relationships that might otherwise be destroyed by "trivial treacheries," goes on to say

The great civilizing processes of transition to system trust give humanity a stable attitude towards what is contingent in a complex world make it possible to live with the realization that everything could be otherwise. These processes make man able to be aware of the social contingency of the world. This thought gives rise to the question of transcendental trust in the meaningful constitution of the world (Luhmann, 1979, p. 58).

For one as versed in sociological functional theory as Luhmann, who is described as one who "out-Parsons Parsons," it is a bit of a surprise finding transcendental trust even mentioned. Perhaps it shouldn't be. It is these somewhat divergent thoughts that occur in all of us that account for the need for trust at all.

Politics, that endgame to drive forever the wedge of distrust into work life, if it is not handled with extreme care and purpose, is also core to human endeavour.

Consider the concept of politics. Although the term cannot be easily or uniformly defined, it is generally thought of as a form of social conflict in which individuals of groups attempt to promote self-interests through various deceptive, manipulative, or negotiated activities...embedded within this rather sinister definition is the idea that in complex organizations like schools, political behaviour thrives on conflict, disorder, ambiguity, and a lack of common purposes or goals. In this context, schools resemble organizational or interpersonal disharmony, winner and losers, and compromise at the expense of quality (Davis, Hensley, 1999, p. 384).

\footnotetext{
${ }^{1}$ One curiosity is the physical centrality of trust in the bible as a whole. The shortest chapter in the Bible is Psalm 117. The longest chapter in the Bible is Psalm 119. The exact center, physically, of the bible, is Psalm 118. There are 594 chapters before Psalm 118 and 594 chapters after Psalm 118. If you add these two numbers together you get 1188 chapters in the Bible. The center verse of Psalm 118 is 118:8. The text of this verse is "It is better to trust in the Lord than to put confidence in man.” It's interesting and perhaps worth wondering about. It is possible that it is more than coincidence that trust is centrally situated. The physical position may be a demonstration of the very centrality of trust.
} 
The relevance of this quote is to highlight that it is well known that schools are political organizations, demanding more spending than any other government program in Canada, save health care. Consider the now famous quote referring to Directors of Education "It is not a question of whether a Superintendent/Director of Education will play politics; the only question is how well and how ethically he or she will play” (Hoyle, Skrla, 1999, p. 410).

Trust is important because it reduces social complexity (Luhmann, 1979, p. 71). Education change is also considered to be “technically simple and socially complex” (Fullan, 2006). It isn't the teaching itself that is complicated, although, as the occupation “professionalizes" it becomes clearer that some specific high yield strategies make a difference in student achievement. These strategies, however, are also not difficult. Schools and education are and always will be socially complex. "Schools are fundamentally social institutions that depend daily on the quality of the interpersonal relations with which they are imbued” (Goddard, Salloum, Berebitsky, 2009, p. 293). A focus only on structural reforms (for example, block scheduling efforts), or instructional practice reform, fails to address the staggering complexity of the social relationships in schools (ibid, p. 293). Education and schools are and always will be both social and political. Collegial trust as a social resource is a dimension of school capacity (Cosner, 2009, p. 257).

If trust is so fundamental to our psychological, spiritual and political history, and so central to education and educators, why is this topic so minimally managed in the research on education leadership and in leadership research in general? Is it simply unrealistic to expect trust to be an element of organizational life? We know intuitively there are people we trust, that we trust them because we have seen them in a number of situations and have found behavioural characteristics present in their actions, over time, that lead us to trust them. We have attributed to them, beyond the behavioural characteristics that are essential, some belief that we understand the motivation for the behavioural characteristics, and are "at peace" with the motives.

The need to understand the motives is why "swift trust," as in the trust involved in forming a work group to resolve a particular issue that is focused and time-limited, forms more easily and more quickly than the trust required to sustain a long-term relationship. In swift trust situations, the primary motive is to complete this time-limited project. It is assumed that the motives are first and foremost to get the project completed, and while it may be true that other motives exist, once the team agrees on the primary motive, the team 
can work very effectively together for the short term. It is easier to agree to something that is time-limited, well defined and has mutual dependence than it is to work in a situation that is long term, has multiple goals, involves the cooperation of many, and requires both independence and interdependence in order to be successful.

Finally, much of the best literature and philosophy, from Dante to Shakespeare to Dickens to Garcia and from Aristotle to Kant to Havel, address trust as one of the fundamental human dilemmas and requirements, as humanity at its most noble, and as a core of human tragedy.

The criteria selected by Bryk and Schneider (2002), as best representing those elements of trustworthiness that resulted in the strongest relational trust in the Chicago schools research they completed included competence, integrity, personal regard for others and respect. Bryk and Schneider found that schools with high relational trust were also schools that were making steady improvements in test scores and other measures of school improvement ${ }^{2}$. The rest of the antecedents were not defined by Bryk and Schneider. Some extra explanation and exploration of the terms, therefore, is included. All terms appear alphabetically below.

\section{Trust and Power}

"Put your trust in God, and keep your powder dry."

\section{Oliver Cromwell ${ }^{3}$}

When we are vulnerable in relationships it is often because there is some imbalance of power in play. Vulnerability of one to another is another way of describing a power relationship. Vulnerability of one or more parties is also a central feature of trust (Luhmann, 1979; Gambetta, 1988; Baier, 1986; Mayer et al., 1995; Kollock, 2004; Lapidot, 2007).

It is not only true that the person of greatest age or highest hierarchy is the sole holder of power, although this may be true. For example, parents are sometimes vulnerable to their children because of the tremendous love parents feel for children, and may seek to please

\footnotetext{
${ }^{2}$ There are many problematic issues in the trust research. While defining "trust" itself is the most significant obstacle to progress, defining terms such as "respect," "competence," "integrity" and others is a close second. Some sort of agreement on terms, as imperfect as they may be, is far more important than endless loop discussion of terms. Use of the terms care, integrity, personal regard for others and respect, as defined within the Bryk and Schneider research, may be helpful to someone’s larger research agenda.

${ }^{3}$ Oliver's Advice by Valentine Blacker (1778 - 1823)
} 
children, on occasion, by compromising on decisions or overlooking unmet expectations, while it is also clear that for many years parents hold much power in the relationship. Parents sometimes do endanger aspects of their own security in order to assist a child. Vulnerability can be multi-directional.

Our justice system is one of the ways we manage power relationships. Rules of conduct are established, in laws that identify what is expected. "Trust is based on the expectation that one will find what is expected rather than what is feared" (Deutsch, 1973 in McAllister, 1995, p. 25). When we find what is feared, rather than expected, the justice system, in some instances, enforces the expectations.

Society's values are influenced by the school and in that sense, society is vulnerable to the school. With power comes responsibility. As teachers have responsibility, they must be circumspect. The Supreme Court of Canada considers the issue of societal importance of schools, trust in schools but also the vulnerability of the children served by schools by seeking to establish consistent standards of behaviour that are embedded in teachers' lives.

The Supreme Court of Canada agrees to hear a case because an issue has been identified that is of particular interest to society. The ruling establishes expectations of conduct that need to be articulated clearly, in order to clarify society's expectations on the issue. The Supreme Court articulates both decisions and reasoning, and both form the basis for future decisions in other cases. Case law is based upon precedence.

It is on the basis of the position of trust and influence that we hold the teacher to high standards both on duty and off duty, and it is an erosion of these standards that may lead to a loss in the community of confidence in the public school system (Ross v. New Brunswick, 1996, paragraph 28).

The Supreme Court of Canada is identifying "trust” as central to the teaching profession. There are multiple rulings by the Supreme Court that identify "trust and the teaching profession,” including R. v. Jones (1986), Toronto (city) Board of Education v. O.S.S.T.F., District 15 (1997), and Trinity Western University v. British Columbia College of Teachers (2001). Some of the cases that provide the basis for these decisions include the British Columbia Court of Appeal (1986), where the phrase "checking your hat at the schoolroom gate" was used (followed by multiple, popular presentations related to teachers and leaders wearing piles of hats, each hat representing a role the audience (teachers and/or leaders) held in education), and the Education Relations Commission (1992). 
Regulation is another tool used to ensure that the expected will happen. Extensive regulation may signal an attempt to "balance interests.” In 1996 the government of Ontario, having considered the issue of creating a regulatory body to oversee aspects of the teaching profession since 1981, created the Ontario College of Teachers (OCT). Teaching is now the most regulated profession in Ontario. The Ethical Standards of the Teaching Profession, created by the OCT in 2002, has four expectations: care, respect, integrity and trust. The first three expectations are described as antecedents of the fourth expectation in the research literature, so it may be reasonable to consider the basic ethical standard of the regulatory body is trust. Regulation of the profession, however, demonstrates the public's determination of vulnerability of some members of society. There are 38 regulated professions in Ontario. Regulation is one way of establishing expectations for behaviour for the profession. Where vulnerability of one part of society exists, scrutiny of actions by those with power, distributes vulnerability.

In the case of teachers and education, scrutiny of action through Canadian law and Ontario regulation holds teachers to a high standard of behaviour. Teachers hold their leaders to this named and defined high standard, and expect behaviours that are at least as trustworthy as the actions to which the profession is held.

In a trustworthy leader, and in a trusting relationship, the antecedents of trust distribute power. The person who holds situational or hierarchical power is to some degree personally vulnerable to the other if they have displayed honesty, openness, etc. This should be acknowledged and honoured. It is also reasonable to expect leaders to be vulnerable. This balances power.

The law and power, is a re-casting of The Age of Reason. Barnard wondered, wisely, if this battle, law and power, like reason and enlightenment, was a "recasting of long philosophical battles between church and state” (Smith, 1975, p. 23). Regardless, this colonization of us, via the omnipresent power of both church and state, creates shadows in power relationships, in our understanding of what it means to be in charge, in our expectations of those in charge, and in our acceptance of our own role, and responsibility for that role, every day, as we redefine (or not) our relationships. 


\section{Chapter 2 Review of Research Literature and Framework}

By comparing the data gathered in three high-trust and three low-trust schools, this study aims to answer the following three questions:

1. To what extent do teachers identify antecedents of trust when they are engaged in conversation about their school and the school's leadership;

2. Which antecedents of trust do teachers identify most frequently and are there behaviours exhibited by the school's leadership that they equate to these antecedents; and

3. To what extent do principals and teachers hold similar views on the sources (or antecedents) of trust in principals?

The framework for this study consists of the full range of factors or antecedents that evidence suggests promotes the development of trust.

As Figure 1 indicates, a comprehensive review of empirical evidence suggests 13 such factors or antecedents exist. This figure lists the antecedents in the far left column and the 17 studies that inquired about the antecedents of trust. A check mark $(\checkmark)$ identifies which antecedents were the focuses of inquiry in each study.

Table 1 provides information on each of the 17 studies including research design, sample size and unit, instruments for collecting data, which antecedents were of interest, and a brief synopsis of results.

Samples range in size from four companies to 980 hospitals across four states. The data gathered are from both private and public sectors. Dyadic as well as group relationships are studied. Employer/employee data is also gathered in several studies. Of the 17 studies, four were carried out in school settings.

Survey data are gathered in nine of the studies included in the table and this is the most common type of instrument used in trust research. Each survey used its own questions to determine trust conditions or attributes. While there are similarities in the questions, there is enough dissimilarity to make difficult the drawing of firm conclusions. Student achievement data and census data are used in one study. Interviews, case studies, observation, behavioural tracking, and descriptive "lifting” from critical incident reports; 
make up the qualitative instruments, however, these procedures are research specific and not used across other research. 


\begin{tabular}{|c|c|c|c|c|c|c|c|c|c|c|c|c|c|c|c|c|c|}
\hline $\begin{array}{c}\text { Author } \\
\text { Element }\end{array}$ & Bryk & Dirks & $\begin{array}{c}\text { Doole } \\
y\end{array}$ & Ellis & Gabarro & $\operatorname{Hoy}(3)$ & $\begin{array}{l}\text { Koch- } \\
\text { anek }\end{array}$ & Kollock & $\begin{array}{l}\text { Kors- } \\
\text { gaard }\end{array}$ & Lapidot & Lines & $\begin{array}{c}\text { Mc } \\
\text { Allister }\end{array}$ & Mishra & $\begin{array}{l}\text { Para- } \\
\text { yitam }\end{array}$ & $\underset{s}{\operatorname{Simon}}$ & $\begin{array}{l}\text { Strick- } \\
\text { land }\end{array}$ & $\begin{array}{l}\text { Tscha } \\
\text {-nnen- } \\
\text { Moran }\end{array}$ \\
\hline $\begin{array}{l}1 . \\
\text { Benevolence }\end{array}$ & & & & & & $\checkmark$ & & & & $\checkmark$ & $\checkmark$ & & & & & $\checkmark$ & $\checkmark$ \\
\hline $\begin{array}{l}2 . \\
\text { Caring/ } \\
\text { Concern }\end{array}$ & & $\checkmark$ & & & & & & & & & & $\checkmark$ & $\checkmark$ & & & & \\
\hline $\begin{array}{l}3 . \\
\text { Competence }\end{array}$ & $\checkmark$ & & $\checkmark$ & $\checkmark$ & & $\checkmark$ & $\checkmark$ & & & $\checkmark$ & $\checkmark$ & $\checkmark$ & $\checkmark$ & & & & $\checkmark$ \\
\hline $\begin{array}{l}4 . \\
\text { Consistency/ } \\
\text { Reliability }\end{array}$ & & & & $\checkmark$ & & $\checkmark$ & & & & & & $\checkmark$ & $\checkmark$ & & & & $\checkmark$ \\
\hline $\begin{array}{l}5 . \\
\text { Fairness }\end{array}$ & & $\checkmark$ & & & & & & & $\checkmark$ & $\checkmark$ & & $\checkmark$ & & & & & \\
\hline $\begin{array}{l}6 . \\
\text { Forgiveness }\end{array}$ & & & & & & & & & & & & & & $\checkmark$ & & & \\
\hline $\begin{array}{l}7 . \\
\text { Honesty }\end{array}$ & & & & $\checkmark$ & & $\checkmark$ & & & & & & & $\checkmark$ & & & & $\checkmark$ \\
\hline $\begin{array}{l}8 . \\
\text { Integrity }\end{array}$ & $\checkmark$ & & & & $\checkmark$ & & $\checkmark$ & & & $\checkmark$ & & & & & $\checkmark$ & & \\
\hline $\begin{array}{l}9 . \\
\text { Loyalty }\end{array}$ & & & $\checkmark$ & & & & & & & & & & & & & & \\
\hline $\begin{array}{l}10 . \\
\text { Openness }\end{array}$ & & & & $\checkmark$ & $\checkmark$ & $\checkmark$ & & & & $\checkmark$ & & & $\checkmark$ & & & & $\checkmark$ \\
\hline $\begin{array}{l}11 . \\
\text { Personal } \\
\text { Regard }\end{array}$ & $\checkmark$ & & & & & & $\checkmark$ & & & & & & & & & & \\
\hline $\begin{array}{l}12 . \\
\text { Respect }\end{array}$ & $\checkmark$ & & & & & & $\checkmark$ & & $\checkmark$ & & & & & & & & \\
\hline $\begin{array}{l}13 . \\
\text { Vulnerability }\end{array}$ & & & & & & & & $\checkmark$ & & $\checkmark$ & & & & & & & \\
\hline
\end{tabular}

Figure 1: A summary of antecedents of trust and their sources 


\section{Table 1}

Characteristics of research about antecedents giving rise to perceptions of leader trustworthiness

\begin{tabular}{|c|c|c|}
\hline Author & $\begin{array}{l}\text { Research } \\
\text { Design }\end{array}$ & Sample \\
\hline $\begin{array}{l}\text { Bryk and } \\
\text { Schneider; } \\
\text { Kochanek }\end{array}$ & $\begin{array}{l}\text { Quantitative } \\
\text { Qualitative } \\
\text { Longitudinal }\end{array}$ & 12 schools \\
\hline Dirks & $\begin{array}{l}\text { Quantitative, } \\
\text { qualitative }\end{array}$ & 30 teams \\
\hline
\end{tabular}

Dirks and

Ferrin

Meta-analysis 1960-2000

Examines relationships btwn trust in leadership and outcomes,

antecedents, and

correlates

Dooley and Quantitative $\quad$ Entire population of 450

Fryxell

hospitals in three states

Ellis

Quantitative,

longitudinal

2068 respondents, 60

organizations, 14 year

period, cities, Italy and

$\begin{array}{lll}\text { Gabarro } & \text { Qualitative, } & 4 \text { companies each with a } \\ & \text { longitudinal } & \text { new CEO, } \\ & & 33 \text { relationships over } 3\end{array}$

$\begin{array}{cl}\text { Gabarro } & \begin{array}{l}\text { Qualitative, } \\ \text { longitudinal }\end{array} \\ & \text { new CEO, } \\ & 33 \text { relationships over } 3\end{array}$

$\begin{array}{ll}\text { longitudinal } & \text { new CEO, } \\ & 33 \text { relationships over } 3\end{array}$

United States

33 relationships over
years plus 40 single

interviews of new

managers to check

generalizability

Hoy and

Witkoskie;

Hoy and

Tschannen-

Moran;

Hoy and

Sweetland

Kollock

94 schools in Ohio

98 schools in Ohio

97 schools in Ohio

80 subjects in groups of

\section{Instruments}

Survey, interview, observation and

student-

achievement data

Survey, interview

and achievement

data

Antecedents

Studied $^{\mathrm{a}}$

$4,9,12,14$

Schools with high relational trust are more likely to make improvements

in achievement scores over time

Trust mediates the relationship between past and future performance; trust in leadership is critical to team effectiveness in some situations; trust in teammates does not affect performance; however, team talent does affect outcomes; 4, 9 and 15 are all factors related to trust in leader

Direct leaders (supervisors) are an important referent of trust,

particularly as related to $3,5,6$

Survey

Survey

Interviews

Survey

Quantitative/

eight, random

assignment of role
Behavioural tracking, postexperimental
$8,11,13,14$

$9,11,13$

Importance of different attributes as information for trustworthiness may be situation specific; virtues of dissent are important; concerns about social desirability of responses expressed

Trust matters, and matters more in relation to top management than to immediate supervisors; amount and quality of communication is key in

CEOs or subordinates did not perceive trust as uni-dimensional; both affect- and cognition-based components relevant; key was working out dimensions of relationship prior to stabilization period

Each aspect is important in trust relations in schools; they are key ingredients for trustworthy leadership; relative weight will depend on nature of interdependence

Trust scores higher in uncertain-quality (vulnerable) conditions $(p<.01)$; trust is a resource that needs to be used or it will atrophy 


\begin{tabular}{|c|c|c|c|c|}
\hline & & & Questionnaire & \\
\hline $\begin{array}{l}\text { Konovsky and } \\
\text { Pugh }\end{array}$ & Quantitative & $\begin{array}{l}630 \text { employees at one } \\
\text { hospital, self-selected }\end{array}$ & $\begin{array}{l}\text { Questionnaire/ } \\
\text { survey; supervisor } \\
\text { OCB rating form }\end{array}$ & 6 \\
\hline Korsgaard & $\begin{array}{l}\text { Quantitative/ } \\
\text { experimental }\end{array}$ & $\begin{array}{l}20 \text { management teams } \\
\text { with } 89 \text { team members } \\
\text { and } 20 \text { team leaders }\end{array}$ & Survey & 6,14 \\
\hline Lapidot & Qualitative & $\begin{array}{l}988 \text { critical incidents } \\
\text { from } 733 \text { cadets in } \\
\text { officer training courses }\end{array}$ & Descriptive & $1,2,9$ \\
\hline McAllister & $\begin{array}{l}\text { Quantitative/ } \\
\text { experimental }\end{array}$ & 194 managers & $\begin{array}{l}\text { Questionnaire/ } \\
\text { survey }\end{array}$ & $3,4,6,13$ \\
\hline Mishra & $\begin{array}{l}\text { Qualitative/ } \\
\text { inductive }\end{array}$ & $\begin{array}{l}33 \text { semi-structured } \\
\text { interviews with top-level } \\
\text { automotive managers } \\
\text { during economic } \\
\text { downturn }\end{array}$ & Interviews & $4,5,8,11,13$ \\
\hline $\begin{array}{l}\text { Parayitam } \\
\text { and Dooley }\end{array}$ & Quantitative & $\begin{array}{l}\text { Staff in } 980 \text { hospitals in } \\
\text { four states }\end{array}$ & Survey & 7 \\
\hline Simons & $\begin{array}{l}\text { Review of } \\
\text { literature }\end{array}$ & & & 9 \\
\hline Strickland & Quantitative & $\begin{array}{l}40 \text { male business } \\
\text { students }\end{array}$ & Experimental & 2 \\
\hline $\begin{array}{l}\text { Tschannen- } \\
\text { Moran }\end{array}$ & $\begin{array}{l}\text { Quantitative/ } \\
\text { qualitative }\end{array}$ & 300 schools & $\begin{array}{l}\text { Survey and case } \\
\text { study }\end{array}$ & $2,4,8,11,13$ \\
\hline
\end{tabular}

Procedural justice (fairness) is an important determinant of employee behaviour; distributive justice did not predict OCB or trust; procedura justice is not subordinate to distributive justice in determining OCBS

6,14 are significant

1,9 are most salient in trust erosion incidents; 9 was most salient in trust-building incidents

Vulnerability of subordinate increased the importance of behaviours reflecting leader integrity and ability (competence)

Cognition-based trust needs to exist for affect-based trust to develop; while they may be causally connected each has a unique function to fulfill in a trusting relationship

These attributes matter if trust is to be retained during times of crisis; evidence gathered confirms previous researchers' findings of significance

Cognitive and affect based trust play different roles, forgiveness appears to bridge affect to cognitive in conflict situations

Need to develop an instrument to measure behavioural integrity

Confirms Solomon's motive attribution and that 1 ) interpersonal trust is situational; 2) benevolent intentions matter; 3) a wider range of attributed elements may be functioning

These attributes matter in schools 


\section{Review of Evidence from the 17 Studies}

Both the number of antecedents of trust and their definitions vary widely across studies. Most researchers identified no more than five antecedents for trust. Strickland (1958) listed only one, benevolence, thus supporting Deutsch’s work (1957) that identified the trustee's apparent benevolent intent as being key as the motivational attribute identified by the trustor in order for the trustor to trust. Strickland went on, however, to state "There may be a wider variety of attributed internal causality” (1958, p. 212). The studies had a tremendous amount of overlap in the terms themselves, as shall be seen in the following attempt to define the terms. The lack of clarity and of agreed-upon terminology is one of the pervasive characteristics of trust research.

\section{Meaning of Antecedents of Trust}

The remainder of this chapter clarifies the meaning of each of the 13 antecedents of trust identified in Figure 1 and discusses the results of the research about one, which is summarized in Table 1.

\section{Benevolence}

Benevolence can be defined as "caring, extending good will, having positive intentions, supporting teachers, expressing appreciation for staff efforts, being fair, guarding confidential information” (Tschannen-Moran, 2004, p. 34). Mayer defines benevolence as "the extent to which a trustor believes that a trustee will act in the best interest of the trustor" (in Gill, Boies, Finegan, McNally, 2005, p. 289). Lapidot, Kark and Shamir use multiple definitions from a variety of researchers. In summary, their definition of benevolence includes the belief on the part of the trustor that the trustee "wants to do good to the trustor," and this desire is not related to a self-centered profit motive. There is a desire to "help" the trustor, but no requirement to help the trustor. "This type of behaviour [benevolence] is not a perquisite to interactions with another individual.

When they are apparent they are likely to promote trust.” (Lapidot, Kark, Shamir, 2007, p. 18, 19). Lines, Selart, Espedal, and Johansen reference benevolence as "the extent to which a trustee is believed to want to do good to the trustor, aside from an egocentric profit motive” (p. 225). Strickland's 1958 experimental data confirms the early writing of Deutsch: "Perception of a benevolent orientation on the part of the worker toward others may prompt the trusting behaviour although it may have no personal relevance for the donor” (Strickland, 
1958, p. 213). The actual definition of benevolence is vague, but the conclusion that benevolence matters is clear.

\section{Caring}

Caring is defined as

address and response; it requires different behaviors from situation to situation and from person to person. It sometimes calls for toughness, sometimes for tenderness. With cool, formal people, we respond caringly with deference and respect; with warm, informal people we respond caringly with hugs and overt affection. Some situations require only a few minutes of attentive care; others require continuous effort over long periods of time (Noddings, 1992, p. xi).

Further to the above definition, caring is linked to some forms of trust. Findings from attribution research indicate that behavior recognized as personally chosen rather than roleprescribed, serving to meet legitimate needs, and demonstrating interpersonal care and concern rather than enlightened self-interest may be critical for the development of affectbased trust (McAllister, 1995, p. 29).

Caring in particular, but not exclusively, is a component of organizational citizenship behaviour (OCB). Altruism may be roughly analogous to caring, and is defined as a specific form of OCB. Altruism is behaviour that is "directly and intentionally aimed at helping a specific person in face-to-face situations” (Smith, Organ and Near, 1983 in McAllister, p. 29). "It can be viewed as being personally chosen, and not being directly rewarded" (MacKenzie, Podsakoff, and Fetter, 1991 in McAllister, p. 29). Mishra (1996) uses a definition by Bromiley and Cummings, saying "one party believes it will not be taken unfair advantage of by another” (Mishra, 1996, p. 267). Mishra does not directly define care and concern; however, after providing several examples of them, he states “... trust in terms of concern (and care) means that such self-interest is balanced by interest in the welfare of others” (p. 267).

\section{Competence}

Competence allows for a situation-specific orientation for the decision to trust or not trust. Competence is a term more commonly associated with functional, work-related skills such as producing an accurate timetable that reflects the priorities of the learning environment and is in staff mailboxes on time. Functional competence is also defined as "setting an example, working hard, pressing for results, setting standards, buffering teachers" (Tschannen-Moran, 2004, p. 34). 
Functional competence may refer to ability, which Gill defines as "knowledge, skills and competencies” (Gill, 2005, p. 289). The timetable that meets a goal but is achieved "on the backs" of relationships may not be quite as appreciated as one that achieved the goal and, in it being achieved, the individuals affected are aware that they continue to be highly valued. This seems to suggest that functional competence can be separated from interpersonal competence.

Interpersonal competence is defined as “engaging in problem solving, fostering conflict resolution (rather than avoidance), handling difficult situations, being flexible” (Tschannen-Moran, 2004, p. 34). Dooley and Fryxell do not identify specific attributes that contribute to competence, but their research indicates that competence and loyalty are necessary components of effective strategic decision-making teams that express dissent (1999, p. 399). Lapidot et al. do not directly define competence, or, in their case, "ability”; however, they do say:

if leaders do not display behaviours that reflect integrity and ability, followers are likely to notice it and this in turn, may affect trust erosion. In other words, their lack is predicted here to affect trust erosion more strongly than their presence might have on trust building (Lapidot et al., 2007, p.19).

Lines et al. states:

Competence is vital since people are unlikely to listen to or depend upon someone whose abilities they don't respect. Generally, employees need to believe that the leader has the skills and abilities to carry out what he or she says they will do. A closely related construct is ability, that reflects the group of skills, competencies, and characteristics that make it possible for people to influence a particular environment (Mayer et al, 1995) (Lines et al., 2005, p. 225).

Ellis (2001) Mishra (1996) and McAllister (1995) fail to provide an exact definition of competence; however all three conclude that competence is essential to a trusting relationship.

\section{Consistency and reliability}

Consistency and reliability are closely connected terms. Both Tschannen-Moran and Hoy define reliability as "having consistency, being dependable, demonstrating commitment, having dedication, being diligent” (Tschannen-Moran, 2004, p. 34). “Reliability, dependability or consistency between words and action” (Mishra in Kramer and Tyler, 1996, p. 268) are all terms used fairly interchangeably and are seen as important aspects of trust. Ellis uses a definition of McGregor’s (1967) “reliability, defined as the expectation for 
consistent, dependable behavior, including congruency between words and actions” (2001, p. 383). Predictability seems to also fit into this category of terms. All are tools for uncertainty reduction (Mayer, Davis and Schoorman, 1995, p. 714).

Many theorists discuss this category of terms as components of trust, but there is a need to go beyond this to be meaningful. "A party who can be expected to consistently ignore the needs of others and act in a self-interested fashion is therefore trusted, because the party is predictable" (ibid, p. 714). The absence of reliability and the associated terms is a strong rationale for withholding trust, if we consider that trusting itself "is to behave as though the future were certain”(Luhmann, 1979, p. 10). "The presence of reliability and dependability expectations must be met for trust relationships to exist and develop" (Zucker, 1986 in McAllister, 1995, p. 26). Some sort of positive association needs to be connected to the behaviours that enact reliability, predictability, consistency, and similar terms of known present to unknown future complexity reduction, if trustworthiness and trusting relationships are to exist.

\section{Fairness}

Fairness, procedural fairness, judgment, and decision-making judgment may all relate to each other. Dirks and Ferrin state:

Employees trust in their leaders will be influenced by the level of perceived fairness or justice in the organizational practices or decisions, because the practices are likely to be seen as a signal of the nature of the relationship with the leader or the character of the leader (2002, p. 614).

Lapidot et al. identified fairness as a sub-component of integrity, and found this broad description of integrity comprised $33.7 \%$ of the reports made by cadets in relation to trusting behaviours in leaders (Lapidot et al., 2007, p.24). Some studies indicate that perceptions of procedural fairness had more impact on employees' support for authorities when the outcomes associated with decisions were relatively unfavourable (Brockner and Wiesenfeld, 1996, p. 204). To convolute the words, of course, "benevolence and integrity shape individuals' perceptions of the party's motivation or intention to enact decisions properly.

Procedural fairness, in turn, may shape individuals' perceptions of benevolence or integrity” (ibid, p. 204). Leventhal, Karuza, and Fry (1980) in Brockner, Siegel, Daly, Tyler and Martin (1997) suggest that consistency is a criteria for procedural fairness. Mayer, Davis, and Schoorman similarly suggest that "such issues as the consistency of the party's past 
actions, ... belief that the trustee has a strong sense of justice, and the extent to which the party's actions are congruent with his or her words all affect the degree to which the party is judged to have integrity” (1995, p. 719).

Norms of reciprocity and fairness are identified as an important antecedent to cognition- based trust (McAllister, 1995, p. 28). Rather than throwing one's hands up in the air as the attempt to untangle the verbiage suggests might be wise, dwell, instead, on the issue that perceived fairness matters because "just procedures assure people that a structure exists to protect their material self-interests in the long run. ... Fair procedures thus help protect and strengthen individuals’ identification with the group or organization.” (Johnson, Korsgaard, Sapienza, 2002, p. 1145). Further, “Organizational commitment and trust create social capital, which in turn fosters and supports knowledge creation and organizational learning” (Nahapiet and Ghoshal, 1998, in ibid, p. 1142). Fairness also seems to be one method for bridging cognition-based trust and affect-based trust.

\section{Forgiveness}

Forgiveness does not appear to be a researched antecedent of trust, although Bies and Tripp identify the need to do research in the area (in Kramer and Tyler, 1996, p. 259). Perhaps the view is that forgiveness is implicit, or is not an antecedent but rather a consequence. Neither is likely true. There is evidence that relationships become "thicker" (Ostrom and Walker, 2003, p.92) over time, that bandwidth likely grows over time, but that time is only one factor. The quality of that time, the diversity of experience within the relationship also affects the thickness of the relationship. Most, if not all, personal and professional relationships of depth or quality will require forgiveness precisely because of the increased risk inherent in a thick relationship. "The ability to build, maintain, and repair cooperative interactions has become a critical management competency” (Lewicki and Bunker, 1996, p. 118).

Forgiveness provides the security that the risk will not be so great as to be foolhardy. The assurance of forgiveness reduces the vulnerability of others. Forgiveness may be seen as one essential path for re-establishing functioning norms. It may be that forgiveness provides one mechanism, often of last resort, to move from sub-optimal to optimal functioning. 


\section{Honesty}

Honesty is defined as "having integrity, telling the truth, keeping promises, honoring agreements, having authenticity, accepting responsibility, avoiding manipulation, being real, being true to oneself” (Tschannen-Moran, 2004, p. 34). Ellis et al. describe both openness and honesty as including “sincerity in communication” (2001, p. 383). Honesty is always truth in the moment. Within the factors known, with reflection on the situation, A tells the truth in relation to how they view the situation. Ideally, the information then provided by B sheds light on A's view of reality and vice versa, creating a new honest. Honesty may be the risk of all risks. In a recent article in the Harvard Management Update, employees who are "honest" with those who hold power are relegated to the "B" list, the group of solid but not promotable employees (Field, 2008). This means those who are honest in power relationships may:

- $\quad$ be prepared to tell the truth at the cost of their careers;

- $\quad$ be indifferent to their careers;

- $\quad$ hold the individual to whom they are telling the truth and sharing truth in such regard that they believe honesty can be tolerated and worked with (which it often can't, thus, the B list);

- believe they themselves have the skills to survive the challenges honesty may cause; or

- some combination of the above.

While Mishra identifies “openness and honesty” as one of four preconditions for trust, he limits this sub-dimension saying:

Openness beyond a certain level may, however, serve to impair rather than enhance trust. For example, telling someone the complete truth, with elaborate detail, about his or her character flaws may decrease trust between two parties. Such extreme honesty impairs the overall trust level by lowering trust in terms of the concern or competence dimensions, rather than the openness dimension per se (Mishra in Kramer et al., 1996, p. 267).

\section{Integrity}

Integrity, as used by Bryk and Schneider, implies that a moral-ethical perspective guides one's work, and that when conflict arises, the adjudication of that conflict will "reaffirm the primary principles of the institution. In the context of schooling, when all is said and done, actions must be understood as advancing the best interests of children.” (2002, p. 26). Integrity has a significant relationship to modeling. Staff is attuned to what the leader 
says, sometimes being hyper-analytical and drawing meaning from turns of phrase that the leader did not intend. They couple this with intent watchfulness of the leader's actions, often noting small details of behaviour. Integrity is the result of a very close match between words and deeds. Tony Simons defines behavioural integrity as an "ascribed trait, describing a perceived pattern of alignment between another's words and deeds. Behavioural integrity is a present-time trait whose ascription draws on history” (Simons, 2002, p.20). In an earlier article Simons defined integrity as "the perceived level of match or mismatch between the espoused and the enacted” (1999, p.90). As defined by Mayer et al., integrity refers to "the extent to which the trustor perceives the trustee as acting in accord with a set of principles that the trustor finds acceptable” (Mayer, Davis and Shoorman, 1995, p. 719). Integrity, as explained by Lapidot, involves the trustor's perception that the trustee adheres to a set of principles that the trustor finds acceptable. A sense of integrity involves both the adherence to and acceptability of the principles, since if a set of principles held by the trustee is not found acceptable by the trustor, the trustee would not be considered to have integrity (Lapidot, 2007, p.18).

\section{Loyalty}

Loyalty, like honesty and truthfulness, is multidimensional. Both the roles of dissent and consensus are important in quality decision-making within teams, and managing the tension between the two is a key question in strategy research (Rumelt, Schendel and Teece, 1994 in Dooley and Fryxell, 1999, p. 389). Loyalty seems to encourage a more complete exploration of ideas as people can

"concentrate on the content and cognitive meaning of messages (Gibb, 1964)...(those) deemed loyal will be viewed prima facie as working toward group goals...fears of reprisals or possible scapegoating are mitigated. Thus, the attribution of loyalty promotes the fuller processing of information provided by a dissenting party” (ibid, p. 292).

Loyalty can "transcend narrow parochial interests and display that blend of responsibility and reciprocity we sometimes call honor” (Webb in Tyler et al., 1996, p. 294). Loyalty can, however, go too far; at its least desirable it can lead to foolishness or feeding immorality (ibid, p. 296). Loyalty does, however, sometimes serve to simplify. Many of us are loyal; in full recognition of the imperfectness of a situation, a response, or even personal slight ... we are able to "silo” or "envelope,” while maintaining loyalty. 


\section{Openness}

Openness is the demonstration of actions or attitudes that make an individual vulnerable to the actions and attitudes of the other through the sharing of information, influence, and control. "When people are open, they give and get rapid and direct disclosure of relevant information” (Zand, 1997, p. 114). A more all-encompassing definition states openness is "sharing important information, delegating, sharing decision making, sharing power” (Tschannen-Moran, 2004, p. 34). Further “Openness in information means disclosure of facts, alternatives, judgments, intentions, and feelings” (ibid, p. 34). Openness and flexibility is seen by Lapidot et al. as the

opposite of defensiveness and hence as reflecting integrity, and may also show a willingness to reduce social distance, and hence as reflecting closeness to the subordinates (possibly a component of benevolence) (2007, p. 28).

Openness in control accepts dependence rooted in a confidence in the reliability of others and delegation of important tasks to them. Openness in influence allows others to initiate changes to plans, goals, concepts, criteria and resources” (ibid, p. 25). Gabarro found in his study of chief executive officers that each of the four CEOs he studied displayed considerable openness to subordinates and ideas and displayed integrity and reliability. He found these attributes were particularly important to display during the stabilization period of the relationship, a time when the "norms” for effective working relationships were being agreed upon.

\section{Personal regard}

Personal regard for others is understood as "actions taken by a member of a role set to reduce others' sense of vulnerability ... such actions typically are interpreted as an expression of benevolent intentions, and understood as signaling personal regard for the other” (Bryk et al., 2002, p. 25). Bryk and Schneider expanded the concept of benevolence as a core aspect of trust to personal regard for others in order to "reach beyond what might be thought of in some sense as doing a good job. Expressions of personal regard entail not only reducing vulnerability, but also positive expressions of care and concern.” (ibid, p. 185).

\section{Respect}

Respect "involves recognition of the important role each person plays in a child's education and the mutual dependencies that exist among various parties involved in this activity” (ibid, p. 23). While the definition of respect is closely linked to fairness, Korsgaard, 
Schwiger, and Sapienza found that “...leaders may not need to relinquish control over decision quality to gain commitment and subsequent cooperation; they merely have to treat people fairly and with respect” (1995, p. 77). Ellis, Shockley, and Zalabak investigated aspects of information flow to and from management, something that is a component of openness as well as respect, and found that both the quantity and quality of information were significant and that both affected employees' perceptions of organizational effectiveness (2001, p. 393).

\section{Vulnerability}

Vulnerability seems to conflate with a definition of trust itself (Baier, 1986; Bigley and Pearce, 1998). Risk is also used as a stand-in for vulnerability (Rousseau, Sitkin, Burt, and Camerer, 1998; Solomon and Flores, 2001). Luhmann states that "to show trust is to anticipate the future. It is to behave as though the future were certain” (1979, p.10). Luhmann further states that "Trust rests on illusion. In actuality, there is less information available than would be required to give assurance of success” (p. 32). Vulnerability is related to the dependence on the other person to act with good intention. Vulnerability and trust are tightly entwined. Lapidot et al. found in their study with cadets and trust that the preponderance of negative over positive incidents was situation dependent and related to the cadets' vulnerability.

Our findings suggest that followers' vulnerability increases the likelihood that their trust in the leader will be eroded relative to the likelihood that trust will develop...Thus, the relationship between vulnerability and trust is more complex than the literature suggests in the sense that vulnerability not only creates the opportunity to trust, but also increases sensitivity to negative manifestations of the leader's behavior and consequently heightens the likelihood that trust will be eroded (2007, p.27).

Two categories are sometimes used to distinguish components of trust. Affect-based trust focuses on emotional or interpersonal antecedents such as care, concern, or benevolence. Cognition-based trust focuses on competence, reliability, and fairness amongst other characteristics. One study found that cognition-based trust when faced with cognitive conflict results in better understood, more detailed decisions, but that the restorative tool needed for the team post-conflict is affect-based trust (Parayitam and Dooley, 2007, p. 66). This sounds quite close to forgiveness, although it is not articulated directly as forgiveness by the researchers. Forgiveness does, nevertheless, appear in Table 1. The act of seeking 
forgiveness includes naming the offense, naming the consequences of the offense, listening to perspectives, considering the impact of this naming on the relationship, stating a clear direction of behaviour and belief that is positive and productive, following through on that direction, and treating the other person with care and respect while the memory of the offense softens and becomes "reunderstood” in the context of the relationship. Most clearly stated, it is a decision to carry the entire experience by the handle of forgiveness, rather than retribution. (Epictetus, interpreted by Lebell, p. 71). There is a metacognitive activity in this decision that "reframes" the entire event using the tools of humility, tolerance, compassion, understanding - and love. These are all affective states. There likely needs to be a behaviour demonstrated that means the affect-based trust is capable of carrying the relationship. Forgiveness articulates an understanding of our humanity, seeing the beauty in all the imperfection. Forgiveness constitutes an honouring of our sacred hearts (Vanier, 1998). Identifying trustworthy attributes in leaders is useful. It articulates what is valued, how, when and perhaps even why it is valued. In the words of a taxi driver in Belfast however, it is clear that having the attributes of trust is not enough.

Criminals are never angry. They are calculating, they know exactly what they want, and they are very cool and calculated. These are the people that can go into prison and can talk to psychiatrists, and they can bluff them and can make people think that they have changed their ways (Gambetta and Hamil, 2005, p. 51).

The display of attributes at the right time, in the right way and over time is significant to trust. The motives, in context, are always in play. 


\section{Chapter 3 Method}

The results for this study were found through secondary analysis of data that had been collected as part of a larger study carried out in a large number of American schools and school districts by other researchers (Louis et al., 2010; Leithwood et al., 2004). In the first stage of the study, the survey data from the larger study was analyzed to identify a sample of high- and low-trust schools. In the second stage of the study used, qualitative data from the larger study was used to answer the three research questions.

\section{Stage One}

Stage One of this study drew on teacher survey data collected in the larger study between March and June 2008. The teacher survey included questions about the teacher's trust in leaders. Responses to these questions were used to select three high-trust and three low-trust schools.

The survey had been mailed to teachers in 39 districts and 138 schools located in nine states, selected to represent the four quadrants of the United States. Schools and districts within states were selected using a stratified random procedure that over weighted the data for schools serving disadvantaged students. Each survey was accompanied by a blank envelope to ensure confidentiality. No one at the school site or school district had access to the teachers' responses.

The trust level in the schools had been determined by answers given to 17 questions. A six-point Likert scale, ranging from strongly disagree to strongly agree, was used and was consistent with the format of the larger survey. The questions were derived from Bryk and Schneider (2002) and from Tschannen-Moran (2004).

The questions from Bryk and Schneider (2002), who had studied schools in the Chicago school system, were as follows:

To what extent do you agree with the following statements?

- Our principal ignores weak teaching;

- When teachers are struggling, our principal provides support for them;

- Our principal ensures that all students get high quality teachers;

- In general, I believe my principal's motives and intentions are good;

- I feel free to discuss work problems with my principal without fear of having it used against me later; 
- Teachers support the principal in enforcing rules;

- The learning environment is orderly and supportive;

- In this school, the teachers and the administration are in close agreement on school discipline policy;

- In our school problems are viewed as issues to be solved, not as barriers to action;

- How many teachers in this school are willing to take risks to make this school a better place?

The questions from Tschannen-Morin (2004), who had studied 300 schools, were as follows:

To what extent do you agree with the following statements about your school administrator(s)?

My school administrator(s) ...

- Develops an atmosphere of caring and trust;

- Explores all sides of topics and admits that other opinions exist;

- Is willing to make changes;

- Models a high level of professional practice;

- Is effective in building community support for the school's improvement efforts;

- Promotes leadership development among teachers;

- Helps us find time for professional development.

The reliability of the scale including these questions was .894 (Cronbach’s Alpha).

\section{Selection of Schools}

All schools in the larger study were rank ordered according to the aggregated mean response of teachers to the 17 trust items on the survey. The three highest-ranked and lowestranked schools were selected for the second stage of this study. 
Table 2

Teacher trust-in-leader score

School

One

Two

Three

Four

Five

Six
State

Middle

South-west

Middle

South-west

Southern

Mid-west

\section{Level of Instruction}

Elementary

Elementary

Middle

Elementary

Middle

Elementary
Teacher Trust-

in-Leader

Mean $^{\mathrm{a}}$

5.84

5.78

5.64

4.59

4.26

1.0

${ }^{a}$ Maximum: 6

Each of the six schools used for this study is identified by a number, listed in Table 2 in the school column. Two of the schools are in the same middle state; two are in southwestern states and one each in a southern state and a mid-west state. Schools One, Two and Four provide instructional programs from Kindergarten to Grade 5. School Three programs are for students in Grades 7 and 8. School Five students are in Grades 5, 6, 7 and 8. School Six provides instructional programs to students from Kindergarten to Grade 4. The teacher trust in leader column indicates the mean of the scores of teachers on the teacher trust questions, within each school. The schools are arranged from highest to lowest scores on the teacher-trust-in-leader mean.

\section{Stage Two}

Survey data is viewed by some as a "weak" method for determining or for understanding trust (Ostrom et al., 2003, p. 14). Relational trust is highly contextual and often dependent on the opportunity for many interactions, where understanding and clarifying of thought and intent can occur (Hardin, 1998, p. 25). Lewicki refers to the "bandwidth" of a relationship, which reflects iterated interaction and multiple contexts. Hardin refers to "thick relationships" which also embeds trust and trustworthiness completely in context, familiarity and opportunity for reciprocity (Ostrom et al, 2003, p. 92). This limitation of survey data for measuring trust in leadership is part of the rationale for considering the data from the second, qualitative, stage of the study. Additionally, the study 
attempted to identify the antecedents of trust mentioned without direct questioning about trust. If trust does matter antecedents of trust should be embedded in the interview data.

\section{Sample}

Three to five teachers at each of the six high - and low-trust-in-leader sites volunteered to be observed and interviewed. The principal at each site was also interviewed. The study used relevant parts of the interviews, including but not limited to the direct trust questions, conducted with both teachers and the principal in all six schools.

\section{Instrument}

An extensive set of questions were asked of each teacher (Appendix A) and principal (Appendix B) who participated in the qualitative study. Full transcript results were examined for information relevant to the research questions.

\section{Data Collection and Analysis}

Interviewers observed each teacher teaching a class for approximately an hour prior to each interview. All interviews were tape recorded and transcribed. Principal interviews were also tape-recorded and transcribed. Answers to all questions were examined for evidence of "trust- relevant" data and separated from the other data gathered. The antecedents of trust identified in the literature review were used for initial coding of the data (Auerbach and Silverstein, 2003). Patterns in the responses that might identify high-trust or low-trust environments were identified.

The results of the teacher and principal interview data that involve leadership and trust without directly asking questions about the relationship of leadership and trust, and without sculpting questions to elicit direct answers about specific elements of antecedents of trust, is destined to be less than crisp. This backwards mapping approach to the issue of trust is something not done in previous research, although various authors have recommended it in their discussion of "next steps.” The difficulty in clear categorization of what is meant by words describing antecedents however, explains why backward mapping has not been done.

While most statements relevant to this research provide an example of a distinct antecedent and element, some statements made by principals and teachers represent several antecedents. Several examples of interview data serve to illustrate the difficulty of coding some evidence in relation to only one antecedent. Example One: School One, Teacher 1 
Interviewer (I): What student needs does your school do a particularly good job in addressing?

Response: The whole child.

I: Can you elaborate on that a little bit?

R: Everybody here is very good about caring for our kids. That starts with Ms. H., our principal. There are kids here and I'm sure it's every school, but their only meals are breakfast and lunch when they are at school. They are coming with the same dirty clothes every day. They are not being taken care of very well. People are always stepping up and doing the right thing for our kids. When our kids come and the water has been shut off and the electricity has been shut off, things are being rallied and things are getting take care of for our kids. There is a washing machine and a dryer here. We get the clothes washing during the day. It's just things like that all the time. The kids that didn't get a good night's sleep last night because there was complete chaos in their life; the police were there. Things like that, that happen consistently, we are taking care of our kids that aren't the educational part. This is the extra part. We are trying to teach them about things they are not getting taught at home, things that should normally be taught at home. We are giving them some extra things that we are teaching at school. I think that is what our school does well.

This teacher provides evidence of benevolence: positive intentions, although benevolence: extending good will is also a feature. The example also fits within the antecedent consistency because these positive intentions are demonstrated over and over again, and appear to cross several types of behaviours. Words like "everybody,” “it’s just things like that all the time," "things like that, that happen consistently,” point the reader towards consistency. The statement "Everybody here is very good about caring for our kids. That starts with Ms. H., our principal” expresses competence: setting an example. It also references caring, another antecedent of trust. It would be possible to break apart the statement, but in doing this, what is important is lost. Without directly asking the teacher which of the four mentioned possibilities she would like this statement coded as it is not possible to know where she most believes this statement belongs. And she may not believe the message is singular. People use information in many different ways, often with a multidimensionality of interpretation, even when they offer a single example. She might have a difficult time choosing the one true path as well, particularly if her intention, upon reflection, was more complex.

Example Two: School Five, Teacher 2

I: When would be the last time [the superintendent] came in and what was that about? 


\section{R: Last week.}

I: What did she do when she was here?

R: Apparently some teacher had thought there was some type of reprisal, what was the word now? He [the principal] was harassing some teacher. She wanted to let us know if that ever happens to come to her.

This is a good, albeit negative, example of loyalty: fears of reprisals or scapegoating are mitigated. It is also, however, clearly a negative instance of vulnerability: related to the dependence on the other person to act with good intention. To not include it in both would likely mean to miss the impact such an event would have on staff. Note that a "good intention" in vulnerability sounds similar to "positive intentions" in benevolence. In this instance I chose to code the example as vulnerability; a person's career affects livelihood and most aspects of their well being. Vulnerability in job security is a much more profound issue than benevolence, in my opinion. The example also speaks to personal regard for others: positive expressions of care and concern as a negative instance. It might also fit as a positive instance in fairness: just procedures assure people that a structure exists to protect their material self-interests in the long-run, in that a superintendent appears to have stepped in; but it would seem to be a negative instance as well, as most teachers would hope that the fairness component exists in the principal, their immediate supervisor.

Could this fit in competence: setting an example as a negative instance? What is the difference between competence: setting an example and integrity: modeling? The subject word creates a feel of difference. Competence is not the same as integrity, so the elements, while they seem the same, are not describing identical behaviours. In coding, the context has to be carefully considered, and it is personal to the actor as well as to the audience, so making choices about coding can be difficult. Having read the principal and teacher interview data at School Five, I settled on loyalty, vulnerability and personal regard for others as covering the possible intentions in the comment. The effect that harassment by the principal would have had on a staff is likely not overstated by its multiple placements.

Example Three: School Five, Teacher 3

I: Outside of formal professional development workshops and so on, where do you get your ideas for improving instruction? Who are the leaders in that?

R: If a certain department thinks that they need a little bit more help on assigned writing papers or solving word problems or whatever, we just get together and say can we have this one? We talk with the principal and usually he says yes. 
This statement fit cleanly into Respect: and the mutual dependencies that exist among various parties involved in this activity. This illustrates that it was possible to select a single antecedent and related element of trust. This happened frequently.

A component of the teacher interview data was analyzed by a doctoral student at OISE/UToronto. The level of agreement between me and the verifier on the placement in the antecedents was fairly high. The verifier selected fewer words when placing a statement in the table of antecedents. This may reflect less concern about the context of the statement, possibly related to the singularity of the task of coding a single interview. There was not complete agreement on the coding of statements, a situation very much related to the previously mentioned overlapping in the definition of terms. Please see Appendix C.

Trust is difficult to define, as noted in the review of literature. One of the reasons is the overlap of elements within the antecedents themselves. That is also the complexity and the richness. I have decided to respect the issues and not oversimplify or diminish the information that was generously shared by all who participated in the interviews.

\section{Description of Schools in this Study}

The six schools that were studied are described below and are organized from the school identified as having the highest trust in the school leadership to the one having the lowest trust, in surveys of the teaching staff. The highest trust school is called School One. The lowest trust school is called School Six. The results, in general, are reported within sections in order of highest to lowest trust school.

\section{School One.}

School One was an elementary school in a middle state, with 476 students according to the principal's interview report. The National Centre for Educational Statistics reports it has 420 students $^{4}$. Approximately $75 \%$ of the school community lived in poverty. It was a Title 1 school and made adequate yearly progress (AYP), but the school had to consistently

\footnotetext{
${ }^{4}$ Throughout the description of schools section, various school data details differ when comparing the interview data with the National Centre for Educational Statistics data, particularly as related to number of students attending the school. In the descriptions of schools section, data derives from details provided in interviews. In Table 3, the data derives from the National Centre for Educational Statistics (NCES). One can never be sure why the numbers would vary; however, my experience in schools is that the principal/ staff will be reporting numbers that are "head counts at this precise moment in time" whereas a national or provincial body will be reporting numbers gathered annually, often early in the school year. Schools often increase or decrease in size over the course of an academic year. In many schools the data that is truly telling are "ins and outs" by month because this relates to the stability, and often economic security, of the school population. This data was not available either from the staff report or from the NCES.
} 
struggle to achieve AYP, according to the principal. The school was in the process of becoming a magnet school, whose identified focus was to be global studies with international studies and cultural arts, a change that was to occur the following school year. School One would continue to be the home school for $50 \%$ of the student population; those who lived within its boundaries were entitled to attend, and the school was expecting to admit $50 \%$ of students who had expressed interest in this international baccalaureate focus.

The four teachers interviewed had experience that ranged from 4 to 25 years. One teacher had taught at the school for 23 years; one teacher had taught there for five of her six years of teaching; the third teacher had taught at the school for five of her five years of teaching; and the final teacher taught all four of her teaching years at the school.

As will be seen, the staff interviewed at School One's staff had relatively less experience than the staff interviewed at the other five schools. Two of the teachers had taught for their entire careers at School One and one teacher had had one year of experience, her first year, at a different school, before returning to School One, where she had done her practice teaching.

The principal's first experience at School One was as the school's assistant principal some time ago, a position she held for two years. She moved on to other positions and returned as principal of School One five years ago. She described herself as a person who read research on effective instructional strategies regularly.

\section{School Two.}

School Two was a Kindergarten to Grade Five school in a south-western state with approximately 400 students. The principal stated that about $80 \%$ of the children lived in poverty conditions. Two-thirds of the students were Navajo. “Technically” about 40 percent of the students were described as "second language," although the principal indicated that the students were

limited English speakers because (first) they are poor, that's probably more of an issue than the fact that they are Navajo, and then sometimes there is a second language background ... on a social language, they are as fluent as you or I ... what they don't have is academic vocabulary.

In almost all cases, the students who comprised the 40 percent identified as secondlanguage learners, had Spanish rather than Navajo as their first language.

This south-western state has a three-tiered licensure system for recognition of teacher qualifications. The principal described this school as "we're down to not very many now" 
(Level-One Licensed Teachers). Teaching experience amongst the five teachers interviewed ranged from 10 to 37 years. All five teachers had been teaching at School Two for at least seven years, and one had been teaching at School Two for 29 years. The teaching population within the school included seven teachers who were Navajo and one who was Laguna Pueblo.

The school had had three principals in the last 16 years. The current principal was in her fourth year at the school. It was her $16^{\text {th }}$ year as a school principal and this as her third principalship. She had been working in education as either a teacher or a principal for 36 years. Because the school had made AYP for the last two years it was no longer a part of the state school improvement status. The school made AYP in the principal's first year at the school and missed AYP in her second year. In terms of state involvement at the school, the principal indicated:

Well, other than the funding that I was able to get through that grant the state has, the best influence the state has had on us is leaving us alone. We kind of lucked out...we made (AYP) two years consecutively ... you have to do two years consecutively to get out of the school improvement process. I really have had few dealings with the state at all. AYP is described by the principal as "a bit of a crapshoot," her experience being "there is one way to pass and 35 ways to fail.

The school district had supported this school with grant money, which the principal had requested. The grant allowed the staff to become deeply engaged in curriculum analysis and understandings, and in particular, vocabulary development. This direction was an initiative of the principal, but all teachers interviewed indicated that the staff was completely supportive and engaged in this direction. In fact, the district was now visiting the school and implementing a number of strategies the school had used. The school district office itself "has been fairly stable this year." It seemed to the principal that the district was highly reactive to state pressure "and it has taken us awhile to be proactive." Based on the interviews, it would be fair to say that the district office had very little to do with this school's efforts at improvement, beyond some financial support to hire a consultant. When asked if there had ever been a district meeting where the topic was instructional issues, one teacher responded, "You know, I honestly ... it seems like it’s been so long.” To give credit where credit is due, when the principal approached the district and asked them to cancel a day of school so the staff could work with an external consultant, they approved this. 
According to the principal, the best influence the state has had "is leaving us alone." The state's standards were performance based and tightly linked to the test the state used to assess student performance. According to the principal, "If you know the standards, you'll do well on the test." While this linkage may seem to be self-evident, it was not true in every state. This school had been declared a "School on the Rise" by the state, and selected staff was able to attend a celebration in the capital city of the state, an event intended to honour these schools.

\section{School Three.}

School Three had eight classrooms of Grade Seven and Eight students with roughly 250 students in total. One teacher commented on the flood the school had experienced in 1999 saying "Water was in the school for around two weeks ... I think we are still recovering. We have certain spots in the floor that have mold, mildew and all that stuff.” It was a Title 1 school. They used the Title 1 money to fund tutors who came in. An extensive after school program ran four days a week until 6:00 p.m. The principal reported, "It is a poverty stricken area. We transport the kids' home in the afternoon from after school. We feed them when they are here.” School Three did not make adequate yearly progress for the second (or third) year in a row. They were struggling with scores in Math, and had many indicators to address ("We had more to address than any other schools in the county") in order to meet AYP in the next year.

A teacher who was upgrading her licensing mentioned teacher licensure in this middle state. Several of the teachers interviewed were doing graduate work at nearby universities. One teacher reported the state had a significant teaching shortage

because they don't pay as well as some states in teaching. So they opened up the possibility of people being able to come into teaching if you had a four-year degree in the subject area you are going to teach. Then you could take the necessary education courses while you were teaching.

Teaching experience amongst the five teachers interviewed ranged from 5 to 32 years. All five teachers had been at School Three for at least five years.

At the time of the interview, the principal was in her twelfth day as the principal of School Three. She had been working in the county for the past two years. She had been the assistant principal for eight months at School Three prior to being appointed principal, and had been the principal of a school for about a year at an earlier point in her career. After that she had returned to the classroom for personal reasons. In total, she had approximately eight 
years of experience in school administration when she was made principal of School Three, seven years as an assistant principal and one year as a principal. The previous principal had been at School Three for eight months before being appointed principal of a nearby secondary school. There had been five principals in five years at School Three, something the staff found frustrating. One teacher said, "Anyone here would tell you we want a principal to stay here for a while and not just come in and move on.”

The school district was small, with an economic divide occurring by regional geography. One teacher reported:

Typically the better school achievement is west of (I) 95, which cuts the center part of the state in the eastern part. Most of your lower performing, so to speak, would be east of (this street) which is where you find, I would speculate and I'm not sure of the exact statistic, that is where more of the Title 1 schools are actually at. Title 1 in (this middle state) also refers to the small rural because a lot of counties in the mountains of our state only have like three or four schools in the county because of the terrain and so they are considered Title 1 because of the economic disadvantage.

This teacher reported that the county was "a large county land wise, it's not a large county people wise.” Another teacher reported:

We are such a small county. Our superintendent knows us by name. Assistant superintendents know us by name ... We know everyone in central office and they basically know all of us. ... There is a real camaraderie of everyone knows each other and interacts with each other." In terms of stability at the central office, however, the perception seemed to be there was a great deal of turnover. The principal reported "somebody told me four superintendents in six years or something like that. They just don’t believe in anybody staying.

Despite the turnover, it was clear the district was involved in the day-to-day operations of the school. The curriculum director "pops in and does writing lessons and things in the classrooms.” Other reports supported the perception that district people frequently visited and the staff frequently visited the district office.

\section{School Four.}

School Four's student population spanned from Kindergarten to Grade Five with 600 students. The school had been under construction for the past year (or longer), which had required both patience and flexibility from everyone. The principal reported the population as being $85 \%$ mobile, with a high percentage of students moving out of the school in the autumn and returning in the spring. The school had met AYP every year except the past year. School Four was one of the few Title 1 schools still meeting AYP. Seventy percent of the 
students were on "free lunch.” In addition, the full inclusion policy for the school tended to attract students with special education needs, which affected the balance in the school.

There was no indication from the principal or the teachers regarding the licensure levels of the teaching staff. Like School Two, this school was within the same south western state and, consequently, licensure was related to credentials. Teaching experience among the three teachers interviewed ranged from 2 years to 20 years. The least experienced teacher had taught her two teaching years at School Four. One teacher had taught all 15 of her teaching years at School Four. The third teacher had been teaching at School Four 10 years, and teaching 20 years.

There was no assistant principal, although one teacher reported that she thought the principal may have given up the assistant principal position in order to hire an instructional coach. The principal reported he would not make an assistant principal a priority because it would have cost him six teaching assistants to do this, a cost some of his colleagues had borne, but one he was not prepared to incur. He had been principal at School Four for six years, and a principal in a capital city in the state for 30 years. He was planning to retire (again!) at the end of the current year, something about which two teachers express sadness.

The school district had been in a state of some flux because the superintendent left mid-year, taking a job in the south. A new superintendent had committed to being present in the district staring July $1^{\text {st }}$, but for the past number of months he had been coming in once or twice a week from a nearby capital city to meet people. An interim superintendent was handling the daily functioning of the district in the meantime. The principal reported "Everyone is kind of waiting to see what's going to happen.” The principal reported significant change at the state level as well, with an expansion in curriculum positions, and large turnover.

\section{School Five.}

School Five was a middle school in the southern states, comprised of approximately 500 students in grades 5, 6, 7 and 8. Free meal programs for breakfast and lunch served the $75 \%$ of the school population who were identified as living in poverty, although free meals were provided to all, as identification of the group that was not entitled to free meals was more effort than it was worth. Uniformed police had been in the school for several years, reportedly because of the presence of gangs and escaped convicts, possibly related to the number of prisons in the area as well as to the school's proximity to the Mexican border. The 
school had failed to meet AYP for the past two years. Tutoring was available both before and after school, and late buses ran to facilitate extended programming. There was significant focus on a large array of testing results, as evidenced in the conversation of the principal and the teachers. New programs had steadily been introduced to increase the scores on the various tests.

Licensure of teachers was not discussed. Three of the four teachers interviewed had been at the school for at least five years. It was unclear how long the fourth teacher had been there; however, the fourth teacher had spent eight years as a vice-principal at a neighbouring school before returning to the classroom, so she was an experienced teacher. Two teachers had careers prior to entering the teaching profession. The teachers were not unionized. The lack of job security was apparent in the interviews, although it was sometimes difficult to determine if it was only the lack of a union that had created a sense of vulnerability or it the issues with the district and the school principal were also a component of this. Teachers were paid for their "extracurricular" involvement. One teacher reported that one teacher teaches so she or he can also earn money for tutoring before or after. Another teacher who was at work at 7:45 a.m., as required of all teachers, began coaching the junior and senior football teams after school finished at 3:20 p.m. The teacher coached daily from 3:30 until 6:30 p.m. One teacher reported that the community, while supportive, was very focused on football and the band, with academics being of secondary importance. Teachers were required to sign-in to departmental meetings.

The principal was in his third year at School Five, his first school as principal. There was no indication of the length of his teaching career prior to this assignment, nor was it clear whether he had had experience as a vice-principal. He had worked previously for the army. The school had had three principals in the last nine years. There were two assistant principals at the school. Administrative bonuses were tied to test scores, which might have accounted, in part, for the tremendous focus on testing. A state-wide quota system quantified the expected frequency of administrative performance of walk-throughs. Performance appraisal of all teaching staff was done annually. The district appeared to be completely focused on test results, which reflected the focus of the particular state.

\section{School Six.}

School Six was a Title 1 elementary (Kindergarten to Grade 4) school in a midwestern state that had made AYP until this year. The school was scheduled to have 
extensive renovations in the coming year or so and students and staff would be moved to a neighbouring school temporarily. There was some community discussion about the merits of tearing the school down and rebuilding versus renovating. The school board elected to renovate.

The teachers interviewed were all experienced. The least experienced teacher had taught for 10 years; the most experienced teacher had taught for 43 years. All had been at the school for at least five years; one teacher had been at the school for 27 years. There was no indication of licensure levels related to the teachers interviewed; however, interview evidence revealed at least one of the teachers had a Master's degree in Education.

The principal had been a school principal for 15 years and had been at three schools. She had been at her first school as a principal for just over 10 years, the next school for three years, and this school for almost one year. She reported that she did not want to come to this school; she was told by the district that she had been assigned to the school anyway. The principal reported they told her they needed someone who was strong with discipline for School Six. She had worked in the same school district throughout her time as a principal.

Both the teachers and the principal provided interview data that indicated the transition for the current principal may not have been easy. The principal identified program delivery as a problem in the school when she arrived, and stated in the interview:

I think it's had a change in the teachers in the sense that there are some administrators that kind of go with the flow and they let teachers do what they want to do and then there's some that, my expectations are there and you have to do it my way, not my way so to speak, but the way it's designed with the corporation and I expect them to do it that way. As a result of that, usually, it's been my experience when I've gone to a building and I set the expectations high that teachers do job preferences and they leave. Because it's like, “we been used to doing it this way so why you comin' in and makin' a change?" I get paid to do a job and it has to be done the way the (school board) has outlined it to be or I don't feel that I'm doing my job.

The principal did report that a number of teachers had picked up "job preference” forms, a sign that at the very least some teachers were thinking about their "options."

There was very little comment about the district. Contract negotiations with teachers were occurring at the time of the interviews. The principal reported this was not adding stress; however, it seems likely there would have been added stress, even if it was not affecting daily work. There appeared to be monthly principal meetings. The principal 
reported her most frequent contact with the district office was when parents called to complain.

Table 3 summarizes some of the information found in the six schools that some researchers consider by to be related to trust in schools.

Table 3

School Information Sometimes Associated with Trust in Schools ${ }^{5}$

\begin{tabular}{|c|c|c|c|c|c|c|c|}
\hline & $\begin{array}{l}\text { School } \\
\text { One }\end{array}$ & $\begin{array}{c}\text { School } \\
\text { Two }\end{array}$ & $\begin{array}{c}\text { School } \\
\text { Three }\end{array}$ & $\begin{array}{c}\text { School } \\
\text { Four }\end{array}$ & $\begin{array}{l}\text { School } \\
\text { Five }\end{array}$ & $\begin{array}{l}\text { School } \\
\text { Six }\end{array}$ \\
\hline \multicolumn{2}{|l|}{ Grades } & K- 5 & K-5 & 7,8 & K-5 & $6-8$ & K-4 \\
\hline \multicolumn{2}{|c|}{ Size of Population } & 420 & 458 & 171 & 518 & 514 & 366 \\
\hline \multicolumn{2}{|l|}{ Title 1} & Yes & Yes & Yes & Yes & & Yes \\
\hline \multicolumn{2}{|c|}{$\begin{array}{l}\text { Student/ Teacher } \\
\text { Ratio }\end{array}$} & 15.4 & 13.3 & 10.7 & 14.0 & 12.5 & 16.5 \\
\hline \multicolumn{2}{|c|}{$\begin{array}{l}\text { Adequate Yearly } \\
\text { Progress }\end{array}$} & Yes & Yes & No & Yes & No & $\begin{array}{l}\text { No, but } 1^{\text {st }} \\
\text { year to have } \\
\text { missed it }\end{array}$ \\
\hline \multicolumn{2}{|c|}{$\begin{array}{l}\text { Years of Tenure of } \\
\text { Principal }\end{array}$} & 5 years & 4 years & 12 days & 6 years & 3 years & 1 year \\
\hline \multicolumn{2}{|c|}{ Free Lunch Eligible } & 195 & 307 & $\begin{array}{l}\text { Not } \\
\text { applicable }\end{array}$ & 242 & 217 & 263 \\
\hline \multicolumn{2}{|c|}{$\begin{array}{l}\text { Reduced Lunch } \\
\text { Eligible }\end{array}$} & 60 & 60 & $\begin{array}{l}\text { Not } \\
\text { applicable }\end{array}$ & 47 & 23 & 38 \\
\hline \multirow{5}{*}{$\begin{array}{l}\text { Racial } \\
\text { Diversity }\end{array}$} & $\begin{array}{l}\text { American } \\
\text { Indian/ } \\
\text { Alaska } \\
\text { Native }\end{array}$ & 3 & 299 & 2 & 59 & 0 & 2 \\
\hline & $\begin{array}{l}\text { Asian/ } \\
\text { Pacific } \\
\text { Islander }\end{array}$ & 7 & 1 & 0 & 24 & 3 & 6 \\
\hline & Black & 227 & 7 & 95 & 32 & 4 & 110 \\
\hline & Hispanic & 26 & 83 & 5 & 182 & 433 & 48 \\
\hline & White & 157 & 68 & 69 & 221 & 74 & 144 \\
\hline
\end{tabular}

In considering the antecedents, examples are offered that are illustrative of the antecedent and its element categories via direct quotes from teachers and principals in each school. School One was the school with the highest trust (in leader) rating, as identified on the survey of trust, by the teaching staff, and School Six was the lowest trust (in leader) school, as identified on the survey of trust by the teaching staff. I will indicate the number of

\footnotetext{
${ }^{5}$ Data related to grades, size of population, Title 1, Free Lunch Eligible, Reduced Lunch Eligible and Racial Diversity were gathered from National Center for Educational Statistics, 2008. Adequate Yearly Progress and Years of Tenure of Principal are gathered from the interview data. In some cases, the numbers given by principals or others in interviews do not match those reported by the National Centre for Educational Statistics.
} 
"thought units” for each antecedent, from highest to lowest trust schools, and then answer the research questions.

For qualitative work, reporting means narrative reporting that shows not only things that happened in the setting and the meanings of those happenings to participants, but the relative frequency of occurrence of those happenings - so that the reader gets to see rich details and also the broad patterns within which the details fit. The reader comes away both tree-wise and forest-wise-not tree-wise and forest-foolish, or vice versa (Erickson in Moss, Phillips, et.al, 2009, p. 504).

\section{Reporting of Results}

The results of the study appear in the next four chapters (4-7), with three or four antecedents of trust in leaders being covered in each chapter. Chapter 4 includes the antecedents benevolence, caring and competence, Chapter 5 reports on consistency and reliability, fairness, forgiveness and honesty, Chapter 6 reports the results related to integrity, loyalty and openness, and Chapter 7 includes the results related to personal regard for others, respect and vulnerability. The antecedents are alphabetically divided into chapters in order to assist the reader. In the case of each antecedent, the data includes quantitative counts of idea units related to trust identified in the transcribed interviews as well as a detailed description of the qualitative data. The results reported for each antecedent are organized around each of the three research questions driving the study. 


\section{Chapter 4 Results: Benevolence, Caring and Competence}

This chapter begins the report on the results about the antecedents of trust in leaders. In this chapter, the focus is on benevolence, caring and competence. The results are summarized quantitatively in Tables 4, 6 and 8 respectively and Tables 5, 7 and 9 compare high- and low-trust schools on these antecedents.

\section{Reading the Tables}

The tables in chapters 4 to 7 summarize the evidence used to answer the research question above.

\section{Evidence Tables}

At the top left corner of each table is the name of the antecedent is on which results are being reported. Proceeding to the right, the table is split into two categories of school trust-in-leader categories, high trust and low trust. The teacher and principal results are reported separately.

The names of schools are in the second row and are separate according to whether they are high trust or low trust. The next row identifies how many teachers could have responded (Max \# Teachers) and how many made statements related to the antecedent (Actual \# Teachers).

The fourth row of the second column is labelled elements, and the column under it lists elements/ sub-dimensions of the antecedent. The elements appear in order from the one with the highest number of respondents and thought units first to the one with the least.

In the fourth row, to the right of the word elements, is the heading for a column called totals for antecedent. The two columns below it summarize the data for all six schools, with the total number of (teacher) respondents who comment in relation to the element appear on the left, and the number of positive and negative statements related to the element beside it.

Below the four elements is a line called totals which is reporting the total thought units expressed about the antecedent, first the overall total and then the total by school. Two numbers appear here, the first is the number of positive thought units related to the antecedent, followed by the number of thought units that occurred that were negative (i.e., a lack of the antecedent).

The data for teachers and principals are reported separately as indicated in the tables. 
The elements of Benevolence then appear again. These are ordered according to the total number of (principal) respondents as well as the total number of thought units expressed by principals, the element with the highest number of respondents/ thought units appearing first, the rest following in descending order. The data for each school is beside the Totals for antecedent data, as in the teacher data. In all cases of principal data only one individual responded or did not respond, so the cell is greyed out. The total number of respondents within an element appears in the totals area along with the total number of positive or negative thought units. The rows identified as totals contain the total number of comments relate to the antecedent that were made by the teachers and the principals.

\section{Summary Tables}

The summary tables show the total number of respondents and thought records for each element of the antecedent. The data are sorted by high-trust and low trust schools and are listed in order from most frequent to least frequent. 


\section{Benevolence}

To what extent do teachers identify benevolence of the principal when engaged in conversation about educational practices?

Table 4

Evidence of Benevolence

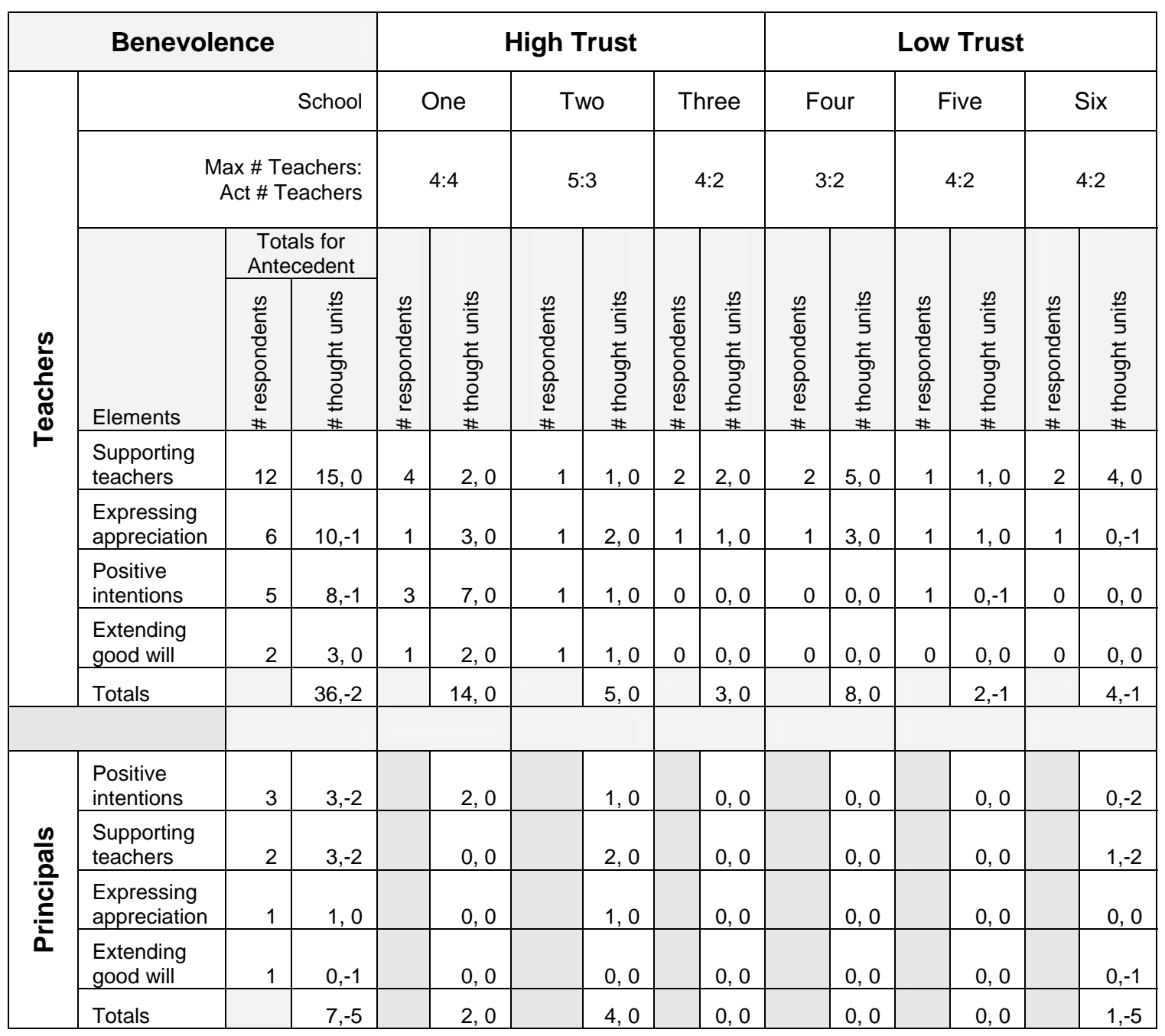

There were many more thought units indicating leader benevolence among teachers at the highest trust schools than in the other schools, a total of 22 positive statements as compared with the low-trust schools with 14 positive and 2 negative thought units. In sum, teachers did identify benevolence, an antecedent of trust, when engaged in conversation about their school's educational practices. They did not use the word benevolence, something that was generally true for all the antecedents. They described the elements or sub- 
dimensions of the antecedent using examples of situations, but more often teachers named actual behaviours they, or the staff, had observed.

Which elements of leader benevolence do teachers identify most frequently and what leader behaviours do they associate with those elements?

Analysis of the teacher comments (a "grounded" analysis) indicated four elements or sub-dimensions of benevolence, including:

- $\quad$ supporting teachers;

- $\quad$ expressing appreciation;

- $\quad$ positive intentions; and

- $\quad$ extending good will.

\section{Supporting Teachers.}

Teachers identified all of the sub-dimensions of benevolence; however, supporting teachers was identified most frequently and by the most number of teachers. Leadership behaviours that related to supporting teachers clustered around administrators being positive and encouraging of next steps, concrete actions, specific knowledge of individuals and particularly of children, and clear knowledge of classroom learning programs.

Examples of teacher comments about this element included:

School One:

She also understands that there are certain parents that we can't get in here at all. She has a policy that we all support because we believe in it too. (Teacher 2)

She gives us feedback, that we are doing a great job. (Teacher 4)

School Two:

That was one of the things that Dr. Marzano was just shocked to find out that we had so much work to do and we didn't have any turnover. I think the leadership is critical in keeping the staff together, focused. She is very understanding. If you are having a hard time comprehending something that's going on. She's right there. She is supportive. (Teacher 5)

School Three:

If there is a problem or not a problem, my principal backs me. She is there with me to support me. (Teacher 4)

School Four:

He is very supportive of your personal styles and very supportive of us using our professional judgment as how I might do that in our classroom and I appreciate that about him. (Teacher 1) 
He's been very supportive of the teachers and dealing with parents, more difficult parents. (Teacher 2)

I think he has and I can only speak for me, I know some teachers, he's had a harder time or they've had a harder time with him. I don't know what the whole story was, the teacher and the child. He does support us if he knows everything that is going on. (Teacher 2)

School Five:

He is very supportive in my opinion. Whatever we need, he is behind us and he supports us. (Teacher 1)

School Six:

She has been very supportive of every time that I have had a dealing with a parent. (Teacher 2)

She has even offered to help...even offered to help me with the computer, since I'm not good at it. (Teacher 2)

\section{Expressing appreciation.}

Expressing appreciation was identified less frequently and by half as many teachers

as supporting teachers. The related comments mostly identified specific actions or behaviours by leaders that were viewed as expressions of appreciation. The two lower trust schools gave examples of this element that were more conditional and less concrete.

Examples of teacher comments about comments about this element included: School One:

Ms. H. makes that a priority. Not just by giving you things, which she does. When you go to those monthly PLOT (Parents Lending Out Time) meetings she will put a little coupon in your box the next day where you can leave fifteen minutes early or you can have a free dress down day. Just things like that. She gave everybody on teacher appreciation week \$15.00 for Barnes and Noble. She gave us the lanyards for our new magnet school. It's not just those things, it's like I said, it's like leaving fifteen minutes early. Just things like that, when you go to those meetings, instead of being home that night, just a little token of appreciation for things like that. It's "I know you have to do one more thing, but here is how I'm showing you I know that you did. I'm acknowledging it. Being acknowledged. (Teacher 1)

School Two:

She’ll write me a nice not on my report card saying “good job.” (Teacher 4)

School Three:

Because you can get thanks. They always say that they appreciate what you do. (Teacher 2) 
School Four:

They make popcorn for us on payday. (Teacher 1)

School Five:

Every so often he will call just to let us know whether we are doing something right or wrong... a lot of times, it's this went good. The kids are saying that they like it. Good job. (Teacher 2)

School Six:

I feel valued here. I don't know that I don't get a lot of that from myself. I would say. (Negative instance, Teacher 2)

\section{Positive intentions.}

Positive intentions was ranked third, according to the teacher data. Most of these comments were similar to the element supporting teachers, reflecting that the leader was displaying positive behaviours related to the teacher's actions, and was encouraging of the teacher in relation to next steps. Specific knowledge of people, particularly children, was significant to teachers, as was concrete action in relation to classroom work part of the commentary related to positive intentions.

Examples of comments by teachers related to this element included:

\section{School One:}

Everybody here is very good about caring for our kids. That starts with Ms. H., the principal...People are always stepping up and doing the right thing for our kids, we are taking care of our kids that aren't the educational part. This is the extra part. (Teacher 1)

They are kind in their ideas. It's not done to be negative, it's just let me help you think of some of the different things you can do with this. (Teacher 2)

She gives us feedback, that we are doing a great job. She tells us to integrate more technology. The technology kind of scares me a little bit but she is very encouraging. Oh try it. You'll get it. She's very positive with that. She is very affirming and she will tell you that you are doing a great job on the lesson. She always seems to know what you are doing. (Teacher 4)

She is very affirming and she will tell you that you are doing a great job on the lesson. She always seems to know what you are doing. (Teacher 4)

\section{School Two:}

She is really a kind of person that makes sure she does positive first and then, I know, with some teachers she will use making sure that they have someone to look towards to help them with their classroom management for discipline.

(Teacher 2) 


\section{School Five:}

I: Is that what being valued means? Like you get praise from the principal when he comes through your room?

R: Right.

I: You said that feels good to get praise.

R: Yes, but I don't know if that is the case with everyone. (Negative instance, Teacher 1)

\section{Extending good will.}

Extending good will was fourth in terms of frequency and number of teachers citing examples related to this sub-dimension. Once again, the behaviours identified in the leader were very concrete and specific. The comment in School One indicated that knowing the students (children) in the school seemed to matter to teachers.

Examples of comments by teachers related to this element included: School One:

To me, she's not the typical principal. She knows every child. She knows something about the families. She has a very close relationship with the kids too. (Teacher 2)

School Two:

She has even hosted parties at her home for us. (Teacher 2)

Evidence from all schools indicated that benevolent behaviours were valued by teachers. In the two highest trust schools behaviours were identified that related to each of the four elements. In the highest trust school all four teachers referenced some element of work and school life that equated to benevolence. "Positive intentions" was repeatedly mentioned in the highest trust school, far beyond all other elements in any school. In the lowest trust school there were more comments related to the element "supporting teachers." Overall, teachers commented in every school about “expressing appreciation,” but it was mentioned in each school by only one teacher. Teachers commented in every school about the element "supporting teachers" and this element was seen, in total, in more teachers' transcripts. 
To what extent do principals and teachers hold similar views on the sources (or antecedents) of trust in principals?

Principals did describe components of the antecedent benevolence. They tended to use longer phrases, and the descriptions were generally of a situation that demonstrated benevolence rather than of specific behaviours.

The number of respondents and/or the number of related thought units resulted in the elements appearing in a different order than teachers, see below:

- positive intentions;

- supporting teachers;

- expressing appreciation; and

- extending good will.

\section{Positive Intentions.}

Positive intentions for principals included specific knowledge of people, but the focus of that knowledge, based on the relevant comments provided, appeared to be related to teachers and parents. Principals displayed understanding of a variety of stressors for both parents and teachers, and were pleased when the stressors did not get in the way of a productive relationship. Examples of comments principals made that reflect positive intentions included:

School One:

I want them to - I know that they can't always come to school, you know, I'm a working parent. I'm missing my oldest child's all day track meet today. What I expect of them is that they set a level of expectation at home that their child is going to come to school and be actively engaged in the learning process. Basically they are going to be respectful and responsible. They are going to keep those lines of communication between home and school open through phone calls, through e-mails, through communicating in our student agendas. Those are my expectations. Sometimes that's hard. In this age of cell phones parents are changing their cell phone numbers like I change the filter at home in the air conditioning unit. Sometimes that communication is hard. The parents that you need to speak to the most are the most difficult to reach...We are very fortunate too because we have some parents that will come in a little early to see the teacher, to eat breakfast and you can go sit down at a table in the cafeteria and have that discussion. You can go 'You know, I know you didn't have the opportunity to come the other night, but I just wanted to talk to you about some of the highlights we talked about.' We have that nice relationship, I think, with parents.

We are very fortunate too because we have some parents that will come in a little early to see the teacher, to eat breakfast and you can go sit down at a table in the cafeteria and have that discussion. You can go "You know, I know you didn't have 
the opportunity to come the other night, but I just wanted to talk to you about some of the highlights we talked about.” We have that nice relationship, I think, with parents.

School Two:

This is a great staff. The nice thing, the exciting thing about this for them, is there has been no turnover. We have had turnover in Special Ed and one bi-lingual. But in the classrooms, the classroom teachers, we've had no turnover at all. We're going to get to hire a new $5^{\text {th }}$ grade teacher next year, but that's because of enrollment increase. There are the same teachers that were in the school when it was in re-structure so it's really nice for them. Right now we have people coming over here from other schools to observe our classrooms. It's just, that's a real ego booster for these guys because they took a real beating when they were in corrective action.

School Six:

I think teachers when they get a new principal they kind of test the waters just like kids to see what they can get away with. (Negative instance.)

\section{Supporting teachers.}

Supporting teachers, for principals, related to providing professional development opportunities, positive, concrete feedback about the teacher or situation, and support or assistance for teachers when problems arise. Examples of principals' comment included: School Two:

I did have one person who has been really quite phenomenal who came and asked me if there was any chance they could go to a math conference that was in Austin, Texas that had to do with the way they teach math in Hong Kong. I was able to get funding through Title 1 for her to go to that. You know, that's something that's real direct. Indirectly, you want to be careful not to overly praise people because then you will have back stabbing going on, you know teacher's pet type thing. I think to give people, I think the best way honestly is to give people create (sic) so they come in and say "hey, I have this idea.” Well, I'll go back to A. Pasture. A teacher walked in and said, "I would really love to see what everyone else is doing is there any way we can put that on the computer?" So I took that idea and sent it off to the IT people and they created it. In essence, what that gave her was feedback that "I had a great idea and it bore through.

School Six:

One thing that I have done is that I always tell teachers that I support you as long as you are right. If you are correct in the way that you discipline a student then you have my $100 \%$ trust. You know, my support. There have been some situations that have happened here where teachers really need the principal to back them. I always gather all the information and I make it clear to teachers on day one. If you are correct, then I support you. If you're not, then you are out there by yourself. So, the one teacher that really is like the key person in this building. She had a terrible situation with a parent and I dealt with it and got the parent up off her back and she told everybody, 
“She’s okay...” I have heard teachers say, "Well, at least she's not afraid to talk to the parents.”

\section{Expressing appreciation.}

Expressing appreciation was addressed by principals, but in this case, it related to parent appreciation. Principals generally did not say a great deal about what they may (or may not) have done in terms of expressing appreciation for teachers. This might be a "kiss and tell” situation, where, in order to share a positive aspect of themselves with an interviewer (expressing appreciation gestures) they would first have to share what is sometimes seen as a less desirable attribute, what might be described as a bit boastful. Saying what an individual did is sometimes viewed negatively by others. One example of a principal comment related to this element follows:

School Two:

This school has more parent involvement than any school I have ever actually worked in...my parents are working poor...it's difficult to have room mothers or whatever, but I do have a core of volunteer parents that come in and work in classrooms a lot...they are very involved. I have a parent who coordinates all this. It's wonderful. We have almost $100 \%$ at parent conferences, we have a huge turn out at Open House.

This same principal used staff examples of both positive intentions and supporting teachers, both quite lengthy examples.

\section{Extending good will.}

Principals did not comment directly on extending good will, except in this instance, where the principal referenced the union steward.

School Six:

Yeah, she tries to dictate everything around here. (Negative instance)

The two principals at low-trust schools, as opposed to the lowest trust school, did not make comments related to benevolence. The principal at the lowest trust school did comment in the areas related to benevolence. She used roughly the same number of words as the hightrust principals, however, a quarter of her words were a disconfirmation of benevolence. The disconfirmation statements related directly to teachers.

Overall, principals made many fewer comments than teachers related to benevolence, and three school principals made no comments at all. The principal who was trusted the least made several negative statements related to benevolence and made the most comments related to this antecedent in total. 
There were differences between teacher words and principal words related to benevolence. Teachers tended to describe specific behaviours, related to the principal, briefly. Teachers in both high- and low-trust schools used their words sparingly. Principals described scenarios. The scenarios may have involved teachers, but they also involved parents. The principal in the lowest trust school was willing to articulate disconfirmation (negative instance) evidence.

In addition to differences in content and length, principals' evidence resulted in a different ordering of the elements of benevolence, with "positive intentions” appearing as the most commented on antecedent, followed by "supporting teachers," “expressing appreciation” and finally “extending good will.” There was very little comment on the last two elements, and the only comment regarding “extending good will” was a negative instance, made by the principal in School Six.

\section{Summary of Benevolence}

Table 5 places the elements in order from most frequent to least frequent. The frequency of teacher thought units in high-trust schools determines the order of the elements in the upper left quadrant of the table. The frequency of teacher thought units in low-trust schools determines the order of elements in the upper right quadrant of the table. Similarly, in the bottom left quadrant, the frequency of principal thought units in high-trust schools determines the order of the elements, as occurs in the bottom right quadrant of the table. 


\section{Table 5}

\section{Summary Comparison of High Trust and Low Trust: Benevolence}

\begin{tabular}{|c|c|c|c|c|c|c|}
\hline \multirow{7}{*}{ 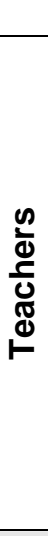 } & \multicolumn{3}{|c|}{ High Trust } & \multicolumn{3}{|c|}{ Low Trust } \\
\hline & Elements & 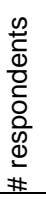 & 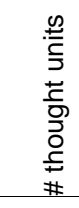 & Elements & $\begin{array}{l}\frac{0}{c} \\
\frac{1}{0} \\
\frac{0}{0} \\
\frac{0}{0} \\
\frac{0}{d} \\
\#\end{array}$ & 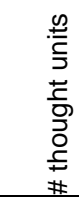 \\
\hline & Supporting teachers & 7 & 5,0 & Supporting teachers & 5 & 10,0 \\
\hline & Positive intentions & 4 & 8,0 & Expressing appreciation & 3 & $4,-1$ \\
\hline & Expressing appreciation & 3 & 6,0 & Positive intentions & 1 & $0,-1$ \\
\hline & Extending good will & 2 & 3,0 & Extending good will & 0 & 0,0 \\
\hline & Total & & 22,0 & Total & & $14,-2$ \\
\hline \multirow{5}{*}{ 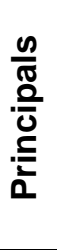 } & Positive intentions & 2 & 3,0 & Supporting teachers & 1 & $1,-2$ \\
\hline & Supporting teachers & 1 & 2,0 & Expressing appreciation & 0 & 0,0 \\
\hline & Expressing appreciation & 1 & 1,0 & Extending good will & 1 & $0,-1$ \\
\hline & Extending good will & 0 & 0,0 & Positive intentions & 1 & $0-2$ \\
\hline & Total & & 6,0 & Total & & $1,-5$ \\
\hline
\end{tabular}

When high- and low-trust schools were compared, the order of the elements changes, however, the effect of negative thought units (or positive thought units for that matter) has not been considered, only that they existed and have been totalled. While supporting teachers' ranks first among principals in the low-trust environments, it needs to be considered in light of the actual positive and negative indicators represented in the thought units.

Positive intentions appeared to be more significant to principals than to teachers, as an overall total, as the principals were describing their own actions, and had access to their own thoughts. "Thought, word and deed" would seem to apply. The deed is what mattered to teachers. Thought and word held relevance to principals, when considering themselves.

Teachers in high-trust schools used more words and examples that related to components of benevolence, and there were no disconfirmations of benevolence in high-trust schools. Supporting teachers drew the most respondents among teachers, and teachers in lowtrust schools had many more thought units about what this meant to them than teachers in high-trust schools. Positive intentions drew many more thought units and respondents in high-trust versus low-trust-in-leader environments, while expressing appreciation was commented on to a fairly similar level in both environments. 
Teachers in both high- and low-trust schools did not expand on benevolence in conversation about school and teaching life, in general. Teachers in high-trust schools used more distinct thoughts to describe positive intentions and expressing appreciation. Teachers in low-trust schools described in more detail thoughts related to supporting teachers, although these thoughts were more conditional. Overall, the phrases teachers used were short, narrowly defined, and limited in their descriptive language. "Very supportive," "very positive," "very close” were phrases that appeared throughout this antecedent. Actual descriptions of what "very" described, or why the word "very" was present, were absent. Based on the comments, teachers saw supporting teachers as most important. Principals saw positive intentions, as most important. It might be concluded that there are many ways of knowing, but actions seem to speak louder than intentions.

The substance of the thought units related to benevolence suggested that benevolence was not particularly important to teachers. However, the contrast in number of teachers who made comments and the number of comments made between high- and low-trust schools may belie this conclusion. 


\section{Caring}

To what extent do teachers identify influences on their trust in principals when they are engaged in conversation about their school and the school's leadership?

Table $6^{6}$

\section{Evidence of Caring}

\begin{tabular}{|c|c|c|c|c|c|c|c|c|c|c|c|c|c|c|c|}
\hline \multicolumn{4}{|c|}{ Caring } & \multicolumn{6}{|c|}{ High Trust } & \multicolumn{6}{|c|}{ Low Trust } \\
\hline \multirow{9}{*}{ 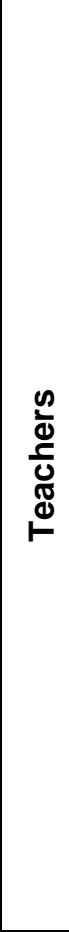 } & School & & & \multicolumn{2}{|c|}{ One } & \multicolumn{2}{|c|}{ Two } & \multicolumn{2}{|c|}{ Three } & \multicolumn{2}{|c|}{ Four } & \multicolumn{2}{|c|}{ Five } & \multicolumn{2}{|c|}{ Six } \\
\hline & $\begin{array}{l}\text { Max \# } \\
\text { Teachers: } \\
\text { Actual \# }\end{array}$ & & & \multicolumn{2}{|c|}{$4: 3$} & \multicolumn{2}{|c|}{ 5: 4} & \multicolumn{2}{|c|}{$4: 1$} & \multicolumn{2}{|c|}{$3: 1$} & \multicolumn{2}{|c|}{$4: 1$} & \multicolumn{2}{|c|}{$4: 1$} \\
\hline & & \multicolumn{2}{|c|}{$\begin{array}{c}\text { Totals for } \\
\text { Antecedent }\end{array}$} & \multirow[b]{2}{*}{ 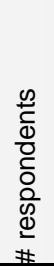 } & \multirow[b]{2}{*}{ 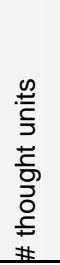 } & \multirow[b]{2}{*}{$\begin{array}{l}\frac{0}{0} \\
\frac{0}{0} \\
0 \\
0 \\
\frac{0}{0} \\
\stackrel{0}{0} \\
\#\end{array}$} & \multirow[b]{2}{*}{ 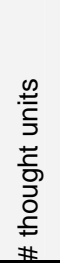 } & \multirow[b]{2}{*}{ 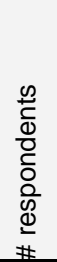 } & \multirow[b]{2}{*}{ 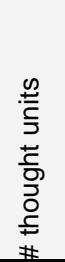 } & \multirow[b]{2}{*}{ 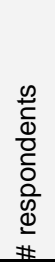 } & \multirow[b]{2}{*}{ 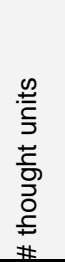 } & \multirow[b]{2}{*}{ 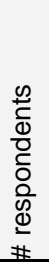 } & \multirow[b]{2}{*}{ 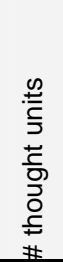 } & \multirow[b]{2}{*}{ 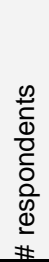 } & \multirow[b]{2}{*}{ 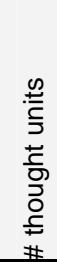 } \\
\hline & Elements & 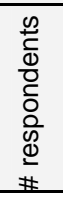 & 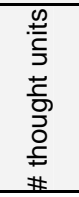 & & & & & & & & & & & & \\
\hline & $\begin{array}{l}\text { Situation/ } \\
\text { person } \\
\text { specific } \\
\text { (tenderness) }\end{array}$ & 5 & 5,0 & 1 & 3,0 & 3 & 1,0 & 0 & 0,0 & 1 & 1,0 & 0 & 0,0 & 0 & 0,0 \\
\hline & $\begin{array}{l}\text { Direct, } \\
\text { intentional }\end{array}$ & 4 & 4,0 & 3 & 3,0 & 1 & 1,0 & 0 & 0,0 & 0 & 0,0 & 0 & 0,0 & 0 & 0,0 \\
\hline & $\begin{array}{l}\text { Personally } \\
\text { chosen, not } \\
\text { directly } \\
\text { rewarded }\end{array}$ & 4 & 4,0 & 2 & 2,0 & 1 & 1,0 & 1 & 1,0 & 0 & 0,0 & 0 & 0,0 & 0 & 0,0 \\
\hline & $\begin{array}{l}\text { Behaviour } \\
\text { specific } \\
\text { (toughness) }\end{array}$ & 2 & $1,-2$ & 0 & 0,0 & 0 & 0,0 & 0 & 0,0 & 1 & $1,-1$ & 0 & 0,0 & 1 & $0,-1$ \\
\hline & Totals & & $14,-2$ & & 8,0 & & 3,0 & & 1,0 & & $2,-1$ & & 0,0 & & $0,-1$ \\
\hline \multirow{5}{*}{$\begin{array}{l}\frac{n}{\mathfrak{0}} \\
\frac{0}{0} \\
\frac{0}{2} \\
\frac{1}{2}\end{array}$} & $\begin{array}{l}\text { Situation/ } \\
\text { person } \\
\text { specific } \\
\text { (tenderness) }\end{array}$ & 0 & 0,0 & & 0,0 & & 0,0 & & 0,0 & & 0,0 & & 0,0 & & 0,0 \\
\hline & $\begin{array}{l}\text { Direct, } \\
\text { intentional, }\end{array}$ & 0 & 0,0 & & 0,0 & & 0,0 & & 0,0 & & 0,0 & & 0,0 & & 0,0 \\
\hline & $\begin{array}{l}\text { Personally } \\
\text { chosen, not } \\
\text { directly } \\
\text { rewarded }\end{array}$ & 0 & 0,0 & & 0,0 & & 0,0 & & 0,0 & & 0,0 & & 0,0 & & 0,0 \\
\hline & $\begin{array}{l}\text { Behaviour } \\
\text { specific } \\
\text { (toughness) }\end{array}$ & 1 & $0,-1$ & & 0,0 & & 0,0 & & 0,0 & & 0,0 & & $0,-1$ & & 0,0 \\
\hline & Totals & & $0,-1$ & & 0,0 & & 0,0 & & 0,0 & & 0,0 & & $0,-1$ & & 0,0 \\
\hline
\end{tabular}

\footnotetext{
${ }^{6}$ For an explanation of how to read the table, see reading the tables in chapter 4 .
} 
Teachers did acknowledge demonstrations of leader caring in conversation with interviewers. The school with the highest trust in the leader also had the most number of thought units about caring expressed, by the greatest number of teachers. There was a large difference in the recorded evidence of caring between high- and low-trust schools. Teachers provided 12 statements related to caring in the high-trust schools, as compared to 3 positive and 2 negative statements in the low-trust schools. Behaviour that expressed caring that is direct, personal and exhibits aspects of tenderness drew the most thought units.

Which elements of leader caring do teachers identify most frequently and what leader behaviours do they associate with those elements?

Caring has four element categories, including behaviours that are:

1. oriented to a specific situation and person (sometimes tenderness);

2. direct, intentional and face to face;

3. personally chosen and not directly rewarded; and

4. oriented to a specific situation and person (sometimes toughness).

Oriented to a specific situation and person (sometimes tenderness).

Behaviour oriented to specific situation and person, (sometimes tenderness) focused on both specific care of students and of staff. It was both personal to the person and more broadly staff related, and related to professional skills or contributions as well as to understanding of individual situations. Examples of comments by teachers related to this element included:

School One:

When my husband was deployed she supported me those times that I had to do things and I couldn't be at meetings because of my son. That's the kind of place you want to come back to. (Teacher 2)

The other thing is nice is they allow us to have the children go to them for good things. (Teacher)

When I first came on board, L. told me family comes first. (Teacher 2)

I think my school is very good at just taking care and loving the children here. (Teacher 4)

School Two:

She will, she tried to help you find someone that can help you learn. (Teacher 2) 
She listens and validates the things we are doing. (Teacher 3)

School Four:

He tells us all the time. He really does. (Teacher One)

Direct, intentional, face to face.

Direct, intentional, face to face, much like behaviour oriented to specific situation and person (sometimes tenderness), was personally enacted and understood by staff as being a one to one relationship. Both personal and instructional reasons were significant.

Examples of comments related to this element included:

School One:

She knows every child. (Teacher 2)

It's always been run (data). It's always given me the papers, but this is the first day that she actually came in and was like "Here, let's talk about it. Let's sit down. (Teacher 1)

School Two:

I'm sure there's one or two that do not feel valued, but the majority do. (Teacher 2)

Personally chosen, not directly rewarded.

Personally chosen, not directly rewarded comments indicated teachers acknowledged the principal was focused on large goals which may not have been rewarding to her or him personally. Examples of comments by teachers related to this element included:

School One:

For the first open house of the year she has cooked hot dogs so the people will come in to get free food. (Teacher 1)

She used to give away coupons for the washer dryer because not everybody has access to a washer and dryer that lives in this neighbourhood. People could come up and use our washer and dryer at the school to wash their clothes, as long as they attend. (Teacher 1)

School Two:

We primarily focus on the Marzano piece with Dianne Painter, but we are always encouraged. (Teacher 5)

School Three:

Ms. S. has been a Godsend because she's proofed a lot of papers for me, just given me ideas about, well I would say it this way or go back and check this fact. (Teacher 1) 


\section{Oriented to specific situation and person (sometimes toughness).}

Behaviour oriented to specific situation and person, sometimes toughness, not surprisingly, indicated awareness of a quiet, but "felt" presence (both appreciation and direction). Examples of comments by teachers related to this element included:

School Four:

He is not a very - he is a little bit formal. He is a little bit - he is not a touchy feely kind of person. He is not one of those to come up and give you a big hug or anything like that and he is very professional, but he will let us know. (Teacher 1)

School Six:

I mean, she never really has said anything. I just get messages, “call this parent or that parent. (Teacher 1 )

It may be that teachers did not feel caring behaviours were very important in the workplace, and therefore they were not demonstrated, or teachers may not have commented on caring behaviours even if they were demonstrated. Caring behaviours may have been demonstrated as a result of some element of personal vulnerability, and individuals, whether teacher or principal, may have been unlikely to expose this. It may have been that the interviews were not structured in such a way as to invite comments related to caring behaviours. Regardless of the reason(s), caring behaviours were not widely reported in this data. Teachers did not regularly or frequently identify caring behaviours when engaged in conversation about their school and the school's leadership.

To what extent do principals and teachers hold similar views on the sources (or antecedents) of trust in principals?

Apart from the principal who described following the scenario, quite a negative instance of caring, there was no interview data from the principals that fit in caring.

\section{Oriented to specific situation and person (sometimes toughness)}

School Five:

I guess one of the biggest things that I can tell you about trust is one teacher decided to donate part of her liver to her aunt in California. I said, "I trust that you are going to do the right thing. But I also trust that you are going to do well with the kids before you leave.” The lady left everything intact for the sub to go $100 \mathrm{mph}$ and the Reading scores showed that that was the case. Not that I could have kept her from doing that, but I trusted her that she was able to fulfill her duty as a teacher. I'm very big on that. That they need to fulfill their duty. 
Principals did not describe caring in the interviews. This was quite similar to teachers who made minimal mention of caring.

\section{Summary of Caring}

Table $7^{7}$

Summary Comparison of High Trust and Low Trust: Caring

\begin{tabular}{|c|c|c|c|c|c|c|}
\hline & \multicolumn{3}{|c|}{ High Trust } & \multicolumn{3}{|c|}{ Low Trust } \\
\hline & Elements & 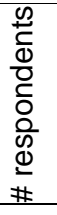 & 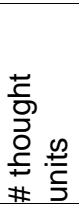 & Elements & 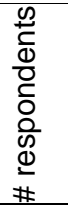 & 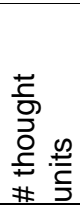 \\
\hline \multirow{5}{*}{ 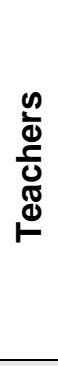 } & $\begin{array}{l}\text { Situation/person specific } \\
\text { (tenderness) }\end{array}$ & 4 & 4,0 & $\begin{array}{l}\text { Situation/ person specific } \\
\text { (toughness) }\end{array}$ & 2 & $1,-2$ \\
\hline & Direct, intentional & 4 & 4,0 & $\begin{array}{l}\text { Situation/person specific } \\
\text { (tenderness) }\end{array}$ & 1 & 1,0 \\
\hline & $\begin{array}{l}\text { Personally chosen, } \\
\text { not directly rewarded }\end{array}$ & 4 & 4,0 & $\begin{array}{l}\text { Direct, intentional, } \\
\text { face to face }\end{array}$ & 0 & 0,0 \\
\hline & $\begin{array}{l}\text { Situation/ person specific } \\
\text { (toughness) }\end{array}$ & 0 & 0,0 & $\begin{array}{l}\text { Personally chosen, } \\
\text { not directly rewarded }\end{array}$ & 0 & 0,0 \\
\hline & Total & & 12,0 & Total & & $2,-2$ \\
\hline \multirow{5}{*}{ 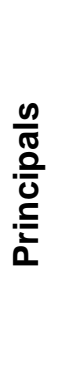 } & $\begin{array}{l}\text { Situation/person specific } \\
\text { (tenderness) }\end{array}$ & 0 & 0,0 & $\begin{array}{l}\text { Situation/ person specific } \\
\text { (toughness) }\end{array}$ & 1 & $0,-1$ \\
\hline & Direct, intentional & 0 & 0,0 & $\begin{array}{l}\text { Situation/person specific } \\
\text { (tenderness) }\end{array}$ & 0 & 0,0 \\
\hline & $\begin{array}{l}\text { Personally chosen, } \\
\text { not directly rewarded }\end{array}$ & 0 & 0,0 & Direct, intentional & 0 & 0,0 \\
\hline & $\begin{array}{l}\text { Situation/ person specific } \\
\text { (toughness) }\end{array}$ & 0 & 0,0 & $\begin{array}{l}\text { Personally chosen, } \\
\text { not directly rewarded }\end{array}$ & 0 & 0,0 \\
\hline & Total & & 0,0 & Total & & $0,-1$ \\
\hline
\end{tabular}

Teachers tended to be quite concrete in describing caring, however, there was so little representation in some of the elements that focus on this antecedent, given the evidence provided, may not be warranted.

Behaviour oriented to specific situation and person (sometimes toughness), was not represented in any of the high-trust teacher data. It was, however, present in two low-trust schools. In the two thought units present in this element, the focus was on staff, one being instructionally focused, the other personally focused. It was not possible to determine the significance of this data, but it may have been significant.

Principals made no comments in high-trust environments regarding this antecedent. The only comment made by principals was a negative instance of behaviour oriented to

\footnotetext{
${ }^{7}$ For an explanation of how to read the table, see reading the tables in chapter 4 .
} 
specific situation and person (sometimes toughness). Negativity in this area may have had no effect, or it may have been significant. Given the absence of other comment it was not possible to determine this from the evidence.

\section{Competence}

To what extent do teachers identify competence when they are engaged in conversation about their school and the school's leadership?

Table $8^{8}$

Evidence of Competence

\footnotetext{
${ }^{8}$ For an explanation of how to read the table, see reading the tables in chapter 4 .
} 
62

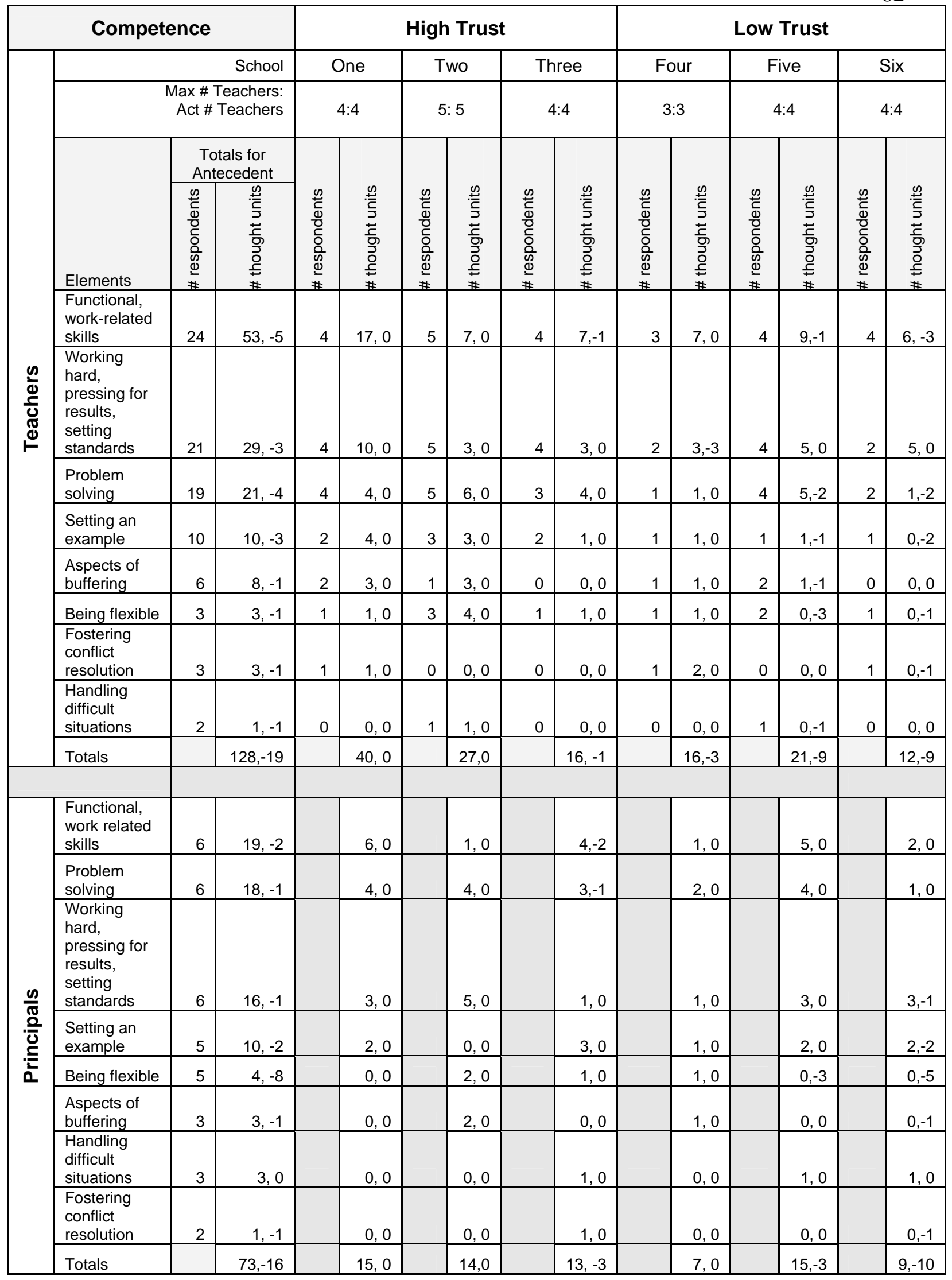

All teachers made comments in elements included in the antecedent competence.

Functional, work related skills as well as working hard, pressing for results, setting standards 
drew by far the most comment. Teachers articulated detailed thought units, with the total number of negative thought units for the antecedent aligning the schools in precisely the order of highest trust in leaders to lowest trust in leaders. In high-trust schools teachers made 83 positive comments about competence and 1 negative comment. In low-trust schools teachers made 49 positive comments and 21 negative comments.

Which elements of leader competence do teachers identify most frequently and what leader behaviours do they associate with those elements?

Competence has eight elements. These are presented in order, from most to least frequently commented on, overall. The element categories are:

1) functional, work-related skills;

2) problem solving;

3) working hard, pressing for results, setting standards

4) setting an example;

5) some aspects of buffering;

6) being flexible;

7) fostering conflict resolution (rather than avoidance); and

8) handling difficult situations.

\section{Functional, work related skills.}

Functional, work related skills was identified most frequently and by every single teacher interviewed. This was the only sub-dimension to be addressed unanimously in the commentary, not only within competence, but across all sub-dimensions in all antecedents. Leadership behaviours that teachers identified related to functional, work related skills included visibility of the principal, which was often identified by teachers as presence in the classroom or classroom observations. It often included the principal being involved with classroom learning activities and planning, and feedback from the principal regarding what the principal saw when they were in classrooms or planning with teachers, either formally or informally. Professional development of staff was seen as related to this sub-dimension in School One, and structures creating a smooth and effective workplace were seen across competence, but within this sub-dimension as well.

Examples of teacher comments about this element included: School One: 
Ms. $H$. is very forward thinking in providing opportunities for the staff and seeking out professional development for the staff and sending us to relevant places. (Teacher 1)

The whole school works on the positive reinforcement, the token economy system and all that kind of stuff. Beyond that, just following the O. County Schools handbook, if you do this, then this happens basically. (Teacher 1)

They just come in and it might be like seven minutes to see how the kids are doing. It keeps it so the kids are comfortable. It's not like 'Oh, the principal walked in.' (Teacher 2)

She came in one time and observed my children when we were talking about Afghanistan. The kids had learned different information about the children there compared to here. She actually brought in some readings that she had been doing about Afghanistan so it's kind of neat because she got to share with the children. (Teacher 2)

At the beginning of the year, she came up to me and she goes 'Do you have any $\mathrm{M}$ and M's?' I said 'Yeah, I do. How do you know I did?' She said 'Well, I saw in your lesson plan that you are doing an $\mathrm{M}$ and $\mathrm{M}$ graph. One of the kindergartners came in and needed M and M's for something. Do you have some?' I was like 'Sure'. She always seems to know what is going on with everybody. It's wonderful. (Teacher 4)

We turn our lesson plans in to her on Monday. She reviews our lesson plans. The cultural arts and global studies. She gives us feedback, that we are doing a great job. (Teacher 4)

School Two:

She'll come in and do scripted notes of what she sees and makes feedback from that. It is a little bit different procedure if you're on formal. She is very specific, which is nice. She will talk about the lesson itself. (Teacher 1)

The standards based units that we have developed using the state standards and benchmarks and unpacking them. Like, she has taught us to learn the meat of what we need to do in order to add on proficient students at every grade level. That's how I would see it. (Teacher 4)

But four years ago she was instrumental in getting us a consultant from the Robert Marzano Associates, so Dianne Painter is and Robert Marzano have both been on our campus. We are using strategies that they both have found through research work the best. The vocabulary strategy you saw us doing was a Marzano piece. D.B., our principal, keeps in close contact with Dianne Painter and she goes to workshops. Then when Dianne can't be with us, she supplements with the training. (Teacher 5)

Having a common prep. I have waited 30 years in education without a prep period. (Teacher 5)

She pops in on what she calls a pop visit. (Teacher 5) 
School Three:

She will just come in and make herself visible, stay in and even initiate assistance of the students. They are very good at assisting us with instruction. You know, they try to get all the materials that we need and ask for. (Teacher 2)

School Four:

He will do things kind of interesting little things like he will deliver our paychecks to us. I think it's his way of making sure that he actually gets into the classrooms, which I like. (Teacher 1)

He doesn’t stay long, but he is in and out of the classrooms. (Teacher 1)

He just gives us things that he saw happening that he liked. He might tell us sometimes, there is something that we didn't even notice, a child over there doing something that we didn't notice but he is very good about giving information back without it being in a threatening way at all. (Teacher 1)

School Five:

They make recommendations of what they saw... Let's say you need to keep an eye on those girls in the back. They don't seem to be doing their work. You need to walk around more and check on kids. Just little things like that. (Teacher 2)

I would say once or twice a month. Not too much. I don't think they should be in there much more than that, because a lot of times when they walk in the kids get distracted. (Teacher 3)

I think our school does a particularly good job in achieving the objectives that are delineated by the state. In other words, that is what is non-negotiable. You know what I mean? I think that our strongest suit would be in meeting the state requirements. (Teacher 4)

School Six:

She has a chart that she actually put up for visits. (Teacher 1)

I think that she has been in enough to know that I am on top of things. (Teacher 1)

They make recommendations of what they saw...Let's say you need to keep an eye on those girls in the back. They don't seem to be doing their work. You need to walk around more and check on kids. Just little things like that. (Teacher 2)

Working hard.

Working hard, pressing for results, setting standards was identified less frequently

than functional, work related skills, but was still seen as highly relevant to teachers. All teachers in high-trust schools made comments in this area, and there were teachers in all schools whose comments related to this sub-dimension. Support for teachers when working 
with parents, and skills when working with parents, as well as involvement with classroom learning activities and planning, professional development and creating a smooth and efficiently functioning school environment were teacher identified leadership behaviours. Examples of comments by teachers related to this element included:

School One:

In the morning she expects us to be greeting our students at the door. (Teacher 1)

We also have a Friday Footnotes. Every Friday she sends us messages when we are working on upcoming things. She shares that with us - one when she hires us. She also shares every time at the staff meetings, different expectations. She likes that Friday Footnotes. (Teacher 2)

She wants us to ensure that we attend our PT(A) meetings, that we are communicating regularly, that our kids have planners, that every week you are trying to write like a little note to the parents, she want us to have the monthly newsletters, she wants us to try to meet with parents at least twice a quarter... She has a policy that we all support because we believe in it too, that if a parent wants to come to the classroom, the parents comes and visits the classroom. (Teacher 2)

They poke in regularly to check on the children, just to see what's going on. (Teacher 4)

\section{School Two:}

But as a school right now, we are working really hard on going through our curriculum standards based units. As a grade level we had done quite a bit with the reading before just making sure that everyone is on the same track so make sure that each of the kids is getting the same material in the reading groups. But it was because of her guidance that we went into making the standards based units. (Teacher 2)

The principal expects us to be in communication with our parents. I have to be very specific about the student goals and parent responsibility with this. (Teacher 3)

School Three:

We are supposed to contact parents, keep the parents informed of all aspects of the academic, behavior - good behavior and bad behavior. High academics, low academics. (Teacher 4)

School Four:

We all of course have to teach the same information. We have to follow the standards. (Teacher 1)

School Five:

Well, we have to turn in a list of our parent phone calls and he requires a certain number of parent phone calls per six weeks. (Teacher 1 ) 
We also have a parent liaison and if you have any problems you contact her and let her know. Fill out a form and she gets hold of the parent whether she needs to go there or call but she gets the parents in for conferences and of course he really wants that happening for us to be meeting with the parents. We have something called the PAC meetings, Parent Academic Conferences and we have those, I think twice a year, once in the fall and once in the spring. (Teacher 1)

I know technology and technology staff development became very important and Thursdays became taken over by technology training for teachers for us to have a certain minimum level of competence with technology. (Teacher 4)

He expects frequent phone contacts, frequent communication. He would like to see more of me personally in terms of technology and like a website and stuff like that. I would love to do that. I will... what I know the principal would like of me is to if you go to our district webpage you will see my picture and my conference time. I could add more to that so that the parents could log on and get more information. That is a goal for me. Right now, it's more a phone call. (Teacher 4)

School Six:

I know that every child when they go down to the office has to have a red folder and within that red folder all the notes for any discipline problem are included in that...she is very, very stern with discipline. I think she does a good job with that. (Teacher 1)

\section{Problem solving.}

Problem solving was commented on by all teachers in the two highest trust schools, and was commented on in every school, although not by all teachers, almost as frequently commented on as working hard. In the four highest trust schools all comments were positive. Leadership behaviours that related to problem solving included professional development of staff and support for teachers when working with parents as well as skills when working with parents. Examples of comments by teachers related to this element included:

School One:

We did have J.N. who helped us to understand how to use the reading diagnostics. Mrs. H. (the principal) arranged for L.T. to come from the county office, I think it was three times to help us interpret the data... we have had formal opportunities...J.N., not so much (help), ...L.T., on the other hand, brought in some new stuff. (Teacher 2)

School Two:

Of all of the time that I've been here I have had three principals, I think, that I have been under at this school. Since I have started here there has always been the problem of language development and we have always known that there are so many students that are lacking in their language base and she is really the only one that has taken steps to address that and to make changes in that. The real "how-to." Before, we 
always identify-identify-identify the problem, but as a school we weren't able to school-wide align things enough to really make a change in the problem The things we have done as a school-wide development are steps in making a change in that. (Teacher 3)

School Three:

He's the one that taught me how to use the graphing calculator because we did not have graphing calculators for all our eighth graders last year and that was one of the first things he did is he said that every eighth grader needs a graphing calculator for eighth grade. (Teacher 3, note: this comment refers to the previous principal, who left the school 12 days before the interviews)

We have what we call math-wise. Every two weeks we have a principal's quiz. It is just math problems that the principal gives the students. He had at the beginning of the year, he gave us a list of problems. Two weeks I want you to work on maybe computation, fractions, adding and subtracting. I want you to work on decimals and then after you work on the two weeks, that Friday there was a test. Then in my class, Ms. S. did that with language arts. There was a topic and they worked each day on it and then after a certain length of time we put it all together and that was it. (Teacher 4)

School Four:

He has a very, I don't know how he did it, but over a period of a couple of years, he was actually able to make those people choose to move on. Either retire or move on. It was good. It was kind of a cleansing... (Teacher 1)

School Five:

R: We have two or three parent conferences where we invite them up here and hand them the report cards. He is definitely making an effort to involve the community. Not all of them show up but a lot of them do. More parents are showing up now than ever have.

I: What do you see is being done differently that might account for that?

R: Just the fact that he is involved with them. He really does. (Teacher 2)

We have two or three parent conferences where we invite them up here and hand them the report cards. He is definitely making an effort to involve the community. Not all of them show up but a lot of them do. More parents are showing up now than ever have...Just the fact that he is involved with them.”(Teacher 2)

School Six:

Even when we go out to workshops together we might come back and I say, 'I really like this, what do you think about this?' And she'll say 'hey, maybe I can even come up and work with you in your classroom and we can try it.' Or whatever. (Teacher 4) 


\section{Setting an example.}

Setting an example was commented on in each school, but the number of teachers making comments related to setting an example was half that of problem solving, and the number of related thought units was much fewer than the preceding sub-dimensions. Leadership behaviours related to setting an example included involvement with classroom learning activities and interactions with students, interaction directed towards building a friendly, welcoming environment, interaction that focused on instructional needs including planning and the professional development of staff, and development of structures within the school that created a smooth and effectively functioning facility, including discipline.

Examples of comments by teachers related to this element included:

School One:

She will be in the hallway in the morning greeting our students. (Teacher 1)

She knows all our students. (Teacher 1)

Everybody here is very good about caring for our kids. That starts with Ms. H., our principal. (Teacher 1)

School Two:

She came in on Friday and did a lesson on tepees in our class. She did a 45 minute lesson on it. (Teacher 1)

We meet with her and then she tells us about the new learning that she has learned. (Teacher 3)

School Three:

She even came in and taught the class and assisted there. Since she was the language arts person, she did that with the language arts. You know they sit down and they plan different things. One of the things that they both did, they provided problems and topics during that period of time that students would work on doing every day. She or the other principal are not just those people that say 'This is it. Do it.' They are out in the trenches helping you to get it done. (Teacher 4)

School Four:

Dr. $\mathrm{H}$ is very good with trying to treat kids with respect and he personally does not believe in sending kids home. So eventually the child goes before Dr. H., the really rough ones. (Teacher 2)

School Five:

...coming in and saying that looks like fun or that seems to be working or sometimes he will just walk in and sit down and try whatever we are doing. Like, if there is a warm-up on the overhead, a few questions and he will try it. (Teacher 1) 
School Six:

I think she is very stern. You don't see her in the hallways so much. I think, though, that her leg is not in good shape...so, you used to see her more in the hallway, but I think she's really having some health issues. I haven't had her for long so I'm trying not to judge. (Teacher 1 )

\section{Some aspects of buffering.}

Some aspects of buffering was commented on unevenly, and not all schools had teachers make comments in this area. Leadership behaviours that related to this subdimension included principal involvement with classroom learning activities and planning, the creation of structures within the school that ensured a smooth and effectively functioning facility, including discipline, support for teachers when working with parents and skills when working with parents, and interactions with students directed towards building a friendly, welcoming environment or interaction that focused on instructional needs. Examples of comments by teachers related to this element included:

School One:

I went to her and told her the whole scenario. She said "You're fine." In other instances, she and the assistant principal have stepped in when I have a parent who was being very ugly. (Teacher 2)

One of the things that we provide the students with is homework haven...It's just a little something extra in the morning just to kind of get their day going. (Teacher 4)

School Two:

When the district wanted to bring in some other stuff, our principal buffered us from that and said 'we already have a schematic of things we want to accomplish. We are already pretty successful in that area.' (Teacher 4)

School Four:

He just gives us things that he saw happening that he liked. (Teacher 1)

School Five:

We do have a discipline code of course. I think it could be stricter. I think that some kids get away with things and it's actually the bad kids because they are in trouble all the time. Even if they are not learning right, at least they are not hitting anybody today. So they let them get away with stuff. (Teacher 1)

I know when I've had issues with discipline the support has been there 100\%. I have never had a problem with a student where I did not receive the appropriate assistance. (Teacher 4) 


\section{Being flexible.}

Being flexible was seen in leadership behaviours related to involvement with classroom learning activities and planning, professional development, and developing structures within the school that created a smooth and effectively functioning facility, including discipline. This area was commented on in every school, but by half the number of teachers who commented in the area of buffering. Examples of comments by teachers related to this element included:

School One:

Ms. H. is always giving us opportunities. There is a meeting here. Who would like to go? Myself, a kindergarten teacher and two third-grade teachers just came back from Charlotte a couple of weeks ago. We went to a dual language conference in Charlotte. It was a chance for me. (Teacher 4)

School Two:

I have the freedom to be creative and teach using my own style, but I also have directives on which to focus and I know that I'm on the right track. (Teacher 2)

School Three:

They try to survey us and come up with a consensus of things that we actually need. What folks feel like they need to focus on and with that, they plan staff development for us. (Teacher 3)

School Four:

I think at staff meetings. Like you say, it's not required, but he is always, if you are up front with parents, you are going to be better off and the whole school will be better off. Invite them in. It's not mandatory because some are very uncomfortable. (Teacher 2)

School Five:

Unfortunately, and I'm trying to be diplomatic here, we have not met as much as we could or should. At one time we were supposed to meet as a department every Thursday. I know technology and technology staff development became very important and Thursdays became taken over by technology training for teachers for us to have a certain minimum level of competence with technology. I think some of us still believe in paper and pencil. So the technology training has been very helpful. (Teacher 4)

School Six:

I: What leadership roles do you and other teachers play in the school?

R: I am a demonstration classroom teacher...I, we have team leaders. Each grade level usually has a team leader. 
I: Do you aspire to that role?

R: Not in this school. In other schools I think so, yes.

I: Why not in this school?

R: I don’t know. I honestly don’t know. It's a lot of work for not getting paid very much. (Teacher 1)

\section{Fostering conflict resolution.}

Fostering conflict resolution (rather than avoidance) was commented on as frequently and by as many respondents as buffering. Leadership behaviours related to supporting teachers in working with parents and skills when working with parents. Examples of comments by teachers related to this element included:

School One:

Ms. H. and Ms. G. have very strong beliefs and very high expectations on what student behaviour is like. This year, I've had quite a bit of behaviour in my room that I haven't had to address before. I'm with them on the very first day and I'm like 'Oh my God. I had to call nine parents. I've not had this in five years. What do I do?'” She gave me a book this thick on behaviour and different strategies to deal with it. She's like 'I'm here for whatever you need.' Some got better and I've had a couple situations where one kid's been suspended like six times this year. They feel like the student is not going to do that. This is going to get taken care of. He's going home. They are not going to have that. They back you up if there is a problem with the parents. What happened? This is what happened. Let's get it straightened out. They are very strong in their expectations with us and the children. (Teacher 4)

\section{School Four:}

I think we have the advantage of having some fantastic teachers that have been here for awhile and have chosen to stay, which I'm thrilled at. We also have the advantage of having a lot of new blood in too...You can just feel the tension sometimes walking into a room and I don't feel that anymore. (Teacher 1)

\section{School Six:}

She's new so I don't really, I think as long as you are getting along with the parents and I'm not someone who has a lot of issues with parents very often, so, I mean, she never really has said anything. I just get messages, 'call this parent or that parent'. (Teacher 1 - mixed instance)

\section{Handling difficult situations.}

Handling difficult situations was commented on the least in the antecedent competence. Only two teachers in two schools made comments related to this sub-dimension. Examples of comments by teachers related to this element included: 
School Two:

Again, this year, the district had wanted each school to have a leadership team and had given out ideas on how to come up with a leadership team and our principal said, you know, and she told us this in a staff meeting, I trust that any of you could be on the leadership team, it isn't, but I am going to take one person from each level and you are now our leadership team so if there are district meetings where they need representation, you guys will be the ones that go. (Teacher 2)

School Five:

It's not as strict. They used to say that you couldn't have any writing on your shirt at all and now you saw on the video, I'm sure some kids had big lettering on their shirts and they don't really say anything. So it's not as strict as it could be (Teacher 1 negative instance)

To what extent do principals and teachers hold similar views on the sources (or antecedents) of trust in principals?

Principals described, in detail, incidents or actions that related to the elements of competence. Principals in schools with high-trust-in-leader made 42 positive comments and 3 negative comments. The principals in schools with low trust made 31 positive comments and 13 negative comments. The order of the elements was different for principals than that of the teachers, although functional, work related skills still had the most respondents and thought units. Competence was, by far, the most frequently identified antecedent for both teachers and principals.

Principal respondents and thought units resulted in the following order for the elements:

1) Functional, work related skills;

2) Problem solving;

3) Working hard, pressing for results, setting standards;

4) Setting an example;

5) Being flexible;

6) Some aspects of buffering;

7) Handling difficult situations; and

8) Fostering conflict resolution.

\section{Functional, work related skills.}

Principals comment on functional, work related skills in relation to visibility in the school and providing feedback to teachers. Providing professional development for staff was 
part of a functional, work related skill as was creating a school structure that was smooth,

efficient, and effective. Examples of comments by principals related to this element included:

School One:

I go in and out of classrooms all the time. I went out last week...that was an invitation. They were teaching as the activity was occurring. It wasn't just we are outside playing in the dirt but that it was an opportunity for active engagement and learning...I just told them how fantastic it was and how I liked what kids' learned. As teachers would ask questions, as they were going, children really had excellent recall of the information they had already learned about farming.

Then of course, looking at their individual growth plans and knowing specifically what professional development they feel they personally need to carry out the job I've asked them to do. So that's what I've done. I've sent them to dual language. I've sent them to other schools in (this middle state) to visit when they wanted to see specific things. With the technology that is offered, the professional development, in our county that is offered, they have all taken advantage of that as well.

I look at lesson plans. I am in team meetings. We, of course, have our monthly meetings.

School Two:

I do drop in visits. I use a clinical supervision model and I go in and observe and script and I do a post-conference with them. But I also do drop in observations and I'll just go in and have a little form that I write up and I write a brief summary at the top of what I observed. I have a "I liked...because" and then I'll tell them something they were doing well. Again, this comes from clinical supervision. Then I have another section at the bottom that just might say 'other' and I might have something else I liked or if there is something I might make a suggestion. If there is actually a real issue with anything, I will tell them at the bottom, come and see me, we need to sit down and talk.

School Three:

I do (visit classrooms) formally and informally. I try to always offer feedback.

School Four:

I visit classrooms all the time. Okay. The last time I visited a classroom was this morning.

School Five:

The only time that we have done this (teachers visiting each other's classrooms) is when we have concerns with the instruction of a teacher. So, after the second or third Walk Through or after each one of us has seen that one teacher, we put a plan together, a Plan of Action for that teacher. That includes please go observe Mrs. So and So or Mr. So and So. And then bring me back what you observed during that 
time. It does require them to go in there for the whole entire 50 minutes to observe that teacher.

First of all, we modified the master schedule to reflect an extra period for Math class. Our weakest subject was Math.

Our personal files for every single kid are up to date...not only our special eds, but also our ESL population... with her help as well as with the help of the ladies, because we go through all the files at the beginning of the year. We break it down by four people and all of our files are updated.

\section{School Six:}

The time that I spend more than five or ten minutes in the classroom is when I'm doing evaluations. So I just finished up with my last round of evaluations on April $1^{\text {st }}$.

There's professional development at least once a month where the teacher leaders, they have teacher leader meetings. They have grade level meetings. So the teacher leader is supposed to be talking about students, how students are progressing. They are supposed to be discussing curriculum. Writing prompts and those kinds of things. Then they are supposed to give me notes from their meetings. So, my $2^{\text {nd }}$ grade teacher was one of the ones that I had to evaluate this year, this is all confidential, right? I gave her a part 2, a part 2 is like needs improvement. And I said to her, guided reading is one of the things that you are not implementing the way that it's supposed to be implemented and you are the teacher leader. So you are supposed to be the role model of how are the other $2^{\text {nd }}$ grade teachers are supposed to implement this and you're not doing it. Next year, I expect you to do that. She's one of the ones that got a job preference form. That's fine. But that's, if you're getting paid to do that, you need to do it. (possibly a negative instance)

I guess my concern is bringing it back and implementing it in the classroom. (possibly a negative instance)

Which it was more important to get in here and to establish myself as an administrator with the things like the schedule. Making sure that teachers knew their schedule and making sure that I have my teams set up so they know that they are accountable to each other.

\section{Problem solving.}

Problem solving was of second greatest importance to principals. Staff professional development was a high priority for principals and appeared as part of the problem solving sub-dimension. Developing structures for smooth and efficient operation and interactions with students, in terms of meeting their needs personally and/or instructionally and support for teachers when working with parents was also part of problem solving for principals.

Examples of comments by principals related to this element included:

School One: 
I use Title 1 dollars to fund a technology facilitator and a curriculum facilitator because that was very key. I have awesome teachers here but you know we are all digital immigrants and not necessarily all very comfortable with technology. So having that person here who eats it, breathes it, sleeps it and loves children at the same time was just key to this being successful. A curriculum facilitator to help teachers know how to best take the curriculum framework we have and integrate that globalization way key at all.

When I initially got here we had a PTA. We could never have a quorum of parents at PTA meetings. It was unbelievable. I'm out and about and I talk to parents all the time. Why don't you come? Basically what we learned is they thought it was cliquish. So I wanted to dissolve the PTA and to dissolve a PTA you almost have to give them your first-born child. You do, it's amazing. However, something fabulous happened in Thompson. That was a pre-K-5 school that closed as a pre K-5 school and became our pre-school center. So I absorbed the majority of their student population and quite a few of their teachers during the redistricting. Well because of that change that was my avenue to dissolve my PTA, which I did. We created what was called the PLOT team. PLOT stands for People Lending out Their Time. We told parents we recognized how busy they are. Any time that they can come to our school we appreciate it. Since I dissolved the PTA we use every last chair we've got for our meetings, because nobody - we don't have a president or vice-president and all of that. It's whoever can help in whatever way is needed at any given time. So we have tremendous parental support in that regard.

The majority of our children are economically disadvantaged - 75\% of them. Even with the best practices we have implemented it's still difficult. So in all of our research, we felt that moving towards a magnet school would not only be innovative, it would not only challenge the status quo but that it would also create conditions in which our children had the opportunity to be more academically successful. Our ultimate goal is that our economically disadvantaged children will break the cycle of generational poverty. You know, for five years now, I've researched and researched and done what I can do to meet their needs because they are very bright...so all of my research led me to the magnet approach because then you look at an integration of a variety of economic areas. We also looked at - as a magnet school two of the components that you want to make sure you had is that $50 \%$ of your population is your districted population, those students that live closest to your school and then you have to have a specific instructional focus...so with all of our efforts I again started having this conversation about a magnet approach when I came back here as the principal five years ago. Then I have just worked on research, worked on best practices... all moved towards that common goal. That had a lot to do with instruction.

School Two:

So, like I had a new teacher this year that was having some problems with classroom management and so she came in and we sat and talked about it and I said, "you know, you're tolerating too much" and went through the stuff. And then I would go in and do a little bit more targeted observation and give her some feedback. Eventually I brought in kind of a facilitator from Special Ed to help her with some behavior mod 
stuff because it's not my background and she made a lot of improvement in that area... she has got a couple of kids in there that are emotionally disturbed and it's just not my strength. I don't have to have all the answers, but I need to connect them with the people that do.

I think, I don't read a lot on leadership as such, I mean I love to read on leadership, but it's like when you first take classes you think, "I am going to be this kind, or I'm going to be that kind.” The fact of the matter is you are who you are and I am very organized and I look at part of my role is to make the teacher's job easier. I want thing to run smoothly. I want to take care of details for them. I want to give them opportunities and time to do the things that they need to do. Our schedule really works out well with that. I spent the summer before I came here talking to each group of staff members to learn about the school and then to come up with a schedule that would help them. The schedule probably helped them more than anything and then Dianne Painter would be the second bit. I mean, I guess that if you're going to ask me what my philosophy of leadership is, it would be to help everybody else do their job in a better way.

School Three:

My big push and big goal for the rest of this year and summer, staff development and next year, is to bring this place a little bit back to looking like a middle school and not like a little mini high school. I think there are some fine teachers here. There is a little more stand and deliver instruction than what I'm comfortable with for this age of child. The result is antsy children who get in trouble because they are not engaged. They need to move. So that is my focus is I think if they teach the curriculum, the kids will pass the test.

I shared with them a system that sort of had the kinks worked out of it already which they liked and so we have done that this year. It puts academic performance and discipline together and there are some rewards and things. It's simple. They got on board with that so we've been doing that this year.

They are just not here that much. It's no more or no less than any other place I've been...Getting parents involved with middle school is a challenge, just flat-out. They don't bring cupcakes anymore. They have to come when they are called for discipline issues. They hate that. They don't like coming to PTO because they've seen all that before. They've done it all and they don't. It's hard to get them out. We have parent nights for them to pick up report cards. We don't let the kids take them home. The parents have to come get the report cards so we can pull them out that way. There is none (example of collaboration). I'm just going to tell you that there is none. We have PTO on Tuesday night and I got two parents to sign up to be on the leadership team and I was thrilled. The PTO has floundered and has fallen flat this year and that's an area of - it's a real area of need for us here is to get the parents involved. Title 1 you have to. It's hard. Well, what I would love to happen and what I realistically expect are really different.

School Five: 
So the Math, the whole Math department was able to go together, but because of funds and because of when it was set up in the year, the other conferences we sent three other teachers. So, all together about 13 out of my 41 teachers got to go to a state conference. Which is pretty good.

These are the five kids that we have, what are we going to do with them? We are going to break them down and we're going to keep them with C.G. because she is still servicing them. We are going to bring them every Saturday from here until the end of June. Then the plan is for them to come to Summer School. What materials do we need? Why is it working well?

\section{Working hard.}

Working hard, setting standards, pressing for results was described by principals as including aspects of professional development for teachers and support for teachers when working with parents. Examples of comments by principals related to this element included: School One:

I want them to - I know that they can't always come to school, you know, I'm a working parent. I'm missing my oldest child's all day track meet today. What I expect of them is that they set a level of expectation at home that their child is going to come to school and be actively engaged in the learning process. Basically they are going to be respectful and responsible. They are going to keep those lines of communication between home and school open through phone calls, through e-mails, through communicating in our student agendas. Those are my expectations. Sometimes that's hard. In this age of cell phones parents are changing their cell phone numbers like I change the filter at home in the air conditioning unit. Sometimes that communication is hard. The parents that you need to speak to the most are the most difficult to reach.

School Two:

I worked with Dianne (Painter, from Marzano) in K....So, as it were, the first year that I was here, I ran into a colleague that we had both taught in K. together and she was a principal in Blandon, Utah. She mentioned that Dianne Painter had been to her building and was only teaching the vocabulary piece. I jumped on that because I realized after a couple of months here that this staff was extremely well-trained in teaching reading and that one of the issues really with kids, again of poverty and kids of second language, was that they needed that vocabulary development. I remembered how strong that piece was because some of my teachers from $\mathrm{K}$. that were really using that, they were starting to spike after a couple of years, and we didn't have state testing, but it was like the CTBS or whatever it was, one of the TBS tests. We always, our comprehension scores were always higher than our vocabulary scores because the vocabulary was used in assimilation and our kids just didn't have that wide of a vocabulary...so with that in mind, I thought what this group really needs is vocabulary. We have something called a Student Initiative Grant that you can ask for here in the district and you go before a district office administrator so I asked for money to bring Dianne in. I contacted her. I got on the line the next Monday and found her and asked her what she charged. I had never arranged for her, I was just a principal...I initiated it and it was happening here. Dianne came in and did a two-day 
training. We actually cancelled school. I had to go to the School Board and ask them to cancel school on a Friday so we did Thursday afternoon and Friday training. The staff loved her. They wanted to know when was she coming back. So I was able to get funding from the district for two days in June right after school was out and had huge turnout by my staff attending that. The next year, we weren't able to bring her in until I think until the summer, but the last year, I wrote a grant. It came from Advanced Placement of all things, here we were a school in re-structuring, and it was called a Core Curriculum grant. Since we had been doing so much with standards based curriculum development, I wrote for that grant and asked for $\$ 56,000$. I got the grant and they gave me $\$ 76,000 \ldots$ So, I had like $\$ 45,000$ or something for training. We were able to bring her in for 12 days last year. I had to pay for substitutes and things, too...Technically, about 40\% (are Navajo)...they are all Spanish. But the way the law works and everything else, is that what we have is kids who are Navajo children who are limited English speakers because they are (a) poor, that's probably more of an issue than the fact that they are Navajo and then sometimes there is a second language background because the parents do not speak fluent English, but the kids speak English only... what they don't have is academic vocabulary.

School Four:

I said, "I want to see, I want you to identify what areas you want to grow in and what things you're interested in. I want to see that growth every year. So keep moving forward.” Some grow a little bit, some grow immense amounts. But again, it's, that's a challenge to them all the time to see where we're growing.

We did a lot more contact with the parents. With that came documentation, 'show me where you contact parents, show me where you worked with them with grades.'

School Five:

More on the instructional setting. Students nowadays, lecture does not work. Independent study doesn't work. It's more like show me, prove to me.

... (instructional strategies/ affect on text scores) it has been showing in the past two years. Not only in Math, but in Reading (improvement in results listed).

"My best teacher that I have, that I believe is my best teacher, she is my main English teacher. She is superb. But she has never been able to include technology in the class. So, my goal was for her, because she is an English and Reading teacher...instead of reading a novel to them or reading a passage or whatever, you put that book in that projector and it projects it and you have the kids read along. ... She has been sold on that. She is able to get the kids more involved in the reading. She seems to finally have taken a bite of the food and likes it now. So, she enjoys using technology now where she never wanted to."

(walk-throughs) I focus on the connection of the learning...the kids need to be $90 \%$ a part of the process. Not the teacher. The kids nowadays need to learn by tactical, visual, not just read, read, read, raise a hand and answer the question. 
School Six:

There's professional development at least once a month where the teacher leaders, they have teacher leader meetings. They have grade level meetings. So the teacher leader is supposed to be talking about students, how students are progressing. They are supposed to be discussing curriculum. Writing prompts and those kinds of things. Then they are supposed to give me notes from their meetings. So, my $2^{\text {nd }}$ grade teacher was one of the ones that I had to evaluate this year, this is all confidential, right? I gave her a part 2, a part 2 is like needs improvement. And I said to her, guided reading is one of the things that you are not implementing the way that it's supposed to be implemented and you are the teacher leader. So you are supposed to be the role model of how are the other $2^{\text {nd }}$ grade teachers are supposed to implement this and you're not doing it. Next year, I expect you to do that. She's one of the ones that got a job preference form. That's fine. But that's, if you're getting paid to do that, you need to do it. (Negative instance)

That's the biggest challenge that I have. I think the behaviour of kids, I think the kids are pretty good. I can handle upset parents. That doesn't bother me. Dealing with teachers. I just have to let them know what my expectations are and those that don't like it I say, "get a job preference form. Gotta go.” (Negative instance)

I guess my concern is bringing it back and implementing it in the classroom. If you're going to it, use it. (I see this) in some classrooms, yes. But not all. (Negative instance)

\section{Setting an example.}

Setting an example was described by principals as including interactions with

students, in terms of meeting their needs, personally and/or instructionally. Professional development comments sometimes referred to that of the principal her or himself. Examples of comments by principals on this element included:

\section{School One:}

Also, I'm engaged in conversations with children a lot. I will tell them "Tell me what you are doing in class.” Or they willingly talk to me about what they are doing that is exciting. I came in from my principal's meeting the other day and it was later in the afternoon, in fact, there were some children staying after school. We have children in the building until 6:00. T. was running down the hall and I said "What are you in such a hurry for?" She said "We are just having the best time." She's in fourth grade. "We are on Illuminate and we are talking to our friends in Mexico. I left Canala the bear in Ms. C.'s room but Ms. C.'s room is locked.” I said "Sweetheart, you go back to your Illuminate session. Let me go grab my keys and I'll go get Canala.” Canala is the bear. Canala is cinnamon in Spanish and that matches the color of the bear. That is a bear that goes home with the children in fourth grade. They take it home and they keep a journal and they share it with their friends in Mexico. We took them a bear when we went. To see that excitement in children, it makes me know and it makes the adults know how worthwhile it is that we are working this hard on the initiatives that we are. 
School Five:

So we packed up all the Math teachers and I went with them to (a city some distance away). We were there for three days. In every conference we send one administrator. So myself or one of my assistants always go with a group of teachers.

School Six:

I really haven't had time. I haven't done anything lately, within this last year, other than talk to my colleagues. I had talked about going to a couple of them this summer, but with our summers being so short now, we have like 30 days, and then for the past two summers I have been moving from one building to another so I haven't really had a chance to do anything. (Negative instance).

\section{Being flexible.}

Being flexible was described by principals in terms of creating a smooth and effectively functioning facility, including discipline. Examples of comments related to this element included:

School Four:

Well, most principals just divide it by eight and it's $\$ 1,000$ a piece. We look at it on the basis of an hourly rate. I take each person that's interested.

School Five:

I am the leader of the committee. But every department and every grade level is represented. We meet once a month. Now, a principal that likes to have control over the campus will say no to a lot of things, will say, "no, we can't do that or we can't purchase that.” But I'm different. Even though I seem rigid or strong, they know that they understand that if they can prove that it's useful and we have the funds and we have the funds and we want to use that program...I provide not only information on the budget, here's the budget, tell me what you want to change, tell me how we want to spend this money. But also to prove to me that we are going to use it the right way and who is going to be leading the pack and how are we going to use this for the kids and how many times and how are we going to evaluate it at the very end too?

\section{Some aspects of buffering.}

A principal who was expressing frustration with government policy described some aspects of buffering and its relationship to competence.

School Four:

Parents accept it. I tell them as a matter-of-fact situation that this is ridiculous. I just tell them. This doesn't make any sense. I said "every school is going to be in need of improvement.” I don't care what school you are. Every school is going to be in need of improvement by 2014 if nothing changes. Because it's, that's inevitable. That's what's going to happen...the attitude becomes "well you don't have good teachers." I said, "We have great teachers.” And I said "those teachers are showing lots of 
growth.” But that is also why this year I said earlier we focused on charts showing the growth and getting those things, showing that picture to the parents so the parent can say "well, I don't know what this AYP is, but I know my child learned and grew because I saw it.” That's what we're trying to deal with. I project that it's the demise of the Democratic and Republican parties as we know them in this country. If they don't fix this thing by 2014, you talk about their credibility will be in the toilet. The populace is going to say...this is huge because this affects kids and when you personalize something, what parents get really upset about is, "my children." So, when it comes down to that you're telling us that all the kids in the nation are failing and are incompetent. I think it's the government that's incompetent. It's causing teachers, because of all of the assessments that are being required connected with the whole thing, you have got teachers that are wanting, saying, "I'm looking for something else. Teaching was always difficult. This is becoming ridiculous.

\section{Handling difficult situations.}

Handling difficult situations included supporting teachers for principals.

Examples of comments by principals related to this element included:

School Three:

I talk with them. Every day I try to talk to every single person. Which is not hard. We are tiny...I have a goal of trying to affirm, there are a few people whose esteem is low, particularly our seventh grade math teacher. She is the only one teaching math this year that taught math last year. She feels like, and I don't think it's been done to her and I don't think it's real, but she perceives it's her fault we didn't meet AYP because she is the only one that is teaching math this year that taught math last year. She is a really good teacher. She needs to be validated. She works so hard. I just try to acknowledge, to let them know I see how hard they are working. I ask their opinion on things and I don't tell them what to do. My granny used to say the road to hell is paved with good intentions. All of the intense math help that the teachers got, I think it fostered that feeling for that teacher that she was inadequate in a way. You can't do it yourself. Let me come in your room and do it for you. So I think that it's good that he helped them with some areas that they had weaknesses in. I think that was the best thing that he did. I think that all of that teaching for them business may help the kids; I don't think it did a lot to help the teachers. I just think it's a feeling. Let me say that they have not made that complaint; that's just my observation.

School Six:

Whenever I talk to a parent whether it's a black or a white parent. If they are coming in here yelling and screaming or whatever, I tell them, "We can sit down and talk like adults or you can keep screaming and you gotta go. It's just that simple. I am not going to have you badger me. I'm not going to have you badger my teacher. If you wanna talk, we can talk. Otherwise the conversation is ended.” I put parents out of my office. They called downtown on me. I tell them, "Fine, call my boss. I don't care, but you aren’t gonna sit here and cuss at me and you're not going to badger my teacher.” 


\section{Fostering conflict resolution.}

Fostering conflict resolution seemed to relate, at least in part, to establishing structures within the school that enhanced smooth operation and efficiency. An example of a comment by a principal related to this element was:

School Six:

This is my first year here, so I will know at the end of this year. I have had feedback from some of the teams that they like it because they know the kids that they are getting next year and you know, for some of those that are just kind of stuck in their ways, they are saying, "so does that mean that I have to get all Ms. So-and-so's kids. Even the bad ones?" "Yes, even the bad ones." But what is going to happen now is that at the end of the year you make out a list of all your kids and if there are two kids that don't need to be together. Let me know that. I'll be the one to decide which classroom they go into. You will find that teachers are loyal to each other. If I have a friend that's in $2^{\text {nd }}$ grade, and I'm teaching $1^{\text {st }}$ grade, I certainly don't want to send my bad kids to my friend who is in $2^{\text {nd }}$ grade. Which stops a lot of that too. In the past, we used to let teachers make out the class list. What was happening was that one teacher would end up with a lot of the behaviour problems or a lot of the special ed kids and one wouldn't get any. As principal we kind of signed off and let it be. But I kind of stopped that because I didn't like that. I was a teacher that taught $2^{\text {nd }}$ grade and came in and got a lot of the behaviour problems.

Finally, principals commented a great deal on testing, scores and school improvement. Teachers commented on this, but to a lesser degree. In low-trust schools the focus was on specific strategies with teachers. While these strategies most likely had instructional and learning benefits, principals noted the effect on scores. In high-trust schools principals still focused on specific instructional strategies with teachers, but the tone of that focus tended to be either defeatist, in the sense that this was an impossible task, as in the principal at School Four, or directly negative towards teachers, as in the principal at School Six. 


\section{Summary of Competence}

Table $9^{9}$

\section{Summary Comparison of High Trust and Low Trust: Competence}

\begin{tabular}{|c|c|c|c|c|c|c|}
\hline & \multicolumn{3}{|c|}{ High Trust } & \multicolumn{3}{|c|}{ Low Trust } \\
\hline & Elements & 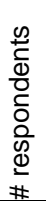 & 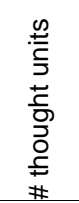 & Elements & 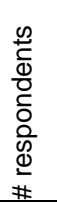 & 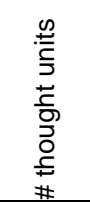 \\
\hline \multirow{9}{*}{ 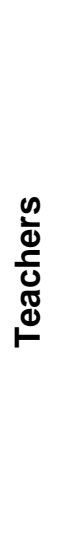 } & $\begin{array}{l}\text { Functional, } \\
\text { work-related skills }\end{array}$ & 13 & $31,-1$ & $\begin{array}{l}\text { Functional, } \\
\text { work-related skills }\end{array}$ & 11 & $22,-4$ \\
\hline & $\begin{array}{l}\text { Working hard, } \\
\text { pressing for results, } \\
\text { setting standards }\end{array}$ & 13 & 16,0 & $\begin{array}{l}\text { Working hard, } \\
\text { pressing for results, } \\
\text { setting standards }\end{array}$ & 8 & $13,-3$ \\
\hline & Problem solving & 12 & 14,0 & Problem solving & 7 & $7,-4$ \\
\hline & Setting an example & 7 & 8,0 & Flexibility & 4 & $1,-4$ \\
\hline & Flexibility & 5 & 6,0 & Setting an example & 3 & $2,-3$ \\
\hline & Buffering & 3 & 6,0 & Buffering & 3 & $2,-1$ \\
\hline & Conflict resolution & 1 & 1,0 & Conflict resolution & 2 & $2,-1$ \\
\hline & $\begin{array}{l}\text { Handling } \\
\text { difficult situations }\end{array}$ & 1 & 1,0 & $\begin{array}{l}\text { Handling } \\
\text { difficult situations }\end{array}$ & 1 & $0,-1$ \\
\hline & Total & & $83,-1$ & Total & & $47,-21$ \\
\hline \multirow{9}{*}{ 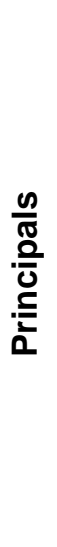 } & $\begin{array}{l}\text { Functional, } \\
\text { work-related skills }\end{array}$ & 3 & $11,-2$ & $\begin{array}{l}\text { Functional, } \\
\text { work-related skills }\end{array}$ & 3 & 8,0 \\
\hline & Problem solving & 3 & $11,-1$ & Flexibility & 3 & $1,-8$ \\
\hline & $\begin{array}{l}\text { Working hard, } \\
\text { pressing for results, } \\
\text { setting standards }\end{array}$ & 3 & 9,0 & $\begin{array}{l}\text { Working hard, } \\
\text { pressing for results, } \\
\text { setting standards }\end{array}$ & 3 & $7,-1$ \\
\hline & Setting an example & 2 & 5,0 & Problem solving & 3 & 7,0 \\
\hline & Flexibility & 2 & 3,0 & Setting an example & 3 & $5,-2$ \\
\hline & Buffering & 1 & 2,0 & Buffering & 2 & $1,-1$ \\
\hline & $\begin{array}{l}\text { Handling } \\
\text { difficult situations }\end{array}$ & 1 & 1,0 & $\begin{array}{l}\text { Handling } \\
\text { difficult situations }\end{array}$ & 2 & $1,-1$ \\
\hline & Conflict resolution & 1 & 1,0 & Conflict resolution & 1 & $0-1$ \\
\hline & Total & & $43,-3$ & Total & & $30,-14$ \\
\hline
\end{tabular}

Teachers in high-trust schools made only one negative comment in relation to competence, that being in functional, work related skills, the element that drew, by far, the most thought units in both high- and low-trust schools. Teachers and principals in high- and low-trust environments commented almost equally, when comparing the totals lines, if the positive and negative statements are added together as a total response, although teachers in high-trust schools did generate slightly more thought units. Competence matters and it would

\footnotetext{
${ }^{9}$ For an explanation of how to read the table, see reading the tables in chapter 4 .
} 
appear that all teachers think about the competence of their principals in determining their trustworthiness. 


\section{Chapter 5 Results: Consistency and Reliability, Fairness, Forgiveness,} Honesty

This chapter continues the results about the antecedents of trust in leaders. In this second of four results chapters the focus is on consistency and reliability, fairness, forgiveness and honesty. Results are summarized quantitatively in Tables 10, 12 and 14 respectively. Tables 11, 13 and 15 compare high- and low-trust schools on these same three antecedents of trust in leaders. 


\section{Consistency and Reliability}

To what extent do teachers identify influences on their trust in principals when they are engaged in conversation about their school and the school's leadership?

Table $10^{10}$

\section{Evidence of Consistency and Reliability}

\begin{tabular}{|c|c|c|c|c|c|c|c|c|c|c|c|c|c|c|c|}
\hline \multicolumn{4}{|c|}{ Consistency and Reliability } & \multicolumn{6}{|c|}{ High Trust } & \multicolumn{6}{|c|}{ Low Trust } \\
\hline \multirow{10}{*}{ 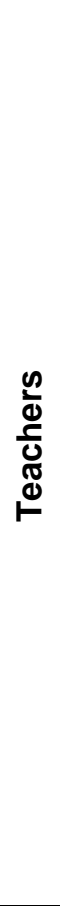 } & & & School & \multicolumn{2}{|c|}{ One } & \multicolumn{2}{|c|}{ Two } & \multicolumn{2}{|c|}{ Three } & \multicolumn{2}{|c|}{ Four } & \multicolumn{2}{|c|}{ Five } & \multicolumn{2}{|c|}{ Six } \\
\hline & & \multicolumn{2}{|c|}{$\begin{array}{r}\text { Max \# Teachers: } \\
\text { Act \# Teachers }\end{array}$} & \multicolumn{2}{|c|}{$4: 4$} & \multicolumn{2}{|c|}{ 5: 3} & \multicolumn{2}{|c|}{$4: 4$} & \multicolumn{2}{|c|}{$3: 3$} & \multicolumn{2}{|c|}{$4: 4$} & \multicolumn{2}{|c|}{$4: 2$} \\
\hline & & \multicolumn{2}{|c|}{$\begin{array}{l}\text { Totals for } \\
\text { Antecedent }\end{array}$} & \multirow[b]{2}{*}{ 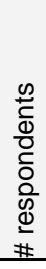 } & \multirow[b]{2}{*}{ 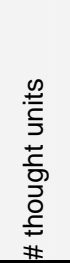 } & \multirow[b]{2}{*}{$\begin{array}{l}\frac{0}{c} \\
\frac{\tilde{d}}{0} \\
\frac{0}{0} \\
\frac{0}{0} \\
\frac{0}{0} \\
\end{array}$} & \multirow[b]{2}{*}{ 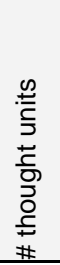 } & \multirow[b]{2}{*}{ 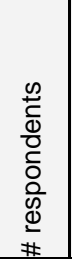 } & \multirow[b]{2}{*}{ 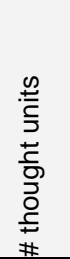 } & \multirow[b]{2}{*}{$\begin{array}{l}\frac{n}{c} \\
\frac{0}{0} \\
\frac{0}{0} \\
\frac{0}{0} \\
\frac{d}{2} \\
\end{array}$} & \multirow[b]{2}{*}{ 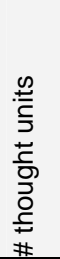 } & \multirow[b]{2}{*}{ 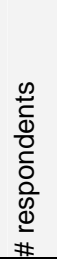 } & \multirow[b]{2}{*}{ 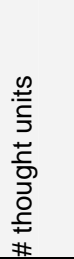 } & \multirow[b]{2}{*}{$\begin{array}{l}\frac{n}{2} \\
\frac{0}{0} \\
\frac{0}{0} \\
\frac{0}{0} \\
\frac{0}{0} \\
\frac{0}{4}\end{array}$} & \multirow[b]{2}{*}{ 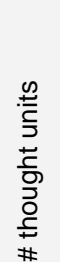 } \\
\hline & Elements & 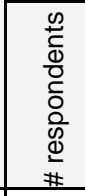 & 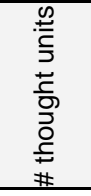 & & & & & & & & & & & & \\
\hline & Consistency & 20 & $32,-7$ & 4 & 12,0 & 3 & 6,0 & 4 & $4,-2$ & 3 & $2,-2$ & 4 & $6,-3$ & 2 & 2,0 \\
\hline & \begin{tabular}{|l|} 
Tools for \\
uncertainty \\
reduction \\
\end{tabular} & 10 & $10,-3$ & 3 & 3,0 & 2 & 3,0 & 2 & $1,-1$ & 1 & $2,-1$ & 1 & $0,-1$ & 1 & 1,0 \\
\hline & Diligence & 7 & $6,-2$ & 1 & 2,0 & 1 & 1,0 & 1 & 1,0 & 1 & $0,-1$ & 2 & $1,-1$ & 1 & 1,0 \\
\hline & Dependable & 6 & $4,-3$ & 1 & 2,0 & 0 & 0,0 & 2 & $1,-1$ & 0 & 0,0 & 2 & $1,-1$ & 1 & $0,-1$ \\
\hline & $\begin{array}{l}\text { Committed, } \\
\text { dedicated }\end{array}$ & 4 & $5,-2$ & 1 & 2,0 & 1 & 1,0 & 0 & 0,0 & 0 & 0,0 & 2 & $2,-2$ & 0 & 0,0 \\
\hline & Totals & & $57,-17$ & & 21,0 & & 11,0 & & $7,-4$ & & $4,-4$ & & $10,-8$ & & $4,-1$ \\
\hline \multirow{6}{*}{ 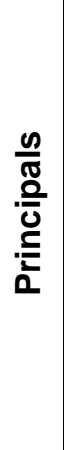 } & Consistency & 5 & 11,0 & & 2,0 & & 2,0 & & 0,0 & & 3,0 & & 3,0 & & 1,0 \\
\hline & $\begin{array}{l}\text { Tools for } \\
\text { uncertainty } \\
\text { reduction }\end{array}$ & 4 & $8,-2$ & & 3,0 & & 3,0 & & 0,0 & & $2,-1$ & & 0,0 & & $0,-1$ \\
\hline & $\begin{array}{l}\text { Demonstrating } \\
\text { commitment, } \\
\text { having } \\
\text { dedication }\end{array}$ & 3 & 3,0 & & 1,0 & & 0,0 & & 0,0 & & 1,0 & & 0,0 & & 1,0 \\
\hline & Diligence & 2 & 3,0 & & 1,0 & & 2,0 & & 0,0 & & 0,0 & & 0,0 & & 0,0 \\
\hline & Dependability & 1 & 1,0 & & 0,0 & & 0,0 & & 0,0 & & 0,0 & & 0,0 & & 1,0 \\
\hline & Totals & & $26,-2$ & & 7,0 & & 7,0 & & 0,0 & & $6,-1$ & & 3,0 & & $3,-1$ \\
\hline
\end{tabular}

\footnotetext{
${ }^{10}$ For an explanation of how to read the table, see reading the tables in chapter 4.
} 
While fewer teachers commented than did in relation to competence, there were only two schools where not all teachers made comments related to consistency. Having consistency was the element more teachers commented on in the antecedent. Teachers in high-trust schools made 39 positive comments and 4 negative comments. Teachers in lowtrust schools made 18 positive comments and 13 negative comments.

Which elements of leader consistency and reliability do teachers identify most frequently and what leader behaviours do they associate with those elements?

Consistency and reliability has five elements, including:

1. having consistency;

2. tools for uncertainty reduction;

3. being diligent;

4. being dependable; and

5. demonstrating commitment, having dedication.

\section{Having consistency.}

Having consistency had the most respondents and the most number of thought units. Leadership behaviours identified by teachers that clustered around the concept of having consistency included leader visibility in the classrooms and in the school that had a regular, predictable pattern to it, timely feedback about classroom and instructional activities, availability of classroom materials and supplies, routines related to discipline, and regular demonstrations of involvement with children and/or their families that was unrelated to discipline. A teacher in the highest trust school did comment on predictability of the leader's expressions of appreciation, and a teacher in the second highest trust school commented on the consistent and constant use of data, with support.

Examples by school of teacher comments about this element included:

School One:

She absolutely expects us to be involved with our parents, to speak with them and to keep them well-informed of academic progress, any behaviors as they occur. I mean that is the first one you contact if there is a behavior, is the parent, not her. That's why I feel crazy, because that question is how would a principal not expect you to be involved with a parent? Do teachers actually answer that a principal doesn't expect that? (Teacher 1)

The whole school works on the positive reinforcement, the token economy system and all that kind of stuff. Beyond that, just following the O. County Schools handbook, if you do this, then this happens basically. (Teacher 1) 
Everybody here is very good about caring for our kids. That starts with Ms. H., our principal...People are always stepping up and doing the right thing for our kids... There is a washing machine and a dryer here. We get the clothes washing during the day. It's just things like that all the time... we are taking care of our kids that aren't the educational part. This is the extra part. We are giving them some extra things that we are teaching at school. I think that is what our school does well.

(Teacher 1)

She will be in the hallway in the morning greeting our students. She knows all of our students. (Teacher 1 )

I: Do teachers feel valued here?

R: Yes.

I: Why is that?

R: Because Ms. H. makes that a priority. Not just by giving you things, which she does. When you go to those monthly PLOT meetings she will put a little coupon in your box the next day where you can leave fifteen minutes early or you can have a free dress down day. Just things like that. She gave everybody on teacher appreciation week \$15.00 for Barnes and Noble. She gave us the lanyards for our new magnet school. It's not just those things, it's like I said it's like leaving fifteen minutes early. Just things like that, when you go to those meetings, instead of being home that night, just a little token of appreciation for things like that. End of grade testing, when you had to be trained for that, she will give you a free snack for of the office. I know you have to do one more thing, but here is how I'm showing you I know that you did. I'm acknowledging it. Being acknowledged. (Teacher 1)

We try to ensure that we have the technology we need for what we are doing as well as other resources. (Teacher 2)

Probably at least once or twice a week she is in and out of the room for something. (Teacher 5)

We turn our lesson plans in to her on Monday. She reviews our lesson plans...she gives us feedback, that we are doing a great job. (Teacher 5)

School Two:

We are aligning the curriculum Kindergarten through Fifth grade. The vocabulary development was a piece that we learned when we first stated and four years later, I'm still using that. So it's made a very positive impact. (Teacher 1)

I: How often and in what ways does your school use student performance data?

R: All the time. We use it for everything. (Teacher 1)

I: How often and in what ways does your school use student performance data? 
R: All the time. We use it for everything. (Teacher 2)

It is in our handbook that we get at the beginning of the year. "I want parent involvement for specific things. She would like grade level to be sending home a grade level newsletter so that is one goal that she has formally told us. That is one goal that we all need to try to achieve. Then there are, I want to say that we have had two parent nights, family nights, that were mandatory. It's like an Open House and Science Fair Night. Actually, Science Fair was optional, I'm sure there was another that was mandatory, but then like you say, with the Parent/Teacher conferences she expects us to reach $100 \%$. If it's calling, if it's meeting somebody at work. She does. (Teacher 2)

I have the freedom to be creative and teach using my own style, but I also have directives on which to focus and I know that I'm on the right track. In the past, in other schools where I worked, everyone did their own thing. Now that we have common goals it makes it really nice to work here, to help and share ideas. (Teacher 3)

School Three:

Every morning we have warmups, either reading or math...we also do principal quizzes every two weeks. So we go to nine weeks and then there is a challenge. Whichever class in eighth grade has the highest percentage we get the ice cream party or the pizza party, whichever. We do a lot. (Teacher 2)

School Four:

Not real often. He is the kind of person who, he visits but not formally very often. He will visit formally a couple of times a year because for our evaluations but he is the type of principal that will just drop in. He doesn't stay long, but he is in and out of the classrooms. He will do things kind of interesting little things like he will deliver our paychecks to us. I think it's his way of making sure that he actually gets into the classrooms, which I like. The kids are used to him just popping in. You don't know when he is coming in, but like I said formally where he actually stays and spends a great amount of time, probably just a couple of times a year, but yes he is in and out of the classrooms. (Teacher 1 )

I: What does your principal expect of you in terms of parental engagement?

R: ...We don't have to send out newsletters. Some send them out every month. Some of us don't. I was for a while. Our progress reports...send something home so the parents are involved. (Teacher 2)

\section{School Five:}

That is pretty much been the standard code but he is following it to the letter. He is a military type. He was in the military so he is more... (Teacher 2)

I: Well, with the math department meetings, when do you meet? 
R: In the morning. We are supposed to be here at 7:45. The bell doesn't ring until $8: 25$. So we will have a 45 minute meeting. We used to do it once a week. Now it's more like once a month but I have a feeling we are going to get back to it hopefully. (Teacher 2)

If we fail more than $9 \%$ of our kids there is a problem. There have been teachers that have been written up for failing more than $9 \%$ so there is a policy of keeping them moving on. It's kind of an unwritten law but I don't know if you are aware of that. That probably happens everywhere. What are you going to do, right? I hate to say that. (Teacher 2)

We have to keep a phone log and communicate with parents whose kids are either passing or failing or improving. (Teacher 2)

He wants to see our phone log every six weeks. If we hand in our phone log with all our parental contacts and it better have some because there are always going to be problem kids. (Teacher 2)

They just come in and sit down and they sit down for ten or fifteen minutes and they just write down what they see...I get a copy of it and I am more than welcome to either respond back or come in and talk. There are always recommendations.

(Teacher 4)

School Six:

I think she has been in enough to know that I am on top of things.” (Teacher 1)

Well, there is this color card system that all teachers are supposed to use. (Teacher 2)

Tools for uncertainty reduction.

Tools for uncertainty reduction included visibility in classrooms and in the school with a regular, predictable pattern to it, feedback about classroom and instructional activities that flowed from the activities occurring in the school in a timely way, a predictable pattern to discipline, and use of data in a constructive, helpful manner.

Examples of teacher comments related to this element included: School One:

They just check in to see if we have any questions or if our team has any questions. (Teacher 4)

School Two:

Again, D., our principal is the one that is...she will collect the data, she will gt it up on charts, she will make sure that we understand as a whole school what the graphs are meaning, where we are deficient. (Teacher 2) 
School Three:

We don't mind taking on tasks, offer some of that leadership so a lot of that the continuation comes from the faculty... and through the changes of administration and we always, when a new administrator comes in, really have high hopes and hope that they will be here with us for a while. Then we find our disappointment. We keep hoping - we were very delighted with Dr. M. (Teacher 3)

School Four:

This room is a textbook room that is open to anybody. We can walk in and we can get books when we need them. We don't have to sign them out. We don't have to sign our life away, saying I need one more math book. May I please have one? The supply room the workroom. We have pencils and pens and things that we can help ourselves to. That was never the case here...that has really gone away. The feeling before was well you can't trust teachers. They will hoard everything. I'm like you know, we can be trusted. (Teacher 1)

He is very good about giving information back without it being in a threatening way at all. (Teacher 1)

I think there is some low morale right now about some discipline issues around the school. I think the feeling sometimes is that nothing happens with the kids who are having serious problems and are the bullying kind of things, some teasing kinds of things. Just kids not being very kind. I pick it up some. I don't have much contact with the older kids but just in passing sometimes. They don't have a lot of respect for each other and for adults and that is one of those issues I feel like has gotten a little out of control here. (Teacher 1)

\section{School Five:}

R: ...but every principal has his own style and it permeates the school. But you've got to work with them right. That is just part of life. They are not perfect. Not everybody is going to agree with them.

I: Does it vary from week to week?

R: It varies.

I: Is there a set schedule here?

R: No, it's whatever comes up. (Teacher 2)

School Six:

She has a chart that she actually put up for visits. (Teacher 1) 


\section{Being diligent.}

Being diligent related to visibility in the classroom and the school, discipline, and balancing instructional priorities. Examples of teacher comments related to this element included:

School One:

The other day just in talking with her and she was talking about going to see a special needs class. (Teacher 4)

School Two:

She is very active in our classroom as well as the school. (Teacher 1)

School Three:

Both the principal and the assistant principal when they were here. When we had both (referencing discipline). (Teacher 4)

School Four:

I: Is there a discipline code?

$\mathrm{R}$ : There is a code. I think that is where we maybe have slipped a little bit is that sometimes things do need to be addressed and I don't think it's a terrible situation but I just think that we’ve gotten a little lax about

I: It could use a tune-up.

R: Yeah. I think we've gotten a little bit lax about some things, where I think there are some kids at this school...I don't know if it is just a lack of follow through or if it's an actual philosophy that no we shouldn't ever suspend a child. We shouldn't ever do this because that is too negative. I can understand that part...It's not out of control or anything but I can sense a little bit of frustration from some that I have heard from, some upper level teachers who feel like they have kids that the can't do anything with. There is no consequence there. (Teacher 1 )

Up until last year we had been making AYP, adequate yearly progress, and last year we didn't for the first year. (Teacher 1)

School Five:

I: Where do you get your best ideas for improving or expanding your teaching?

$\mathrm{R}$ : When we meet the other teachers.

I: When does that happen?

R: We used to do it once a week. Now it's like they've stressed this technology so much it took from our math meetings. We don't do it as much anymore. I would say once a month now. (Teacher 2) 
School Six:

I think that we do a better job at teaching reading than when I first got here 10 years ago...So we do a really good job that way. We really have made a lot of strides in that area. (Teacher 1)

\section{Being dependable.}

Being dependable drew comments that related to discipline, supervision of staff and visibility of the leader in the classroom and the school. The teacher in School Three commented on the instability they had experienced in school leadership, due to frequent turnover of principals. Examples of teacher comments about this element included:

School One:

I: Disciplinary school climate....

R: Very strong. Ms. H. and Ms. G. have very strong beliefs and very high expectations on what student behaviour is like. This year, I've had quite a bit of behaviour in my room that I haven't had to address before. I'm with them on the very first day and I'm like "Oh my God. I had to call nine parents. I've not had this in five years. What do I do?" She gave me a book this thick on behaviour and different strategies to deal with it. She's like "I'm here for whatever you need." Some got better and I've had a couple situations where one kid's been suspended like six times this year. They feel like the student is not going to do that. This is going to get taken care of. He's going home. They are not going to have that. They back you up if there is a problem with the parents. What happened? This is what happened. Let's get it straightened out. (Teacher 4)

School Three:

Anyone here would tell you we want a principal to stay here for awhile and not just come in and move on. (Teacher 3)

School Five:

Oh gosh, he is really on top of us. (Teacher 2)

School Six:

Initially she came in quite a bit. (Teacher 1)

\section{Demonstrating commitment, having dedication.}

Demonstrating commitment, having dedication comments focused on visibility in classrooms and in the school that had a regular, predictable pattern to it and the use of data. In School Five comments in both of these areas were negative. Examples of teacher comments related to this element included:

School One: 
She knows all of our students. (Teacher 1)

School Two:

She is very active in our classroom as well as the school...she came in on Friday and did a lesson on tepees in our class. She did a 45 minute lesson on it. (Teacher 1)

School Five:

He is always coming around looking in the window and walking through the classroom. They do several walk-throughs every year. They have to make a quota. (Teacher 2)

It seems like we take two benchmarks before Christmas and then another one after Christmas. We are constantly evaluating them but the kids don't take it serious. It's not very accurate. They usually do much better on the real thing. I feel like we waste a lot of time doing that. (Teacher 2)

Teachers provided considerable information about consistency and reliability, producing thought units that ranked this antecedent as second in importance when compared to other antecedents, if ranking matters and if the questions asked were able to produce a ranking. The comments made were often quite specific, and they frequently articulated details of behaviour, as seen in the examples provided.

To what extent do principals and teachers hold similar views on the sources (or antecedents) of trust in principals?

Principals did comment in the area of consistency and reliability, but the distribution of their comments was inconsistent. The order of the elements was different for principals than for teachers; however, the elements of highest priority were the same for both. Principal respondents and thought units resulted in the following order for the elements:

1. Having consistency;

2. Tools for uncertainty reduction;

3. Demonstrating commitment, having dedication;

4. Being diligent; and

5. Being dependable.

Principals in high-trust schools made 14 positive comments, with a slightly more frequent thought unit count in the area of tools for uncertainty reduction. In the third school, the lowest trust of the high-trust schools, the principal made no comments. Principals in the three low-trust schools made 12 positive comments and 2 negative comments and thought units were slightly higher in the element of having consistency. 
Principal comments clustered around visibility in classrooms and in the school, feedback to teachers about classroom and instructional activities, including professional development opportunities, school or team meetings and use of student achievement data and/or explaining data to teachers or parents. Teachers also commented on principal visibility, but they extended this to include a predictable nature to that visibility. Teachers did comment on feedback from principals. Only one teacher commented on student achievement data. Teachers were also focused on availability of classroom materials and supplies, routines related to discipline, and regular demonstrations of involvement with children and/or their families that was unrelated to discipline. A teacher in the highest trust school commented on the predictability of the leader's expressions of appreciation, and a teacher in the second highest trust school commented on the consistent and constant use of data, with support. In sum, there were similarities between the principal and teacher data, but there were also differences.

\section{Having consistency.}

Having consistency was articulated by principals in examples that illustrated principal visibility in classrooms and in the school, as well as scheduling of things such as meetings. Examples of principal comments related to this element y included:

School One:

I'm out and about, very visible and very accessible. I am very approachable. Teachers know that if there is something that I'm asking them to do, that they don't feel comfortable with, that I will help them either by sending them to see a teacher who does that very well or sending them to a school where this is an initiative.

School Two:

Once a week minimum. I think a lot of grade levels meet more than that, it depends on if they have things to do. But once a week they have a common prep each grade level does and I just for consistency and to make sure they are meeting. Tuesdays is their day ...then they give me a PLC feedback sheet each Tuesday. Then if they have any questions for me from their conversation they can write those on the bottom and I'll respond back to them on that. Then I also meet with them once a month. Tomorrow is my day...so I'll pretty much be meeting all day tomorrow.

School Four:

I go in and observe a variety of things. People, the staff knows, over the last six years that I have been here, they are totally comfortable with it now. Initially, they were a little bit uneasy those that were here six years ago. I said, "I'm in and out of your rooms all the time.” I said “Don’t worry about me being in your room. Just keep on going. If I need to deliver something I'm going to pop in your room to give it to you. 
When I do, I want to see what's happening. I may talk to a child. I may ask some questions. Let them explain something to me. I may not be there for more than two minutes and I'm off to some other place.” I said "you will see that I'm around the school all the time in and out. There will be times that I'm going to come in and I'll talk to you and say I want to formally see something.” Or, you have invited me in and asked me to formally see something.

We tell people that you need to figure out that you as a group need to figure out, “okay, who is going to be your representative?" But you need to rotate through your representatives so it should not, if you do it for a year. It shouldn't be the same person every year doing it. You need to rotate through so more and more people can be experiencing this. They are doing a much better job of that result of that over the years. Where now it's not a problem. They are willing to share and willing to do that.

School Five:

The departments themselves, they have meetings every single week. Normally, it's on Tuesdays. There is also another meeting called a grade level meeting on Thursday. I normally don't attend both of them. Most of the time I only attend the department meeting.

The walk through allows for the teacher to read and understand what they are ding. Most of the time the walk through we grade them on the $1^{\text {st }}$ four domains in the right hand side, which includes student participation, learner center instruction, evaluation and feedback and then the management of the discipline in the classroom. Really, those are the ones that we focus on. As well as domain 5, but only maybe two or three of those which includes written information, verbal and are you supportive...the rest of the time they just turn it in and we put it in their file. It means that they signed it, they read it and they understood where their instruction was at, at that time... we are required to do 40 walk throughs every six weeks.

\section{Tools for uncertainty reduction.}

Principals identified tools for uncertainty reduction as including communication to staff and the community as important. Examples of comments related to this element included:

School One:

We explain those when we have our PLOT team meetings. I spend a certain amount of time talking about state initiatives, county initiatives and school initiatives. We do that on a very regular basis. It's part of our newsletters. We talk about it on our website so that's an easy one.

School Two:

Explaining state tests to parents ... so you just have to simplify it. Then tell them, "you can access more information by going to this website or if you want more information than this, we'll give it to you." Invariably there will be that parent that wants to know every bit of it. But most of them don't. 
What we do have, again, with my parent that runs the parent volunteer staff, she puts out a weekly newspaper called the Monday Minute. She works it off my bulletin so she knows all the events that are coming up. She puts like a corner with "this is what you could do, or how you could do this." As a Title 1 school we also have parent nights maybe four times a year, but they are not usually instructional type things like "this is how you can help your kid." I think more of that comes informally with parents and teachers talking at parent teacher conferences.

School Four:

That's probably the biggest thing is to see some things that are graphed so that they can start seeing the growth and comparisons and they can talk to parents about it at conferences and discuss that ... I want them to have more visible things, not just my child is growing, but let's look at what is the growth.

I have told them, "If I have a concern about anything or a question, I will address it to you. Not at that moment, unless I feel that the class is totally out of control and I have to do something. I am not going to address it then. I'm going to wait, but I will address it.

\section{Demonstrating commitment.}

Demonstrating commitment, having dedication was described by principals as related to visibility in classrooms and throughout the school. Following up on information encountered as a result of visibility was important to principals. The principal in School One expressed specific self-reflection on her own practice. Examples of this element included: School One:

I just don't see myself as principal of the year...I just don't unless me being principal of the year is more about the staff that I have. It truly made me reflect on all of those areas and it just makes me go "Okay, well I need to kick it up a notch then. If this is what they think of me, well then I need to do some professional reflection and I need to see how I can kick it up a notch because I have to set a good example.

School Four:

Yes, I do (formal observations) also. But I, the staff, I know the school and I know what's going on because I'm in and out of the rooms all the time.

School Six:

I just go to any of them. If I'm going upstairs, I try to get everybody upstairs on the same day. If I'm downstairs, I hit everybody on the downstairs on that same day.

I look to see how they are engaged the students in the learning activity. Whether or not the teacher is focused in on what's going on in the classroom. I look to see if they have the components of the balanced literacy up in their classroom like whether or not they have the state standards posted. If they don't, I always take a little post-it note. This is my clipboard. I always keep a post-it note in here, a pack of post-it 
notes. But I have them, this is what I do my observation notes on and I'll just jot them a note saying, "see me afterwards" or "like what I see" or "what's going on" or "I didn’t see your standards listed.” But you know, then I just kind of leave it. Then I have my little check list of who I saw.

\section{Being diligent.}

One principal referred to being diligent when she described the process she undertook to bring about a change in school focus. She revealed that for her planning, persistence, and perseverance focused on instructional and program improvement were all part of diligence. These themes were seen in other comments related to diligence. Examples of principal comments related to this element included:

\section{School One:}

The whole magnet process. It has been a tremendous undertaking. We created the video. We created a notebook for all of the executive staff to see and then we had to create the program. We did eleven redistrict team meetings in ten days in which I went with the assistant superintendent throughout the county. I had the opportunity to go to every area in O. County and talk to groups of parents. Then I presented to the board. So, it has been C. E. on parade all year long. This has put me in a position where you and I can sit here and talk all day long but as soon as you stand me up in front of a group of people, I absolutely hate it. I have had to just get over it because I have had to stand up and do my show no less than twenty to twenty-five times. That is one component of building my leadership skills.

\section{Dependability.}

Only one principal made a comment in which dependability was a major element. The comment had a bit of an edge, and while not marked as a negative instance because it was not expanded upon in the interview data and the context was not explicit, it may have been a negative instance. Dependability in this example, related to visibility in the classroom and around the school. An example of a principal comment related to this element was: School Six:

No, it doesn't go in their file. It's just a way of letting them know that I'm observing to see what's going on. 


\section{Summary of Consistency and Reliability}

\section{Table $11^{11}$}

Summary Comparison of High Trust and Low Trust: Consistency and Reliability

\begin{tabular}{|c|c|c|c|c|c|c|}
\hline \multirow{8}{*}{ 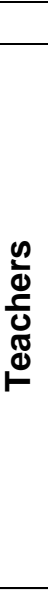 } & \multicolumn{3}{|l|}{ High Trust } & \multicolumn{3}{|l|}{ Low Trust } \\
\hline & Elements & $\begin{array}{l}\frac{0}{0} \\
\frac{0}{0} \\
\frac{0}{0} \\
\frac{0}{0} \\
\frac{0}{0} \\
\#\end{array}$ & 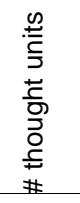 & Elements & $\begin{array}{l}\frac{n}{2} \\
\frac{0}{0} \\
\frac{0}{0} \\
\frac{0}{0} \\
\frac{0}{0} \\
\frac{d}{2} \\
\#\end{array}$ & 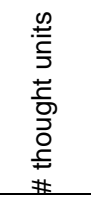 \\
\hline & Having consistency & 11 & $22,-2$ & Having consistency & 9 & $10,-5$ \\
\hline & Tools for uncertainty reduction & 7 & $7,-1$ & $\begin{array}{l}\text { Tools for uncertainty } \\
\text { reduction }\end{array}$ & 3 & $3,-2$ \\
\hline & Diligence & 3 & 4,0 & Diligence & 4 & $2,-2$ \\
\hline & Dependability & 3 & $3,-1$ & Dependability & 3 & $2,-2$ \\
\hline & $\begin{array}{l}\text { Demonstrating commitment, } \\
\text { having dedication }\end{array}$ & 2 & 3,0 & $\begin{array}{l}\text { Demonstrating commitment, } \\
\text { having dedication }\end{array}$ & 2 & $2,-2$ \\
\hline & Total & & $39,-4$ & Total & & $19,-13$ \\
\hline \multirow{6}{*}{ 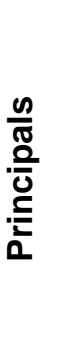 } & Tools for uncertainty reduction & 2 & 6,0 & Having consistency & 3 & 7,0 \\
\hline & Having consistency & 2 & 4,0 & $\begin{array}{l}\text { Tools for uncertainty } \\
\text { reduction }\end{array}$ & 2 & $2,-2$ \\
\hline & Being diligent & 2 & 3,0 & Commitment, dedication & 2 & 2,0 \\
\hline & Commitment, dedication & 1 & 1,0 & Dependability & 1 & 1,0 \\
\hline & Dependability & 0 & 0,0 & Diligence & 0 & 0,0 \\
\hline & Total & & 14,0 & Total & & $12,-2$ \\
\hline
\end{tabular}

There were both similarities and differences in what principals and teachers described, in relation to consistency and reliability. Principals were focused on the tasks for which they tended to be accountable, such as data, feedback / performance appraisal, and parent / community dialogue. They did not mention discipline, something that was very much in evidence in teacher comments related to consistency and reliability. Being diligent was not commented on at all in the low-trust principal data, yet it appeared as third most commented on by teachers in both high- and low-trust schools.

\footnotetext{
${ }^{11}$ For an explanation of how to read the table, see reading the tables in chapter 4.
} 


\section{Fairness}

To what extent do teachers identify influences on their trust in principals when they are engaged in conversation about their school and the school's leadership?

Table $12^{12}$

\section{Evidence of Fairness}

\begin{tabular}{|c|c|c|c|c|c|c|c|c|c|c|c|c|c|c|}
\hline \multicolumn{3}{|c|}{ Fairness } & \multicolumn{6}{|c|}{ High Trust } & \multicolumn{6}{|c|}{ Low Trust } \\
\hline & & School & \multicolumn{2}{|c|}{ One } & \multicolumn{2}{|c|}{ Two } & \multicolumn{2}{|c|}{ Three } & \multicolumn{2}{|c|}{ Four } & \multicolumn{2}{|c|}{ Five } & \multicolumn{2}{|c|}{ Six } \\
\hline \multicolumn{3}{|c|}{$\begin{array}{r}\text { Max \# Teachers: } \\
\text { Act \# Teachers }\end{array}$} & \multicolumn{2}{|c|}{$4: 2$} & \multicolumn{2}{|c|}{ 5: 4} & \multicolumn{2}{|c|}{$4: 0$} & \multicolumn{2}{|c|}{$3: 2$} & \multicolumn{2}{|c|}{$4: 1$} & \multicolumn{2}{|c|}{$4: 1$} \\
\hline & \multicolumn{2}{|c|}{$\begin{array}{l}\text { Totals for } \\
\text { Antecedent }\end{array}$} & \multirow[b]{2}{*}{$\begin{array}{l}\frac{0}{0} \\
\frac{1}{0} \\
\frac{0}{0} \\
\frac{0}{0} \\
\varrho \\
\frac{1}{\#}\end{array}$} & \multirow[b]{2}{*}{ 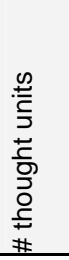 } & \multirow[b]{2}{*}{$\begin{array}{l}\frac{0}{0} \\
\frac{0}{0} \\
\frac{0}{0} \\
\frac{0}{0} \\
\text { ఏ } \\
\frac{1}{\#}\end{array}$} & \multirow[b]{2}{*}{ 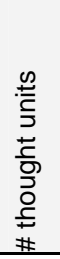 } & \multirow[b]{2}{*}{$\begin{array}{l}\frac{0}{0} \\
\frac{1}{0} \\
\frac{0}{0} \\
\frac{0}{0} \\
0 \\
\frac{0}{1} \\
\end{array}$} & \multirow[b]{2}{*}{ 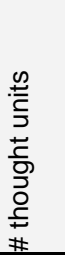 } & \multirow[b]{2}{*}{ 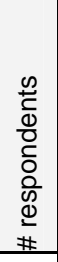 } & \multirow[b]{2}{*}{ 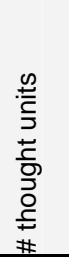 } & \multirow[b]{2}{*}{$\begin{array}{l}0 \\
\frac{0}{0} \\
0 \\
0 \\
0 \\
0 \\
0 \\
0 \\
0 \\
\end{array}$} & \multirow[b]{2}{*}{ 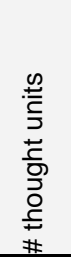 } & \multirow[b]{2}{*}{$\begin{array}{l}\frac{n}{2} \\
\frac{0}{0} \\
\frac{0}{0} \\
\frac{0}{0} \\
\frac{0}{0} \\
\frac{d}{2}\end{array}$} & \multirow[b]{2}{*}{ 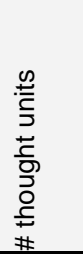 } \\
\hline Elements & 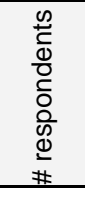 & 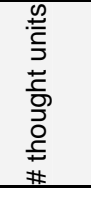 & & & & & & & & & & & & \\
\hline $\begin{array}{l}\text { Just } \\
\text { procedures }\end{array}$ & 7 & $7,-2$ & 2 & 2,0 & 3 & 4,0 & 0 & 0,0 & 0 & 0 & 1 & $0,-1$ & 1 & $1,-1$ \\
\hline $\begin{array}{l}\text { Fair } \\
\text { procedures }\end{array}$ & 5 & 6,0 & 2 & 2,0 & 3 & 4,0 & 0 & 0,0 & 0 & 0 & $\underline{0}$ & 0,0 & 0 & 0,0 \\
\hline $\begin{array}{l}\text { Intention to } \\
\text { enact } \\
\text { decisions } \\
\text { properly }\end{array}$ & 5 & $5,-3$ & 0 & 0,0 & 2 & 4,0 & 0 & 0,0 & 2 & $1,-2$ & 1 & $0,-1$ & 0 & 0,0 \\
\hline $\begin{array}{l}\text { Accepting an } \\
\text { unfavourable } \\
\text { outcome }\end{array}$ & 3 & 4,0 & 0 & 0,0 & 2 & 3,0 & 0 & 0,0 & 1 & 1 & 0 & 0,0 & 0 & 0,0 \\
\hline Totals & & $22,-5$ & & 4,0 & & 15,0 & & 0,0 & & $2,-2$ & & $0,-2$ & & $1-1$ \\
\hline $\begin{array}{l}\text { Intention to } \\
\text { enact } \\
\text { decisions } \\
\text { properly }\end{array}$ & 4 & $3,-4$ & & 0,0 & & 0,0 & & 1,0 & & 1 & & 1,0 & & $0,-4$ \\
\hline $\begin{array}{l}\text { Fair } \\
\text { procedures }\end{array}$ & 3 & 4,0 & & 0,0 & & 0,0 & & 0,0 & & 3 & & 1,0 & & 0,0 \\
\hline $\begin{array}{l}\text { Just } \\
\text { procedures }\end{array}$ & 3 & $1,-3$ & & 0,0 & & 0,0 & & 0,0 & & 1 & & $0,-1$ & & $0,-2$ \\
\hline $\begin{array}{l}\text { Accepting an } \\
\text { unfavourable } \\
\text { outcome }\end{array}$ & 1 & 1,0 & & 0,0 & & 0,0 & & 0,0 & & 1 & & 0,0 & & 0,0 \\
\hline Totals & & $9,-7$ & & 0,0 & & 0,0 & & 1,0 & & 6 & & $2,-1$ & & $0,-6$ \\
\hline
\end{tabular}

Fairness was a big part of the dialogue among teachers at the school with the second highest trust-in-leader ratings, with four of the five teachers commenting. Negative thought

\footnotetext{
${ }^{12}$ For an explanation of how to read the table, see reading the tables in chapter 4.
} 
units were more frequent than positive thought units among teachers in low-trust schools. There were no teacher thought units related to fairness in the lowest high-trust school.

The principals in the two highest trust schools had no thought units that equated to fairness. The only negative thought units appear in the two lowest trust schools.

Which elements of leader fairness to teachers identify most frequently and what leader behaviours do they associate with those elements?

Fairness has four element categories, including:

1. just procedures that assure people that a structure exists to protect their material self-interests in the long-run;

2. fair procedures that help protect and strengthen individuals identification with the group or organization;

3. intention to enact decisions properly; and fairness is

4. very related to accepting an unfavourable outcome, and as such, is connected to integrity.

\section{Just procedures.}

Just procedures that assure people that a structure exists to protect their material selfinterests in the long-run included meetings being scheduled regularly and designed to increase the involvement of and the understanding of teachers in terms of details of programs or events and the procedures related to the programs or events, discipline was seen as being fair for the student and family as well as for the teacher, and parent involvement expectations were clear and understood. Examples of teacher comments about this element included: School One:

She absolutely expects us to be involved with our parents, to speak with them and to keep them well-informed of academic progress, any behaviors as they occur. I mean that is the first one you contact if there is a behavior, is the parent, not her. That's why I feel crazy, because that question is how would a principal not expect you to be involved with a parent? Do teachers actually answer that a principal doesn't expect that? (Teacher 1)

Very strong. Ms. H. and Ms. G. have very strong beliefs and very high expectations on what student behaviour is like. This year, I've had quite a bit of behaviour in my room that I haven't had to address before. I'm with them on the very first day and I'm like "Oh my God. I had to call nine parents. I've not had this in five years. What do I do?" She gave me a book this thick on behaviour and different strategies to deal with it. She's like "I'm here for whatever you need." Some got better and I've had a couple situations where one kid's been suspended like six times this year. They feel like the student is not going to do that. This is going to get taken care of. He's going home. 
They are not going to have that. They back you up if there is a problem with the parents. What happened? This is what happened. Let's get it straightened out. They are very strong in their expectations with us and the children. (Teacher 4)

\section{School Two:}

I would say as a classroom teacher I would be first (in terms of discipline). Then when I need support I go to the counselor and then to the principal. Usually it seems like most of the discipline issues go to the counselor first and she tries to talk to them. If the child does do something really not good, that's when they get sent to the principal right away. (Teacher 4)

I: What about in terms of talking about general student performance issues with parents. What are the expectations there?

R: We have conferences twice a year. I send home notes and I always tell the parents that if they have any concerns to call me, and they do. They call me and I call them back. Usually by the end of the school day. I find that the parents really care about their children doing well in school.

I: How does the principal relay these expectations to you? Is there something in the staff handbook that outlines what your responsibilities are as a teacher? Or is it more subtle and indirect? How are those expectations communicated to you?

R: I would definitely say the staff handbook that we get at the beginning of every school year. Definitely.

I: Is it something that you're reminded of throughout the year?

R: No, she usually goes over that with us at the beginning of the year and if there are any issues that come up then she will review them with us. (Teacher 4)

We have them once a week. We have a goal sheet. We set out the goal for the meeting. The three teachers that are in that grade, plus our special ed teacher meets with us. Once a month we meet with the principal. But we meet weekly. We talk about student performance. We talk about our testing. We work on developing our testing. The needs that we have. What's going well, what's not going well. Kind of a post-Delta to see what we need to be doing. Then we go through a work timeline of what needs to be done and when. We don't take care of a lot of housekeeping ideas. (Teacher 5)

School Five:

I: What leadership role do you and other teachers play in this school?

R: I don't know. I don't think we have a real big - I know a lot of them try to go in there and get his ear. You know how that is. It's kind of political but as far as he makes a decision, that's it. (Teacher 1 , negative instance)

School Six: 
I: How much influence do teachers have in making decisions related to improving student learning?

R: On a classroom level, quite a bit. Beyond that, not so much. (Teacher 2, negative instance)

\section{Fair procedures.}

Fair procedures that help protect and strengthen individuals identification with the group or organization were seen by teachers as being evidenced in meetings being scheduled regularly that increased the involvement of, and the understanding of, teachers in terms of details of programs or events and the procedures related to the programs or events. In addition, commentary suggested opportunities such as professional development and other resources being equally available to all seemed to matter. Examples of teacher comments about this element included:

School One:

I: ...distributed leadership, can you talk about leadership roles that you and other teachers play in this school?

R: We all are in charge of saying how things are run here...We are the ones that are getting together and writing the goals for ... I feel like that is writing our goals for the school. Right? ... So, we are the ones doing it, along with Ms. H. and Ms. G., our assistant principal. We are playing an active role.

I: You mentioned earlier too, that everybody has a say. (Teacher 1)

We are the ones that are getting together and writing the goals for...I feel like that is writing our goals for the school. Right? ... so we are the ones doing it, along with Ms. H. and Ms. G., our assistant principal. We are playing an active role. (Teacher 1)

\section{School Two:}

We believe it takes a whole village to raise a child. So, we work not only with our own grade level PLC's but we are each a part of another, for example, I'm a part of a math PLC. There is also a reading and a writing. The math PLC has worked to align K-5. The reading has done the same and so has the writing. Every person on campus was assigned to one of those three committees.

I: The aids too?

R: Absolutely. Everyone except the counselor...everyone is a part of the group” (Teacher 5)

Again, this year, the district had wanted each school to have a leadership team and had given out ideas on how to come up with a leadership team and our principal said, you know, and she told us this in a staff meeting, I trust that any of you could be on 
the leadership team, it isn't, but I am going to take one person from each level and you are now our leadership team so if there are district meetings where they need representation, you guys will be the ones that go. (Teacher 2)

\section{Intention to enact decisions properly.}

Intention to enact decisions properly once again involved meetings being scheduled regularly and designed to increase the involvement of and the understanding of teachers in terms of details of programs or events and the procedures related to the programs or events was commented on. Parent involvement expectations being clear and understood was also prevalent in this element. Examples of teacher comments about this element included: School Two:

She likes for if the parents want to come in and volunteer, that's great. We have a parent work day at least once a month. We have a parent here that puts it together. We turn in the items that we would like for the parent group to work on like Weekly Readers. I get Weekly Readers and it takes so much time to separate them....any common tasks that we always do as classroom teachers, they help us out with those. (Teacher 4)

We are very geared, D and previous principals we had had also required $100 \%$ at conferences. So if you didn't get them to come on the day of conferences, we have two day conferences, $1 / 2$ a day afternoon one and morning of another. If you don't get them in that round, you are really encouraged to keep on them until you do. (Teacher 5)

\section{School Four:}

We also have collaboration at the school. It's supposed to be grade level collaboration but it really isn't collaboration. It's really a little meeting where they just give us information. It's really not a time to share. That is when we do most of our sharing is at lunchtime. (Teacher 1)

We also have collaboration at the school. It's supposed to be grade level collaboration but it really isn't collaboration. It's really a little meeting where they just give us information. It's really not a time to share. That is when we do most of our sharing is at lunchtime. (Teacher 1 , negative instance)

School Five:

I: Once a kid starts on that, is there any follow-up from the administration? Is there any monitoring?

R: If we fail more than $9 \%$ of our kids there is a problem. There have been teachers that have been written up for failing more than $9 \%$ so there is a policy of keeping them moving on. It's kind of an unwritten law but I don't know if you are aware of that. That probably happens everywhere. What are you going to do, right? I hate to say that. (Teacher 1) 
Accepting an unfavourable outcome, connected to integrity comments indicated that support for teachers and transparency mattered. Examples of teacher comments about this element included:

School Two:

I: The third question, would you characterize this as a trusting environment?

R: Yes. Even if your students don't perform as well as the other classes do, there is a lot of encouragement, a lot of feedback, a lot of sharing of what you could do differently to get your kids where they need to be. (Teacher 1)

School Four:

So when Dr. H came in it was great to see that he could make decisions, that okay, I want your ideas but sometimes I might have to change because something else has come in but I really want your opinions on what we should do. That has been valuable for us. (Teacher 2)

To what extent do principals and teachers hold similar views on the sources (or antecedents) of trust in principals?

Principal data showed some described parts of fairness in their conversation. There were no thought units related to fairness in the two highest trust schools, and there was a higher than average presence of negative instances for any antecedent in the low-trust schools. Because the principal in School Six made comments that were multiple negative instances, this element was weighted more heavily towards negative instance, something that did not happen in any other antecedent.

The order of the elements was different for principals than for the teachers. Principal respondents and thought units resulted in the following order for the elements:

1. Intention to enact decisions properly;

2. Fair procedures help protect, strengthen individuals identification with group or organization;

3. Just procedures assure people a structure exists to protect their material selfinterests in the long-run; and

4. Related to accepting an unfavourable outcome; connected to integrity.

\section{Intention to enact decisions.}

Principals most frequently identified intention to enact decisions properly. Principals were focused on interpretation of rules, often provided by a central office, as well as interpretation of events within the school. Regular scheduling of meetings intended to 
involve teachers in understanding through planning and details was a priority. Resources needed to be available to all. Examples of principal comments about this element included: School Three:

There were a lot of children in the Avid class that maybe were not the appropriate choices. They were not the middle students, like they are supposed to be. They were low children. There were a lot of discipline problems in there. So we couldn't ask the previous teacher why these children were selected so we re-interviewed people. We sort of revamped and regrouped. We've had a really good year with Avid as a result, but we had to do some regrouping at the beginning to sort of catch up.

School Four:

I can compensate differently out of that pot, but I can't compensate more than eight people. So we follow guidelines that way.

We tell people that you need to figure out that you as a group need to figure out, "okay, who is going to be your representative?" But you need to rotate through your representatives so it should not, if you do it for a year. It shouldn't be the same person every year doing it. You need to rotate through so more and more people can be experiencing this. They are doing a much better job of that result of that over the years. Where now it's not a problem. They are willing to share and willing to do that.

School Five:

They selected themselves. The department said, “ok, who wants to go?” "No, I don't want to go because I have this date or whatever.” ...self selection. Because you don't want to ever make them think that they are your favorites. You go, you go, you go. Just to do it means, "he likes them three.” No.

School Six:

I didn't want to come over here, but I know that there's a reason for me to be here. I'm trying to do my job. (Negative instance)

Just procedures assure people a structure exists to protect their material self-interests in the long-run was seen by principals as related to resources.

Examples of principal comments related to just procedures included:

School Four:

And we have two people on the staff that co-ordinate that. They submit a plan to the instructional council that says "we want to be the sponsors of the Brain Day. We feel we need so many hours to do what we need to do and this is what we're going to do." We have a person, a level book room, we have a person who is in charge of the level book room. These are all extra kinds of things. She identifies how much time she thinks she needs. We have a science coordinator that helps when all the science kits come in and gets it back and deals with all the issues there. We have a person that deals with test situations. They have to identify the time they think. I take the total 
number of hours and divide it into the total amount of money and come up with an hourly rate that can be multiplied out. So, when we go back it's, this person needs 30 hours, this one needs 300 hours, this one needs 150 hours, or whatever during the year to do what it is they are going to do.

The workroom is an open stock. I don’t say, here's your \$100 worth of supplies for the year. You go and take what you need. We take care of having things available for you to do your job and expect you to share.

\section{School Five:}

The only time that we have done this (teachers visiting each other's classrooms) is when we have concerns with the instruction of a teacher. So, after the second or third Walk Through or after each one of us has seen that one teacher, we put a plan together, a Plan of Action for that teacher. That includes please go observe Mrs. So and So or Mr. So and So. And then bring me back what you observed during that time. It does require them to go in there for the whole entire 50 minutes to observe that teacher (a colleague). Now, they are welcome to go and observe any time as long as the teacher knows that you're coming in. I know that it's happened, but in writing itself, we ask them to do that when there are concerns with their instruction. (likely viewed by teachers as a negative instance)

School Six:

That's the biggest challenge that I have. I think the behaviour of kids, I think the kids are pretty good. I can handle upset parents. That doesn't bother me. Dealing with teachers. I just have to let them know what my expectations are and those that don't like it I say, "get a job preference form. Gotta go.” (Principal)

Fair procedures related to procedural fairness, treating people equitably, and giving

them the benefit of the doubt. Examples of principal comments related to fair procedures...

included:

School Four:

Well, most principals just divide it by eight and it's $\$ 1,000$ a piece. We look at it on the basis of an hourly rate. I take each person that's interested. So, we take the money and we feel we do a better job with it because we make it more equitable and it goes to the amount of time that you put in. Everyone seems to be real supportive of that because, otherwise, you know, you want the job that is only 20 hours. It gives me $\$ 1000$ not the one that is 200 hours. This way, they are compensated.

School Five:

Remember, it's just a snapshot of those 15 minutes. You know, when they come in and they say "well, you didn't stay behind and we did this and everything was great and wonderful.” I understand that. But when I walked in, this is what I saw. Now, I'm going to go back in another week or so, hopefully I can see that or, "what time during the period do you do this that you claim that everything became better?” You give 
them the benefit of the doubt and you go back a week later and let me go in at the end of the period and see what I was looking for.

Unfavourable outcomes was only commented on by one principal, and the comment related to resources (or lack thereof).

\section{School Four:}

Yes, there are some monies, not much, but there are some monies that we can use and we do that. Try to do it as fair as I can.

Of particular interest was that the lowest trust school, School Six, had a very high negative thought unit count. The principal herself undoubtedly believed she was presenting her best to the interviewer. This should make the number of negative thought units particularly salient.

Table $13^{13}$

Summary Comparison of High Trust and Low Trust: Fairness

\begin{tabular}{|c|c|c|c|c|c|c|}
\hline \multirow{7}{*}{ 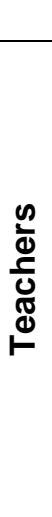 } & \multicolumn{3}{|l|}{ High Trust } & \multicolumn{3}{|l|}{ Low Trust } \\
\hline & Elements & $\begin{array}{l}\frac{0}{0} \\
\frac{1}{d} \\
\frac{0}{0} \\
0 \\
\frac{0}{0} \\
\varrho \\
\frac{1}{\#}\end{array}$ & 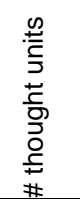 & Elements & 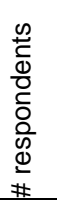 & 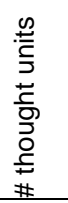 \\
\hline & Just procedures & 5 & 6,0 & Intention to enact decisions properly & 3 & $1,-3$ \\
\hline & Fair procedures & 5 & 6,0 & Just procedures & 2 & $1,-2$ \\
\hline & Intention to enact decision properly & 2 & 4,0 & $\begin{array}{l}\text { Related to accepting an } \\
\text { unfavourable outcome }\end{array}$ & 1 & 1,0 \\
\hline & Accepting an unfavourable outcome & 2 & 3,0 & Fair procedures & 0 & 0,0 \\
\hline & Total & & 19,0 & Total & & $3,-5$ \\
\hline \multirow{5}{*}{ 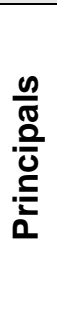 } & $\begin{array}{l}\text { Intention to enact decisions } \\
\text { properly }\end{array}$ & 1 & 1,0 & Intention to enact decisions properly & 3 & $2,-4$ \\
\hline & Just procedures & 0 & 0,0 & Just procedures & 3 & $1,-3$ \\
\hline & Fair procedures & 0 & 0,0 & Fair procedures & 2 & 4,0 \\
\hline & $\begin{array}{l}\text { Related to accepting an } \\
\text { unfavourable outcome }\end{array}$ & 0 & 0,0 & $\begin{array}{l}\text { Related to accepting an } \\
\text { unfavourable outcome }\end{array}$ & 1 & 1,0 \\
\hline & Total & & 1,0 & Total & & $8,-7$ \\
\hline
\end{tabular}

The relationship of the low-trust teacher data to the low-trust principal data was not something seen in other antecedents. There were eleven teachers who could have commented in relation to fairness among the three low-trust schools, and only three principals, yet the

\footnotetext{
${ }^{13}$ For an explanation of how to read the table, see reading the tables in chapter 4.
} 
principal comments were more than double those of the teacher comments in terms of positive instances, and the response rate of the principals was much higher than that of the teachers. In contrast, teachers in high-trust environments commented in each element, and while not extensive commentary was present, all the thought units were positive. The principals in high-trust environments commented very little.

\section{Forgiveness}

To what extent do teachers identify influences on their trust in principals when they are engaged in conversation about their school and the school's leadership?

There was only one comment made that relates to forgiveness in all the teacher data.

Which elements of leader forgiveness do teachers identify most frequently and what leader behaviours do they associate with those elements?

Teachers did not identify this antecedent, apart from a single reference by one teacher at one school. Based on the evidence provided, forgiveness was not salient.

There was only one comment made that relates to forgiveness in all the teacher and principal data. Teacher 4 at School Four stated:

If you've done a blunder - the other day I did one. I said 'Okay. I messed up on this but I just want you to know. I apologized but the parent should be coming in to see you.' I apologized to her. I'm willing, if I goof up, you are not perfect. There are too many parents, too many personalities, too many kids. Just say 'I'm sorry, I didn’t realize that'. He will support you.

To what extent do principals and teachers hold similar views on the sources (or antecedents) of trust in principals?

Principals did not describe this antecedent. It was not mentioned.

\section{Summary of Forgiveness}

In the sense that there was no comment there was a high level of agreement about forgiveness between teachers and principals that forgiveness was not a component of their relationships. 


\section{Honesty}

To what extent do teachers identify influences on their trust in principals when they are engaged in conversation about their school and the school's leadership?

Table $14^{14}$

\section{Evidence of Honesty}

\begin{tabular}{|c|c|c|c|c|c|c|c|c|c|c|c|c|c|c|c|}
\hline \multicolumn{4}{|c|}{ Honesty } & \multicolumn{6}{|c|}{ High Trust } & \multicolumn{6}{|c|}{ Low Trust } \\
\hline & \multicolumn{3}{|r|}{ School } & \multicolumn{2}{|c|}{ One } & \multicolumn{2}{|c|}{ Two } & \multicolumn{2}{|c|}{ Three } & \multicolumn{2}{|c|}{ Four } & \multicolumn{2}{|c|}{ Five } & \multicolumn{2}{|c|}{ Six } \\
\hline & \multicolumn{3}{|c|}{$\begin{array}{r}\text { Max \# Teachers: } \\
\text { Act \# Teachers }\end{array}$} & \multicolumn{2}{|c|}{$4: 1$} & \multicolumn{2}{|c|}{ 5: 2} & \multicolumn{2}{|c|}{$4: 0$} & \multicolumn{2}{|c|}{$3: 2$} & \multicolumn{2}{|c|}{$4: 1$} & \multicolumn{2}{|c|}{$4: 1$} \\
\hline \multirow{8}{*}{ 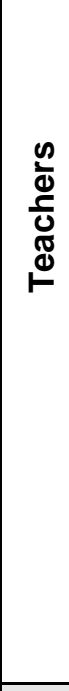 } & & \multicolumn{2}{|c|}{$\begin{array}{c}\text { Totals for } \\
\text { Antecedent }\end{array}$} & \multirow[b]{2}{*}{$\begin{array}{l}\frac{0}{0} \\
\frac{0}{0} \\
\frac{0}{0} \\
0 \\
\frac{0}{0} \\
\frac{1}{1} \\
\#\end{array}$} & \multirow[b]{2}{*}{ 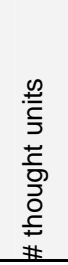 } & \multirow[b]{2}{*}{ 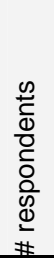 } & \multirow[b]{2}{*}{ 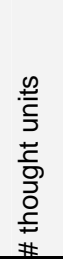 } & \multirow[b]{2}{*}{ 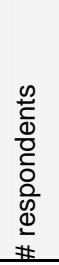 } & \multirow[b]{2}{*}{ 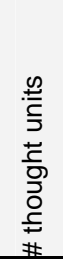 } & \multirow[b]{2}{*}{$\begin{array}{l}\frac{0}{2} \\
\frac{0}{0} \\
\frac{0}{0} \\
\frac{0}{0} \\
\frac{0}{d} \\
\frac{1}{\#}\end{array}$} & \multirow[b]{2}{*}{ 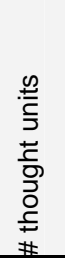 } & \multirow[b]{2}{*}{ 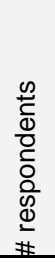 } & \multirow[b]{2}{*}{ 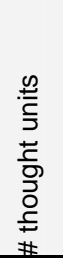 } & \multirow[b]{2}{*}{ 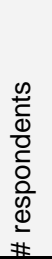 } & \multirow[b]{2}{*}{ 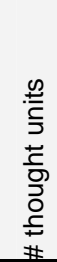 } \\
\hline & Elements & 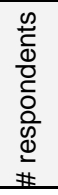 & 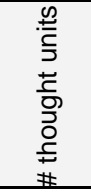 & & & & & & & & & & & & \\
\hline & $\begin{array}{l}\text { Telling the } \\
\text { truth }\end{array}$ & 5 & 5,0 & 1 & 1,0 & 1 & 1,0 & 0 & 0,0 & 2 & 2,0 & 0 & 0,0 & 1 & 1,0 \\
\hline & Authenticity & 4 & 6,0 & 1 & 1,0 & 1 & 1,0 & 0 & 0,0 & 1 & 2,0 & 1 & 2,0 & 0 & 0,0 \\
\hline & $\begin{array}{l}\text { Avoiding } \\
\text { manipulation }\end{array}$ & 2 & $2,-1$ & 1 & 2,0 & 0 & 0,0 & 0 & $0, c$ & 0 & 0,0 & 1 & $0,-1$ & 0 & 0,0 \\
\hline & $\begin{array}{l}\text { Keeping } \\
\text { promises }\end{array}$ & 1 & 1,0 & 0 & 0,0 & 1 & 1,0 & 0 & $0, \mathrm{C}$ & 0 & 0,0 & 0 & 0,0 & 0 & 0,0 \\
\hline & $\begin{array}{l}\text { Accepting } \\
\text { responsibility }\end{array}$ & 0 & 0,0 & 0 & 0,0 & 0 & 0,0 & 0 & 0,0 & 0 & 0,0 & 0 & 0,0 & 0 & 0,0 \\
\hline & Totals & & $14,-1$ & & 4,0 & & 3,0 & & 0,0 & & 4,0 & & $2,-1$ & & 1,0 \\
\hline \multirow{6}{*}{ 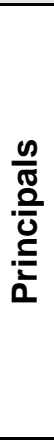 } & $\begin{array}{l}\text { Telling the } \\
\text { truth }\end{array}$ & 3 & $7,-2$ & & 4,0 & & 3,0 & & 0,0 & & 0,0 & & 0,0 & & $0,-2$ \\
\hline & $\begin{array}{l}\text { Accepting } \\
\text { responsibility }\end{array}$ & 2 & $2,-3$ & & 0,0 & & 0,0 & & 0,0 & & 0,0 & & 2,0 & & $0,-3$ \\
\hline & $\begin{array}{l}\text { Keeping } \\
\text { promises }\end{array}$ & 1 & 2,0 & & 0,0 & & 2,0 & & 0,0 & & 0,0 & & 0,0 & & 0,0 \\
\hline & Authenticity & 1 & 2,0 & & 0,0 & & 2,0 & & 0,0 & & 0,0 & & 0,0 & & 0,0 \\
\hline & $\begin{array}{l}\text { Avoiding } \\
\text { manipulation }\end{array}$ & 1 & 1,0 & & 1,0 & & 0,0 & & 0,0 & & 0,0 & & 0,0 & & 0,0 \\
\hline & Totals & & $14,-5$ & & 5,0 & & 7,0 & & 0,0 & & 0,0 & & 2,0 & & $0,-5$ \\
\hline
\end{tabular}

Teachers in both environments commented on honesty. The number of teachers who commented on this antecedent was relatively low. There were 7 positive comments by

\footnotetext{
${ }^{14}$ For an explanation of how to read the table, see reading the tables in chapter 4.
} 
teachers in the high-trust schools, compared to 7 positive comments and 1 negative comment in the low-trust schools. It was unusual to see an antecedent where the totals were so similar, albeit a low count.

Which elements of leader honesty do teachers identify most frequently and what leader behaviours do they associate with those elements?

Honesty has five element categories, including:

1. telling the truth;

2. having authenticity/ being real/ being true to oneself/ having integrity;

3. avoiding manipulation;

4. keeping promises and honouring agreements; and

5. accepting responsibility.

The most number of teachers identified telling the truth, however, more comments existed that related to having authenticity/being real/ being true to oneself/ having integrity, suggesting both of these elements mattered to teachers.

Telling the truth.

Telling the truth included various aspects of parent communication and honesty, as well as aspects of comments related to observations of teachers in their daily tasks. Examples of teacher comments related to this element included:

School One:

In their write-out, they record step-by-step the different things you had done. So it's almost as if you were reading everything you had done, step-by-step and typed out. (Teacher 2)

School Two:

The principal does not want us to have any surprises for parents. (Teacher 2)

School Four:

I think at staff meetings. Like you say, it's not required, but he is always, if you are up front with parents, you are going to be better off and the whole school will be better off. Invite them in. It's not mandatory because some are very uncomfortable. (Teacher 2)

School Six:

She expects that you communicate honestly (with parents). (Teacher 4) 


\section{Having authenticity.}

Having authenticity, being real, being true to oneself, having integrity included aspects of the style of the principal that are "true" to what the staff knows about the principal. Examples of teacher comments related to this element included:

School One:

It's not done to be negative, it's just let me help you think of some of the different things you can do with this. (Teacher 2)

School Two:

I: How much influence do teachers have in the decision making process in the school related to student learning?

R: A lot. Yes. High end. D, our principal, wants to hear our ideas...(Teacher 1)

School Four:

He doesn't pretend though that he is always going to take our side. (Teacher 1)

He will tell you I don't always agree with you. I won't always take a consensus. He doesn't do that. Like some people will feel like they have to reach consensus. (Teacher 1)

School Five:

He was a military type. He was in the military so he is more - but every principal has his own style and it permeates the school. (Teacher 1)

He is real big on technology. (Teacher 1)

\section{Avoiding manipulation.}

Avoiding manipulation included curriculum and related issues as well as issues related to teacher management of the principal. Examples of teacher comments related to this element included:

School One:

As far as suggestions go they will come up with different twists. For example, I had done a lesson with (Seats) and they suggested that I could have done that with Graph Club too. I thought 'Yeah, we could have had that graphed.' That is a little technology component. They are kind in their ideas. (Teacher 2)

School Five:

Anyway, you know, you've got to be careful. You have to get along with your principal, otherwise you may be out of a job. I just try to get along but I'm not a real politician. (Teacher 1 , negative instance) 


\section{Keeping promises.}

Keeping promises, honouring agreements involved knowing what was expected and being consistent within that. In the example provided this related to curriculum. School Two:

She has never, I mean, the only thing that she has said we will be doing is we will get to work with Dianne Painter. We will have our standards based units. And this is what we're working on. (Teacher 1)

\section{Accepting responsibility.}

Accepting responsibility, an element commented on by principals, was not something teachers offered comments about.

Honesty mattered; teachers did make comments about honesty. Teachers expressed that they watch principals closely. Honesty, in terms of authenticity, was closely related to integrity. In no school did all the teachers comment, and in three schools only one teacher made comments related to honesty. Honesty may matter more to some teachers than others. It may be that honesty is assumed. It may be that honesty is encapsulated in thoughts that related more to other antecedents.

To what extent do principals and teachers hold similar views on the sources (or antecedents) of trust in principals?

Principals did describe the antecedent of honesty in their conversation. Not all principals made comments, and no principal made extensive related comments. Their comments about honesty generally fell into two areas, those being their perceptions of others and the relationship to themselves and perceptions of the job.

There was quite a large discrepancy among principals, with 12 positive comments in the high-trust schools and 2 positive comments and 5 negative comments in the low-trust schools. Note the absence of all comment by principals in School Three and School Four. In the area of telling the truth principals in high-trust schools made repeated positive statements and the principal in the lowest trust environment made negative statements. There were also several negative instances regarding accepting responsibility for the principal in the lowest trust school.

The elements appeared in a different order among principals than that of teachers, although telling the truth was the most frequent element for both teachers and principals. Avoiding manipulation drew the fewest comments from principals, something that was a 
midpoint element for teachers. Accepting responsibility was placed in second position among principals, but was the least significant element among teachers. The elements were ordered:

1. telling the truth;

2. accepting responsibility;

3. keeping promises, honouring agreements;

4. having authenticity, being real, being true to oneself, having integrity; and

5. avoiding manipulation.

Telling the Truth.

Telling the Truth for principals, involved perceptions or realities of the job as well as

the relationships with staff. Examples of principal comments related to this element included: School One:

I am not good with disaggregating data. I like to see it disaggregated. I love for somebody to hand it to me and say this is what the data tells us. You know, oftentimes your staff kind of mirrors your strengths as well. I think we knew as a staff that we needed to really work on using that data to tell us more about our children and to help us drive our instruction. So in third, fourth and fifth grade L., who is the accountability person at the county office, she is just amazing in the way her brain is wired with data. I just want a part of that. But she has come and worked with us as grade levels, all together as grade levels, specifically looking at a variety of ways to take the data, disaggregate it and use it. Now we have a much easier time with our data with our K-2 assessment, which is an assessment instrument that was created and was ...it gives wonderful data on math skills, on very specific reading skills, fluency, comprehension, phonics, and those kinds of things. That is an easier thing for me to look at, because it's apples and apples. When you look at EOG data, sometimes it almost seems like apples to oranges. It's a little more difficult, I think, to look at. (perceptions of the job)

My teachers have trusted that as soon as I knew what was going to happen that I was going to tell them that. I think that it's not just this year. It's been during my five years and they know that there is a level of trust and that it's that kind of thing where they can disagree with me and they are not going to get in trouble for it. That I'm going to respect our differences and that they can share those with me. They don't feel like they have to go talk in a little corner behind my back. I think that takes a huge amount of trust. Yesterday we had a meeting where I had to explain that our budget this year in Title 1 is $\$ 200,000$ less than it was last year, which brings great change. Again, that wasn't something that I sat in here and secretly crunched numbers and said "I'm not going to tell.” I said “This is what this means for (School One).” I think they trust me.

School Two:

Well, other than the funding that I was able to get through that grant the state has the best influence the state has had on us is leaving us alone. We kind of lucked out...we 
made (AYP) two years consecutively...you have to do two years consecutively to get out of the school improvement process. I really have had few dealings with the state at all.

\section{School Six:}

Before my leg got messed up I was doing a walk around every day. But, I have a problem with my knee right now. It's been going on for about a month. Generally, I try to do a walk around every day. (This may have been a negative instance as a teacher reported that the principal had not been in one part of the school for over four months.)

\section{Accepting Responsibility.}

Accepting responsibility involved both perceptions of the job as well as perceptions

of relationships with others. Examples of principal comments related to this element included:

School Five:

The most recent hard decision that we did was when we got the Math scores back and I said "how about we take out the kids from Mr. L's class, he’s got 9, and we break those down into your two classes...throughout the year we have done schedule changes because a kid might perform well, believe it or not, with a female than a male or vice versa. And we happen to have enough teachers for that to be incorporated. As well as if the teacher is too strong willed and the kid is very shy. We might move him to another teacher to help facilitate that. The intent is for the kid to start with that teacher at the beginning of the year and to end with that teacher at the end of the year.

Through my guidance and setting the goals...they understood that our goal here in this campus, of course, guided through me, was to be an exemplary campus. To be at least a recognized campus. Also to make sure that we fostered an environment where the kids felt safe here because that was another problem, too, was a safety issue. There was a lot of referrals. A lot of problems with people fighting, I'm talking about the kids. So, my leadership style in a sense that I was very rigid. It really helped, but I started doing a little bit more of self-analysis when it comes to more people friendly, a lot more smiles. Other than the crossing of the arms. Believe it or not that made the biggest difference for me. Not only with my staff, but with my kids, with my students. Because I was more approachable. It helped me because the students were able to know that I was there for them and I was guiding their instruction not just being Mr. Army Man and that was it. So, my style included that. Now, when it comes to academics, I got a lot of guidance from my own peers... a lot of collaboration. That in itself helped me a lot, too...they have been able to say "hey, why don't you hold back on this and do a little bit more of this. You are doing everything really well on this, but your demeanor needs to be fixed up. Why don't you work on this.” So, really to be honest with you and to wrap that up, is my first summer after I completed my first year, I went through a lot of self-evaluation. That included also to provide a survey to my teachers on what I needed to work on. Anonymous. I made a list of about 25 different questions to improve my leadership style. My academic leadership. Handling parents. Handling teachers. Handling students. I took it to heart and I 
evaluated myself on everything. When I came back, I was a totally different principal. Not that I changed a lot of things, but the things that were getting in my way which was a lot of PR work. So, that also included me distributing some of my responsibilities to my Assistants so I could work on that more on the PR side. I was against also to the kind of person that kind of "I need to get everything done because otherwise it won't get done." And I have learned in the last two years, "give this to her, give this to him.” And then you go out there and you be more visible.

\section{School Six:}

And then, you know, all administrators make changes when they come into the building. I made some changes. That kind of, when teachers have taught for a long time at a certain building they feel that they don't want things to change, but we all know that change happens and it needs to happen. Sometimes things are done in an old way and just like me coming over here. I didn't want to come over here, but I know that there's a reason for me to be here. I'm trying to do my job. (Negative instance)

(School Six) has been a school that has maintained its AYP and we didn't make it this year, but I don't attribute that to the fact that I'm here. (Negative instance)

\section{Keeping promises.}

Keeping promises, honouring agreements involved managing the expectations and perceptions of others and being true to commitments made. An example of a principal comment related to this element was:

\section{School Two:}

I cannot think of a specific instance (of trust). I think a lot of that is so embedded. This is one of those things that I'll wake up at 2 am and go, "that's what I should have told her!” But off the top of my head, trust is an interesting issue. It's not something that just sort of happens and I think it's kind of the same thing. If you give people those opportunities when you follow through on things you say you're going to. Another thing that I think is helpful is that if you say you're going to follow through on something and you don't, you are honest enough it, you say, “Oh my God! I forgot to do that!” (perceptions of others and the relationship to themselves)

\section{Having authenticity.}

Having authenticity, being real, being true to oneself, having integrity related to perceptions of the job and articulation of the individual's understanding of this. Examples of two comments from one principal related to this element were:

School Two:

People here have accepted the fact, and it's something I would have liked to have them accept, but I never told them you need to believe in this, that textbooks are just a resource and they are not your curriculum. It's a change for me. When I taught, my textbook was the curriculum. I might have picked and chose and maybe go through in different order, but I still was textbook based ... (the standards movement) has really 
changed education...I'm not meaning to Marzano you to death, but they ...(long articulation of standards based, etc.)

I've gotten to the point where there is just not a lot of ego in what you do anymore because it's nice to be this age. You don't care anymore. That sort of stuff doesn't matter. Nobody is trying to prove anything. It's just need to do. Like with this school. Everything that is going on is just neat.

\section{Avoiding manipulation.}

Avoiding manipulation, like keeping promises, involved understanding and managing the perceptions of others, and working with these in a direct and transparent manner, fostering shared understanding. One principal comment related to this element was: School One:

Sure, as we went through this magnet process, I have told them they were with me in every part of it. It wasn't like some hush, hush. They were part of the initiative and I think that certainly built trust because I'm a real honest person. I'm a very transparent leader. I tell people all the time that what they see is what they get, like it, love it, lump it or stump it. I believe in telling the truth. I don't believe in secrets.

Principals did express thoughts that related to honesty. Some of the principals were more introspective than teachers, identifying their own weaknesses, whether instructional or in relation to others. Teachers were much more focused on tasks and events. 


\section{Summary of Honesty}

Table $15^{15}$

Summary Comparison of High Trust and Low Trust: Honesty

\begin{tabular}{|c|c|c|c|c|c|c|}
\hline & \multicolumn{3}{|c|}{ High Trust } & \multicolumn{3}{|c|}{ Low Trust } \\
\hline & Elements & 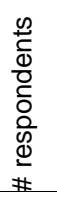 & 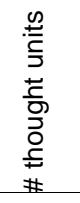 & Elements & 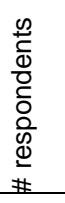 & 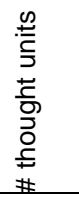 \\
\hline \multirow{6}{*}{ 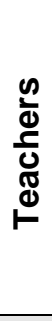 } & Telling the truth & 2 & 2,0 & Authenticity & 2 & 4,0 \\
\hline & Being authentic & 2 & 2,0 & Telling the truth & 3 & 3,0 \\
\hline & Avoiding manipulation & 1 & 2,0 & Avoiding manipulation & 1 & $0,-1$ \\
\hline & Keeping promises & 1 & 1,0 & Keeping promises & 0 & 0,0 \\
\hline & $\begin{array}{l}\text { Accepting } \\
\text { responsibility }\end{array}$ & 0 & 0,0 & $\begin{array}{l}\text { Accepting } \\
\text { responsibility }\end{array}$ & 0 & 0,0 \\
\hline & Total & & 7,0 & Total & & $7,-1$ \\
\hline \multirow{6}{*}{ 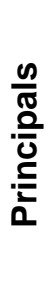 } & Telling the truth & 2 & 7,0 & Taking responsibility & 2 & $2,-3$ \\
\hline & Authenticity & 1 & 2,0 & Telling the truth & 1 & $0,-2$ \\
\hline & Keeping promises & 1 & 2,0 & Authenticity & 0 & 0,0 \\
\hline & Avoiding manipulation & 1 & 1,0 & Avoiding manipulation & 0 & 0,0 \\
\hline & Responsibility & 0 & 0,0 & Keeping promises & 0 & 0,0 \\
\hline & Total & & 12,0 & Total & & $2,-5$ \\
\hline
\end{tabular}

Overall, not many thought units related specifically, and only, to honesty. Many connected easily to integrity, openness or other antecedents. There was very little commentary from teachers about this antecedent and the quantity of comment was very similar between high- and low-trust environments. Telling the truth and being authentic were in similar "first and second" positions for both environments. There was a fairly wide gap in the number of thought units between high-trust principals and low-trust principals. Principals in high-trust environments articulated a particular focus on telling the truth in their commentary, while principals in high-trust environments were slightly more focused on taking responsibility, albeit with mixed results.

\footnotetext{
${ }^{15}$ For an explanation of how to read the table, see reading the tables in chapter 4.
} 


\section{Chapter 6 Results: Integrity, Loyalty, Openness}

This chapter continues the report of results about the antecedents of trust in leaders. In this third of four results chapters the focus is on integrity, loyalty and openness. Results are summarized quantitatively in Tables 16, 18 and 20 respectively. Tables 17, 19 and 21 compare high- and low-trust schools on these same three antecedents of trust in leaders.

\section{Integrity}

To what extent do teachers identify influences on their trust in principals when they are engaged in conversation about their school and the school's leadership?

Table $16^{16}$

\section{Evidence of Integrity.}

\begin{tabular}{|c|c|c|c|c|c|c|c|c|c|c|c|c|c|c|c|}
\hline \multicolumn{4}{|c|}{ Integrity } & \multicolumn{6}{|c|}{ High Trust } & \multicolumn{6}{|c|}{ Low Trust } \\
\hline & \multicolumn{3}{|c|}{ School } & \multicolumn{2}{|c|}{ One } & \multicolumn{2}{|c|}{ Two } & \multicolumn{2}{|c|}{ Three } & \multicolumn{2}{|c|}{ Four } & \multicolumn{2}{|c|}{ Five } & \multicolumn{2}{|c|}{ Six } \\
\hline & \multicolumn{3}{|c|}{$\begin{array}{r}\text { Max \# Teachers: } \\
\text { Act \# Teachers }\end{array}$} & \multicolumn{2}{|c|}{$4: 4$} & \multicolumn{2}{|c|}{ 5: 4} & \multicolumn{2}{|c|}{$4: 1$} & \multicolumn{2}{|c|}{$3: 2$} & \multicolumn{2}{|c|}{ 4:0 } & \multicolumn{2}{|c|}{ 4:0 } \\
\hline & & \multicolumn{2}{|c|}{$\begin{array}{l}\text { Totals for } \\
\text { Antecedent }\end{array}$} & \multirow[b]{2}{*}{ 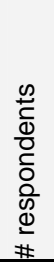 } & \multirow[b]{2}{*}{ 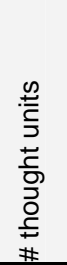 } & \multirow[b]{2}{*}{$\begin{array}{l}\frac{n}{0} \\
\frac{0}{0} \\
\frac{0}{0} \\
\frac{0}{0} \\
00 \\
\frac{0}{0} \\
\end{array}$} & \multirow[b]{2}{*}{ 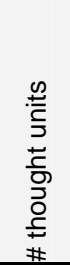 } & \multirow[b]{2}{*}{ 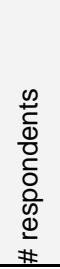 } & \multirow[b]{2}{*}{ 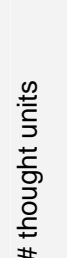 } & \multirow[b]{2}{*}{ 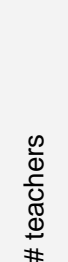 } & \multirow[b]{2}{*}{ 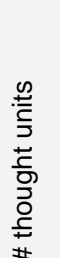 } & \multirow[b]{2}{*}{ 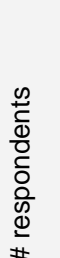 } & \multirow[b]{2}{*}{ 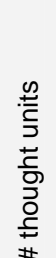 } & \multirow[b]{2}{*}{ 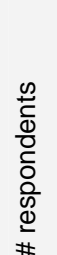 } & \multirow[b]{2}{*}{ 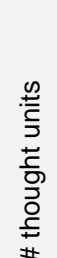 } \\
\hline \multirow[t]{5}{*}{ 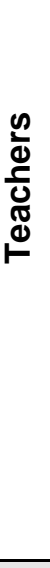 } & Elements & 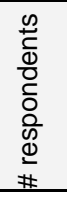 & 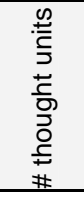 & & & & & & & & & & & & \\
\hline & $\begin{array}{l}\text { Moral-ethical } \\
\text { perspective } \\
\text { guides work }\end{array}$ & 9 & 15,0 & 4 & 9, & 4 & 5,0 & 0 & 0,0 & 1 & 1,0 & 0 & 0,0 & 0 & 0,0 \\
\hline & $\begin{array}{l}\text { Leader's } \\
\text { actions and } \\
\text { words match }\end{array}$ & 7 & $11,-2$ & 1 & $2, c$ & 4 & 7,0 & 0 & 0,0 & 2 & $2,-2$ & 0 & 0,0 & 0 & 0,0 \\
\hline & Modeling & 7 & $10,-1$ & 3 & $4, c$ & 2 & 4,0 & 1 & 1,0 & 1 & $1,-1$ & 0 & 0,0 & 0 & 0,0 \\
\hline & Totals & & $36,-3$ & & 15, & & 16,0 & & 1,0 & & $4,-3$ & & 0,0 & & 0,0 \\
\hline & & & & & & & & & & & & & & & \\
\hline \multirow{4}{*}{ 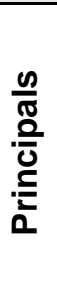 } & $\begin{array}{l}\text { Moral-ethical } \\
\text { perspective } \\
\text { guides work }\end{array}$ & 6 & $11,-1$ & & $3, \mathrm{C}$ & & 1,0 & & 2,0 & & 4,0 & & 1,0 & & $0,-1$ \\
\hline & Modeling & 2 & 2,0 & & $1, \mathrm{C}$ & & 0,0 & & 0,0 & & 1,0 & & 0,0 & & 0,0 \\
\hline & $\begin{array}{l}\text { Leader's } \\
\text { actions and } \\
\text { words match }\end{array}$ & 2 & $1,-2$ & & $0, \mathrm{C}$ & & 0,0 & & 0,0 & & 1,0 & & $, 0,0$ & & $0,-2$ \\
\hline & Totals & & $14,-3$ & & $4, c$ & & 1,0 & & 2,0 & & 6,0 & & 1,0 & & $0,-3$ \\
\hline
\end{tabular}

\footnotetext{
${ }^{16}$ For an explanation of how to read the table, see reading the tables in chapter 4.
} 
Teachers made 31 positive comments about integrity in the high-trust schools. This contrasted with 4 positive comments and 3 negative comments in the low-trust schools. Note the absence of all comment in the two lowest trust schools. In the highest trust school, four of four teachers made comments. In the school with the second highest trust in the school leader, four of five teachers commented on Integrity.

Which elements of leader integrity do teachers identify most frequently and what leader behaviours do they associate with those elements?

Integrity has three element categories, including:

1. moral-ethical perspective guides one's work in schools actions are understood as advancing the best interests of children;

2. intense staff watchfulness of leader actions including a match between words and deeds; and

3. modeling.

\section{Moral-ethical perspective guides one's work - in schools.}

Moral-ethical perspective guides one's work in schools, like most of integrity,

seemed to be focused in two broad areas, children and learning and staff and teaching.

Examples of teacher comments related to this element included:

School One:

When it comes down to it, regardless of what a teacher thinks, it will always come down to what is in the best interests of the student. So, if you have a teacher who is resistant to what is in the best interests of the student, they will be heard, but it will come back to what is in the best interests. (Teacher 2)

We focus on the diversity of the learners. We have great diversity here. We are a Title 1 school so Ms. H and Ms. G want to make sure that everybody has an opportunity to learn, can learn and that we find the best strategy that can teach every child. (Teacher 3)

She makes sure that we are all teaching the (middle) State curriculum. She does give us leeway about strategies and techniques that are best for the children. (Teacher 3)

If you are thinking of a particular idea, as long as Ms. H says, it's in the best interests of children, then she is very, that is her thing. If you think that this is in the best interests of your child, then she is okay with it. As long as you can make a case or prove that you think this is the very best thing for my children, then she will take your suggestion or whatever. She will really listen. (Teacher 4)

School Two: 
She will, she tried to help you find someone that can help you learn or she will also, with all of our curriculum that we have been going through, she has provided a lot of resources and books that we have gone through and read as a group or just she has offered them and said, here they are if you want them. (Teacher 2)

I have the freedom to be creative and teach using my own style, but I also have directives on which to focus and I know that I'm on the right track. In the past, in other schools where I worked everyone did their own thing. Now that we have common goals it makes it really nice to work here to help and share ideas. (Teacher 3)

We have been meeting with Dianne Painter. She helps us to unpack the standards... Right now we are working on measurement so we have specific vocabulary terms and a specific unit that we want to teach in order to meet that goal. I think that helps to eliminate a lot of the extras that we would try to do or just even wondering is this really what they need? There is no question of that anymore. That really helps. (Teacher 4)

School Four:

R: Dr. H. is very good with trying to treat kids with respect and he personally does not believe in sending kids home. So eventually the child just goes before Dr. H., the really rough ones. Most of the other ones are "okay."

I: There is a little bit of fear still there.

R: Yeah. (Teacher 2)

Intense staff watchfulness.

Intense staff watchfulness of leader actions, match between words and deeds included examples focused mostly on staff and teaching. Examples of teacher comments related to this element included:

School One:

Ms. H. is very forward thinking in providing opportunities for the staff and seeking out professional development for the staff and sending us to relevant places. (Teacher 1)

School Two:

She is really a kind of person that makes sure she does positive first and then, I know, with some teachers she will use making sure that they have someone to look towards to help them with their classroom management for discipline.(Teacher 2)

That was one of the things that Dr. Marzano was just shocked to find out that we had so much work to do and we didn't have any turnover. I think the leadership is critical in keeping the staff together, focused. She is very understanding. If you are having a hard time comprehending something that's going on. She's right there. She is supportive... The team, we are in grade level teams, she meets with us once a month 
as a team. She has found prep time for us every day so we have a prep time every day. A common prep period. We are required to meet once a week as a group. The other four days we use that prep as we need, or we meet often. We'll say, "Let's get together on Thursday and finish that project.” Having a common prep, I have waited 30 years in education without a prep period.(Teacher 5)

\section{School Four:}

He is very honest too. He will tell you I don't always agree with you. I won't always take a consensus. He doesn't do that. Like some people will feel like they have to reach a consensus. He will ask our opinions about things. I think he is very good about asking our opinions. He does listen. He doesn't pretend though that he is always going to take our side but he does listen and he does ask for our opinions about things so I appreciate that in him too. (Teacher 1)

\section{Modeling.}

Modeling was also described in the same two broad categories of children and

learning, staff and teaching. Examples of teacher comments related to this element included: School One:

In the mornings, she expects us to be greeting our students at the door. She will be in the hallway in the morning greeting our students. She knows all of our students. (Teacher 1)

She makes sure that we are integrating everything that we need to with technology, cultural arts and global studies. She gives us feedback, that we are doing a great job. (Teacher 4)

School Two:

D.B., our principal, keeps in close contact with Dianne Painter and she goes to workshops. Then when Dianne can't be with us, she supplements with the training. (Teacher 5)

Absolutely. I believe that she has put a very, very strong professional attitude towards how we handle our classrooms, how we handle ourselves and how she handles us. She doesn't micromanage. She really sets the standard high. (Teacher 5)

School Three:

Every morning we have warmups, either reading or math... we also do principal quizzes every two weeks. So we go to nine weeks and then there is a challenge. Whichever class in eighth grade has the highest percentage we get the ice cream party or the pizza party, whichever. We do a lot. (Teacher 2 - this practice was established by the recently departed former principal) 


\section{School Four:}

R: I think for the most part except for those that need a little more. There isn't something for those... at the end of the year some of the fifth graders and fourth graders need just a little bit more

I: Would you say that the discipline then is enforced primarily, the responsibility is shared with the teachers and with this redirect person and also with the school administration?

R: Yes. The only place that it's lacking is for the real severe.

I: At that point then would you say that's an administrative -

R: That's where it's lacking. We all know that. (Teacher 2, negative instance)

There was evidence that in high-trust schools teachers notice integrity. There was a dramatic drop in teacher comments related to integrity the lower the trust-in-leader, by school. There was a far greater focus on children and learning evident in School One, the highest trust school within this antecedent. It was interesting to consider how much this antecedent matters, how salient was the antecedent. The absence of conversation or thought units in lower trust schools may speak very loudly to what teachers were experiencing.

To what extent do principals and teachers hold similar views on the sources (or antecedents) of trust in principals?

Principals commented in relation to integrity, at an average rate, in comparison to comments related to other antecedents of trust. There were 8 positive comments made by principals in the high-trust schools. There were 7 positive comments and 3 negative comments made by principals in the low-trust schools. The words did align with the two broad themes identified in the teacher data, those being children and learning and staff and teaching. The order of the elements for principals also placed moral-ethical perspective as most significant, but modeling was in second for principals rather than third, which was where it fit for teachers. The elements were ordered:

1. moral-ethical perspective guides one's work - in schools: actions are understood as advancing the best interests of children

2. modeling

3. intense staff watchfulness of leader actions; match between words and deeds. 


\section{Moral-ethical perspective guides one's work-in schools.}

Moral-ethical perspective guides one's work -in schools: actions are understood as advancing the best interests of children words did align with the two broad themes identified in the teacher data, those being children and learning and staff and teaching in School One, and a strong focus on teachers (staff) and teaching in School Four. Examples of principal comments related to this element included:

School One:

I want children to be engaged. Teachers are moving from - and elementary teachers don't all do stand and deliver, sit and get. But the level of engagement that we are looking for, that is a difficult move for some of them. It's hard to move to being that facilitator and letting children kind of create their own learning. As educators, we are in control. We have some control issues. When students are involved in activities that are so engaged and so integrated, teachers have to give up a certain amount of control.

The one that they set over and over still is the technology. Not my very young teachers, but my more veteran teachers, it's just more difficult for them. They know that, they recognize that and they will say "I need to do a better job of this. Can you please help me?” You know, they are extremely professional and I think what guides them to do that and to not act like they know it all, is that our guiding philosophy here, regardless of the position you hold in this school, is that every decision we make has to be weighed against what is in the best interests of children. Not what's easy, not what's comfortable. We understand that there is a little discomfort that comes with challenging our students in a manner of what is going to be rewarding for them.

School Four:

Growth is important and it's important that teachers, and there's been some plusses with No Child Left Behind. I mean, when you look at an emphasis on well, "don’t just tell me a child is doing better. Can you show me that a child is doing better?" That's important. Teachers should be able to do that. A lot of teachers couldn't do that. They need to understand how you assess and what is says and see the growth. But the key is seeing growth and how much growth are we seeing and not these ridiculous points that they want us to meet at a certain point in time for all kids... but watch a special ed child just sit there and cry because they are told they are a $4^{\text {th }}$ grades and you have to take the $4^{\text {th }}$ grade assessment and you have no choice and even if it's read to them, they are functioning two to three years below. They don't know the content. They can't deal with it. They are just frustrated. They just sit there and just cry and we have to take them through. I mean. We're being bushwhacked.

I project that it's the demise of the Democratic and Republican parties as we know them in this country. If they don't fix this thing by 2014, you talk about their credibility will be in the toilet. The populace is going to say...this is huge because this affects kids and when you personalize something, what parents get really upset about is, "my children." So, when it comes down to that you're telling us that all the kids in the nation are failing and are incompetent. I think it's the government that's 
incompetent. It's causing teachers, because of all of the assessments that are being required connected with the whole thing, you have got teachers that are wanting, saying, "I'm looking for something else. Teaching was always difficult. This is becoming ridiculous.

\section{Modeling.}

Two principals commented on modeling, once each. Both comments related to teachers and teaching. One principal comment related to this element was:

\section{School One:}

Yes. I don't know if you've ever thought about this, but having worked about half of my career in middle school and half of my career in elementary school, I very much see teachers taking on the personalities of the children that they teach. Middle school teachers can be a little challenging and they use a lot more ugly words than elementary teachers. In elementary school, they tattle on each other. They used to here. They don't so much any more. They would come initially and say "Well, I heard that such and so said this about me. That's just really not what I'm doing or how this is played out." I would say "Well, did you go and ask them about that?" "No." It was like I was Mom and I was Mother Hubbard and I was going to go take care of it. I would say "You are a professional. You are an adult. Schedule a time after school when it's just you and this person and you can say that this is what you heard through the grapevine.” I want to get it out on the table and work through that. That builds trust among your staff and it takes away the tattle-tales. I think that does build trust. I can sit in team meetings where they can disagree with one another, but its respectful disagreement. That again takes trust and that trust has been built through the culture of this school.

\section{Intense staff watchfulness.}

Intense staff watchfulness of leader actions; match between words and deeds

appeared to relate to procedures within the school for principals, not specifically to children and learning or teachers and teaching, although both exist within procedures.

Examples of principal comments related to this element included:

School Four:

I visit classrooms all the time. Okay. The last time I visited a classroom was this morning.

School Six:

When we have Open House or when we have anything that deals with parents coming out, they generally come out. I try to do something once a month. I did, we haven't done anything actually since January because I put that in the hands of my family and community resource person.(it’s May - negative instance) 
Finally, the principal in School Two brought both themes together, children and learning and teachers and teaching, and all the elements of integrity, in a quote that pretty much summarized integrity, all aspects of it.

I worked with Dianne (Painter, from Marzano) in K...So, as it were, the first year that I was here, I ran into a colleague that we had both taught in $\mathrm{K}$. together and she was a principal in B., Utah. She mentioned that Dianne Painter had been to her building and was only teaching the vocabulary piece. I jumped on that because I realized after a couple of months here that this staff was extremely well-trained in teaching reading and that one of the issues really with kids, again of poverty and kids of second language, was that they needed that vocabulary development. I remembered how strong that piece was because some of my teachers from K. that were really using that, they were starting to spike after a couple of years, and we didn't have state testing, but it was like the CTBS or whatever it was, one of the TBS tests. We always, our comprehension scores were always higher than our vocabulary scores because the vocabulary was used in assimilation and our kids just didn't have that wide of a vocabulary...so with that in mind, I thought what this group really needs is vocabulary. We have something called a Student Initiative Grant that you can ask for here in the district and you go before a district office administrator so I asked for money to bring Dianne in. I contacted her. I got on the line the next Monday and found her and asked her what she charged. I had never arranged for her, I was just a principal...I initiated it and it was happening here. Dianne came in and did a two day training. We actually cancelled school. I had to go to the School Board and ask them to cancel school on a Friday so we did Thursday afternoon and Friday training. The staff loved her. They wanted to know when was she coming back. So I was able to get funding from the district for two days in June right after school was out and had huge turnout by my staff attending that. The next year, we weren't able to bring her in until I think until the summer, but the last year, I wrote a grant. It came from Advanced Placement of all things, here we were a school in re-structuring, and it was called a Core Curriculum grant. Since we had been doing so much with standards based curriculum development, I wrote for that grant and asked for $\$ 56,000$. I got the grant and they gave me $\$ 76,000 \ldots$ So, I had like $\$ 45,000$ or something for training. We were able to bring her in for 12 days last year. I had to pay for substitutes and things, too...Technically, about 40\% (are Navajo)...they are all Spanish. But the way the law works and everything else, is that what we have is kids who are Navajo children who are limited English speakers because they are (a) poor, that's probably more of an issue than the fact that they are Navajo and then sometimes there is a second language background because the parents do not speak fluent English, but the kids speak English only... what they don’t have is academic vocabulary. 


\section{Summary of Integrity}

Table $17^{17}$

Summary Comparison of High Trust and Low Trust: Integrity

\begin{tabular}{|c|c|c|c|c|c|c|}
\hline & \multicolumn{3}{|l|}{ High Trust } & \multicolumn{3}{|l|}{ Low Trust } \\
\hline & Elements & $\begin{array}{l}\frac{0}{1} \\
\frac{0}{0} \\
\frac{0}{0} \\
\frac{0}{0} \\
0 \\
\frac{0}{1} \\
\#\end{array}$ & 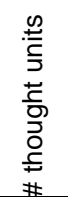 & Elements & 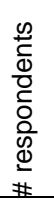 & 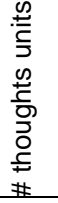 \\
\hline \multirow{4}{*}{ 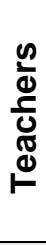 } & $\begin{array}{l}\text { Moral-ethical perspective } \\
\text { guide work }\end{array}$ & 8 & 14,0 & Leader's action match words & 2 & $2,-2$ \\
\hline & Modeling & 6 & 9,0 & Modeling & 1 & $1,-1$ \\
\hline & Leader actions match words & 5 & 9,0 & $\begin{array}{l}\text { Moral-ethical perspective } \\
\text { guides one's work }\end{array}$ & 1 & 1,0 \\
\hline & Total & & 32,0 & Total & & $4,-3$ \\
\hline & & & & & & \\
\hline \multirow{4}{*}{ 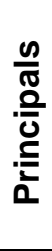 } & $\begin{array}{l}\text { Moral-ethical perspective } \\
\text { guides one's work }\end{array}$ & 3 & 6,0 & $\begin{array}{l}\text { Moral-ethical perspective } \\
\text { guides one's work }\end{array}$ & 3 & $5,-1$ \\
\hline & Modeling & 1 & 1,0 & Leader's actions match words & 1 & $1,-2$ \\
\hline & $\begin{array}{l}\text { Leader's actions match } \\
\text { words }\end{array}$ & 0 & 0,0 & Modeling & 1 & 1,0 \\
\hline & Total & & 7,0 & Total & & $7,-3$ \\
\hline
\end{tabular}

Teachers commented much more frequently and in higher numbers in high-trust schools. All elements of integrity attracted comment from teachers, and there wasn't an enormous discrepancy between the most commented on element (moral-ethical), and the least commented on element (staff watchfulness, word, and deed). There was a similar, but not identical, "ranking” of the elements as seen by teachers and principals. Principals in both high- and low-trust schools commented with similar frequency, the low-trust schools had some negative instance.

\footnotetext{
${ }^{17}$ For an explanation of how to read the table, see reading the tables in chapter 4.
} 


\section{Loyalty}

To what extent do teachers identify influences on their trust in principals when they are engaged in conversation about their school and the school's leadership?

Table $18^{18}$

\section{Evidence of Loyalty}

\begin{tabular}{|c|c|c|c|c|c|c|c|c|c|c|c|c|c|c|c|}
\hline \multicolumn{4}{|c|}{ Loyalty } & \multicolumn{6}{|c|}{ High Trust } & \multicolumn{6}{|c|}{ Low Trust } \\
\hline \multirow{8}{*}{ 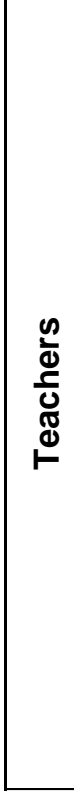 } & \multicolumn{3}{|c|}{ School } & \multicolumn{2}{|c|}{ One } & \multicolumn{2}{|c|}{ Two } & \multicolumn{2}{|c|}{ Three } & \multicolumn{2}{|c|}{ Four } & \multicolumn{2}{|c|}{ Five } & \multicolumn{2}{|c|}{ Six } \\
\hline & \multicolumn{3}{|c|}{$\begin{array}{r}\text { Max \# Teachers: } \\
\text { Act \# Teachers }\end{array}$} & \multicolumn{2}{|c|}{$4: 2$} & \multicolumn{2}{|c|}{ 5: 1} & \multicolumn{2}{|c|}{$4: 3$} & \multicolumn{2}{|c|}{$3: 1$} & \multicolumn{2}{|c|}{$4: 3$} & \multicolumn{2}{|c|}{$4: 0$} \\
\hline & & $\begin{array}{r}\text { To } \\
\text { Ant }\end{array}$ & $\begin{array}{l}\text { Is for } \\
\text { edent }\end{array}$ & \multirow[b]{2}{*}{$\begin{array}{l}0 \\
\frac{0}{c} \\
\frac{0}{0} \\
\frac{0}{0} \\
\frac{0}{0} \\
\frac{0}{1}\end{array}$} & \multirow[b]{2}{*}{ 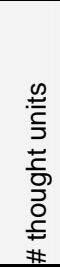 } & \multirow[b]{2}{*}{ 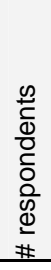 } & \multirow[b]{2}{*}{ 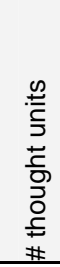 } & \multirow[b]{2}{*}{$\begin{array}{l}\frac{0}{1} \\
\frac{0}{0} \\
\frac{0}{0} \\
\frac{0}{0} \\
\frac{0}{0} \\
\end{array}$} & \multirow[b]{2}{*}{ 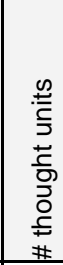 } & \multirow[b]{2}{*}{$\begin{array}{l}0 \\
\frac{0}{0} \\
\frac{0}{0} \\
0 \\
0 \\
\frac{0}{0} \\
\frac{0}{0} \\
\end{array}$} & \multirow[b]{2}{*}{ 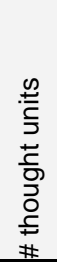 } & \multirow[b]{2}{*}{$\begin{array}{l}0 \\
\stackrel{0}{0} \\
\frac{0}{0} \\
\frac{0}{0} \\
\frac{0}{n} \\
\frac{0}{2} \\
\#\end{array}$} & \multirow[b]{2}{*}{ 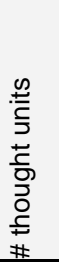 } & \multirow[b]{2}{*}{$\begin{array}{l}\frac{0}{0} \\
\frac{0}{0} \\
\frac{0}{0} \\
\frac{0}{0} \\
\frac{0}{0} \\
\frac{0}{1}\end{array}$} & \multirow[b]{2}{*}{ 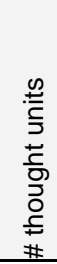 } \\
\hline & Elements & $\begin{array}{l}\frac{0}{0} \\
\frac{0}{0} \\
\frac{0}{0} \\
\frac{0}{0} \\
0 \\
\frac{0}{0} \\
\end{array}$ & 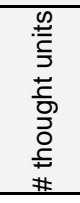 & & & & & & & & & & & & \\
\hline & $\begin{array}{l}\text { Fears or reprisals } \\
\text { mitigated }\end{array}$ & 4 & $6,-3$ & 1 & 1,0 & 1 & 4,0 & 1 & 1,0 & 0 & 0,0 & 1 & $0,-3$ & 0 & 0,0 \\
\hline & $\begin{array}{l}\text { Working towards } \\
\text { group goals }\end{array}$ & 5 & $4,-3$ & 1 & 2,0 & 0 & 0,0 & 2 & 2, & 0 & 0,0 & 2 & $0,-3$ & 0 & 0,0 \\
\hline & $\begin{array}{l}\text { Seems to } \\
\text { encourage a more } \\
\text { complete } \\
\text { exploration of ideas }\end{array}$ & 3 & $3,-1$ & 0 & 0,0 & 0 & 0,0 & 1 & 1,0 & 1 & 2,0 & 1 & $0,-1$ & 0 & 0,0 \\
\hline & Totals & & $13,-7$ & & 3,0 & & 4,0 & & 4,0 & & 2,0 & & $0,-7$ & & 0,0 \\
\hline \multirow{4}{*}{$\begin{array}{l}\frac{n}{\pi} \\
\frac{0}{0} \\
\frac{D}{2}\end{array}$} & $\begin{array}{l}\text { Working towards } \\
\text { group goals }\end{array}$ & 4 & 6,0 & & 1,0 & & 1 & & 0,0 & & 0,0 & & 2,0 & & 2,0 \\
\hline & $\begin{array}{l}\text { Seems to } \\
\text { encourage a more } \\
\text { complete } \\
\text { exploration of ideas }\end{array}$ & 1 & 1,0 & & 0,0 & & 1 & & 0,0 & & 0,0 & & 0,0 & & 0,0 \\
\hline & $\begin{array}{l}\text { Fears of reprisals } \\
\text { mitigated }\end{array}$ & 1 & $0,-1$ & & 0,0 & & 0 & & 0,0 & & 0,0 & & 0,0 & & $0,-1$ \\
\hline & Totals & & $7,-1$ & & 1,0 & & 2,0 & & 0,0 & & 0,0 & & 2,0 & & $2,-1$ \\
\hline
\end{tabular}

Teachers didn’t comment a great deal about loyalty, although the teachers in School Five made many comments and three of four teachers at School Five made these comments. Every comment in School Five was negative. Teachers in the high-trust schools made 11 positive comments about loyalty. Teachers in the low-trust school made 2 positive comments and 7 negative comments.

\footnotetext{
${ }^{18}$ For an explanation of how to read the table, see reading the tables in chapter 4 .
} 
Which elements of leader loyalty do teachers identify most frequently and what leader behaviours do they associate with those elements?

Loyalty has three element categories, including:

1. fears of reprisals or scapegoating are mitigated;

2. people will be working towards group goals; and

3. seems to encourage a more complete exploration of ideas as people can concentrate on the content and cognitive meaning of messages.

Teachers commented in all of the sub-dimensions of loyalty, however, there were no comments from teachers in the lowest trust school, School Six, and there were subdimensions in some schools that did not draw comments. Fears of reprisals or scapegoating are mitigated received the most comment, but not the most respondents. Generally, one teacher made comments in schools where comments were made, with the exception of School Five, where two teachers commented in relation to people will be working towards group goals.

\section{Fears of reprisals.}

Fears of reprisals or scapegoating are mitigated did attract some, but not a lot, of commentary. The comments focused on there being support for the teachers if it was needed. Examples of teacher comments related to this element included:

School One:

In a positive way she is there for us. (Teacher 1)

School Two:

A testimony again I think to her good leadership is that this year we are losing the music teacher, that's all. Last year we lost the two special ed teachers, that was all. A regular classroom teacher has not left this campus, well, I'll take that back, last year we lost a $3^{\text {rd }}$ grade teacher because her husband got transferred. We have a very steady staff and when they come, they stay. (Teacher 5)

She is very understanding. If you are having a hard time comprehending something that's going on. She's right there. She is supportive. (Teacher 5)

School Three:

I can go to Ms. S. and talk to her. I don't expect it to get out and it doesn't. (Teacher 2) 


\section{School Five:}

They are like tying bonuses to those guys now I heard plus their job is on the line...They've got to motivate us to do our work. (Teacher 2, likely a negative instance)

Apparently some teacher had thought there was some type of reprisal, what was the word now. He was harassing some teacher. She (the superintendent) wanted to let us know if that ever happens to come to her. (Teacher 2, negative instance)

\section{Means people will be working towards group goals.}

Means people will be working towards group goals included comments focused on a team-like nature to the instructional program development and/or delivery, and support for the teachers if it is needed. Examples of teacher comments related to this element included: School One:

Our principal and vice-principal, you can poke your head in their door all the time. They are always asking what is going on. (Teacher 4)

Everybody knows everybody and everybody is all together. (Teacher 4)

School Three:

She or the other principal are not just those people that say "This is it. Do it.” They are out in the trenches helping you to get it done. (it's very supportive) Very. I have really enjoyed working with both of them this year. (Teacher 4)

School Five:

I: The question was when was the last time you had a grade level or department meeting, what was your conversation like?

R: We had one today...He is just worried about the TAKS scores. That is all we ever talk about.

I: He is, in this case, the principal. (Teacher 2)

But what I see as a problem is there are a lot of teachers that miss a lot of time. They miss a lot of days. Then we had a teacher drop out. They just walk out on contracts down here. She got another job so then that is going to come down on me. We've had subs in there ever since. Those kind of things are happening. (Teacher 2, negative instance)

\section{Seems to encourage a more complete exploration of ideas.}

Seems to encourage a more complete exploration of ideas as people can concentrate on the content and cognitive meaning of messages, a confusing series of words related to loyalty, likely relates to some sense of certainty that the leader will not punish or abandon the follower/ teacher because of disagreement or "asking the wrong question." Comments within 
the interviews related to a team-like nature to the instructional program development and/or delivery, and support for the teachers if it is needed. Examples of teacher comments related to this element included:

School Three:

Her statements have been she wants to be a middle school principal and she would like to be here and that she is comfortable here so I hope that is what will happen. (Teacher 3)

School Four:

He does listen and he does ask for our opinions about things so I appreciate that in him too. (Teacher 1 )

School Five:

On a general level I don't think it's like that. I know for example in the science department they have three different seventh grade science teachers and each one is doing something different. (Teacher 1 , negative instance)

Loyalty seemed to be a component of other antecedents of trust. Each of the examples provided were included in other antecedents. This did not mean loyalty didn't matter. The number of thought units by school very much reflected my understanding of these schools. The high-trust schools had many more positive thought units. School Three, where the staff appeared to be very loyal to each other, despite the constant turnover of principals, demonstrated loyalty to the principal, despite her presence in the role for less than four weeks. It was that kind of school. The frustration in School Five was exposed with the loyalty antecedent. And the silence in School Six was deafening. Loyalty did matter, but the thought units were encompassed in other antecedents.

To what extent do principals and teachers hold similar views on the sources (or antecedents) of trust in principals?

Principals in high-trust schools made a total of 3 comments, and principals in lowtrust schools made a total of 4 positive comments and 1 negative comment. Most comments appeared within the sub-dimension of 'people will be working towards group goals'. Principal comments were similar to teacher comments, indicating support for teachers when needed mattered, as did team work. The elements, when ranked, appeared in this order:

1) Means people will be working towards group goals;

2) Seems to encourage a more complete exploration of ideas as people can concentrate on the content and cognitive meaning of messages; and 
3) Fears of reprisals or scapegoating are mitigated.

Means people will be working towards group goals.

Means people will be working towards group goals focused on a team-like nature to the instructional program development and/or delivery. Support for teachers, if or when needed, was identified. Examples of principal comments related to this element included: School One:

Our teachers have always worked diligently, they’ve always worked hard, but knowing that you are moving to an international baccalaureate framework, the way we've termed it is kicked up a notch. They have been very diligent in digging into the IB information, preliminary to us even being approved as a magnet. Having very open dialogue about what can I do here? Will you come observe me do this? Give me feedback...I think something that is very telling about their commitment to how much learning has to occur is every year in our county all staff has the opportunity to request a transfer to another school. No one here requested a transfer. They are up for a challenge.

School Two:

I think that work is critical. I think that a lot of schools, when we go, my school, my teachers have become like missionaries when it comes to standards based work. When they go on district curriculum committees or stuff like that, and it's not coming from me, it's coming because they have done the work and they believe in what they are doing.

School Five:

Through the help of some of the teachers, some of the teachers that you met, but some other groups that we've had, we have been able to implement the technology.

So, as a matter of fact, CG., the one you are going to be talking to, she is the one who is going to be doing Summer School with these four kids. Which is also the teacher that went above and beyond and said, "give me all those 9 kids and I'll instruct them and help them pass the test" after the first administration...she took on there 9 kids, she was able to get 5 of them to pass. The other 4 , by the way you cannot tell her that because I need to tell her that. She doesn't know yet. Anyway, she loves for me to tell her exactly. She took, so she is going to be very happy that she was able to get 5 out of 9 and now in Summer School she will be able to instruct these kids.

School Six:

Then there were, like my $2^{\text {nd }}$ grade teachers they were pleased to have the opportunity to administer the test because they felt they didn't know anything about ISTEP. Now they feel that they know what to expect in regards to getting their kids prepared for the next year.

I gave the pieces that I put together to a $1^{\text {st }}$ grade teacher because she really liked it. 


\section{Seems to encourage a more complete exploration of ideas.}

Seems to encourage a more complete exploration of ideas as people can concentrate on the content and cognitive meaning of messages focused on comments related to support for the teachers if it was needed. Examples of principal comments related to this element included:

School Two:

Our teachers have always worked diligently, they've always worked hard, but knowing that you are moving to an international baccalaureate framework, the way we've termed it is kicked up a notch. They have been very diligent in digging into the IB information, preliminary to us even being approved as a magnet. Having very open dialogue about what can I do here? Will you come observe me do this? Give me feedback....I think something that is very telling about their commitment to how much learning has to occur is every year in our county all staff has the opportunity to request a transfer to another school. No one here requested a transfer. They are up for a challenge.

One of my teachers, $5^{\text {th }}$ grade teachers, he's very quiet, but deep young man. When I started with his evaluation conference, what I do in an evaluation conference is, after we have done paperwork and we sign it, but then I ask them to kind of please tell of their year. Tell me what went well, is there anything you would like to see changed? That really helps me for the next year. And the first thing out of his mouth, the topics alignment was huge. He says, do we understand what we've created? Very few see it.

\section{Fears of reprisals.}

Principals did not comment on fears of reprisals or scapegoating are mitigated, with the exception of the principal in School Six, who provided a negative instance. An example of a principal comment related to this element was:

School Six:

I don't have a teacher leader for each grade level because they have not implemented the balanced literacy the way it's supposed to be. I don't have one for kindergarten, I don't have one for $1^{\text {st }}$ grade. I have one for $3^{\text {rd }}$ and $4^{\text {th }}$. It's basically because they don't want to implement it the way it's supposed to be implemented. I had one for $2^{\text {nd }}$, but and I've talked to $\mathrm{m} 2^{\text {nd }}$ grade teacher and I have said to her, “as the teacher leader, it's your responsibility to make sure that as you go through this training it's up to you to train the other $2^{\text {nd }}$ grade teachers and right now, I don't see that happening with you. (Negative instance)

It is interesting to note that in the school with the lowest trust-in-leader, School Six, teachers had no thought units about loyalty. They were silent. The principal, however, had three thought units, albeit one was a negative instance. There were more thought units about loyalty expressed by principals in this school than in any other school. It is also of interest 
that in School Five, the teachers had seven negative thought units, but the principal had two positive thought units.

\section{Summary of Loyalty}

Table $19^{19}$

Summary Comparison of High Trust and Low Trust: Loyalty

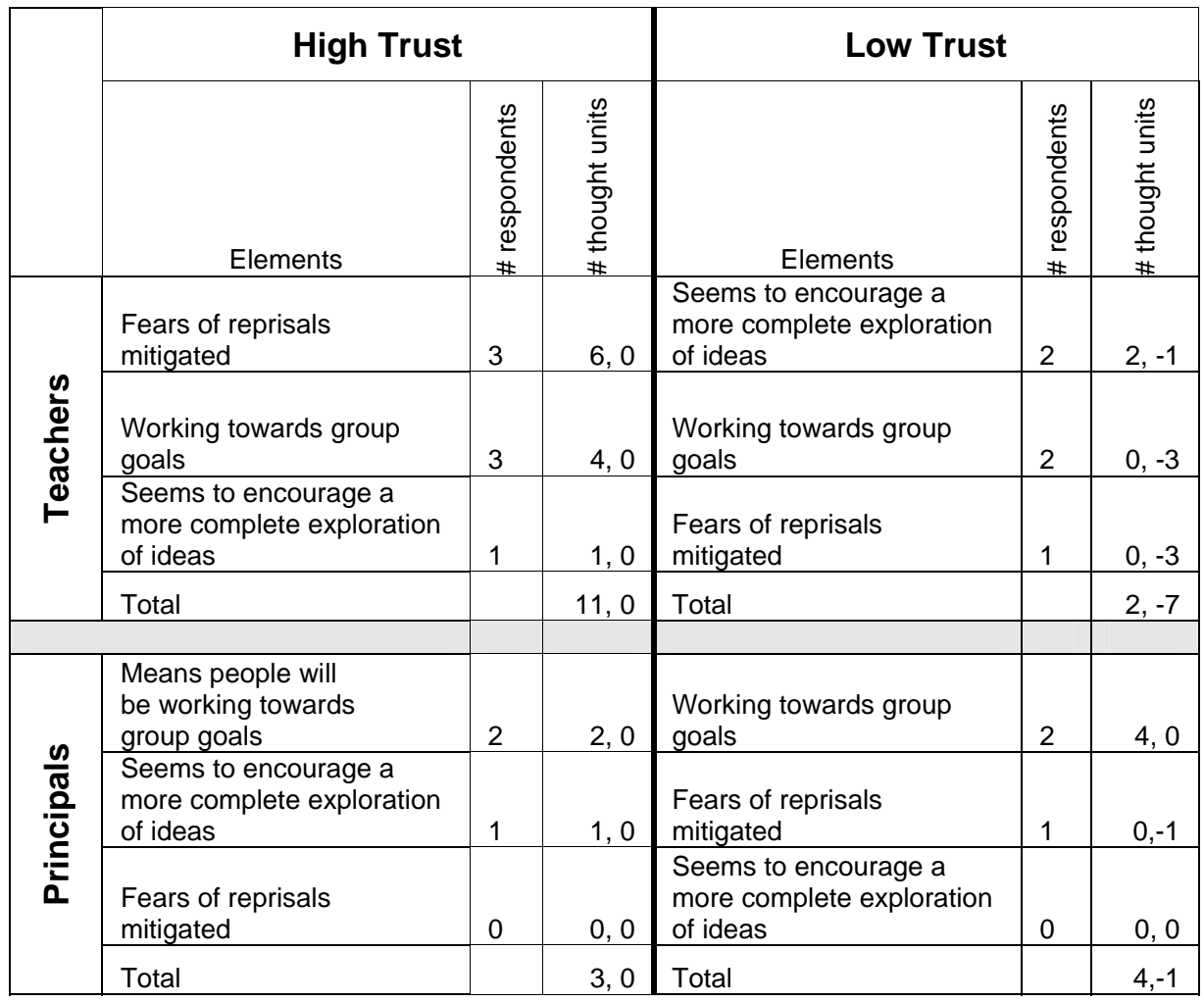

There were fewer teacher respondents in low-trust-in-leader environments than in high-trust environments, but the total thought units were similar. Low-trust-in-leader environments expressed many negative instances, which was what made the totals overall similar. Principals in both environments had a similar number of thought units, and an identical number of individuals responding.

\footnotetext{
${ }^{19}$ For an explanation of how to read the table, see reading the tables in chapter 4.
} 


\section{Openness}

To what extent do teachers identify influences on their trust in principals when they are engaged in conversation about their school and the school's leadership?

Table $20^{20}$

\section{Evidence of Openness}

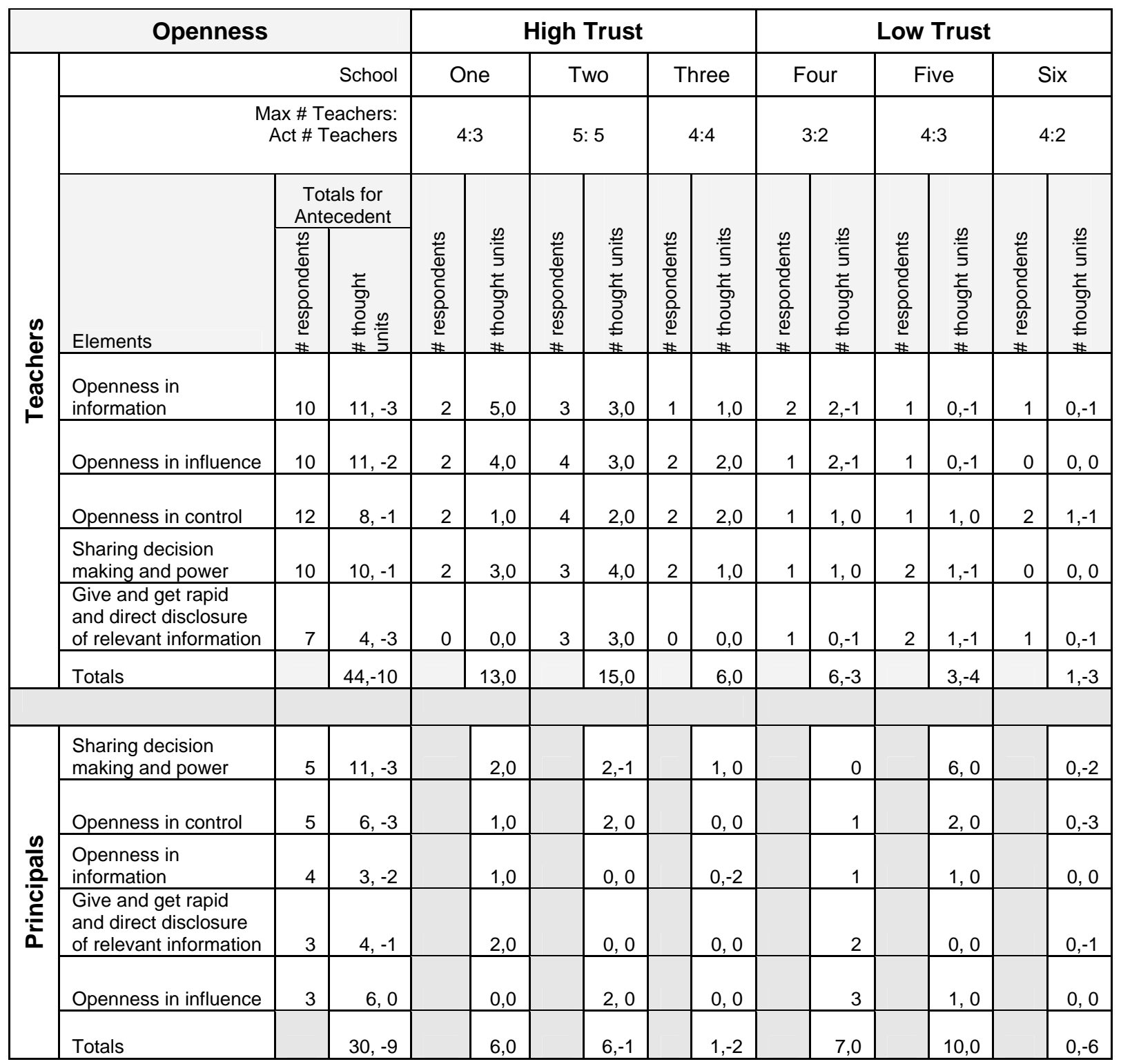

Openness was commented on by many teachers, in every school. In the high-trust schools teachers made a total of 34 positive comments. In low-trust schools teachers

\footnotetext{
${ }^{20}$ For an explanation of how to read the table, see reading the tables in chapter 4.
} 
comments divided equally, 10 positive comments and 10 negative. The comments were focused on the elements sharing decision making/ sharing power, openness in control and openness in influence. There were many more comments in the schools with the two highest trust scores. There was a steady decline in both number and the positive aspects of the comments declining from high- to low-trust schools.

Which elements of leader openness do teachers identify most frequently and what leader behaviours do they associate with those elements?

Openness has five element categories of significance to teachers that appeared in the following order of importance:

1. openness in information means there is disclosure of facts, alternatives, judgments, intention and feelings;

2. openness in influence allows others to initiate changes to plans, goals, concepts, criteria and resources;

3. openness in control accepts the dependence rooted in a confidence in the reliability of others and delegation of important tasks to them;

4. sharing decision making and sharing power; and

5. giving and getting of rapid and direct disclosure of relevant information and sharing of important information.

\section{Openness in information.}

Openness in information means disclosure of facts, alternatives, judgments, intentions, and feelings. Teachers viewed this type of openness as related to recognition of the individual teacher's skills as well as recognition of the contributions of groups of teachers. Examples of teacher comments related to this element included:

School One:

So they are always giving suggestions. I found a new one. I saw this. That sounds like something you would like. She is very helpful doing that. (Teacher 4)

As far as feedback, they point out the different collaborative things that you had done that they recognized. (Teacher 2)

School Two:

Again, just dropping in and observing and, 'hey, I saw this happen' and she will say things to other people while you're there in order for you to hear it. She'll talk to the counselor, ‘yes, S. doesn’t ever have any discipline problems, she's such a good teacher.' You know. You hear things from her mouth. (Teacher 2) 
School Three:

Usually with a suggestion that is made...it might not happen, but they are heard. (Teacher 4)

School Four:

He will tell us how much he appreciates our hard work. (Teacher 1)

So when Dr. H. came in it was great to see that he could make decisions, that okay, I want your ideas but sometimes I might have to change because something else has come in, but I really want your opinions on what we should do. That has been valuable for us. (Teacher 2)

School Five:

I don't know. I don't think we have a real big - I know a lot of them try to go in there and get his ear. You know how that is. It's kind of political but as far as he makes a decision, that's it.”(Teacher 2 - negative instance)

School Six:

$\mathrm{R}$ : Some of us feel very comfortable sharing ideas and sharing materials, I think that is a piece of leadership. Speaking out at meetings.

I: Speaking out in terms of?

$\mathrm{R}$ : About what we do and what we think is effective. (Teacher 2)

Openness in influence.

Openness in influence allows others to initiate change in plans, goals, concepts, criteria, and resource. Teachers viewed encouragement of professional development in relation to instructional strategies, which they have the opportunity to select or direct, as an example of openness in influence. Teachers also viewed openness in influence as including appropriate involvement of parents. Examples of teacher comments related this element included:

School One:

I’m really able to make a lot of choices for my professional development. (Teacher 1) School Two:

This year I went to a Singapore Math Workshop on Instant Mental Drawing so I found one that I was interested in. I asked D. about it and then we got the approval through Title 1 that I was able to go to that. (Teacher 1)

We are working on a unit newsletter that will go home with every unit that we start... as a third grade, as a total, we will be sending the parent newsletter home with each unit. That gives the vocabulary, it gives the standards that we are working on. So 
the parents will be very informed...it was up to us how we were going to communicate that with parents, but the idea really came from the professional development that we were doing. (Teacher 1)

I don't know... I think it's good that the principal likes us to be involved in learning new ways of teaching. It seems to always change. Over the next ten years I'll probably have to change again. (Teacher 4)

School Three:

The leadership team. It will have a seventh grade teacher, an eighth grade teacher, an encore teacher, and ECP teacher and then our AVID teacher and then Ms. S. and whoever our new assistant principal is...when I say we, I'm assuming the leadership team (the leadership team is restructuring itself?) Yes. I would say some of it probably is (initiated by Ms. S.). I guess just to give a little better balance because our schedules will be changing next year where it will be just two four man teams. (Teacher 1)

They try to survey us and come up with a consensus of things that we actually need. What folks feel like they need to focus on and with that, they plan staff development for us. As close as possible...if they couldn't offer it, they provided it - when they found a class or conference, I think we did have a few teachers there that went to a classroom management workshop. They got subs in and let them go to see what they could do there. Ms. S. provided us with the cooperative learning, our workshop that we did this year. Dr. M. worked with his math folks. It's been a while since we've had people that just worked with us as closely as they have done. (Teacher 4)

School Four:

When he first came here, he asked us what do you like about how things are run at this school? What don't you like about how things are at this school? What could I do to - what would you like to see me doing? So I think he’s been real open. (Teacher 1)

School Five:

If we fail more than $9 \%$ of our kids there is a problem. There have been teachers that have been written up for failing more than $9 \%$ so there is a policy of keeping them moving on. It's kind of an unwritten law but I don't know if you are aware of that. That probably happens everywhere. What are you going to do, right? I hate to say that. (Teacher 2)

\section{Openness in control.}

Openness in control accepts dependence rooted in a confidence in the reliability of others and delegation of important tasks to them included support for teachers' professional development in relation to instructional strategies, and resources being made available to support teachers in pursuit of their professional and instructional goals. Examples of teacher comments related to this element included: 
School One:

Ms. $\mathrm{H}$ is always giving us opportunities. There is a meeting here. Who would like to go? Myself, a kindergarten teacher and two third grade teachers just came back from Charlotte a couple of weeks ago. We went to a dual language conference in Charlotte. It was a change for me... There are always opportunities that we can kind of look towards each other or go places, go to meetings, share ideas with others. (Teacher 4)

Ms. $\mathrm{H}$ is always giving us opportunities. There is a meeting here. Who would like to go? (Teacher 4)

School Two:

We each got to select which one we would like to learn about. (Teacher 1)

I also am emcee for all of our school assemblies. The principal doesn't emcee them, I do. So school wide, if I stand up to the microphone and say, 'focus', everyone kind of settles down and we know it's time to start. (Teacher 5)

School Three:

I love the people. It's great. The good thing is it's an open school and we don't have many of those left. We can come on the weekends. They don't bar you from the campus over the weekend. If you want to work, you can come and work Saturday night. I have been here as late as 10:30 or 10:45. You have the freedom to come to your class and you can work. You will see someone else come into work at night and you will have a conversation just like in the daytime but after everyone is gone. (Teacher 2)

School Four:

This room is a textbook room that is open to anybody. We can walk in and we can get books when we need them. We don't have to sign them out. We don't have to sign our life away, saying I need one more math book. May I please have one? The supply room the workroom. We have pencils and pens and things that we can help ourselves to. That was never the case here...that has really gone away. The feeling before was well you can't trust teachers. They will hoard everything. I'm like you know, we can be trusted. (Teacher 1)

School Five:

I: Who makes all those decisions about student placement?

R: Counselors, and we have input. We do our recommendations. (Teacher 2)

School Six:

I: How much influence do teachers have in making decisions related to improving student learning?

R: On a classroom level, quite a bit. Beyond that, not so much. (Teacher 2 - negative instance) 
I go to her, like we had an institute for $3^{\text {rd }}$ and $4^{\text {th }}$ grade and I have said, "Gee, I found this. It's a neat book somebody is using. What if my committee was a math maybe we could order this?” Very supportive of that. (Teacher 4)

\section{Sharing decision making.}

Sharing decision making, sharing power was seen in several areas by teachers, including that teachers had a voice that was influential in determining school goals and priorities, there was recognition of the individual teacher's skills as well as recognition of the contributions of groups of teachers, resources were made available to support teachers in pursuit of their professional and instructional goals and appropriate involvement of parents was apparent. Examples of teacher comments related to this element included:

School One:

We all are in charge of saying how things are run here...we are the ones that are getting together and writing the goals. (Teacher 1)

Yesterday, school-wide we were all taking the leadership role because we are starting to design our transition plan. (Teacher 2)

School Two:

It's pretty powerful. We are asked for a lot of input and it's used. (Teacher 1)

We definitely work together. I would actually like to be a new teacher coming into this because it is so set up ...we grade our assessments as a team so everybody knows what everybody is doing. Very supportive. (Teacher 1)

In the staff meetings we develop goals together and those goals really do work with the district expectations. (Teacher 3)

We do have one parent, Mrs. T., who is the coordinator of the parents. They have a once a month workday and she, any of us who want a project done, we put it down in the workroom, describe the project and the parent volunteers will come. She averages I think 15 to 20 parents per month. They come in with their cribs and their babies and they bring kids with toys and little toddlers. They do the projects for us. Then we have lunch with them. (Teacher 5)

School Three:

We take roles in decisions such as field trips and outings and those types of things because we are a small school we have a lot of input into the activities that go on at the school, the extracurricular activities and so forth. (Teacher 3)

There is a lot of leadership roles in this school I believe for teachers. As you've already mentioned determining our textbooks. We set our own pacing guides. It does not come from the county. We are the only middle school in the county. We are the county in that regard. So at this point, instead of them giving us a pacing guide, they 
are like you create the pacing guide as the teachers there. We will respond and work with that. They will work with us on that and then they try to base the nine week test somewhat on the pacing guide that we've developed. (Teacher 3)

School Four:

Dr. H. asked us that a couple of years ago, did we want to go Baldridge and we all said no. It takes a lot of work. (Teacher 2)

School Five:

I: How much influence do teachers have in improving student learning?

R: I'd say they have a good amount because you are welcome to do whatever you need to do in your classroom of course, and then if there is something that you feel that needs to be addressed that will affect all the kids you can easily bring it up at the faculty meetings or you can tell your SPDM person....and they can address it there. (Teacher 1)

\section{Give and get rapid and direct disclosure of relevant information.}

Give and get rapid and direct disclosure of relevant information; sharing important information was represented in teacher commentary through comments that included the recognition of the individual teacher's skills as well as recognition of the contributions of groups of teachers, and support for teachers’ professional development in relation to instructional strategies. Examples of teacher comments related to this element included: School One:

So they are always giving suggestions. I found a new one. I saw this. That sounds like something you would like. She is very helpful doing that. (Teacher 4)

The other day just in talking with her and she was talking about going to see a special needs class. She said she had thought of something that would be really cool. She was saying that the teacher had some number cards laid out in number order. She said that the child would stand on number three and they had to do three plus three and they would have to jump three spaces. She said she thought that was a cool way of physically getting them moving around. I thought that was really good and wanted it so I could use it for summer school. (Teacher 4)

School Two:

Again, D., our principal is the one that is...She will collect the data. She will get it up on charts. She will make sure that we understand as a whole school what the graphs are meaning, where we are deficient. (Teacher 2)

She listens and validates the things we are doing. She shows this. (Teacher 3) 
School Four:

Like any principal, he is at meetings a lot but he is always willing to listen. He will ask. (Teacher 1 - negative instance)

School Five:

Put it like this. I feel valued if someone takes the time to tell me I need to improve. If I wasn't valued, they would have ignored it. If me or my work were not valued, then if I let my quality slip, it would have been ignored. I mean to me, even if I'm telling you something you may not want to hear, if I took the time to tell you and I went out on a limb to put myself in a non-comfortable position to tell you, you are not doing something very well, I value you, because I want you to be a better teacher and I value the kids because I want them to have a better instruction. So it may not feel good sometimes, but there is value in it because it's made me improve. (Teacher 4)

School Six:

I: Is it encouraged by the administration?

$\mathrm{R}$ : Yes, I think it is.

I: So there would be opportunities created in this school to have input?

R: Yes.

I: It's whether people take advantage of it or not?

R: Yes

I: So at a staff meeting there would be announcements of opportunities to take on?

R: No I think the staff meetings are the opportunities.

I: Where would the opportunities be?

R: Within the staff meeting. (Teacher 2 - negative instance)

Teachers talked about this antecedent, in various ways, quite a bit. Many of the thought units were related to other antecedents, something that was also true with loyalty and honesty. Openness, however, seemed to relate to the ability of teachers to grow. There were many comments, particularly in the high-trust schools, about professional development, collaboration, and being willing to try new things instructionally. The lower trust schools were focused on resource allocation. 
To what extent do principals and teachers hold similar views on the sources (or antecedents) of trust in principals?

Principals did describe aspects of openness. The high-trust principal data showed 13 positive and 3 negative statements, while the low-trust data showed 17 positive and 6 negative statements. The principal in the highest trust school made 6 positive statements, and the principal in the lowest trust school made 6 negative statements. There was an anomaly in the principal data as the principal in School Five made 10 positive statements related to openness, more than any other principal. This seemed to be in contrast to the teachers in School Five whose comments accumulated to four negative instances about openness.

The order of the elements was quite different for principals than that of the teachers, with sharing decision making and sharing power appearing to be of most significance to principals, whereas with teachers this element was fourth. Principal respondents and thought units resulted in the following order for the elements:

1. sharing decision making and sharing power;

2. openness in control accepts the dependence rooted in a confidence in the reliability of others and delegation of important tasks to them;

3. openness in information means there is disclosure of facts, alternatives, judgments, intention and feelings;

4. giving and getting of rapid and direct disclosure of relevant information and sharing of important information; and

5. openness in influence allows others to initiate changes to plans, goals, concepts, criteria and resources.

\section{Sharing decision making.}

Sharing decision making, sharing power was related to teachers having a voice that was influential in determining school goals and priorities, recognition of the individual teacher's skills as well as recognition of the contributions of groups of teachers. Examples of principal comments related to this element included:

School One:

One of the things that I don't have a problem with is empowering my teachers. Based on their interest and talent they have been empowered to do a variety of things. That technology facilitator, I don't tell her what to do. She does it. The curriculum facilitator, I gave her a job description and she has gone above and beyond. 


\section{School Two:}

Earlier this year we had an opportunity, we ended up not going because we got snowed out, but we were supposed to go to Santa Fe for Schools on the Rise celebration. I asked them, we could only bring a limited number of staff, and I asked them to select the people who they thought should, you know, who have you gone to when you had questions about your curriculum and they pretty much selected the same people who were on the leadership team so I think my instincts were the same as theirs.

\section{Openness in control.}

Openness in control accepts the dependence rooted in a confidence in the reliability

of others and delegation of important tasks to them was seen in statements related to teachers having a voice that was influential in determining school goals and priorities, recognition of the individual teacher's skills as well as recognition of the contributions of groups of teachers, and support for teachers' professional development in relation to instructional strategies. Examples of principal comments related to this element included:

School One:

When you are a grade level chairperson, because we are a small school then that person is not only in charge of that grade level, they are also the strategic planning team member for that grade level. For instance, yesterday the person who was going to be the chairperson for kindergarten, she went to the kindergarten contact meeting yesterday at the county office. Today, it's the first grade and next Monday is the second grade. They know my level of expectation is that is a leadership role. They have the opportunity to come back and the obligation to come back and share that information. Again, because of leadership opportunities when I had the chance to fund a curriculum facilitator, I knew who that needed to be. That's who I go to for that. There is my guidance counselor. She is the expert on the military liaison kinds of things and so that goes directly to her. She is our go-to person. It depends on what is needed that I can actually look and say this is the person you need to see. They are the expert on that.

School Two:

In building PLCs the writing, the math and the reading PLCs, they met on their own and selected their own leadership to run each of those meetings because we would meet on the same day and I could be available to any one of them if they needed help, but I couldn't be in three places at once so they selected their own leaders. Within our grade level PLCs they have to do, they have to meet on a weekly basis. They basically have their own leaders in that sense as well.

School Four:

The biggest one is the instructional coach who conveys things that she gets from the district that goes to the instructional coaches to go to the teachers. That happens, that is primarily it. We do have some people. We have a teacher that is early childhood 
literacy person who deals with the literacy. We have another teacher who deals with the math group, so they offer some things. We have another teacher that deals with technology things. So, those are little offerings that they will have before school, after school, whenever, that people can attend on a voluntary basis.

\section{Openness in information.}

Openness in information means there is disclosure of facts, alternatives, judgments, intention and feelings was seen as related to teachers having a voice that was influential in determining school goals and priorities or that this thought mattered to principals, there was recognition of the individual teacher's skills as well as recognition of the contributions of groups of teachers. Examples of principal comments related to this element included:

School One:

The one that they set over and over still is the technology. Not my very young teachers, but my more veteran teachers, it's just more difficult for them. They know that, they recognize that and they will say "I need to do a better job of this. Can you please help me?

School Four:

I have told them, "If I have a concern about anything or a question, I will address it to you. Not at that moment, unless I feel that the class is totally out of control and I have to do something. I am not going to address it then. I'm going to wait, but I will address it.

\section{Giving and getting of rapid and direct disclosure of relevant information.}

Giving and getting of rapid and direct disclosure of relevant information and sharing of important information was comprised of comments such as:

School One:

My teachers have trusted that as soon as I knew what was going to happen that I was going to tell them that. I think that it's not just this year. It's been during my five years and they know that there is a level of trust and that it's that kind of thing where they can disagree with me and they are not going to get in trouble for it. That I'm going to respect our differences and that they can share those with me. They don't feel like they have to go talk in a little corner behind my back. I think that takes a huge amount of trust. Yesterday we had a meeting where I had to explain that our budget this year in Title 1 is \$200,000 less than it was last year, which brings great change. Again, that wasn't something that I sat in here and secretly crunched numbers and said "I'm not going to tell." I said "This is what this means for C. E." I think they trust me.

School Four:

Instructional council, myself and then we have collaboration by level where we have collaborative times where the staff will meet in groups of, there is about five or six at each level, grade level. They get together and meet so the same kind of thing. They 
would be giving input. So we are continually seeking input from everybody to come up with what they think will work and then we will adjust that.

School Six:

and she asked them, "how did she go about picking those people?" And they said, "I don’t know I think she was just taking teacher leaders. I don’t know.”

The teacher came back and told me. I said, "well, if she comes to me, I'll just tell her, this is not a Union thing and you aren't going to tell me who I can put on my committee.” But she never came to me. (Negative instance)

\section{Openness in influence.}

Openness in influence allows others to initiate changes to plans, goals, concepts, criteria and resources included recognition of the individual teacher's skills as well as recognition of the contributions of groups of teachers includes. Resource allocation and opportunities being available to support teachers in pursuit of their professional and instructional goals seemed to matter to principals. There was support for teachers' professional development in relation to instructional strategies.

School Two:

We worked on this in technically I guess they would be goal teams, we call them building PLCs because we use Professional Learning Communities here. So we had somebody from every grade level say on the writing PLC. And they took the standards and they did this work. The end result was that everybody seems very familiar with what all the other grade levels are doing so they are starting to see the whole picture. What our tasks are that we are going to reach and measure are a lot clearer than they are when you just look at standards. We also found a lot of redundancy in the standards. To start this process we literally cut the performance objectives up and we would often times some of them we would find within the same standard the same statement four times. Then there were others that we would read them and re-read them and re-read them and we had no idea what they were asking, we put them in a Ziploc bag. We have our Ziploc standards which is, "we don't even know what they mean by this."

School Four:

Well, we have an instructional council made up of staff members that represent different special ed, regular ed, different grade levels of assistance. Different entities of a staff that meet and we develop what kinds of things we want to have.

I think the other really big source is Professional Learning Communities. They are learning from each other and they are sharing ideas. We have something on our email. It's called the A. Pasture, it's a long story why it's called that, but people are able to post their curriculum work on there. That way, if I'm a Title 1 teacher, I can look on there and see what the First grade is doing so I am able to align some of the 
stuff I'm doing with them. That was one of our teacher's ideas. And one of our IT people at the Central Office put it together for us. It's a real neat piece.

And we have two people on the staff that co-ordinate that. They submit a plan to the instructional council that says "we want to be the sponsors of the Brain Day. We feel we need so many hours to do what we need to do and this is what we're going to do." We have a person, a level book room, we have a person who is in charge of the level book room. These are all extra kinds of things. She identifies how much time she thinks she needs. We have a science coordinator that helps when all the science kits come in and gets it back and deals with all the issues there. We have a person that deals with test situations. They have to identify the time they think. I take the total number of hours and divide it into the total amount of money and come up with an hourly rate that can be multiplied out. So, when we go back it's, this person needs 30 hours, this one needs 300 hours, this one needs 150 hours, or whatever during the year to do what it is they are going to do. So, we take the money and we feel we do a better job with it because we make it more equitable and it goes to the amount of time that you put in. Everyone seems to be real supportive of that because, otherwise, you know, you want the job that is only 20 hours. It gives me $\$ 1000$ not the one that is 200 hours. This way, they are compensated. We can do that. I can compensate differently out of that pot, but I can't compensate more than eight people. So we follow guidelines that way. Yes, there are some monies, not much, but there are some monies that we can use and we do that. Try to do it as fair as I can.

Principals did comment about openness, and they commented directly in the areas that teachers commented, for the most part. Appropriate involvement of parents, a component of several elements of Openness for teachers, was not seen in the principal data. The principal of School Three had relatively few comments about Openness, her longest being a criticism of her predecessor. School Five had little alignment with topics generally discussed related to openness. Those areas mentioned that might relate were negative instances. School Six completely aligned with the topics discussed by teachers but every single example was a negative instance.

Teachers and principals did describe similar behaviours related to Openness. The closer the match, in positive terms, with the exception of School Three, where the principal had been on the job three weeks, the higher the trust. The close connection between the principal and teacher data as well as the number of thought units generated, made it seem likely that Openness was quite important to trust in leadership. 


\section{Summary of Openness}

Table $21^{21}$

Summary Comparison of High Trust and Low Trust: Openness

\begin{tabular}{|c|c|c|c|c|c|c|}
\hline & \multicolumn{3}{|l|}{ High Trust } & \multicolumn{3}{|l|}{ Low Trust } \\
\hline & Elements & 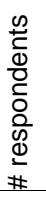 & 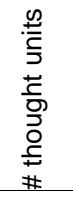 & Elements & 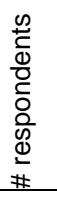 & 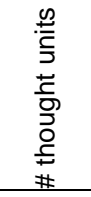 \\
\hline \multirow{6}{*}{$\begin{array}{l}\frac{\mathscr{U}}{\Phi} \\
\frac{C}{0} \\
\stackrel{\widetilde{U}}{-}\end{array}$} & Openness in influence & 8 & 9,0 & Openness in control & 4 & $3,-1$ \\
\hline & Openness in information, feelings & 6 & 9,0 & Openness in information, feelings & 4 & $2,-3$ \\
\hline & $\begin{array}{l}\text { Sharing decision making; } \\
\text { sharing power }\end{array}$ & 7 & 8,0 & $\begin{array}{l}\text { Give and get rapid and direct } \\
\text { disclosure of relevant information }\end{array}$ & 4 & $1,-3$ \\
\hline & Openness in control & 8 & 5,0 & Openness in influence & 2 & $2,-2$ \\
\hline & $\begin{array}{l}\text { Give and get rapid and direct } \\
\text { disclosure of relevant information; }\end{array}$ & 3 & 3,0 & $\begin{array}{l}\text { Sharing decision making; } \\
\text { sharing power }\end{array}$ & 3 & $2,-1$ \\
\hline & Total & & 34,0 & Total & & $10,-10$ \\
\hline \multirow{6}{*}{$\begin{array}{l}\frac{n}{\sqrt{0}} \\
\frac{0}{0} \\
. \frac{E}{0} \\
0\end{array}$} & $\begin{array}{l}\text { Sharing decision making; } \\
\text { sharing power }\end{array}$ & 3 & $5,-1$ & $\begin{array}{l}\text { Sharing decision making; } \\
\text { sharing power }\end{array}$ & 2 & $6,-2$ \\
\hline & Openness in control & 2 & 3,0 & Openness in control & 3 & $3,-3$ \\
\hline & Openness in information & 2 & $1,-2$ & Openness in influence & 2 & 4,0 \\
\hline & $\begin{array}{l}\text { Give and get rapid and direct } \\
\text { disclosure of relevant information }\end{array}$ & 1 & 2,0 & $\begin{array}{l}\text { Give and get rapid and direct } \\
\text { disclosure of relevant information }\end{array}$ & 2 & $2,-1$ \\
\hline & Openness in influence resource & 1 & 2,0 & Openness in information feelings & 2 & 2,0 \\
\hline & Total & & $13,-3$ & Total & & $17,-6$ \\
\hline
\end{tabular}

Openness drew many respondents, and many thought units, particularly from hightrust teachers and low-trust principals. Principal responses resulted in sharing decision making, sharing power being the area of most frequent commentary and response. In contrast, responses from teachers in high-trust schools resulted in this element being third in importance, and responses from teachers in low-trust schools resulted in this element being in fifth position. The word "sharing" may be subsumed in other elements, or it may be there are actions that suggest sharing is not quite the same as openness.

\footnotetext{
${ }^{21}$ For an explanation of how to read the table, see reading the tables in chapter 4.
} 


\section{Chapter 7 Results: Personal Regard for Others, Respect, Vulnerability}

This chapter ends the report of results about the antecedents of trust in leaders. In this last of four results chapters the focus is on personal regard for others, respect, and vulnerability. Results are summarized quantitatively in Tables 22, 24 and 26 respectively. Tables 23, 25 and 27 compare high- and low-trust schools on these same three antecedents of trust in leaders. 


\section{Personal Regard for Others}

To what extent do teachers identify influences on their trust in principals when they are engaged in conversation about their school and the school's leadership?

Table $22^{22}$

\section{Evidence of Personal Regard for Others}

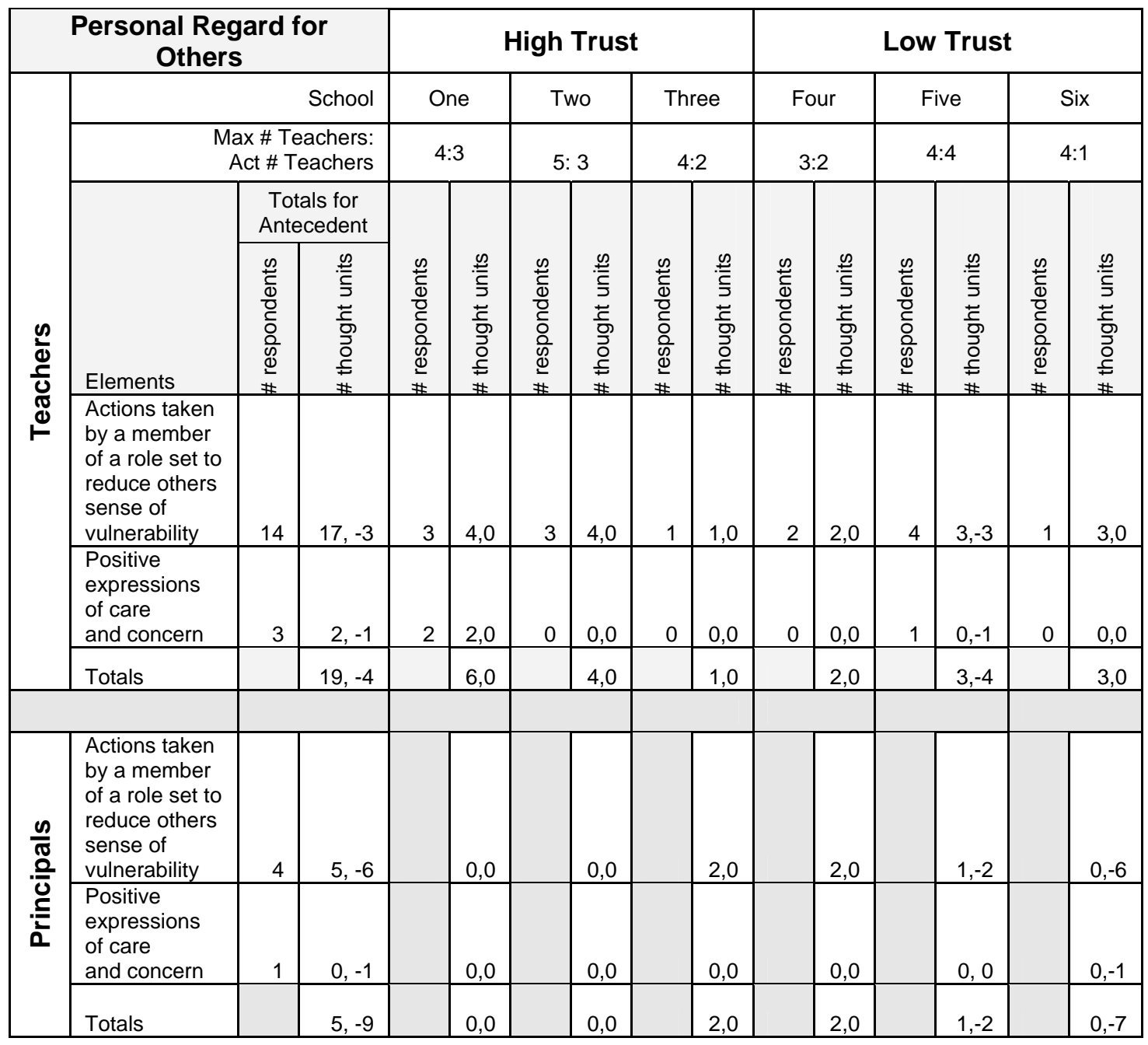

Teacher comments were related to the leaders' personal regard for others, and there were comments from teachers in every school. Teachers in high-trust schools made 11 positive statements related to personal regard while teachers in low-trust schools made 8 positive and 4 negative statements. There were many more teacher comments in the element "actions taken to reduce others sense of vulnerability."

\footnotetext{
${ }^{22}$ For an explanation of how to read the table, see reading the tables in chapter 4.
} 
Which elements of leader personal regard for others do teachers identify most frequently and what leader behaviours do they associate with those elements?

Personal regard for others (PRO) has two element categories:

1. actions taken by a member of a role set to reduce others sense of vulnerability; and

2. positive expressions of care and concern.

\section{Actions to reduce vulnerability.}

Actions taken by a member of a role set to reduce others sense of vulnerability comments focused on affirmations of teacher's work and work related goals. Examples of teacher comments about this element included:

School One:

The technology kind of scares me a little bit but she is very encouraging. Oh, try it. You'll get it. She's very positive with that. (Teacher 4)

She is very affirming and she will tell you that you are doing a great job on the lesson...She always seems to know what you are doing...She always seems to know what is going on with everybody. It’s wonderful. (Teacher 5)

School Two:

Again, just dropping in and observing and, 'hey, I saw this happen' and she will say things to other people while you're there in order for you to hear it. She'll talk to the counselor, 'yes, S. doesn't ever have any discipline problems, she's such a good teacher.' You know. You hear things from her mouth. (Teacher 2)

She listens and validates the things we are doing. (Teacher 3)

During report cards, which is every nine weeks, four times per year, we turn those in to her, she looks them over and she usually leaves a good comment on there. I tell her I have looked at my information and this is the new goal I have. She usually says 'that is attainable, work hard!' Then she'll write 'if there is anything you need me to do, let me know.' (Teacher 4)

School Three:

They are a very good support. Dr. M. (former principal) has always been there just encouraging me to do this and do that (in terms of the Masters degree), yes. (Teacher 1)

School Four:

I actually taught for him many years ago when I first moved back to A. and taught a behavior disorder class of special ed kids and he was my principal at that time and I haven't really had to go to him with a lot of issues since he's been here but I remember back then, I had come from teaching special ed kids in a little small town 
in Minnesota where it was a very different environment and coming here and teaching a behavior disorder class down in one of the roughest parts of town. I needed a lot of support from him then. So he was very good and I think for the newer teachers or teachers that have concerns or questions, he is always available. (Teacher 1)

He has just given me very positive feedback...It’s very helpful. (Teacher 2)

It reaffirms what you are doing and I just think, you know, this is good. Let's try this again. (Teacher 2)

\section{School Five:}

It's a give and take and the administrators help me with discipline. It's a team effort and it's a positive influence they are having on this class. I know it's not always that way. (Teacher 1 , mixed instance)

\section{I: Do teachers feel valued here?}

R: Well now I'm not sure all of them do...There are always going to be politics involved but I feel valued. He has made me feel valued. It took me a while to gain the trust but like I say there are others that there is favoritism but that is going to happen everywhere. Hopefully you try to keep it at a minimum. (Teacher 2, mixed instance)

School Six:

She has been very supportive of every time that I have had a dealing with a parent. (Teacher 4)

\section{Positive expressions of care and concern.}

Positive expressions of care and concern revolved around affirmations of teacher work and a focus on goals, however, while it was more personal in nature, it also was careful. There were very few respondents with related thought units. Examples of teacher comments about this element included:

School One:

In a positive way, she is there for us. (Teacher 2)

School Three:

Yes. I would say it is. We start first thing in the morning. We are standing around chatting about the beginning and how we are going to handle things for today. Wishing each other well as we stand outdoors. (Teacher 2) (note: the beginning of this statement answers the question "Is this a trusting environment?" The end of the statement references collegial behaviours, which may or may not relate to the principal herself.) 
School Five:

I: When would be the last time (the superintendent) came in and what was that about?

R: Last week.

I: What did she do when she was here?

R: Apparently some teacher had thought there was some type of reprisal, what was the word now? He was harassing some teacher. She wanted to let us know if that ever happens to come to her. (Teacher 2, negative instance)

Trust is salient, however only in School Five did all the teachers make comments related to personal regard for others, and the vast majority of the comments were negative instances.

To what extent do principals and teachers hold similar views on the sources (or antecedents) of trust in principals?

Principals did comment in relation to personal regard for others, but it was not frequently commented on. The principals in the two highest trust schools did not comment at all in this area. Principals in high-trust schools made only 2 positive comments, and both of these were made by School Three's principal, who had been principal of the school for 12 days. Principals in low-trust schools commented more, making 3 positive statements and 9 negative statements. It is interesting that principals in the schools with the highest trust scores were silent on this antecedent. As the school trust scores decreased the number of principal comments, in total, increased. The elements themselves did appear in the same order as the order for teachers.

\section{Actions to reduce vulnerability.}

Actions to reduce vulnerability included affirmations of teacher's work and goals, however, the comments are few and far between. Examples of principal comments related to this element included:

School Three:

I talk to them. Every day I try to talk to every single person. Which is not hard. We are tiny. I try to go into the media center. She is the media coordinator and she is amazing. She is such a great teacher. I go in and try to affirm her. I have a goal of trying to affirm, there are a few people whose esteem is low, particularly our seventh grade math teacher. She is the only one teaching math this year that taught math last year. She feels like, and I don't think it's been done to her and I don't think it's real, but she perceives it's her fault we didn't meet AYP because she is the only one that is 
teaching math this year that taught math last year. She is a really good teacher. She needs to be validated. She works so hard.

School Five:

The only time that we have done this (teachers visiting each other's classrooms) is when we have concerns with the instruction of a teacher. So, after the second or third Walk Through or after each one of us has seen that one teacher, we put a plan together, a Plan of Action for that teacher. That includes please go observe Mrs. So and So or Mr. So and So. And then bring me back what you observed during that time. It does require them to go in there for whole entire 50 minutes to observe that teacher (a colleague). Now, they are welcome to go and observe any time as long as the teacher knows that you're coming in. I know that it's happened, but in writing itself, we ask them to do that when there are concerns with their instruction. (Negative instance)

School Six:

That's why I said when I came here, I had battles to fight and one of them was not trying to get them and she doesn't implement guided reading at all. Because, other teachers try to follow her. So I had to make a point this year and put some people on Part 2 to let her know, you all are gonna do this. I even put her on Part 2... and when I was doing her evaluation I was like, either I'm going to make a point and give her a Part 2 for not doing balanced literacy or I'm going to let it slide. And I told, I said, "If I let it slide... then I am saying to her that she can do what she wants to do, and the rest of them that have Part 2s, to, for not doing it they are going to say, you didn't give her one.” She's going to tell them. So I made it a point to give her one to say, "you need to implement balanced literacy the way it was designed." The other people, I gave it to them as well, even some of her little roll dolls. And they were like, "oh, okay." A couple of them have decided to get job preferences to go to another building, which is fine with me. (Negative instance)

So some of them are not doing it at all. What has happened then is I have had to say, "I believe in it so it needs to be taught that way." Some of them are like, you know, I'm hearing through the grapevine, "I'm going to leave, I'm going to another school." And that's fine. Just go to another school because this is what the corporation has adopted and it has to be done.(Negative instance). 


\section{Summary of Personal Regard for Others}

Table $23^{23}$

\section{Summary Comparison of High Trust and Low Trust: Personal Regard for Others}

\begin{tabular}{|c|c|c|c|c|c|c|}
\hline & \multicolumn{3}{|c|}{ High Trust } & \multicolumn{3}{|c|}{ Low Trust } \\
\hline & Elements & 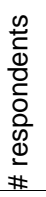 & 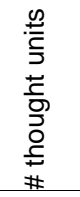 & Elements & 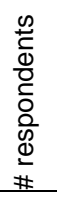 & 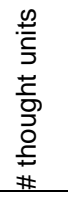 \\
\hline \multirow{3}{*}{ 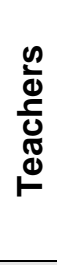 } & $\begin{array}{l}\text { Actions taken by a } \\
\text { member of a role set } \\
\text { to reduce others' sense } \\
\text { of vulnerability }\end{array}$ & 7 & 9,0 & $\begin{array}{l}\text { Actions taken by a } \\
\text { member of a role set } \\
\text { to reduce others' sense } \\
\text { of vulnerability }\end{array}$ & 7 & $8,-3$ \\
\hline & $\begin{array}{l}\text { Positive expressions } \\
\text { of care and concern }\end{array}$ & 2 & 2,0 & $\begin{array}{l}\text { Positive expressions } \\
\text { of care and concern }\end{array}$ & 1 & $0,-1$ \\
\hline & Total & & 11,0 & Total & & $8,-4$ \\
\hline \multirow{3}{*}{$\begin{array}{l}\frac{n}{\pi} \\
\frac{0}{0} \\
\frac{5}{2} \\
\frac{1}{2}\end{array}$} & $\begin{array}{l}\text { Actions taken by a } \\
\text { member of a role set } \\
\text { to reduce others' sense } \\
\text { of vulnerability }\end{array}$ & 1 & 2,0 & $\begin{array}{l}\text { Actions taken by a } \\
\text { member of a role set } \\
\text { to reduce others' sense } \\
\text { of vulnerability }\end{array}$ & 3 & $3,-8$ \\
\hline & $\begin{array}{l}\text { Positive expressions } \\
\text { of care and concern }\end{array}$ & 0 & 0,0 & $\begin{array}{l}\text { Positive expressions } \\
\text { of care and concern }\end{array}$ & 1 & $0,-1$ \\
\hline & Total & & 2,0 & Total & & $3,-9$ \\
\hline
\end{tabular}

Personal regard for others, a term used by Bryk and Schneider, 2002, likely captures aspects of the antecedents of benevolence, care, loyalty and vulnerability. It is certainly a difficult decision determining if a behaviour that fits "positive expressions of care and concern” is better described under caring, vulnerability or here, under personal regard. In the sense that it captures a broader spectrum of behaviours that generally involve, if not putting others first, at least not putting them second, it may be a good "catch-all.” It would certainly save time in a research agenda to lump them all together. If the point, however, is to really describe actions in detail, to see the action in very high relief so that the person acting can better understand the implications of the action for others, then it may not be helpful. In any event, principals do describe themes in personal regard that are similar to what teachers describe.

\footnotetext{
${ }^{23}$ For an explanation of how to read the table, see reading the tables in chapter 4.
} 


\section{Respect}

To what extent do teachers identify influences on their trust in principals when they are engaged in conversation about their school and the school's leadership?

Table $24^{24}$

\section{Evidence of Respect}

\begin{tabular}{|c|c|c|c|c|c|c|c|c|c|c|c|c|c|c|c|}
\hline \multicolumn{4}{|c|}{ Respect } & \multicolumn{6}{|c|}{ High Trust } & \multicolumn{6}{|c|}{ Low Trust } \\
\hline & \multicolumn{3}{|r|}{ School } & \multicolumn{2}{|c|}{ One } & \multicolumn{2}{|c|}{ Two } & \multicolumn{2}{|c|}{ Three } & \multicolumn{2}{|c|}{ Four } & \multicolumn{2}{|c|}{ Five } & \multicolumn{2}{|c|}{ Six } \\
\hline & \multicolumn{3}{|c|}{$\begin{array}{r}\text { Max \# Teachers: } \\
\text { Act \# Teachers }\end{array}$} & \multicolumn{2}{|c|}{$4: 4$} & \multicolumn{2}{|c|}{ 5: 5} & \multicolumn{2}{|c|}{$4: 2$} & \multicolumn{2}{|c|}{$3: 2$} & \multicolumn{2}{|c|}{$4: 3$} & \multicolumn{2}{|c|}{$4: 2$} \\
\hline & & \multicolumn{2}{|c|}{$\begin{array}{c}\text { Totals for } \\
\text { Antecedent }\end{array}$} & \multirow[b]{2}{*}{ 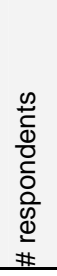 } & \multirow[b]{2}{*}{ 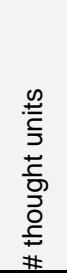 } & \multirow[b]{2}{*}{ 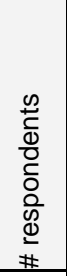 } & \multirow[b]{2}{*}{ 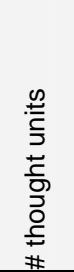 } & \multirow[b]{2}{*}{$\begin{array}{l}\frac{0}{c} \\
\frac{0}{0} \\
\frac{0}{0} \\
\frac{0}{0} \\
\frac{0}{0}\end{array}$} & \multirow[b]{2}{*}{ 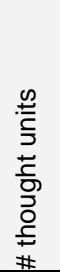 } & \multirow[b]{2}{*}{$\begin{array}{l}\frac{0}{c} \\
\frac{0}{0} \\
\frac{0}{0} \\
\frac{0}{0} \\
\frac{0}{0}\end{array}$} & \multirow[b]{2}{*}{ 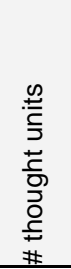 } & \multirow[b]{2}{*}{ 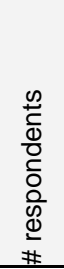 } & \multirow[b]{2}{*}{ 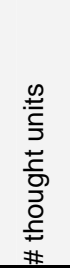 } & \multirow[b]{2}{*}{$\begin{array}{l}\frac{0}{c} \\
\frac{0}{0} \\
\frac{0}{0} \\
\frac{0}{0} \\
\frac{0}{0}\end{array}$} & \multirow[b]{2}{*}{ 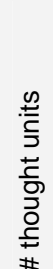 } \\
\hline \multirow[t]{4}{*}{ 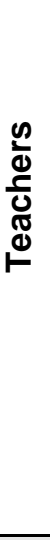 } & Elements & 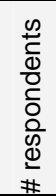 & 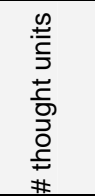 & & & & & & & & & & & & \\
\hline & $\begin{array}{l}\text { Recognition of } \\
\text { the important } \\
\text { role each } \\
\text { person plays }\end{array}$ & 15 & $20,-7$ & 3 & 4,0 & 5 & 8,0 & 1 & 1,0 & 2 & $2,-1$ & 3 & $4,-6$ & 1 & 1,0 \\
\hline & $\begin{array}{l}\text { Mutual } \\
\text { dependencies }\end{array}$ & 14 & $13,-4$ & 4 & 5,0 & 4 & 5,0 & 1 & 1,0 & 2 & $1,-1$ & 2 & $1,-2$ & 1 & $0,-1$ \\
\hline & Totals & & $31,-13$ & & 9,0 & & 13,0 & & $0,-2$ & & $3,-2$ & & $5,-8$ & & $1,-1$ \\
\hline & & & & & & & & & & & & & & & \\
\hline \multirow{3}{*}{ 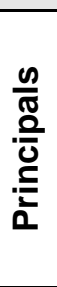 } & $\begin{array}{l}\text { Recognition of } \\
\text { the important } \\
\text { role each } \\
\text { person plays }\end{array}$ & 5 & $8,-6$ & & 2,0 & & 2,0 & & 0,0 & & 1,0 & & $2,-2$ & & $1,-4$ \\
\hline & $\begin{array}{l}\text { Mutual } \\
\text { dependencies }\end{array}$ & 4 & $5,-3$ & & 1,0 & & 0,0 & & 0,0 & & 3,0 & & 1,0 & & $0,-3$ \\
\hline & Totals & & $13,-9$ & & 3,0 & & 2,0 & & 0,0 & & 4,0 & & $3,-2$ & & $1,-7$ \\
\hline
\end{tabular}

Respect was commented on frequently by teachers. There were 22 positive and 2 negative comments related to trust in school with high trust-in-leader, and 9 positive and 11 negative comments made in schools with low trust-in-leader, among teachers.

Which elements of leader respect do teachers identify most frequently and what leader behaviours do they associate with those elements?

Respect has two element categories:

1. involves recognition of the important role each person plays in a child's education; and

\footnotetext{
${ }^{24}$ For an explanation of how to read the table, see reading the tables in chapter 4.
} 
2. the mutual dependencies that exist among various parties involved in this activity.

\section{Recognition.}

Recognition of the important role each person plays in a child's education was described by teachers as support for people professionally. Examples of teacher comments this element included:

School One:

She's very supportive... but she does give us leeway about strategies and techniques. She doesn’t say 'Okay, you have to do this'. (Teacher 3)

\section{School Two:}

We each got to select which one we would like to learn about. (Teacher 1)

Most of us understand that our job is critically important. We are made to understand that we can have whatever tools the budget will allow us to have... but one of the things that $\mathrm{D}$ is a proponent of is that whatever tools you need, if she can get them for us, she will. (Teacher 5)

School Three:

Very supportive in whatever I need supply-wise. Before she was here the other principal provided whatever he could find out math-wise that we needed. (Teacher 4)

\section{School Four:}

Well, he plays a big part. He unfortunately is going to be leaving. I'm very sad. He is very supportive of early childhood education first of all. He supports our philosophy, those of us in kindergarten and first. We have two of us teaching at K-1. Kids really need to be active learners and they need to be involved and they need to be doing hands-on kinds of things and involved in their learning. Not all principals really understand that but they don't have an early childhood background. They see first grade much more traditional and think that first graders are like; he is very supportive of our early childhood philosophy...He is also very supportive in believing that as a professional I have some choices to make about how I run my classroom. He does not dictate how things have to be taught... He is very supportive of your personal styles and very supportive of us using our professional judgment as how I might do that in our classroom and I appreciate that about him. (Teacher 1)

He has been very supportive, treating us teachers like professionals...I appreciate that we are treated like professionals, that he knows we are doing a good job. (Teacher 2)

R: We were told that we had to do this program with Fidelity which means you teach it as you are supposed to. You follow each lesson and you follow the guidelines. You don't go off on your own tangent. I think we've had kind of a hard time with that, because our principal doesn't usually operate that way. He usually gives us much more professional leeway as far as how we present things. That has been a little tough. 
I: Is that coming from above him?

R: Oh yes. That was a district decision. (Teacher 2, negative instance)

School Five:

They pretty much give us autonomy in the classroom as far as we are running our show. (Teacher 2)

I: What does it mean to feel valued to you?

R: To be worthy. To feel like your work is needed, necessary and to feel like you are a worthy person. I feel valued and I will tell you why. Whenever I have not given it my best, I will say this, the principal has had the nerve to bring it to my attention and not sugar coat it. I will say that I have never wondered how he felt. I know exactly and there have been a couple of times where maybe I did not do my best. He has brought it to my attention and people don't really like that. They don't like being told that you are not doing your best. (Teacher 4)

School Six:

But as far as making decisions in my classroom, I don’t think anybody really micromanages you that way as long as you are doing, you have the framework for what they want. (Teacher 1)

I have pretty much been told that as long as you keep that framework, then every classroom will look different than somebody else's. (Teacher 1)

\section{Mutual dependencies.}

The mutual dependencies that exist among various parties involved in this activity included statements about support for people professionally as well as support for people personally. Examples of teacher comments about this element included:

School One:

We also did tutoring... used our judgment... when we went to choose who we wanted to tutor, we could kind of look at - we've got kids who are not showing yearly progress. We can't ignore them. That is something maybe I haven't done in the past is to have somebody help me. She will look at the data. (Teacher 2)

We all are in charge of saying how things are run here... We are the ones that are getting together and writing the goals for...I feel like that is writing our goals for the school. Right? . . . So, we are the ones doing it, along with Ms. H. and Ms. G., our assistant principal. We are playing an active role. (Teacher 2)

School Two:

We definitely work together. I would actually like to be a new teacher coming into this because it is so set up ...We grade our assessments as a team so everybody knows what everybody else is doing. Very supportive. (Teacher 1) 
It's pretty powerful. We are asked for a lot of input and it’s used.” (Teacher 1)

School Three:

I can go to Ms. S. and talk to her. I don't expect it to get out and it doesn't. (Teacher 2)

School Four:

We also have collaboration at the school. It's supposed to be grade level collaboration but it really isn't collaboration. It's really a little meeting where they just give us information. It's really not a time to share. (Teacher 1 , negative instance)

He is, I have had a great experience with him. He has been very supportive. I've had issues with students and parents where he backs me $100 \%$. It's not, "oh the parent has to be right or the student has to be right." He listens to my story and of course he listens to the other story, but we come and we collaborate together to find a solution to the problem. He's very good at that. I feel very confident in going to him when it comes to issues like that. (Teacher 3)

\section{School Five:}

If a certain department thinks that they need a little bit more help on assigned writing papers or solving word problems or whatever, we just get together and say can we have this one? We talk with the principal and he usually says yes. (Teacher 3)

I had been asking for ESL kids at the beginning of the year because we knew that they were going to be taking a test this year and it was going to count for something...I wanted them in there with my regular students just to mainstream them right from the beginning...I wanted them to be ready to take that test, because their scores were going to count also. It wasn't done until late in the year. So I had to work really, really hard with them and pair them up with kids that knew English. When the scores came out and they were talking and they had asked for concerns and I said that I was really aggravated by the fact that they came in so late. I said if they would have come in when I needed them or when I wanted them they would have passed, which would have been really good for them coming in their first year. (Teacher 3, negative instance)

I: Do teachers feel valued here?

R: At some point, I guess they do. That's a good question.

I: Could you elaborate on that a bit?

R: I guess sometimes although they say we are, it's kind of hard to really see it. I'm not sure if it's the testing itself or the teachers are too stressed out or whatever the case may be. I know with me I don't get stressed that easily. Sometimes I guess it looks like it's a problem.

I: It looks like it’s a problem - stress? 
R: Yes.

I: For you?

R: I don't get stressed out so I've been jumped on a few times for not looking stressed.

I: That's an odd thing to say.

R: I said the same thing.

I: Who makes comments like this?

R: Our principal. So things like that tend to bring the morale down.

I: Then would you characterize this as a trusting environment?

R: Well, because of what goes on - I guess it would be kind of iffy with some people.

I: What do you mean by iffy?

R: Sometimes it feels like you are walking on eggshells, even when you are not supposed to be.

I: So you don’t necessarily trust some people to be fair or be -

R: It's kind of hard when you enjoy what you do, when you love making the kids laugh and love a subject that normally everybody hates. Say, if leaving eighth grade and getting ready for ninth grade and know that they are going to do good.

I: Okay, so you feel you are doing a good job. You are a good teacher. You can relate to the kids. You are supportive. You play roles beyond just being their teacher. All of these things, but you are wondering whether it's being recognized by some people.

R: Right. (Teacher 3, negative instance)

School Six:

I think teachers are supported on the decisions they make...I have been (supported) but I think I would like parents to be brought in soon. (Teacher 2, mixed instance)

Support for people, personally, was expressed in all six schools. Note that the final two examples speak more to leaving teachers alone to make wise choices in the classroom than to actual support for their activities in the classroom. In these schools, however, being left alone may be the best that can occur, and may feel like respect, given the context.

Respect was very relevant to teachers, based on the number of thought units represented within the respect data. In high-trust schools there were many thought units that 
related to aspects of respect, almost all of these related to recognition of the professional abilities of teachers. Low-trust schools had many fewer thought units, and there was evidence of negative instances, some of the negative instances being quite significant.

To what extent do principals and teachers hold similar views on the sources (or antecedents) of trust in principals?

Principals described respect and its elements in their conversation. Principals with high trust made 5 positive comments. Principals with low trust made 8 positive comments and 9 negative comments. Many more comments related to the element that respect involves the recognition of the important role each person plays in a child's education. Principals in schools where trust in leadership was lower commented more in relation to the elements of respect than did principals where trust in leadership was higher.

\section{Recognition.}

Respect that involves recognition of the important role each person plays in a child's education was identified by principals, who focused on professional recognition and the teacher's role as a teacher, primarily, in their comments.

Examples of principal comments about this element included:

School One:

They show - you know what has been fun is that teachers, especially in the elementary school, don't always view themselves as leaders so I see it as my job to identify their strongest characteristics and then place them in leadership opportunities that will capitalize on those strengths and help to realize what they are. When I had the opportunity to send four people to the dual language conference, those will be my go-to people for our foreign language instruction. That will be developing but that was the impetus for me to select those folks. One of my teachers, we have case managers for exceptional children...she teaches half a day and she is case manager for the other half. Initially she just didn't think she had what she needed to do that. I said "You are the one that needs to do this." Then this year they had a professional learning community in which every principal could send a teacher that they felt had administrative leadership capability...I sent her. I said "This is you. Are you up to a challenge?” She said “Me?” Like you could see me as an assistant principal or principal? I went "Very readily.” What has been nice is to watch her evolve as she went through that PLC experience. She has now applied for graduate school in educational leadership. Certainly now she has taken that lead position and she is seen as the lead person for us to go to with all our exceptional children questions or issues.

Our curriculum facilitator of course...does an awful lot of research for them (teachers), because we understand the business of teaching is really difficult and there just aren't enough hours in the day...I think that a great amount of information that they get comes from C., our curriculum facilitator. 
School Two:

I think that work is critical. I think that a lot of schools, when we go, my school, my teachers have become like missionaries when it comes to standards based work.

When they go on district curriculum committees or stuff like that, and it's not coming from me, it's coming because they have done the work and they believe in what they are doing.

School Four:

She (curriculum facilitator) helps all the staff in whatever way is needed in instruction. She has my support to do that. Again, it's not tied to any kind of evaluation so it's not. She will talk to me about issues, but we are not, it's not tied to evaluation and I don't use it in evaluating teachers.

School Five:

The other thing I worked on was making sure that we recognize the teachers. I started giving out baseballs. I buy baseballs. It says '07-'08 Teacher. It says PI Junior High School. All of them are labeled with my marker. It says SURGE, that's the acronym that we used for this year. Then Urgency. And then Most Valuable Player in the Fall Diagnostic Exams. This is just one that I kept. Every time a teacher meets goals, I am very big at, they get a baseball. There are teachers out there that have 7 or 8 baseballs in their classrooms that says what they have done for the campus. How they have proven to themselves that there is an urgency to do well. That there is an urgency for leader recognized them and do well in the classroom and outside the classroom. Going above and beyond, let's say that much. (possibly a negative instance)

School Six:

I had to really coerce them into knowing, making them believe that this is what we need to do. (Negative instance)

\section{Mutual dependencies.}

Principals also identified the mutual dependencies that exist among various parties involved in this activity. The comments focused on professional situations, however, the principal of School Four did comment on a personal situation with a teacher and her husband, and the relationship of that situation to the professional relationship at school. Examples of principal comments about this element included:

School One:

I couldn't be that if it weren’t for the phenomenal staff I have. (principal of the year)

School Four:

They know that I have told them "when you come in this office, I let you determine whether you want to close the door or not. Whether you need to keep it in confidence, whatever we're talking about.” There are always other people in the office. If we are talking and I feel that we need to close the door, I just get up and close the door and 
our conversation is continued. But I want them to know that what we talk about is in confidence and it's between us. If it needs to go some other place, I will ask them. Do you want me to take this to this person? Do you want me to extend this further? Or do you want to leave this where we are? Many times they will say, "I just needed to vent. I just needed to talk and I'm glad we were able to talk. I wanted you to know where things were and I don't want it to go any further." Well, that's where it is. They can trust that that's it. That's where it stops at. They know that. So they feel comfortable coming to me and talking about whatever. They know I'm not calling somebody to create a problem for them or whatever else. We can just deal with whatever it is.

The whole relationship there, talking with her, I communicated only what she and her husband wanted me to communicate. Yes, we need to tell people that you have gone to Denver and this is what's happening, but we don't need to deal with details anymore so than you want me to deal with. So, I left it up to her to tell me. She has come back in and been very appreciative of how everything was handled.

\section{School Five:}

The only time that we have done this (teachers visiting each other's classrooms) is when we have concerns with the instruction of a teacher. So, after the second or third Walk Through or after each one of us has seen that one teacher, we put a plan together, a Plan of Action for that teacher. That includes please go observe Mrs. So and So or Mr. So and So. And then bring me back what you observed during that time. It does require them to go in there for whole entire 50 minutes to observe that teacher (a colleague). Now, they are welcome to go and observe any time as long as the teacher knows that you're coming in. I know that it's happened, but in writing itself, we ask them to do that when there are concerns with their instruction. (Negative instance)

School Six:

Myself and my curriculum leader, we sit down and we make out a calendar for the year, the things that we need to implement. This was already made out before I got here with (the previous principal). As I told my teacher, my curriculum leader, I need to see some things other than, all this is centered around balanced literacy. I told her, I changed these to the math part. I told her, teachers already get a lot of balanced literacy. I think that they know, what balanced literacy is. We have to give them some meaningful professional development that they can implement in the classroom. So, next year, I don't want you going through balanced literacy and going “boom, boom, boom." I want you to pick the areas where they have some trouble. Like it might be running records. They probably don't know how to do a running records. Next year I'm going to expect them to have a notebook with running records and give me a quarterly breakdown of running records of what they have done with their students. One of the things that I will look for as far as professional development is doing a session on running records and how I expect them to be conducted and what I expect to see in your notebook when I come and visit your classroom.(Negative instance) 


\section{Summary of Respect}

Table $25^{25}$

\section{Summary Comparison of High Trust and Low Trust: Respect}

\begin{tabular}{|c|c|c|c|c|c|c|}
\hline & \multicolumn{3}{|c|}{ High Trust } & \multicolumn{3}{|c|}{ Low Trust } \\
\hline & Elements & 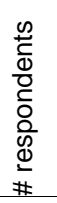 & 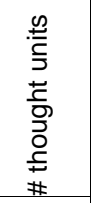 & Elements & 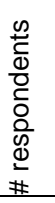 & 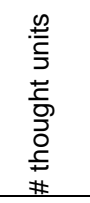 \\
\hline \multirow{3}{*}{ 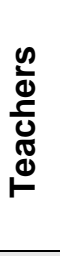 } & $\begin{array}{l}\text { Recognition } \\
\text { of the important role } \\
\text { each person }\end{array}$ & 9 & 13,0 & $\begin{array}{l}\text { Involves the recognition } \\
\text { of the important role } \\
\text { each person }\end{array}$ & 6 & $3,-7$ \\
\hline & $\begin{array}{l}\text { Mutual } \\
\text { dependencies }\end{array}$ & 9 & 11,0 & Mutual dependencies & 5 & $2,-4$ \\
\hline & Total & & 24,0 & Total & & $5,-11$ \\
\hline \multirow{3}{*}{ 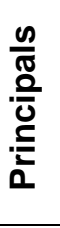 } & $\begin{array}{l}\text { Recognition } \\
\text { of the important role } \\
\text { each person }\end{array}$ & 2 & 4,0 & $\begin{array}{l}\text { Recognition } \\
\text { of the important role } \\
\text { each person plays }\end{array}$ & 3 & $4,-6$ \\
\hline & $\begin{array}{l}\text { Mutual } \\
\text { dependencies }\end{array}$ & 1 & 1,0 & Mutual dependencies & 3 & $4,-3$ \\
\hline & Total & & 5,0 & Total & & $8,-9$ \\
\hline
\end{tabular}

The order of the two elements in respect was the same for both high- and low-trust teachers and principals. There were no negative confirmations in the high-trust environments, among either teachers or principals. In two of the three highest trust schools $100 \%$ of the teachers had thought units related to this antecedent, a very high response rate, and something only seen repeated within consistency and reliability and openness, remembering competence had a response rate of $100 \%$ in all three antecedents. Teacher comments related to support for them professionally, in relation to their role in a child's education, and support for them both professionally and personally, in relation to the various mutual dependencies within a school community. Principal comments focused more on the recognition of teacher professional skills in relation to the roles played in a child's education. Note that within the low-trust principals the rate of response is identical in both elements, only the negative frequency of thought units is different.

\footnotetext{
${ }^{25}$ For an explanation of how to read the table, see reading the tables in chapter 4.
} 


\section{Vulnerability}

To what extent do teachers identify influences on their trust in principals when they are engaged in conversation about their school and the school's leadership?

Table $26^{26}$

\section{Evidence of Vulnerability}

\begin{tabular}{|c|c|c|c|c|c|c|c|c|c|c|c|c|c|c|c|}
\hline \multicolumn{4}{|c|}{ Vulnerability } & \multicolumn{6}{|c|}{ High Trust } & \multicolumn{6}{|c|}{ Low Trust } \\
\hline \multirow{6}{*}{ 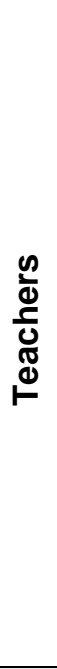 } & \multirow{2}{*}{\multicolumn{3}{|c|}{$\begin{array}{r}\text { School } \\
\text { Max \# Teachers: } \\
\text { Act \# Teachers } \\
\end{array}$}} & \multicolumn{2}{|c|}{ One } & \multicolumn{2}{|c|}{ Two } & \multicolumn{2}{|c|}{ Three } & \multicolumn{2}{|c|}{ Four } & \multicolumn{2}{|c|}{ Five } & \multicolumn{2}{|c|}{ Six } \\
\hline & & & & & $4: 2$ & \multicolumn{2}{|c|}{$5: 5$} & \multicolumn{2}{|c|}{$4: 1$} & \multicolumn{2}{|c|}{$3: 2$} & \multicolumn{2}{|c|}{$4: 2$} & \multicolumn{2}{|c|}{$4: 2$} \\
\hline & \multirow[b]{2}{*}{ Elements } & \multicolumn{2}{|c|}{$\begin{array}{c}\text { Totals for } \\
\text { Antecedent }\end{array}$} & \multirow[b]{2}{*}{ 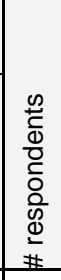 } & \multirow[b]{2}{*}{ 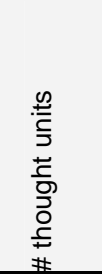 } & \multirow[b]{2}{*}{ 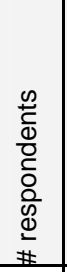 } & \multirow[b]{2}{*}{ 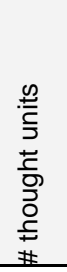 } & \multirow[b]{2}{*}{ 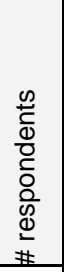 } & \multirow[b]{2}{*}{ 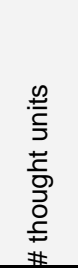 } & \multirow[b]{2}{*}{$\begin{array}{l}\frac{n}{c} \\
\frac{0}{0} \\
\frac{0}{0} \\
\frac{0}{0} \\
\frac{0}{0} \\
\frac{0}{\#}\end{array}$} & \multirow[b]{2}{*}{ 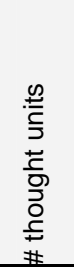 } & \multirow[b]{2}{*}{ 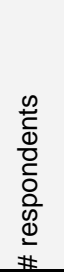 } & \multirow[b]{2}{*}{ 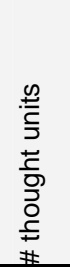 } & \multirow[b]{2}{*}{$\begin{array}{l}\frac{n}{2} \\
\frac{0}{0} \\
\frac{0}{0} \\
\overline{0} \\
\frac{0}{0} \\
\frac{0}{0} \\
\end{array}$} & \multirow[b]{2}{*}{ 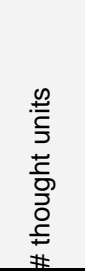 } \\
\hline & & 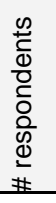 & 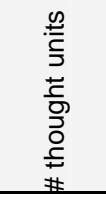 & & & & & & & & & & & & \\
\hline & $\begin{array}{l}\text { Related to the } \\
\text { dependence } \\
\text { on the other } \\
\text { person to act } \\
\text { with good } \\
\text { intention }\end{array}$ & 13 & $26,-10$ & 2 & 10,0 & 5 & 10,0 & 1 & $1,-1$ & 2 & $4,-1$ & 2 & $0,-7$ & 1 & $1,-1$ \\
\hline & Totals & & $26,-10$ & & 10,0 & & 10,0 & & $1,-1$ & & $4,-1$ & & $0,-7$ & & $1,-1$ \\
\hline & & & & & & & & & & & & & & & \\
\hline \multirow[t]{2}{*}{ 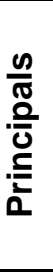 } & $\begin{array}{l}\text { Related to the } \\
\text { dependence } \\
\text { on the other } \\
\text { person to act } \\
\text { with good } \\
\text { intention }\end{array}$ & 2 & $1,-1$ & & 0 & & 0 & & 0 & & 1 & & 0 & & -1 \\
\hline & Totals & & $1,-1$ & & $\begin{array}{r}0,0 \\
\text { (nclb) }\end{array}$ & & 0,0 & & 0,0 & & 1,0 & & 0,0 & & $\begin{array}{r}0,-1 \\
\text { (race) }\end{array}$ \\
\hline
\end{tabular}

There were 21 positive comments and 1 negative comment among teachers in schools with high trust-in-leader. There were 5 positive and 9 negative comments made by teachers with low trust-in-leader. Teacher comments apart from School Two, where all the teachers make comments, had fewer teachers commenting, but those that did comment generated several thought units.

\footnotetext{
${ }^{26}$ For an explanation of how to read the table, see reading the tables in chapter 4.
} 
Which elements of vulnerability do teachers identify most frequently and what leader behaviours do they associate with those elements?

Vulnerability has only one component category, that vulnerability is related to the dependence on the other person to act with good intention. Teachers also commented on the vulnerability created for them by the state or county. Examples of teacher comments about this element included:

School One:

When the principal has had issues with a teacher she pulls the teacher aside. She does not dress down the teacher in front of other people. That makes a difference. (Teacher 2)

I: Would you characterize this as a trusting environment?

R: Yes.

I: Do you have any examples of why you feel that way?

R: Here's one example. We received an e-mail - it's Friends Something. We are trying to collect money for it happens to be a principal whose husband was recently laid off and is having a lot of medical problems. So everyone is pulling together to try to help out. To me, that shows trust because it shows caring and looking out for each other. (Teacher 2)

School Two:

I: I get the sense that you really appreciate your principal and that she is a contributing member, not the dictator. You know? Because that comes out sometimes.

R: No, she is, I am, I am very comfortable. I am comfortable with the families that we service. That is one of the things I live, I pass by every other school in the district before I get to work. And people ask, why do you drive so far? It's just, I don't ever want to leave. It's a good sense of community. (Teacher 2)

I don't know... I think it's good that the principal likes us to be involved in learning new ways of teaching. It seems to always change. Over the next ten years I'll probably have to change again. (Teacher 4)

School Three:

Most of the time. There is always something or someone that you just don't trust. Most of the time, yes, (make it trusting). The people and the administrators. I will leave it like that. (Teacher 4) 


\section{School Four:}

I think we've had kind of a hard time with that, because our principal doesn't usually operate that way. He usually gives us much more professional leeway as far as how we present things. That has been a little tough.

I: Is that coming from above him?

R: Oh yes. That was a district decision. (Teacher 1)

I think he has and I can only speak for me. I know some teacher he's had a harder time or they've had a harder time with him. I don't know what the whole story was, the teacher and the child. He does support us if he knows everything that is going on. (Teacher 2)

School Five:

I: Do teachers feel valued here?

R: Some, I guess. Most. I don't talk to everybody all the time. The lounge is so tiny I don't even eat there anymore. I used to but it got really crowded. I stay in my room so I don't know how everybody feels, but I think most people would feel valued. I'm sure that maybe (those) not doing a good job he kind of is on all the time. (Teacher 1, negative instance)

School Six:

I: What the principal, what the previous principal had in place. So they are succession issues here.

R: Absolutely. I don't, and like I said, I think some people have formed opinions already. I have tried not to do that. (Teacher 1)

Which influences on their trust in principals do teachers identify most frequently?

There is only one component of vulnerability. Teachers, in addition to the examples provided above, describe events that are examples of vulnerability that extend beyond the individual school vulnerability to district or state vulnerability. There is evidence that teachers describe aspects of vulnerability, it is quite prevalent in their conversation, and it is therefore assumed that vulnerability is an antecedent of trust that matters to teachers.

To what extent do principals and teachers hold similar views on the sources (or antecedents) of trust in principals?

Principals in high-trust schools made no comments in relation to vulnerability, with the exception of one general comment regarding educational policy. Principals in low-trust schools made 1 positive and 1 negative comment in relation to vulnerability. The one 
negative comment, made by the principal in School Six was an extensive discourse on race.

While this commentary may have also related to teachers in her school or to parents in her community, she certainly felt victimized by her circumstances. Principals do not comment, for the most part. Principals described vulnerability in the broader sense, involving the district and/ or state as well. Examples of principal comments about vulnerability included: School Four:

I have told them, 'If I have a concern about anything or a question, I will address it to you. Not at that moment, unless I feel that the class is totally out of control and I have to do something. I am not going to address it then. I'm going to wait, but I will address it.

School Six:

It's particularly hard when you are in an inner-city school when you have a predominant population of minority students. For some reason, teachers don't want to talk to minority parents. (Negative instance)

Over all I think it’s pretty good. My first month here I had a really trying month. I think that the parents thought that they were, well, I hate to say it, but they didn't want a black principal. Every time I dealt with a white kid, I was a racist. And I was a "B" and I was this. In fact, there was a situation the first month of school where there was a person who was considered to be a child molester that was coming out side. And nobody said anything to me. I'm down on this end of the building. There were people down on that end of the building. Nobody said anything to me until it just kind of exploded. Then they finally came and said, "Ms. J. there's this child molester out there and the parents aren't happy about it and they are doing this and that." So I go down there and about 4 or 5 parents, kind of gathered around me and said, "You don't care anything about our kids you just let him come up here.” I said, “well, I didn’t know anything about it." One of the parents happens to be a police officer. And I said, "you know what? You're wrong. You are wrong for not coming to the school the first day this person came up to this school to let me know that this person was out here. I am down on the other end of the building and I said, you never said anything. And as a police officer you ought to be ashamed of yourself, because you are the ring leader of these women." It was a male. "You got all these women out here starting a bunch of crap which I could have taken care of before it exploded to this type of a situation. You out here passing out flyers and stuff about this man. It's wrong. It's wrong what you doing." They just gathered around me. "You don't like our kids. We want you to get out of here. We don't want you here anyway.” I said, "whatever.” I turned around and looked her and I said, "all of you have issues and I don't have time to deal with your issues today." I was so mad. I came in and I called my supervisor and I told her what happened. So, we finally got it established that the man was 18 years old and he had sex with a 15 year old girl, with the consent of the girl and the mother got mad and you know and did this to him. Now it's on his record, but he has no restrictions. So, I had to type up a letter and send it to all the parents and tell them there are no restrictions and the police officer, the state police told me to let you all know that you are buckin' on getting a lawsuit because this man has no restrictions so 
there is nothing you can do about him coming up to school to get his kids. So, I dealt with that for about a month and got it straightened out and then after that there were like two or three parents that kept calling every time I'd say something about their kid, I'd say, "You're child is fighting and your child is that." And they'd say, "I bet it was an f*n black kid and that's why you not doing this. You're a racist." One parent even accused me of being at a Christmas party where he was and I know you're a racist because you were at this Christmas party and you were trying to get this black guy who was going with this white woman to come and be with you. I said, "you know, in the first place you don't even know me." "Yes, I do. I know you're a racist." I said, "you see that picture over there? I been married to that man for over 30 years. There is no way that I would try to solicit somebody else. The other thing is. I'm a professional person. You and I don't even run I the same circles. I would never be at a party with you or even near where you're at a party." I said, "I want you to know this, this is the last day that you and your wife are going to come into this office and cuss me out and call me a racist and call me a bigot and everything you can think of. This is the last time you're doing it. I want you to know something else, my Grandmother's white. My father is mixed. So I'm not a racist.” He said, “well I knew you were a mulatto when I saw you.” [Laughter.] I said, “you know what? You got issues. You have a good day.”

\section{I: I'm staggered.}

\section{R: That went on for the first three months that I was here. (Principal)}

There was one quite extensive comment on No Child Left Behind made by the principal in School One that related to the vulnerability of children and schools to the system of American education. It is included here, for the record.

End of grade test and No Child Left Behind. I just truly see that. I think that we are all very ready to deal with the challenges that our children bring. We know that they are being raised in a very different time than when we were children. I think that at least here we have truly accepted that the way our children are today was created by adults. It's not the children's fault, it's the grown-ups fault. The children did not create Nintendo or the games that go along with Nintendo. I think they can accept those challenges. I think we can accept the things we have control over. I don't see us having a great deal of control over No Child Left Behind. I know what my children learn in this building. I am proud to send them after fifth grade to NPM and to hear the reports back that my children are respectful; they are responsible, they know how to access resources, work collaboratively, and utilize technology. The EOG doesn't show that. People can tell me all day long that all of these questions are read for bias. Yeah, they are read for bias by college-educated, middle- class people. If you want me to believe that, then you come over here to the Section 8 housing and you pay some of my people to come read these questions and tell you if they understand them. Then because of No Child Left Behind and because of end of grade test scores, those are published in a newspaper. You send home the (state) report card. That is the picture that is painted of your school. That is a challenge that - I mean you can have a voice. We talk to our legislators and to our various groups: NEA, those types of things. But still we feel that there is just a lack of control and that we don't have 
control of the picture of (our school) or (another school) or (another school) that anybody has when it is simply based on a three day test.

\section{Summary of Vulnerability}

Table $27^{27}$

\section{Summary of Vulnerability}

\begin{tabular}{|c|c|c|c|c|c|c|}
\hline & \multicolumn{3}{|c|}{ High Trust } & \multicolumn{3}{|c|}{ Low Trust } \\
\hline & Elements & 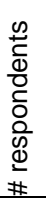 & 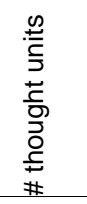 & Elements & 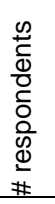 & 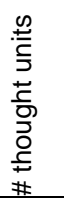 \\
\hline \multirow{2}{*}{ 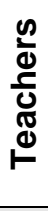 } & $\begin{array}{l}\text { Related to the } \\
\text { dependence on the } \\
\text { other person to act } \\
\text { with good intention }\end{array}$ & 8 & $21,-1$ & $\begin{array}{l}\text { Related to the } \\
\text { dependence on the } \\
\text { other person to act } \\
\text { with good intention }\end{array}$ & 5 & $5,-9$ \\
\hline & Total & & $21,-1$ & Total & & $5,-9$ \\
\hline \multirow{2}{*}{$\begin{array}{l}\frac{n}{\pi} \\
\frac{0}{0} \\
\frac{0}{2} \\
\frac{\Sigma}{2}\end{array}$} & $\begin{array}{l}\text { Related to the } \\
\text { dependence on the } \\
\text { other person to act } \\
\text { with good intention }\end{array}$ & 0 & 0,0 & $\begin{array}{l}\text { Related to the } \\
\text { dependence on the } \\
\text { other person to act } \\
\text { with good intention }\end{array}$ & 2 & $1,-1$ \\
\hline & Total & & 0,0 & Total & & $1,-1$ \\
\hline
\end{tabular}

The presence of many positive teacher comments coupled with only one negative comment in relation to vulnerability suggests teachers in high-trust schools feel minimal risk, as compared to teachers in low-trust schools where teachers feel a predominance of risk. Kollock (1994) identifies trust as having the effect of reducing risk (vulnerability), which would appear to reflect the data in the above table.

Principals have very little to say about vulnerability in relation to teachers, although one principal articulates a detailed concern about American education policy and the risks inherent in that, and another principal expresses a concern about vulnerability in relation to race discrimination and a parent concern. In both cases, principals articulate vulnerability to large, systemic issues.

\footnotetext{
${ }^{27}$ For an explanation of how to read the table, see reading the tables in chapter 4 .
} 


\section{Chapter 8 Discussion and Conclusions}

The study pursued three questions. This chapter first summarizes evidence in response to these questions and then identifies:

- $\quad$ issues for future research in education leadership;

- $\quad$ policy implications; and

- limitations.

Evidence for the study was provided by interviews with 24 teachers and 6 principals in six schools labeled either high or low-trust schools based on survey results from a previous survey, as outlined in Chapter 3.

\section{Discussion}

To what extent do teachers identify antecedents of trust when they are engaged in conversation about their school and the school's leadership?

Antecedents of trust are steadily identified throughout conversations with teachers when they discuss their school and school leadership. Table 28 orders the antecedents of trust, as identified by teacher thought unit totals, within high-trust and low-trust schools. The total column adds negative and positive thought units together as all positive numbers, giving a total of the presence of the antecedent in the teacher interview, regardless of whether the thought unit was positive or negative. The overall total combines both high- and low-trust totals and produces a third sequencing of the antecedents. The total thought unit number at the bottom of the table indicates the total number of thought units related to trust in all antecedents. 
Table 28

Summary Comparison of Overall Totals of Teacher Thought Units and Antecedents of Trust

\begin{tabular}{|c|c|c|c|c|c|c|c|c|}
\hline \multicolumn{3}{|c|}{$\begin{array}{c}\text { Teachers in } \\
\text { High-Trust Schools }\end{array}$} & \multicolumn{3}{|c|}{$\begin{array}{c}\text { Teachers in } \\
\text { Low-Trust Schools }\end{array}$} & \multicolumn{3}{|c|}{ Overall Order } \\
\hline Antecedents & $\begin{array}{c}\text { Thought } \\
\text { Unit } \\
\text { Totals }\end{array}$ & $\begin{array}{l}\text { Grand } \\
\text { Total }\end{array}$ & Antecedents & $\begin{array}{c}\text { Thought } \\
\text { Unit } \\
\text { Totals }\end{array}$ & $\begin{array}{l}\text { Grand } \\
\text { Total }\end{array}$ & Antecedents & $\begin{array}{c}\text { Thought } \\
\text { Unit } \\
\text { Totals }\end{array}$ & $\begin{array}{l}\text { Grand } \\
\text { Total }\end{array}$ \\
\hline Competence & $83,-1$ & 84 & Competence & $49,-21$ & 70 & Competence & $132,-22$ & 154 \\
\hline Consistency & $39,-4$ & 43 & Consistency & $18,-13$ & 31 & Consistency & $57,-17$ & 74 \\
\hline Openness & 34,0 & 34 & Openness & $10,-10$ & 20 & Openness & $44,-10$ & 54 \\
\hline Integrity & 32,0 & 32 & Respect & $9,-11$ & 20 & Respect & $33,-11$ & 44 \\
\hline Respect & 24,0 & 24 & Benevolence & $14,-2$ & 16 & Integrity & $36,-3$ & 39 \\
\hline Benevolence & 22,0 & 22 & Vulnerability & $5,-9$ & 14 & Benevolence & $36,-2$ & 38 \\
\hline Vulnerability & $21,-1$ & 22 & $\begin{array}{l}\text { Personal } \\
\text { Regard }\end{array}$ & $8,-4$ & 12 & Vulnerability & $26,-10$ & 36 \\
\hline Fairness & 19,0 & 19 & Loyalty & $2,-7$ & 9 & Fairness & $22,-5$ & 27 \\
\hline Caring & 12,0 & 12 & Honesty & $7,-1$ & 8 & $\begin{array}{l}\text { Personal } \\
\text { Regard }\end{array}$ & $19,-4$ & 23 \\
\hline $\begin{array}{l}\text { Personal } \\
\text { Regard }\end{array}$ & 11,0 & 11 & Fairness & $3,-5$ & 8 & Loyalty & $13,-7$ & 20 \\
\hline Loyalty & 11,0 & 11 & Integrity & $4,-3$ & 7 & Caring & $14,-2$ & 16 \\
\hline Honesty & 7,0 & 7 & Caring & $2,-2$ & 4 & Honesty & $14,-1$ & 15 \\
\hline Forgiveness & 0,0 & 0 & Forgiveness & 1,0 & 1 & Forgiveness & 1,0 & 1 \\
\hline Total & $315,-6$ & 321 & Total & $132,-78$ & 220 & Total & $447,-84$ & 541 \\
\hline
\end{tabular}

Total thought unit data, seen in Table 28, reveals teachers in low-trust schools generate many fewer thought units related to antecedents of trust than teachers in high-trust schools $^{28}$, even taking into consideration that low-trust schools had two fewer teachers considered than high-trust schools.

While there isn't an overall “everything but trust” thought unit count, the table indicates that teachers identify many antecedents of trust, and they do so frequently, when they are engaged in conversation about their school and the school's leadership.

\footnotetext{
${ }^{28}$ High trust schools had 13 teachers and low trust schools had 11 teachers. It was not possible to select schools with an equal number of teacher interviews and disparate trust scores on the trust scale, as the data was not available. This issue, as well as issues related to principal experience and tenure, will be described in the limitations of the study.
} 
Which antecedents of trust do teachers identify most frequently and are there behaviours exhibited by the school's leadership that they equate to these antecedents?

Table 28 shows the hierarchical order in which antecedents were present in teacher comments by identifying the total number of thought units identified as related to the antecedents of trust in both high- and low-trust schools and indicates there is some difference in the priority of the antecedents depending on whether the school is one with high or low trust-in-leader. The assumption is that the number of thought units reflects something similar to priority for teachers. The Overall Order shows a different order again when high- and lowtrust thought units are combined, theoretically providing an order that relates to an average.

\section{Competence.}

Competence was identified by number of teacher thought units as being of greatest importance in determining trust in the leader in a school. Competence, in part, "is the ability to perform a task as expected, according to appropriate standards” (Tschannen-Moran, 2004, p. 30). Functional, work related skills describes the above phrase and has been shown to be significantly related to competence and trust (Hoy and Tschannen-Moran, 1999; Hoy and Sweetland, 2000, 2001; Hoy and Tarter, 2003). This element of competence drew by far the most thought units in both high- and low-trust schools. In contrast, Bryk and Schneider (2002) began their review of data from the Chicago schools study expecting that functional, work-related conceptions of competence would not be of great importance. "We expect judgments about expert practice to play only a modest role in discernments of trust relations in school settings” (p. 24). In a footnote related to this comment they identify

This observation runs counter to conventional theory about the basis of trust relations in professional-client settings. See, for example, Bidwell (1970), who argues that the technical expertise with which professionals carry out their role is normally a central component in determining professional-client trust (ibid, p. 185).

The review of results found that role competence can be addressed in very different ways, there is

"no one best set of practices...in this regard. A consensus does seem to form quickly, however, around judgments about negligence and gross incompetence in the execution of someone's formal responsibilities. Such behaviour, if allowed to persist, can be highly corrosive to relational trust” (ibid, p. 127).

This is consistent with the findings of Mishra who found "leaders are characterized by how much their followers trust them to make competent decisions” (Kirkpatrick and Locke (1991) in Mishra, 1996, within Kramer and Tyler, 1996, p. 266). The salience of 
perceived ability in decision making is one important component of competence, particularly at times of organizational change or crisis (Lines, Selart, Espedal, and Johansen, 2005, p. 237).

In this study functional, work related skills are identified by teachers as of greatest importance. Additionally, buffering, handling difficult situations, and conflict resolution are identified by thought unit count as the least significant elements in competence. It may depend on how functional, work related skills are defined. If the ability to diffuse, manage or build agreement (buffer, handle difficult situations and conflict resolution) is seen as a functional, work related skill, then it seems likely that all would agree this is most important. Without specifically breaking out this skill set and asking direct questions it seems unlikely that certainty of intent can be determined.

\section{Consistency and Reliability.}

Consistency and reliability was securely in second place, in both high- and low-trust schools, as well as in the overall order. "Trust is based on the expectation that one will find what is expected rather than what is feared” (Deutsch, 1973 in McAllister, 1995, p. 25). Little wonder then that within this antecedent having consistency and tools to reduce uncertainty were the elements where the most number of comments were found. Being diligent appeared as third most commented on, within consistency and reliability, by teachers in both high- and low-trust schools. Teachers watch principals. Followers watch leaders. Where working hard, pressing for results, setting standards, an element in competence drew the second most comments among teachers in that antecedent; being diligent appears third in consistency and reliability. Both elements describe a set of behaviours that are similar, and are visible to others. For some people being diligent or working hard, pressing for results, setting standards may indicate the level of commitment to the job. If part of the job of leader is to motivate the followers through example then being diligent and similar elements is of some importance in setting a desirable tone in the workplace.

Ellis and Shockley-Zabalek state that "behavioural expectations, uncertainty, and dependency undergird perceptions of trust” (2001, p. 383). Consistency and reliability in its many elements, like competence, are important to trust as they foster the growth of cognition-based trust, something which will be present prior to the development of affectbased trust (McAllister, 1995, p.51). As an element of trust, consistency needs to be paired with other antecedents. To be consistently bad at time management will not foster the 
development of trust. Consistency is the ability to deliver something which an individual or group requires over time and repeatedly (Tschannen-Moran, 2004; Hoy and Sweetland, 2000, 2001; Hoy and Tarter, 2003; Hoy and Tschannen-Moran, 1999, Mishra, 1996).

\section{Openness.}

Openness drew many thought units and ranked third in importance in relation to trust among both high- and low-trust teachers. One study found " $26 \%$ of the trust of top management and 13\% of the variance in trust in immediate supervisors underscores the importance of management's attention to information-sending activities” (Ellis, ShockleyZabalak, 2001, p. 393). This finding is confirmed as overall teacher response indicates openness in information means disclosure of facts, alternatives, judgments, intentions and feelings is the most important element in Openness, notwithstanding that "informationsending activities” is not a one-to-one relationship with openness in information means disclosure of facts, alternatives, judgments, intentions and feelings.

Each of the elements within Openness were drawn from Hoy and Tschannen-Moran (1999), who drew general elements of Openness, sharing information, influence and control, from Zand (1997, p.91-92, cited in Tschannen-Moran, 2004, p.25). Trust, using Zand’s approach, involves the creation of vulnerability, by the sharing of information, influence, and control. Certainly teachers identified these broad concepts as relevant in their commentary. Lapidot et al. found openness and flexibility, as a single construct, was important to followers (Lapidot, Kark and Shamir, 2007, p. 24).

At this point in the data, the hierarchy of antecedents begins to appear to be different depending on whether the school is high or low trust. The rest of the summary will be ordered according to the combined total for an antecedent.

\section{Respect.}

Respect high-trust schools had more thought units in relation to respect than low-trust schools; however, integrity superseded respect in high-trust schools, only averaging out as of fourth importance by adding the frequency of thought units in low-trust schools. The order of the two elements in respect was the same for both high -and low-trust schools.

There were no negative thought units in relation to respect in high-trust schools, among teachers. In two of the three highest trust schools $100 \%$ of the teachers had thought units related to this antecedent, a very high response rate, and something only seen repeated within consistency and reliability and openness, remembering competence had a response 
rate of $100 \%$ in all three antecedents across all schools. Teacher comments related to support for them professionally, in relation to their role in a child's education, and support for them both professionally and personally, in relation to the various mutual dependencies within a school community. Korsgaard et al. found that "how leaders interacted with team members during decision making had a significant impact on several dimensions potentially critical to future cooperation (Korsgaard, Schweiger and Sapienza, 1995, p. 77). This attention to interactions between teachers and the principal, including active listening, shared conversation and valuing of input are all components of respect identified by Bryk and Schneider (2002, p. 23).

Integrity.

Teachers commented much more frequently and in higher numbers, in relation to integrity, in high-trust schools. Note the discrepancy in Table 28 between high- and low trust schools on this, and all remaining antecedents.

All elements of integrity attracted comment from teachers. The most commented on element for teachers in high-trust schools was a moral-ethical perspective guides one's work in schools: actions are understood as advancing the best interests of children while intense staff watchfulness of leader actions: match between words and deeds was the most frequently commented on element in low-trust schools.

Bryk and Schneider (2002, p. 25-26; Kochanek, 2005) identify each of the elements as central to integrity. Given the presence of comment in each element it would appear that this is, in fact, so. A factor analysis of 10 conditions of trust resulted in one author concluding "the attribution of integrity was the closest condition to the construct of overall trust in a specific person” (Butler, 1991, p. 652).

Simons also identifies integrity as significant, not only in trust but also within transformational leadership as a whole, stating

“The literature on credibility suggests that managers, by violating behavioral integrity, reduce their ability to induce change through their words. Several leadership theories outside the transformational leadership framework have also recognized the central importance of managerial word-action congruence for effective change management.”(Simons, 1999, p.101).

In a later article Simons provides a conceptual diagram of antecedents and consequences of manager behavioural integrity, suggesting the inputs of managerial fads, fashions and organizational change need to connect positively with managerial actions 
(word-deed alignment) if there is to be employee trust and resulting positive organizational effects (ibid, 2002, p. 19). Gabarro (1979) also references integrity as related to action and word match. The principal in School One was identified as stating "If it's in the best interests of the children” by Teacher Five. It appears that School One largely believes that the principal is acting with this thought, word and deed alignment, it is a high-trust school that has embraced large organizational change, a school that made no negative comments about the principal in any interview data. It is also a school where teacher experience, of those interviewed, ranges from one to five years, something not seen in the other schools and a topic in Limitations.

Lapidot et al. identify integrity as the most salient antecedent in trust eroding incidents (2007, p. 28), but note the silence within teacher comment in Schools Five and Six (as well as the negative comment in School Four). Is there something present in the silence? There is negative comment, and only negative comment, from the principal in School Six. We simply do not know what role integrity may be having in School Six in particular, but more broadly, in Schools Five and Six.

\section{Benevolence.}

Teachers in high-trust schools used more words and examples that related to components of benevolence, and there were no disconfirmations of benevolence in high-trust schools. Supporting teachers drew the most respondents among teachers, and teachers in lowtrust schools had many more thought units about what this meant to them than teachers in high-trust schools. Positive intentions drew many more thought units and respondents in high-trust versus low-trust-in-leader environments, while expressing appreciation was commented on to a fairly similar level in both environments.

Teachers in both high- and low-trust schools did not expand on benevolence in conversation about school and teaching life, in general. Teachers in high-trust schools used more distinct thoughts to describe positive intentions and expressing appreciation. Teachers in low-trust schools described in more detail thoughts related to supporting teachers, although these thoughts were more conditional. Overall, the phrases teachers used were short, narrowly defined, and limited in their descriptive language. "Very supportive," "very positive," "very close” were phrases that appeared throughout this antecedent. Actual descriptions of what "very” described, or why the word "very" was present, were absent. Supporting teachers was seen by teachers, on the basis of the comments, as most important. 
The substance of the thought units related to benevolence suggested that it was not particularly important to teachers, however, the contrast in number of teachers who made comments, as well as the contrast in number of comments made between high- and low-trust schools, may belie this conclusion (see Table 4). By results related to frequency of thought unit alone, the ranking of benevolence for teachers in both high- and low-trust schools is roughly the same.

\section{Vulnerability.}

The presence of many positive teacher comments coupled with only one negative comment in relation to vulnerability suggests teachers in high-trust schools feel minimal risk, as compared to teachers in low-trust schools where teachers feel a predominance of risk. Kollock (1994) identifies trust as having the effect of reducing risk (vulnerability), which would appear to be true, given the data in the above table. Oliver Williamson has written extensively on risk and the organizational effects of same. He recasts trust as simply an issue of risk assessment, stating that trust is not an issue, other than managing the illusion that such a concept could exist; risk management is the organizational issue.

\section{Fairness.}

Teachers in high-trust environments commented in each element of fairness, and while extensive commentary was not present, all the thought units were positive. According to authors cited in Lapidot, et al., self-regulation theory has recently suggested "there are two regulatory systems that motivate individuals: prevention focus and promotion focus. The prevention focus system relates to duties and obligations and satisfies security needs, whereas the promotion focus system relates to accomplishments and aspirations (ideals) and satisfies nurturance needs...The prevention focus associates with conservative behavior, mistake avoidance, tendencies towards accuracy and vigilance” (Lapidot et al., p.20). While fairness and its elements are not specifically cited (these authors are working with the antecedents of ability, benevolence and integrity (ibid, p. 16), these authors dwell in issues of situation specific opportunities to build or erode trust, and focus much time on reducing vulnerability through a prevention focus, fairness and its elements being part of that prevention focus.

Just and fair procedures drew the most comment, all positive, among high-trust teachers. This is consistent with the findings of Dirks and Ferrin who identify interactional justice, procedural justice, participative decision making and distributive justice as leader 
actions that are positively related to trust-in-leader (Dirks and Ferrin, 2002, p. 620). It also reflects the findings of Korsgaard et al., who found leaders who showed strong consideration of members' input resulted in team members viewing processes as fairer, thus increasing member commitment to the decision, greater attachment to the team, and greater trust-inleader (Korsgaard, Schweiger and Sapienza, 1995, p. 76). In addition, Pillai, Schreisheim, and William make a strong connection between transformational leadership, procedural justice, trust and organizational citizenship behaviours (1999, p. 919).

Lewicki, McAllister and Bies, 1998, advocate an approach to trust/distrust as two separate constructs, rather than a continuum. Both trust and distrust exist in healthy, effective relationships, both serving effective purposes for relationship maintenance. Procedurally fair and just processes may establish a basis for the evaluation of trust. "Organization members must know not only when to trust others, and in what respects, but also when to monitor others closely. Furthermore, organization members must develop the capacity to manage the ways in which they are trusted and distrusted by others.”(Lewicki, McAllister and Bies, 1998, p. 453). Fair and just procedures may guard against the negatives of trust, articulated as “groupthink” (ibid, p. 453).

\section{Personal Regard for Others.}

Personal regard for others, a term used by Bryk and Schneider, 2002, and Kochanek, 2005, is likely intended to capture the antecedents of benevolence, care, loyalty, and vulnerability. Kochanek describes it as involving "the display of intentions and behaviours that go beyond the formal requirements” (Kochanek, 2005, p. 8). It is a difficult decision determining if a behaviour that fits "positive expressions of care and concern” is better described under the antecedent caring, vulnerability or here, under personal regard.

In the sense that personal regard captures a broader spectrum of behaviours that generally involve, if not putting others first, at least not putting them second, it may be a good “catch-all.” It would certainly save time in a research agenda to lump them all together. If the point, however, is to really describe actions in detail, to see the action in explicit and high relief so that the person acting can better understand the implications of the action for others, then it may not be helpful.

Teachers in high-trust schools have no negative thought units. Teachers in low-trust schools have twice as many positive thought units as negative. Actions taken by a member of 
a role set to reduce others sense of vulnerability was commented on much more than positive expressions of care and concern, suggesting again that actions do speak louder than words.

\section{Loyalty.}

There were fewer teacher respondents in low-trust schools than in high-trust schools, but the total thought units were similar. Low-trust-in-leader environments expressed many negative instances, which made the totals, overall, similar. The low response rate may mean loyalty is not that significant. Dooley and Fryxell identify loyalty and competence as enhancing decision making quality in teams, identifying that competent team members, who feel free to voice dissent, but assure the team of their loyalty, help to enhance decision making quality. As with vulnerability and respect, the negative thought units outweigh the positive thought units in low-trust schools. In the case of loyalty however, the negative thought units are more than three times as frequent as the positive thought units, so while not many thought units are expressed, those that are seem to be telling a story that needs to be considered carefully.

\section{Caring.}

Teachers did acknowledge demonstrations of leader caring in conversation with interviewers. The school with the highest trust in the leader also had the most number of thought units about caring expressed, by the greatest number of teachers. There was a large difference in the recorded evidence of caring between high- and low-trust schools. Larson, quoted in McAllister stated "The (extra) effort to help is as important as the help itself. The relationship has to be attended to (in McAllister, 1995, p. 53). Teachers seem to have noticed the effort to care because they teachers were quite concrete in describing caring. "Individuals who feel that their leader has, or will, demonstrate care and consideration, will reciprocate this sentiment in the form of desired behaviors” (Dirks, Ferrin, 2002, p. 613). Generally, the affective nature of care is considered to be related to fostering organizational citizenship behaviours which, in turn, may be related to trust (McAllister, 1995, p. 613). It remains; there was so little representation in some of the elements that focus on this antecedent, given the evidence provided, may not be warranted. An alternative interpretation will be put forward in Discussion. 


\section{Honesty.}

Overall, not many thought units related specifically, and only, to honesty. Many also connected easily to integrity, Openness or other antecedents. Mishra, 1996, makes no distinction between honesty and openness. Tschannen-Moran pairs antecedents such as "honest and fair,” stating telling the truth is a component of integrity (Tschannen-Moran, 2004, pgs. 22, 37-38), despite identifying honesty as one of the five essential faces of trust ${ }^{29}$ (ibid, page 22, Hoy and Tschannen-Moran, 1999). There was very little commentary from teachers about this antecedent and the quantity of comment was very similar between highand low-trust environments. Telling the truth and being authentic were in similar first and second positions for both environments.

\section{Forgiveness.}

Parayitam and Dooley, 2007, found affect-based trust, of which forgiveness is a component, is important in resolving some cognitive conflict. While this may be true, either forgiveness was not within the repertoire of possible responses for teachers (and principals), or it was not considered appropriate to discuss as a possibility.

Forgiveness does not appear to be an important component of relationships with teachers, although one teacher did comment on the need to “say you're sorry” when an error has been made with parents. Seeking forgiveness is a desirable attribute among followers, in this case teachers, as the request for forgiveness will result "in less anger from other group members, more granting of forgiveness, and less getting even reactions.” (Stouten and Tripp, 2009, p. 295).

To what extent do principals and teachers hold similar views on the sources (or antecedents) of trust in principals?

Table 29 is organized in the same manner as Table 28 and is explained in the footnote associated with Table 29.

\footnotetext{
${ }^{29}$ Tschannen-Moran (2004) as well as Hoy and Tschannen-Moran (1999) identify five elements of trust, those being Benevolence, Honesty, Openness, Reliability and Competence.
} 
Table $29^{30}$

Summary Comparison of Overall Totals of Principal Thought Units and Antecedents of Trust

\begin{tabular}{|c|c|c|c|c|c|c|c|c|}
\hline \multicolumn{3}{|c|}{$\begin{array}{c}\text { Principals in } \\
\text { High-Trust Schools }\end{array}$} & \multicolumn{3}{|c|}{$\begin{array}{c}\text { Principals in } \\
\text { Low-Trust Schools }\end{array}$} & \multicolumn{3}{|c|}{$\begin{array}{c}\text { Overall Principal } \\
\text { Order }\end{array}$} \\
\hline Antecedents & $\begin{array}{l}\text { Thought } \\
\text { Unit } \\
\text { Totals }\end{array}$ & $\begin{array}{l}\text { Grand } \\
\text { Total }\end{array}$ & Antecedents & $\begin{array}{l}\text { Thought } \\
\text { Unit } \\
\text { Totals }\end{array}$ & $\begin{array}{l}\text { Grand } \\
\text { Total }\end{array}$ & Antecedents & $\begin{array}{l}\text { Thought } \\
\text { Unit Totals }\end{array}$ & $\begin{array}{l}\text { Grand } \\
\text { Total }\end{array}$ \\
\hline Competence & $42,-3$ & 45 & Competence & $31,-13$ & 44 & Competence & $73,-16$ & 89 \\
\hline Openness & $13,-3$ & 16 & Openness & $17,-6$ & 23 & Openness & $30,-9$ & 39 \\
\hline Consistency & 14,0 & 14 & Respect & $8,-9$ & 17 & Consistency & $27,-1$ & 28 \\
\hline Honesty & 12,0 & 12 & Fairness & $8,-7$ & 15 & Respect & $13,-9$ & 22 \\
\hline Integrity & 7,0 & 7 & Consistency & $13,-1$ & 14 & Honesty & $14,-5$ & 19 \\
\hline Benevolence & 6,0 & 6 & $\begin{array}{l}\text { Personal } \\
\text { Regard }\end{array}$ & $3,-9$ & 12 & Integrity & $14,-3$ & 17 \\
\hline Respect & 5,0 & 5 & Integrity & $7,-3$ & 10 & Fairness & $9,-7$ & 16 \\
\hline Loyalty & 3,0 & 3 & Honesty & $2,-5$ & 7 & $\begin{array}{l}\text { Personal } \\
\text { Regard }\end{array}$ & $5,-9$ & 14 \\
\hline $\begin{array}{l}\text { Personal } \\
\text { Regard }\end{array}$ & 2,0 & 2 & Benevolence & $1,-5$ & 6 & Benevolence & $7,-5$ & 12 \\
\hline Fairness & 1,0 & 1 & Loyalty & $4,-1$ & 5 & Loyalty & $7,-1$ & 8 \\
\hline Caring & 0,0 & 0 & Vulnerability & $1,-1$ & 2 & Vulnerability & $1,-1$ & 2 \\
\hline Forgiveness & 0,0 & 0 & Caring & 1,0 & 1 & Caring & 1,0 & 1 \\
\hline Vulnerability & 0,0 & 0 & Forgiveness & 0,0 & 0 & Forgiveness & 0,0 & 0 \\
\hline $\begin{array}{l}\text { Total thought } \\
\text { units }\end{array}$ & $105,-6$ & 111 & $\begin{array}{l}\text { Total thought } \\
\text { units }\end{array}$ & $96,-60$ & 156 & $\begin{array}{l}\text { Total thought } \\
\text { units }\end{array}$ & $201,-66$ & 267 \\
\hline
\end{tabular}

Principals describe antecedents of trust. Principals do not describe these antecedents with exactly the same frequency per antecedent in high- and low-trust environments, and they do not correspond identically with teachers in either environment, with the exception of Competence.

\footnotetext{
${ }^{30}$ Table 28 orders the antecedents of trust, as identified by principal thought unit totals within high trust and low trust schools. The grand totals column are the total of the negative and positive thought units as though all were positive numbers, to identity the total number of references to the antecedent in the principal interview. The total for the overall principal order combines both high and low trust totals and produces a third sequencing of the antecedents. The total thought unit number at the bottom of the table indicates the total number of thought units related to trust in all antecedents.
} 
There are marked similarities between what teachers and principals describe in the antecedent competence, and there are some similarities in what teachers and principals describe in some other antecedents.

There is much less information provided by principals in areas such as benevolence, caring, loyalty, personal regard and vulnerability, despite the fact that principal interviews were much longer and principals spoke in great length in the interviews. Reasons for the silence in these areas might include the personal nature of such thoughts, and therefore the thoughts were not shared. This is only speculation. Principals commented to a much higher degree on interactions with parents, the district office and the state than teachers did.

\section{Competence.}

Teachers and principals in high- and low-trust environments commented almost equally. Functional, work related skills are identified by teachers and principals, in both highand low-trust schools, as of greatest importance. Additionally, buffering, handling difficult situations and conflict resolution are identified by all groups as the least significant elements in competence.

\section{Openness.}

Openness drew many thought units from low-trust principals. Principal responses resulted in sharing decision making, sharing power being the area of most frequent commentary and response. In contrast, responses from teachers in high-trust schools resulted in this element being third in importance, and responses from teachers in low-trust schools resulted in this element being in fifth position. The word "sharing" may be subsumed in other elements, or it may be there are actions that suggest "sharing" is not quite the same as “Openness.”

As stated earlier, Lapidot et al. found openness and flexibility, as a single construct, was important to followers (Lapidot, Kark and Shamir, 2007, p. 24). This might be seen as sharing decision making, sharing power, and was by far the most common element among principals in both high- and low-trust schools.

The first two antecedents were ranked identically for principals in high- and low-trust schools. From this point onward, the ranking is an averaging of high- and low-trust principals, resulting in an overall ranking. The discrepancy in order between high- and lowtrust principals is interesting, but will not be commented on at this time. 


\section{Consistency and Reliability.}

There were both similarities and differences in what principals and teachers described, in relation to Consistency and reliability. Principals were focused on the tasks for which they tended to be accountable, such as data, feedback/ performance appraisal and parent/ community dialogue. They did not mention discipline, a task of considerable importance to most classroom teachers, and something that was very much in evidence in teacher comments related to Consistency and reliability. One possible explanation for principals not addressing discipline is that it is such a daily, ongoing and eternal part of the job they didn't see it as an item of conversation. Another reason, one which would not sit well with most teachers, might be some principals may feel discipline is actually more of a teacher task. In any case, we don't know why there was no principal comment, only that this was so. Being diligent was not commented on at all in the low-trust principal data, yet it appeared as third most commented on by teachers in both high- and low-trust schools. If part of the job of leader is to motivate the followers through example then being diligent is of some importance.

\section{Respect.}

The order of the two elements in respect was the same for both high- and low-trust schools, both teachers and principals. There were no negative thought units in the high-trust schools, among either teachers or principals. Principal comments focused more on the recognition of teacher professional skills in relation to the roles played in a child's education. This corresponds with Korsgaard's findings, stated as "feelings of attachment and trust significantly decreased over time when leaders exhibited no specific signs of consideration of input... (reflecting something similar to)...a "frustration effect'” (ibid, p. 77). Within the high-trust principals, the number of respondents is identical in both elements, only the negative frequency of thought units is different. The order of the two elements in respect was the same for both high- and low-trust schools, both teachers and principals. There were no negative thought units in the high-trust schools, among either teachers or principals. In two of the three highest trust schools $100 \%$ of the teachers had thought units related to this antecedent, a very high response rate, and something only seen repeated within consistency and reliability and openness, remembering competence had a response rate of $100 \%$ in all three antecedents. Teacher comments related to support for them professionally, in relation to their role in a child's education, and support for them both professionally and personally, in 
relation to the various mutual dependencies within a school community. Korsgaard et al. found that "how leaders interacted with team members during decision making had a significant impact on several dimensions potentially critical to future cooperation (Korsgaard, Schweiger and Sapienza, 1995, p. 77). This attention to interactions between teachers and the principal, including genuine listening, genuine conversation and valuing of input are all components of respect identified by Bryk and Schneider (2002, p. 23).

\section{Honesty.}

There was a fairly wide gap in number of thought units related to honesty between high-trust principals and low-trust principals. Principals in high-trust environments articulated a particular focus on telling the truth in their commentary, while principals in lowtrust environments were slightly more focused on taking responsibility, albeit with mixed results. Teachers had little to say about this antecedent and the quantity of comment was very similar between high- and low-trust environments. Telling the truth and being authentic were in similar "first and second" positions for both environments.

\section{Integrity.}

There was a similar, but not identical, "ranking” of the elements seen by both teachers and principals. Principals in both high- and low-trust schools commented with similar frequency. The low-trust schools had some negative instance. A moral-ethical perspective drew the most comment among both high- and low-trust school principals, the other two elements being roughly equivalent, but less present in the interview data than moral-ethical.

\section{Fairness.}

The inverse relationship of comment frequency within the high-trust teacher and high-trust principal data was not something seen in other antecedents. There were eleven teachers who could have commented in relation to fairness among the three high-trust schools, and only three principals, yet the principal comments were more than double those of the teacher comments in terms of positive instances, and the response rate of the principals was much higher than that of the teachers. It would seem possible that this reflects the "frustration effect" noted in Korsgaard, et al., who found "One unexpected result was that feelings of attachment and trust significantly decreased over time when leaders exhibited no specific signs of consideration of input.” (Korsgaard, Schweiger and Sapienza, 1995, p. 77). 
Teachers in high-trust environments commented in each element, and all the thought units were positive, yet the principals in high-trust environments commented very little.

\section{Personal Regard for Others.}

Principals do describe events in thought units in personal regard that are similar to what teachers describe. The elements appear in the same order for number of thought units across all four quadrants (high- or low-trust teachers; high- or low-trust principals), which is unusual in the data. The high-trust schools, both teachers and principals, have no negative thought units. Teachers in low-trust schools have twice as many positive thought units as negative, while the principals in these schools have three times as many negative thought units as positive thought units. The high prevalence, in fact, strong dominance, of negative thought units among low-trust principals is not seen in other antecedents. The vast majority of the negative thought units are collected in School Six, the lowest trust environment, and most of these negative thought units relate to efforts to reduce vulnerability.

\section{Benevolence.}

Positive intentions was seen by principals, based on the number of respondents and the number of comments, as most important. Teachers viewed supporting teachers as most important. Each seems to view benevolence from their own vantage point. It was ever thus.

\section{Loyalty.}

Principals in both environments had a similar number of thought units, and an identical number of individuals responded. The situation of a principal harassing a teacher (School Five- fear of reprisal is mitigated), serves as an example of what most teachers/employees fear, given the power relationship with their principal/supervisor. Regardless, there is not a lot of commentary related to loyalty, not rendering the antecedent irrelevant, but possibly indicating that most of the thought units were better categorized in other antecedents.

\section{Vulnerability.}

Principals have very little to say about vulnerability in relation to teachers, although one principal articulates a detailed concern about American education policy and the risks inherent in that, and another principal expresses a concern about vulnerability in relation to race discrimination and a parent concern. In both cases, principals articulate vulnerability to large, systemic issues. 


\section{Caring.}

Principals made no comments in high-trust environments regarding this antecedent. The only comment made by principals was a negative instance of behaviour oriented to a specific situation and person (sometimes toughness). Negativity in this area may have no effect, or it may have been significant. Given the absence of other comment it is not possible to determine this from the evidence. The absence of comment is shared with the general absence of comment in teacher data.

\section{Forgiveness.}

Either forgiveness was not within the repertoire of possible responses for teachers and principals, or it was not considered appropriate to discuss as a possibility. Forgiveness does not appear to be an important component of relationships with teachers and principals. The absence of leader commentary related to forgiveness is consistent with the findings of Stouten and Tripp, who identified that leaders feel so entitled, simply by virtue of their position, they do not perceive themselves as in a position of being in need of forgiveness (Stouten and Tripp, 2009, p. 287). This has been characterized as a "winner wants all” mentality (Kramer, 2003, p. 62). Kramer further identifies “The sacrifices an individual makes on the way to the top not only make it harder to cope with the rewards when they do come, they also make the person greedier for more of the same (p. 63)." While it is relevant in the extreme to recognize that the role of principal is but the most junior of leadership positions in any educational structure, it is nevertheless a leadership position of significance within any individual school, so while Kramer's concerns certainly apply to senior positions in education, it is may be less prevalent in junior management positions.

Nevertheless, what likely does still matter in schools is that "followers" do not expect leaders to adhere to group norms such as equally sharing cookies, for example. Somewhere in our culture, and possibly we return to Barnard's casting of authority as related in our history to the Divine Right of Kings, we have come to accept that leaders are exempt from the rules of societal behaviour. Leaders are more easily forgiven, despite the research that indicates leaders are more likely to violate norms or break promises than are followers (Stouten and Tripp, 2009, p. 296). 
Table 30

Side by Side: All Teachers, All Principals

\begin{tabular}{|c|c|c|c|c|c|}
\hline \multicolumn{3}{|c|}{ All Teachers } & \multicolumn{3}{|c|}{ All Principals } \\
\hline Antecedents & $\begin{array}{l}\text { Thought Unit } \\
\text { Totals }\end{array}$ & $\begin{array}{l}\text { Grand } \\
\text { Total }\end{array}$ & Antecedents & $\begin{array}{l}\text { Thought Unit } \\
\text { Totals }\end{array}$ & $\begin{array}{l}\text { Grand } \\
\text { Total }\end{array}$ \\
\hline Competence & $132,-22$ & 154 & Competence & $73,-16$ & 89 \\
\hline Consistency & $57,-17$ & 74 & Openness & $30,-9$ & 39 \\
\hline Openness & $44,-10$ & 54 & Consistency & $27,-1$ & 28 \\
\hline Respect & $33,-11$ & 44 & Respect & $13,-9$ & 22 \\
\hline Integrity & $36,-3$ & 39 & Honesty & $14,-5$ & 19 \\
\hline Benevolence & $36,-2$ & 38 & Integrity & $14,-3$ & 17 \\
\hline Vulnerability & $26,-10$ & 36 & Fairness & $9,-7$ & 16 \\
\hline Fairness & $22,-5$ & 27 & Personal Regard & $5,-9$ & 14 \\
\hline Personal Regard & $19,-4$ & 23 & Benevolence & $7,-5$ & 12 \\
\hline Loyalty & $13,-7$ & 20 & Loyalty & $7,-1$ & 8 \\
\hline Caring & $14,-2$ & 16 & Vulnerability & $1,-1$ & 2 \\
\hline Honesty & $14,-1$ & 15 & Caring & 1,0 & 1 \\
\hline Forgiveness & 1,0 & 1 & Forgiveness & 0,0 & 0 \\
\hline Total & $447,-84$ & 531 & Total & $201,-76$ & 277 \\
\hline
\end{tabular}

Principals describe antecedents of trust. Principals do not describe these antecedents with exactly the same frequency per antecedent in high- and low-trust environments, and they do not correspond identically with teachers in either environment, with the exception of Competence.

There are marked similarities between what teachers and principals describe in the antecedent Competence, and there are some similarities in what teachers and principals describe in some other antecedents.

There are two antecedents that are particularly interesting in this table. Note the very low ranking of honesty among all teachers, but the comparatively high ranking of honesty among principals. In addition, vulnerability seems to be much more significant to teachers than it does to principals. It does leave questions as to why the disparity, despite some information provided earlier. 
There is much less information provided by principals in areas such as benevolence, caring, loyalty, personal regard and vulnerability, despite the fact that principal interviews were much longer and principals spoke at great length in the interviews. Reasons for the silence in these areas might include the personal nature of such thoughts and therefore the thoughts were not shared. This is only speculation. Principals commented to a much higher degree on interactions with parents, the district office and the state than teachers did.

There is evidence that competence, consistency and reliability and openness are the dominant antecedents for both teachers and principals. There are behaviours identified by teachers that give some indication of what may be demonstrations of antecedents of trust for them. The behaviours identified by teachers are similar, but not identical, to behaviours principals identify.

It seems that the further down the ordered list of antecedents we go, the deeper into the affective domain we go. In general, there are no absolutes in trust. However, the absence of comment within the more affective elements and/or antecedents raises issues of fluency, of freedom to think because we have the prerequisite repertoire of experience, skills and language to support our thinking. There may be issues related to "knowing" what "extending good will,” as one example, looks like in a supervisor/employee relationship, or in any relationship.

Having now looked at the antecedents and elements and considered what teacher and principal words relate to these, what matters and to whom, there is the remaining issue of why is School One the highest trust school and School Six the lowest trust school. Table 31 provides a comparison of the four most important antecedents, as identified by teachers, for School One and School Six. It is important to remember that while interesting, and providing some information, the sample size is very small. This table is provided only for consideration. 
Table 31

Comparison of Schools One and Six Totals of Teacher Thought Units

\begin{tabular}{|l|r|r|}
\hline & $\begin{array}{c}\text { School One } \\
4 \text { teachers }\end{array}$ & $\begin{array}{c}\text { School Six } \\
4 \text { teachers }\end{array}$ \\
\hline Competence & 40,0 & $12,-9$ \\
\hline Consistency & 21,0 & $4,-1$ \\
\hline Openness & 13,0 & $1,-3$ \\
\hline Respect & 9,0 & $1,-1$ \\
\hline Integrity & 15,0 & 0,0 \\
\hline Benevolence & 14,0 & $4,-1$ \\
\hline Vulnerability & 10,0 & $1,-1$ \\
\hline Fairness & 4,0 & $1,-1$ \\
\hline Personal Regard & 6,0 & 3,0 \\
\hline Loyalty & 3,0 & 0,0 \\
\hline Caring & 8,0 & $0,-1$ \\
\hline Honesty & 3,0 & 1,0 \\
\hline Forgiveness & & $0,-18$ \\
\hline Totals & 3,0 & 0,0 \\
\hline
\end{tabular}

Faced with the above information, if I were the principal going in to School Six, I would listen carefully to words teachers use as they talk with me that describe elements of competence, consistency, openness and respect as this might help me understand in what order the elements fall in terms of hierarchy, as well as exactly what behaviours teachers see in this school as evidence of those elements. Trust is personal and contextual. I would review all details such as timetable, supervision schedules, teaching assignments, office and custodial routines, to name a few, looking for improvements in functional effectiveness. I would spend some time being visible, each and every day, but I would do this first and foremost with children. Things such as yard, hall or lunch duty would regularly occur. Visits to classrooms would relate, for some time, to personal delivery of requested materials, as opposed to critique and/or support of teaching style. Staff meetings and weekly memos 
would focus on students and academics. I would provide the community with a small, but visible "sign of change," something for them to discuss on their walks to and from school that counters the negative tone, something visible to staff and supportive of staff, but also viewed positively by the community.

While integrity does not fall within the four most important antecedents for all schools, there is a large discrepancy between the integrity ratings in School One and School Six. By focusing on functional skills, on children and on program, staff would begin to acquire evidence of a moral-ethical perspective guiding my work as well as serving as a model.

I would also work to ensure that my actions do not provide evidence of a lack of affective consideration, but neither would I draw attention to the affective. The staff in this school is pretty close to crisis. I would work at "stilling the affective waters," and creating a clear, organized and predictable routine that is transparent, respectful and mutual. The second step would be to work at the affective antecedents. Personal interviews with staff would signal a willingness to hear each individual's concerns and to form relationships. Inclusion of support staff in this personal listening would provide a great deal of information about the school from those who sometimes are not asked often enough what they think. This “purposeful listening” would signal respect and a valuing of all perspectives. The agenda for all meetings should be provided ahead of time, and "prying” would not be wise. Let staff tell what they want to tell, remembering all interviewing is an opportunity to share your own priorities. I would be certain the priority was listening and gaining understanding, however, staff will also be listening for hopeful signs. I would have a plan, in the loosest sense of the word, about what hopeful signs I would offer. The meeting is not about me, it is about them.

Positive results in School Six would take time, cultures in schools change slowly. A new principal would need to seek visible change that is viewed positively by staff and the community, early. More substantive change needs to be the result of mutual effort aimed at specific, achievable, shared goals that will benefit students. The long-term goal of a healthy work environment, one with mutual trust, will be a result of today being well-lived, today creating a string of purposeful, shared yesterdays and intentional tomorrows. The school will become resilient.

The suggestions above can be represented as a rough "hierarchy of need" in the development of trust as seen below, in Figure 2. Cells are not intended to be impermeable, 
and as in Maslow, they are not intended to fall literally, in a lock-step manner, sequentially. It is possible to demonstrate Competence as well as Fairness, and this will matter to teachers. It is important, however, to recognize where gaps exist, and make efforts to fulfill those needs as they arise.

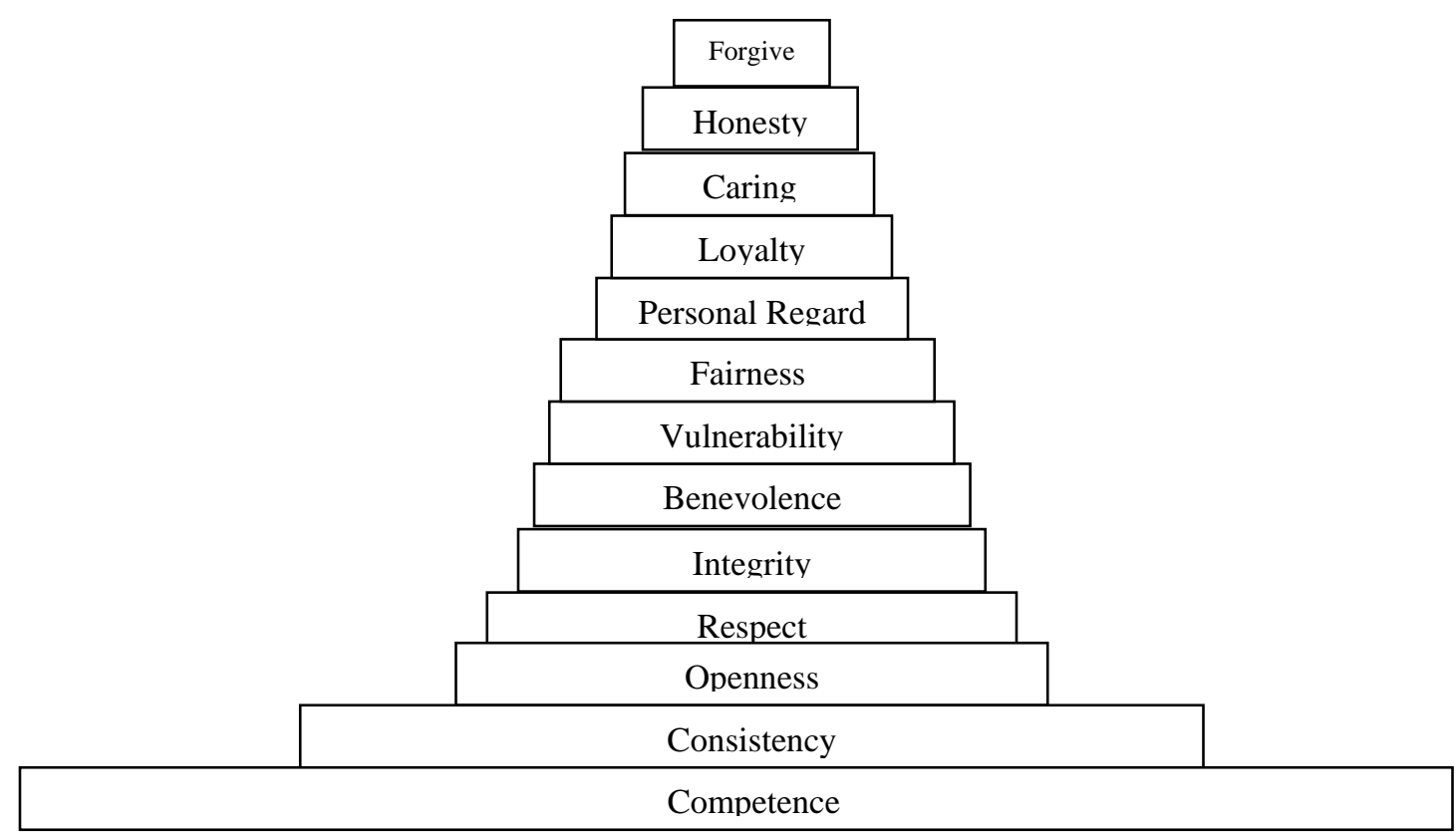

Figure 2: A hierarchy of need as school leaders establish trust with teachers

A 'hierarchy of need' approach needs to be understood from the perspective that Maslow intended. Much as the requirements of 'physical' (food, water, shelter, sex, sleep, etc.), the lowest level on the hierarchy, must be met, it is desirable to go beyond the physical to "what's next". Similarly, while a threshold of Competence must be achieved for others to trust, there is likely a "what's next" that becomes significant for development of the relationship, and benefit for student achievement. Engaging further up the hierarchy, as other steps are addressed, likely achieves a certain "actualizing” benefit. Not surprisingly, in this 'trust hierarchy' illustration above, forgiveness is the least important, in terms of survival; it isn't necessary. Forgiveness, when it does occur however, may be part of moments of personal and/or relational transformation; a moment of self-recognition, of common humanity, and purpose. We don't know how “actualized” the relationship between teachers and the principal needs to be in order for trust to be present, and in order for the relationship 
to benefit student achievement. We do know trust is a factor that positively influences student achievement. Trust matters.

\section{Conclusions}

There is the real possibility that the sum of the parts do not equate to a whole. Teachers, principals - people - do not necessarily "tot up" actions and determine, either in a consciously rational, or in an unconsciously subjective manner, whom they will trust. There is fluidity to our thoughts and decisions in relation to other people and our beliefs about them, particularly over time, that is difficult to quantify.

This thesis has considered 13 antecedents of trust and a number of elements within those antecedents, and tried to identify, from commentary about topics not specifically related to trust, what matters for teachers and principals. The study sought to discover whether there are actions that can determine the differences in the teacher/principal relationship between a high-trust school and a low-trust school. The findings indicated that there are differences in the actions that others describe that make a difference in the relationships. We can name some of them. These findings are significant because high-trust environments are significantly more likely to create the learning conditions that result in student achievement.

\section{Implications for Future Research}

This thesis, a "backward mapping" of trust, provides good indication that trust is present in the commentary about schools and school life in both high- and low-trust schools, with high- and low-trust leaders, for both teachers and principals. Trust does indeed seem to matter, even when people are not queued to say it matters (or doesn't). Some time needs to be spent identifying specific behaviours that add up to positive attribution of trust in the perception in the most significant antecedents (competence, consistency, openness, and respect). Determining which actions enhance trust of school leaders by teachers, when these things matter, if there are stages in a teacher's or a principal's career or stages of organizational evolution where certain antecedents matter more than others are all worthy research questions. Consideration of trustworthy actions of teachers by school leaders should also be investigated. Mutuality is frequently related to trust. Similarly, district leadership and trust should be explored to determine if remnants of the relationship between principal and district leadership affect the school environment and therefore children's learning conditions. 
The elements of trust were derived from words used by previous researchers. This was intentional, as all of the definitions of antecedents, whether defined by an education researcher or by experts in other fields, included multiple and not entirely synonymous descriptions, and often multiple behaviours within a single description. Wherever possible, I used specific words from an educational researcher to isolate the elements within each antecedent. For example, I took great care to identify the elements of trust by employing the words used by Bryk and Schneider and Tschannen-Moran. As stated earlier, one of the difficulties with trust research in general is the definition of terms as there are many variations, making duplication of results or expansion on understanding(s) difficult. Future research should continue to consolidate understanding.

The absence of commentary in the more affective areas does not mean these don't matter; indeed, they may be as or more significant than the easier to name and describe antecedents in the previous paragraph. We don't know. While word count versus a count of thought units is not significant research, it is nonetheless true that there are startlingly fewer thought units as well as fewer overall words used among teachers in low-trust environments as compared with teachers in high-trust environments. There are many fewer words spoken about affective antecedents in both environments. While language and thought historically are viewed as highly related, it is also true that many aboriginal cultures tell us silence signals dissent. Silence does not signal lack of thought. Does silence in affective areas in a work environment signal dissent? The silence on forgiveness by both teachers and leaders should be explored. It is unlikely that forgiveness is never necessary. Detailed understanding and language to encourage discussion of vulnerability, the antecedent with the widest gap between teachers and leaders should be considered. Perhaps work in the area of power, developing a clear understanding of the vulnerability all employees feel to their supervisors, would be helpful with school leaders.

\section{Policy Implications}

The policy implications of the findings of this study loom large. In an era where the school principal is held increasingly accountable for scores, which they have less than $10 \%$ influence over (Leithwood et al., 2010), the principal remains, for now, a title and job function the public recognizes and trusts. Principals are targeted by various and sundry “others” who craft policy. Policies frequently serve the purpose of further dividing the relationship between teacher and principal, holding the principal responsible for endless 
effects but unable (or unwelcome) to even sit at the table as the causes are crafted. The teacher is exhausted by the demands of the day and the season. This is compounded by feelings of dismay when confronted with a system that regards them with minimal consideration. There is little wonder the principal and teacher may struggle.

We wallow in test score data, trying to meet expectations to identify what's going wrong and what's going right, displaying a "focus, focus, focus" mindset. It is sometimes difficult to tell where the generation of need for endless reports and data originated, so laying blame, something that is rarely helpful, may not even be possible. It is common, however, for elementary school leaders to submit reports twice a year on reading achievement from Grades One to Three, general standardized achievement data for Grades Four to Six annually, detailed adaptive and cognitive reports for Kindergarten twice annually, and data related to provincial standardized testing in Grades Three and Six annually. There are reports related to school safety, and achievement on School Goal Plans submitted at least annually. In addition, community engagement data is required, as well as a full report on Community Engagement. There are reports on student enrolment, teacher timetables, special education, English Language Learners, and Technology - all due at least annually. Staff performance appraisal is essential to Human Resource management, and is a constant in all schools. The wise principal recognizes the Superintendent's need to put check marks in the boxes for all required submissions that go on to the great report in the sky ... if the principal wants to keep the Superintendent happy, submit the report on time. There is, of course, the reporting to parents, done three or four times a year, depending on the phase of provincial policy.

There is no expectation that a report on how the school is building relationships and developing people be submitted, unless the pounding of "train the trainer" and the cranking out of professional development for whatever the latest and greatest is counts in this category.

In the midst of all this focusing and moral purpose, apparently believed by some to be captured in this steady flow of reports, trust somehow loses its mediation position. Some policy crafting that enhances the potential for trusting principal/teacher relationships would be helpful. Policies and collective agreements that reduce the sense that leadership is a "guarding the prisoners" function might help (Palmer, 2000, p.64).

Policy might begin with recognizing that teachers and principals share a living space for eight or more hours a day, often for many years, through multiple events. Schools are a 
"we” enterprise. Policy that enhances relationship, that demonstrates full recognition that schools engage people, hurt by indifference, committed to students and their families regardless of their test scores, proud of the differences they can and do make every single day__ and who, over time, develop a complex work relationship that is directly affected by demands made by policies developed by those who have rarely (or not for a very long time) done the actual job would be helpful. Policy should take a look at good practice in the overall health of a school, asking those that live it to the table. Health of the school should then be discussed as a factor, equal in importance to the many other issues senior officials like to consider, with space in the policy initiative that respects this critical feature.

While I am not prepared to "redraw" local or provincial policy, some suggestions include focussing on Competence, Consistency and Openness in principals, including specific work on what teachers describe within these antecedents, remembering that these antecedents relate in immediate day- to- day practice in all leadership dimensions. In Ontario, the Leadership Framework (Ontario Ministry of Education, 2009), serves as the 'image of the leader'. This framework creates “space”, while establishing transformational leadership as the foundation upon which policy and practice will rest. Specific work can and should be done to ensure principals begin well-equipped, and have resources that will support their continuing growth, in areas as specific as the importance of knowing what teachers are teaching (and how), providing materials that support the teaching, visiting classrooms without the "walk-through/check-in-the-box/accountability” mentality, abilities related to articulating connections between work done in classrooms, the school's overall goals and the system's priorities for the year. Additionally, an effort should be made to articulate within the framework the more affective antecedents of trust as something that is vital to effective leadership. Work with the phrase "Personal Regard for Others" is one suggestion. This phrase describes many of the more affective antecedents, with small adjustments. Because there is a research base, because the scope of the phrase itself captures many aspects of the more affective antecedents, it could provide terminology that brings the affective to the rest of the framework, which in its current iteration primarily addresses the antecedent of Competence and, to a lesser degree, Openness and Consistency/Reliability.

Becoming an effective school principal begins to take shape in the "making conscious” process. A detailed explanation of “making conscious” processes exists among several education theorists, but is particularly clearly outlined in music education by Zoltan 
Kodaly. Kodaly outlines a process for (musical) development, from initial sound production to competence as involving: preparation (exposure); making conscious; reinforcement; practice; new creation (Choksy, 1981). It is not strict mastery learning, unlike a Suzuki method, rather, very specific skills are learned without the student knowing what the new skill or technique is. It is learned in the context of music production. Once learned to a zone of proximal development, the student is told specifically what the new is. The teacher then insures further development of the skill through repeated but varied exposure, and the new becomes old as it is reinforced. Finally, it is incorporated into the student's musical repertoire, neither a significant nor an insignificant part of the musician, simply a part of who the musician is. It is a variation on the theme of constructivism.

This, translated into leadership practices, would serve as one excellent model for leadership development. If part of a superintendent or director's repertoire of conversation, consciously, would lead principals to an understanding of what really matters in their school, how their actions effect change, and how to apply creativity in the face of mountains of politics and policy, this would be helpful. Building a leader involves much more than a course or two. It involves exposure to excellent models, a developmental sequencing of skills, conscious practice, and a clear, articulated knowledge of what excellence looks like when it is achieved.

What matters to teachers in terms of leadership is also a significant part of what matters in school effectiveness. What matters, why it matters and the variety of ways this might look when performed by excellent principals is possible. This should be done not only for school principals but also for those who support school principals, including curriculum consultants, external resource staff, and most importantly, school superintendents and directors of education. Policies need to create the space for the multiplicity of needs and purposes that are inherent in public education. Airlines always instruct passengers to "put on your own oxygen mask before you help your child with theirs.” This approach may need to be adapted, and applied, in education. That is how we serve the public's interest. That is in the best interests of the students. And, according to Bryk and Schneider, results from their significant Chicago Schools study indicate it is also highly significant when considering strategies to improve test scores. 


\section{Limitations}

Both teachers and principals commented about competence, and both commented in similar ways. This may mean, and likely does mean, competence in leadership matters a great deal in schools. It may also mean, however, that teachers and principals recognize what competence means in schools, and have rehearsed patterns for expressing what competence means.

The interviews did not provide support for discussing multiple and varied antecedents of trust, as the interviews were not expressly about trust. Had they been structured to "ease" people into these conversations, or had questions focused more on details that might "open the door," there may have been information provided. One question like this might have been When you disagree with the direction the principal is taking for a program or issues involving a child, parent, colleague or yourself in the school, are you silent or do you tell them? What helps you make this decision? Trust hardly ever is assured or even recognized as a factor in moments of agreement. It is nearly always a factor when there isn't agreement, particularly when there is hierarchy and positional authority.

There were many characteristics not held constant in the people and the schools. A host of identity markers related to both teacher and principal may affect trust including, but not limited to years experience, cultural norms and expectations and educational background of the teacher and/or principal. Additionally, the size of school, grades at the school, district culture, and many other community variables may matter.

Despite the limitations, this study has done what others have called for, that is; it has done a backwards mapping from interviews not expressly about trust to determine if people identify trust and its antecedents in their conversation. We can say, quite conclusively, they do. What matters, how much it matters, when or why it matters, that all needs to be researched. Both teachers and principals identify antecedents of trust. They identify some antecedents more frequently than others. This identification seems to relate, in a general sense, to the level of trust identified in the school on a survey. 


\section{References}

Auerbach, C., \& Silverstein, L.B. (2003). Qualitative data: An introduction to coding and analysis. New York: New York University Press.

Baier, A. (1986). Trust and antitrust. Ethics, 96, 231-260.

Bies, R.J., \& Tripp, T.M. (1996). Beyond distrust: “Getting even” and the need for revenge. In R. Kramer \& T. Tyler (Eds.) Trust in organizations: Frontiers of theory and research. Thousand Oaks: Sage Publications. 246-260.

Bigley, G.A., Pearce, J.L. (1998). Straining for shared meaning in organization science: Problems of trust and distrust. The Academy of Management Review, 23 (3),405-421.

Black, S. (2001). Morale matters: When teachers feel good about their work, research shows, student achievement rises. American School Board Journal, 188(1), 40-43.

Braithwaite V., \& Levi, M. (Eds.) (1998). Trust and Governance. New York: Russell Sage.

Brockner J., Siegel, P. \& Daly, J.P. et al. (1997). When trust matters: The moderating effect of outcome favorability. Administrative Science Quarterly, 42(3), 558-583.

Brockner, J., \& Wiesenfeld, B. (1996). An integrative framework for explaining reactions to decisions: The interactive effects of outcomes and procedures. Psychological Bulletin, 120, 189-208.

Brown, A. F. (2005). Consolidated Ontario Education Statues and Regulations. Toronto: Thomson/Carswell.

Bryk, A. S., \& Schneider, B. (2002). Trust in schools: A core resource for improvement. New York: Russell Sage.

Buber, M. (1923). I and Thou. trans. Ronald Gregor Smith. New York: Scribner Classics, 2000.

Butler, J.K. Jr. 1991. Toward understanding and measuring conditions of trust: Evolution of a conditions of trust inventory. Journal of Management, 17, 643-663.

Choksy, L. (1981). The Kodaly context: Creating an environment for musical learning. Englewood Cliffs, New Jersey: Prentice- Hall Inc.

Cosner, S. (2009). Building organizational capacity through trust. Educational Administration Quarterly, 45, 248-291.

Covey, S.M.R. (2006). The speed of trust: The one thing that changes everything. New York: Free Press. 
Craswell, R. (1993). On the uses of "trust": Comment on Williamson, "Calculativeness, Trust and Economic Organization”. Journal of Law and Economics, 36 (1)(2), 487-500.

Cropper, W. H. (2004). Great physicists: The life and times of leading physicists from Galileo to Hawking. North Carolina: Oxford University Press.

Davis, S. H., \& Hensley, P.A. (1999). The politics of principal evaluation. Journal of Personnel Evaluation in Education, 13(4), 383-403

Dirks, K. T. (2000). Trust in leadership and team performance: Evidence from NCAA basketball. Journal of Applied Psychology, 85(6), 1004 - 1012.

Dirks, K.T., \& Ferrin, D.L. (2002). Trust in leadership: Meta-analytic findings and implications for research and practice. Journal of Applied Psychology, 87(4), 611-628.

Dooley, R. S., \& Fryxell, G.E. (1999). Attaining decision quality and commitment from dissent: The moderating effects of loyalty and competence in strategic decision-making teams. Academy of Management Journal, 42(4), 389 - 402.

Education Relations Commission. (1992). Hornepayne Board of Education and O.S.S.T.F., E.R.C. 456

Ellis, K., Shockley, \& Zabalek, P. (2001). Trust in top management and immediate supervisor: The relationship to satisfaction, perceived organizational effectiveness and information receiving. Communication Quarterly, 49(4), 382-398.

Epictetus. The art of living: The classical manual on virtue, happiness, and effectiveness. Interpreted by S. Lebell. (1994). San Francisco: Harper Collins.

Flores, F., \& Solomon, R.C. (1998). Creating trust. Business Ethics Quarterly, 8(2), 205-232.

Field, A. (2008). Managing your solid citizens. Harvard Management Update, 13(9), 1-3.

Fink, A. (2006). How to conduct surveys: A step by step guide, third edition. Thousand Oaks: Sage Publications.

Fullan, M. (2001). The new meaning of educational change, third edition. New York: Teachers College Press.

Fauconnier, G. (2005). Cognitive linguistics. in L. Nadel (Ed), Encyclopedia of cognitive science. New York: Wiley.

Fukuyama, F. (1995). Trust: The social virtues and the creation of prosperity. Toronto: Simon and Schuster.

Gabarro, J. (1979). Socialization at the top: How CEOs and subordinates evolve interpersonal contracts. Organizational Dynamics, Winter, 3-23. 
Glass, G.V., \& Hopkins, K. D. (1996). Statistical methods in education and psychology, third edition.Toronto: Allyn and Bacon.

Greenfield, T. (1984). Leaders in schools: Willfulness and nonnatural order in organizations. in T.J. Sergiovanni: Strengthening the heartbeat: Leading and learning together in schools. San Francisco: Jossey-Bass, 2005.

Gambetta, D. (1988). Can we trust trust? In D. Gambetta (Ed.), Trust: Making and breaking cooperative relations (p.213-237). Oxford, UK: Basil Blackwell.

Gambetta, D., \& Hamill H. (2005). Streetwise: How taxi drivers establish their customers' trustworthiness. New York: Russell Sage.

Gill, H., Boies, K., Finegan, J., \& McNally, J. (2005). Antecedents of Trust: Establishing a Boundary Condition for the Relation Between Propensity to Trust and Intention to Trust. Journal of Business and Psychology, 19(3), 287-302.

Goddard, R. D., Salloum, S.J., \& Berebitsky. (2009). Trust as a mediator of the relationships between poverty, racial composition, and academic achievement: Evidence from Michigan’s public elementary schools. Educational Administration Quarterly, 45, 292 311.

Hardin, R. (2003). Trust and trustworthiness. New York: Russell Sage.

Hardin, R. (1998). Trust in government. In V. Braithwaite and M. Levi (Eds.) Trust and governance. New York: Russell Sage.

Heifetz, R.A., \& Linsky, M. (2002). Leadership on the line. Boston: Harvard Business School Press.

Hosmer, L.T. (1995). The connecting link between organizational theory and philosophical ethics. Academy of Management Review, 20(2), 379-403.

Hoy,W.K., Tarter, \& Witkoskie, (1992). Faculty trust in colleagues: Linking the Principal with school effectiveness. Journal of Research and Development in Education, 26(1).

Hoy, W.K., \& Sweetland, S.R. (2001). Designing better schools: The meaning and nature of enabling school structure. Educational Administration Quarterly, 37, 296-321.

Hoy, W.K., \& Tschannen-Moran, M. (1999). Five faces of trust: An empirical confirmation in urban elementary schools. Journal of School Leadership, 9, 184-208.

Hoyle, J. \& Skrla, L. (1999). The politics of superintendent evaluation. Journal of Personnel Evaluation in Education, 13(4), 405-419. 
Johnson, J.P., Korsgaard, M.A., \& Sapienza, H.J. (2002). Perceived fairness, decision control and commitment in international joint venture management teams. Strategic Management Journal, 23(12), 1141 - 1157.

Kochanek, J.R. (2005). Building trust for better schools: Research-based practices. Thousand Oaks, California: Corwin Press.

Kollock, P. (1994). The emergence of exchange structures: An experimental study of uncertainty, commitment and trust. The American Journal of Sociology, 100(2), 313-345.

Konovsky, M. A., \& Pugh, S. D. (1994). Citizenship behavior and social exchange. Academy of Management Journal, 37(3), 656 - 669.

Korsgaard, M.A., Brodt, S.E., \& Whitener, E.M. (2002). Trust in the face of conflict: The role of managerial trustworthy behavior and organizational context. Journal of Applied Psychology, 87(2), 312-319.

Korsgaard, M.A., Schweiger, D.M. and Sapienza, H.J. (1995). Building commitment, attachment, and trust in strategic decision-making teams: the role of procedural justice, Academy of Management Journal, 38(1), 60-84.

Kosfeld, M., Heinrichs, M., Zak, P., Fischbacher, U., Fehr, E. 2005. Oxytocin increases trust in humans. Nature, 435, 673-676.

Kouzes, J.M., \& Pozner, B.Z. (1987). The leadership challenge. San Francisco: Jossey-Bass.

Kramer, R.M. (2003). The harder they fall. Harvard Business Review, 81, 58-66.

Lapidot, Y., Kark, R., \& Shamir, B. (2007). The impact of situational vulnerability on the development and erosion of followers' trust in their leader. Leadership Quarterly, 18, 1634.

Leithwood, K., Anderson, S., Mascall, B. (2010). How leaders influence student learning: The four paths. In T. Bush and D. Middlewood (Eds.). The principles of educational leadership and management. London: Sage Publishers

Leithwood, K. Louis, K.S., Anderson, S., \&Wahlstrom, K. (2004). How leadership influences student learning. New York: The Wallace Foundation.

Leithwood, K., Jantzi, D., \& Steinbach, R. (1999). Changing leadership for changing times. Maidenhead: Open University Press.

Lewicki, R., \& Bunker, B. (1996). Developing and maintaining trust in work relationships. In R.M. Kramer \& T. Tyler (Eds.), Trust in organizations: Frontiers of theory and research. Newbury Park, CA: Russell Sage. 
Lewicki, R., McAllister, D., \& Bies, R. (1998). Trust and distrust: New relationships and realities. Academy of Management Review, 23(3), 438-458.

Lines, R., \& Selart, M. et al. (2005). The production of trust during organizational change. Journal of Change Management, 5(2), 221-245.

Louis, K.S., Leithwood, K., Wahlstrom, K., Anderson, S. (2010). Learning from Leadership: Investigating the links to improved student learning. New York: Final report of Research, The Wallace Foundation.

Luhmann, N. (1979). Trust and power. John Wiley and Sons Ltd., Toronto.

Mayer, R., Davis, J., \& Schoorman, F.D. (1995). An integrative model of organizational trust. The Academy of Management Review, 20(3), 709-734.

McAllister, D. (1995). Affect- and cognition- based trust as foundations for interpersonal cooperation in organizations. Academy of Management Journal, 38(1), 24-59.

Meier, D. (2002). In schools we trust: Creating communities of learning in an era of testing and standardization. Boston, Massachusetts: Beacon Press.

Merriam, S.B. (1998). Qualitative Research and Case Study Applications in Education: Revised and Expanded from Case Study Research in Education. San Francisco: JosseyBass.

Mishra, A.K. (1996). Organizational responses to crisis: The centrality of trust. In R.M. Kramer and T. Tyler (Eds.), Trust in organizations: Frontiers of theory and research. Newbury Park, CA: Russell Sage, p. 261-287.

Mollering, G. (2001). The nature of trust: From Georg Simmel to a theory of expectation, interpretation and suspension. Sociology, 35(2), 403-420.

Moss, P.A., \& Phillips, D.C., et.al. (2009). Learning from our differences: A dialogue across perspective on quality in education research. Educational Researcher, 38(7), 501-517.

Noddings, N. (1992). The challenge to care in schools: An alternative approach to education. New York: Teachers College Press.

Ostrom, E., \& Walker, J. (Eds.) (2003). Trust and reciprocity: Interdisciplinary lessons from experimental research. New York: Russell Sage.

Palmer, P. 2000. Let your life speak.

Parayitam, S., \& Dooley, R. (2007). The relationship between conflict and decision outcomes: Moderating effects of cognitive- and affect- based trust in strategic decisionmaking teams. International Journal of Conflict Management, 18(1), 42-73. 
Pillai, R., Schreisheim, C. \& Williams, E. (1999). Fairness perceptions and trust as mediators for transformational and transactional leadership: A two-study sample. Journal of Management, 25, 897-933.

Podsakoff, P.M., Mackenzie, S.B, Moorman, R.H., \& Fetter, R. (1990). Transformational leader behaviors and their effects on followers' trust in leader, satisfaction, and organizational citizenship behaviours. Leadership Quarterly, 1(2), 107-142.

Putnam, R.D. (2000). Bowling alone: The collapse and revival of American community. New York: Simon and Schuster.

Reina, D.S., \& Reina, M.L. (1999). Trust and betrayal in the workplace: Building effective relationships in your organization. San Francisco: Berrett-Koehler.

Richardson, (1958). An introduction to the theology of the New Testament. SCM Press, Ltd.

Robinson, S. L. (1996). Trust and breach of the psychological contract. Administrative Science Quarterly, 41(4), 574-599.

Rousseau, M.T., Sitkin, S.B., Burt, S.B. and Camerer, C. 1998. Not so different after all: across-discipline view of trust. Academy of Management Review, 23(3), 393-404.

Seidman, I. (2006). Interviewing as qualitative research: A guide for researchers in education and the social sciences, third edition. New York: Teachers College Press.

Sergiovanni, T.J. (2004). Strengthening the heartbeat: Leading and learning together in schools. San Francisco: JosseyBass.

Shaw, R.B. (1997). Trust in the balance: Building successful organizations on results, integrity, and concern. San Francisco: JosseyBass.

Simons, T. (1999). Behavioural integrity as a critical ingredient for transformational leadership. Journal of Organizational Change, 12(2), 89-104.

Simons, T. (2002). Behavioral integrity: The perceived alignment between managers’ words and deeds as a research focus. Organization Science, Jan/Feb, 18-35.

Smith, E. B. (1975). Chester Barnard's concept of authority. Educational Administration Quarterly, 11(1), 21-37.

Solomon, R.C., Flores, F. (2001). Building trust in business, politics, relationships and life. New York: Oxford University Press.

Strickland, L.H. (1958). Surveillance and trust. Journal of Personality, 26, 200-215.

Supreme Court of Canada Reports. (1996). Ross v. New Brunswick School District No. 15. 1 S.C.R.825, Docket 24002. 
Supreme Court of Canada Reports. (1986). R. v. Jones. 1 S.C.R. 284, Docket 18962.

Supreme Court of Canada Reports. (1997).Toronto (City) Board of Education v. O.S.S.T.F., District 15. 1 S.C.R. 487, Docket 24724.

Supreme Court of Canada Reports. (2001). Trinity Western University v. British Columbia College of Teachers, 1 S.C.R. 772, Docket 27168.

Stouten, J. and Tripp, T. 2009. Claiming more than equality: Should leaders ask for forgiveness? The Leadership Quarterly, 20, 287-298.

Tschannen-Moran, M. (2004). Trust matters: Leadership for successful schools. San Francisco: JosseyBass.

Vanier, Jean. (1998). Becoming human. Toronto: Anansi Press.

Webb, E.J. (1996). Trust and crisis. In R.M. Kramer and T. Tyler (Eds.), Trust in organizations: Frontiers of theory and research. Newbury Park, CA: Russell Sage, p. 288-301.

Williamson, O. E. (1979). Transaction-cost economics: The governance of contractual relations. Journal of Law and Economics, 22 (2), 233-261.

Williamson, O.E. (1993). Calculativeness, trust and economic organization. Journal of Law and Economics, 34: 453-502.

Williamson, O.E. (1996). The mechanisms of governance. New York: Oxford University Press.

Yukl, G.A. (1998). Leadership in organizations, fourth edition. Englewood Cliffs, NJ. Prentice-Hall.

Yukl, G.A. (1989). Managerial leadership: A review of theory and research. Yearly Review of Management, 15, 251-289.

Zand, D. E. (1997). The leadership triad: Knowledge, trust and power. New York: Oxford University Press. 


\section{Appendix A}

\section{Teacher Interview Questions}

1. What is your name? What grade do you teach?

2. How many years have you been teaching?

3. How many years at this school?

4. Is there anything that you would like to highlight about the lesson that I just observed? Was it a typical lesson?

5. What role does your principal play in guiding and supporting your work in the classroom?

6. How often does she observe or visit your classroom?

7. What kinds of feedback or suggestions does she give you to help you with your instruction?

8. Would you say then that her observations and comments and evaluations are helpful to you in forming your practice?

9. Are there other professional development opportunities that have come along recently?

10. Where do you get your ideas for improving education?

11. What student needs does your school do a particularly good job addressing?

12. Do you think there are student learning needs that are not being addressed by the school?

13. How does your school use student performance data?

14. What supports are in place to help with interpreting or using that data?

15. Grade level or department meetings. You said that you have them once a month?

16. What do you talk about at those meetings?

17. When is the last time you had any interaction on the district level? What was that about?

18. What leadership roles do you and other teachers have in the school?

19. What about parent engagement?

20. How is the disciplinary school climate? Do you have a discipline code or?

21. If a new or perspective teacher came into the building today and asked you these questions, what would you say? First one is: Is this a collaborative environment?

22. Do you think teachers feel valued here?

23. Would you characterize this as a trusting environment? 


\section{Appendix B \\ Principal Interview Questions}

1. How many years have you been at the school as principal?

2. Can you give me some examples of specific actions you have taken this year that you think contribute directly or indirectly to improving teaching and learning?

3. Have there been any new initiatives from the District that you have had to work with?

4. How about influences from the state. Other than the accountability you mentioned. Is there anything?

5. Does the district have a curriculum?

6. Every year, what percentage do think, from this school, moves on?

7. What kind of professional development have you offered teachers this year?

8. What's happened either from you or the district related to improving teacher skills?

9. What are two main sources for your teachers to get ideas for improving instruction?

10. Are there any instructional strategies or programs that you encourage teachers to use in particular?

11. Tell me about the last time you visited a classroom and why was that?

12. Do you do formal observations?

13. When was the last time you got state data on student performance?

- What form did you get it in?

- How did you use it?

14. Does the district office have any comments on the state?

15. Has the district offered any in-service or any kind of help with working with data? Like interpreting?

16. Who do you interact with at the district office regularly?

17. Do you have people that you're accountable to?

18. Can you describe an occasion in the last year that added something to your leadership capacity?

19. What was the last occasion when principals met together as a group with district leadership. Now, has there been another occasion where it's everybody?

20. How do new principals coming into the system get helped out?

- What about assistant principals?

21. Are there leadership roles that are filled by teachers in the school?

- How do you develop, or what is being done to develop teacher capacity to take on leadership roles?

22. Can you describe a specific incident or action that you have taken this year that had to do with building trust between you and teachers either individually or as a group? This is a two-pronged question. One is you and the teachers building trust. The other one is building trust between teachers.

23. What is the community like around here and what has been the historic relationship with the school?

24. What are your expectations for parent engagement in support of student learning?

- Are there any other current school initiatives that depend on parent involvement to succeed?

- How do you explain state initiatives to parents, testing and all of that?

25. If you had to choose just one issue, what do you think is the biggest issue facing the principalship? 


\section{Appendix C}

Data Verification: Comparison

\begin{tabular}{|c|c|c|}
\hline Antecedent and Element & Text Selected by Validator & Text Selected by Author \\
\hline \multicolumn{3}{|l|}{ Benevolence } \\
\hline Expressing appreciation & $\begin{array}{l}\text { she gives us feedback, that we are } \\
\text { doing a great job }\end{array}$ & $\begin{array}{l}\text { She gives us feedback, that we are } \\
\text { doing a great job. }\end{array}$ \\
\hline Extending good will & $\begin{array}{l}\text { I've always heard people say that } \\
\text { they went in our school and felt } \\
\text { so comfortable and so warm. }\end{array}$ & \\
\hline \multicolumn{3}{|l|}{ Positive intentions } \\
\hline \multirow[t]{2}{*}{ Supporting teachers } & $\begin{array}{l}\text { The technology kind of scares me } \\
\text { a little bit but she is very } \\
\text { encouraging. Oh, try it, you'll } \\
\text { get it. She's very positive with } \\
\text { that. She is very affirming and } \\
\text { she will tell you that you are } \\
\text { doing a great job on the lesson. }\end{array}$ & $\begin{array}{l}\text { She tells us to integrate more } \\
\text { technology. The technology kind of } \\
\text { scares me a little bit but she is very } \\
\text { encouraging. Oh try it. You'll get it. } \\
\text { She's very positive with that. She is } \\
\text { very affirming and she will tell you that } \\
\text { you are doing a great job on the lesson. } \\
\text { She always seems to know what you } \\
\text { are doing. }\end{array}$ \\
\hline & $\begin{array}{l}\text { I: Do teachers feel valued here? } \\
\text { R: Yes. Our principal and vice- } \\
\text { principal, you can poke your head } \\
\text { in their door all the time. They } \\
\text { are always asking what is going } \\
\text { on. Everybody knows everybody } \\
\text { and everybody is all together. }\end{array}$ & \\
\hline \multicolumn{3}{|l|}{ Caring } \\
\hline \multicolumn{3}{|l|}{ Direct, intentional, face to face } \\
\hline \multirow[t]{2}{*}{$\begin{array}{l}\text { Personally chosen, not directly } \\
\text { rewarded }\end{array}$} & \multirow{2}{*}{$\begin{array}{l}\text { I think my school is very good at } \\
\text { just taking care and loving the } \\
\text { children here. One of the things } \\
\text { that we provide the students with } \\
\text { is homework haven. That is a } \\
\text { program we have in the morning, } \\
\text { where as soon as the children get } \\
\text { off the bus and eat breakfast, they } \\
\text { can come to homework haven. }\end{array}$} & $\begin{array}{l}\text { I think my school is very good at just } \\
\text { taking care and loving the children } \\
\text { here. }\end{array}$ \\
\hline & & $\begin{array}{l}\text { One of the things that we provide the } \\
\text { students with is homework haven...It's } \\
\text { just a little something extra in the } \\
\text { morning just to kind of get their day } \\
\text { going. }\end{array}$ \\
\hline \multicolumn{3}{|l|}{$\begin{array}{l}\text { Behaviour oriented towards a } \\
\text { specific situation and person, } \\
\text { sometimes toughness }\end{array}$} \\
\hline $\begin{array}{l}\text { Behaviour oriented towards a } \\
\text { specific situation and person, } \\
\text { sometimes tenderness }\end{array}$ & & \\
\hline
\end{tabular}




\begin{tabular}{|c|c|c|}
\hline Antecedent and Element & Text Selected by Validator & Text Selected by Author \\
\hline \multicolumn{3}{|l|}{ Competence } \\
\hline \multirow[t]{4}{*}{ Functional, work related skills } & $\begin{array}{l}\text { She always seems to know what } \\
\text { you are doing. At the beginning } \\
\text { of the year, she came up to me } \\
\text { and she goes "Do you have any } \\
\text { M and M's?” I said "Yeah, I do. } \\
\text { How do you know I did?" She } \\
\text { said "Well, I saw in your lesson } \\
\text { plan that you are doing an M and } \\
\text { M graph. } \\
\text { She always seems to know what } \\
\text { is going on with everybody. It's } \\
\text { wonderful. }\end{array}$ & $\begin{array}{l}\text { At the beginning of the year, she came } \\
\text { up to me and she goes “Do you have } \\
\text { any M and M's? I said "Yeah, I do. } \\
\text { How do you know I did?” She said } \\
\text { "Well, I saw in your lesson plan that } \\
\text { you are doing an M and M graph. One } \\
\text { of the kindergartners came in and } \\
\text { needed M and M's for something. Do } \\
\text { you have some?” I was like "Sure”. She } \\
\text { always seems to know what is going on } \\
\text { with everybody. It's wonderful. She } \\
\text { always seems to know what you are } \\
\text { doing. }\end{array}$ \\
\hline & $\begin{array}{l}\text { I mean she may remind you a } \\
\text { little bit about your k-2 } \\
\text { assessments, but actually today } \\
\text { there is an assessment meeting } \\
\text { for just first grade to explain in } \\
\text { detail, this is the new part of the } \\
\text { assessment in phonics. We want } \\
\text { to make sure that you guys have } \\
\text { all the pieces you need. }\end{array}$ & \\
\hline & $\begin{array}{l}\text { They just check in to see if we } \\
\text { have any questions or our team } \\
\text { has any questions or if our team } \\
\text { has any questions. }\end{array}$ & $\begin{array}{l}\text { They just check in to see if we have } \\
\text { any questions or our team has any } \\
\text { questions or if our team has any } \\
\text { questions. }\end{array}$ \\
\hline & $\begin{array}{l}\text { We turn our lesson plans in to her } \\
\text { on Monday. She reviews our } \\
\text { lesson plans. }\end{array}$ & $\begin{array}{l}\text { We turn our lesson plans in to her on } \\
\text { Monday. She reviews our lesson } \\
\text { plans. }\end{array}$ \\
\hline \multirow[t]{3}{*}{ Setting an example } & \multirow{3}{*}{$\begin{array}{l}\text { In the grade level team meetings, } \\
\text { we have a chair who kind of takes } \\
\text { our questions and if our team has } \\
\text { any questions. In the grade level } \\
\text { meetings, we have grade chair } \\
\text { who kind of takes our questions } \\
\text { and kind of keeps them even if he } \\
\text { can’t answer them. He may take } \\
\text { them to Ms. H or to this meeting } \\
\text { today and say... }\end{array}$} & $\begin{array}{l}\text { They just check in to see if we have } \\
\text { any questions or if our team has any } \\
\text { questions }\end{array}$ \\
\hline & & \\
\hline & & $\begin{array}{l}\text { Probably not so much at a staff } \\
\text { meeting. I mean she may remind you a } \\
\text { little bit about your K-2 assessments, } \\
\text { but actually today there is an } \\
\text { assessment meeting for just first grade } \\
\text { to explain in detail, this is the new part } \\
\text { of the assessment in phonics. We want } \\
\text { to make sure you guys have all the } \\
\text { pieces you need. }\end{array}$ \\
\hline
\end{tabular}




\begin{tabular}{|c|c|c|}
\hline Antecedent and Element & Text Selected by Validator & Text Selected by Author \\
\hline \multirow[t]{2}{*}{$\begin{array}{l}\text { Working hard, pressing for } \\
\text { results, setting standards }\end{array}$} & $\begin{array}{l}\text { She tells us to integrate more } \\
\text { technology }\end{array}$ & \\
\hline & $\begin{array}{l}\text { She said she had thought of } \\
\text { something that would be really } \\
\text { cool. She was saying that the } \\
\text { teacher had some number cards } \\
\text { laid out in number order...so they } \\
\text { are always giving suggestions. I } \\
\text { found a new one. I saw this. } \\
\text { That sounds like something you } \\
\text { would like. She is very helpful } \\
\text { doing that. }\end{array}$ & \\
\hline \multicolumn{3}{|l|}{ Some aspects of buffering } \\
\hline \multicolumn{3}{|l|}{ Problem solving } \\
\hline \multirow[t]{2}{*}{$\begin{array}{l}\text { Fostering conflict resolution } \\
\text { (rather than avoidance) }\end{array}$} & $\begin{array}{l}\text { Ms. H and Ms. G have very } \\
\text { strong beliefs and very high } \\
\text { expectations on what student } \\
\text { behaviour is like. "I'm with them } \\
\text { on the very first day and I'm like } \\
\text { "Oh my God. I had to call nine } \\
\text { parents. I've not had this in five } \\
\text { years. What do I do?" She gave } \\
\text { me a book this thick on behaviour } \\
\text { and different strategies to deal } \\
\text { with it. She's like "I'm here for } \\
\text { whatever you need.” }\end{array}$ & $\begin{array}{l}\text { Very strong. Ms. H and Ms. G have } \\
\text { very strong beliefs and very high } \\
\text { expectations on what student behaviour } \\
\text { is like...This year, I've had quite a bit } \\
\text { of behaviour in my room that I haven't } \\
\text { had to address before. I'm with them on } \\
\text { the very first day and I'm like "Oh my } \\
\text { God. I had to call nine parents. I've not } \\
\text { had this in five years. What do I do?” } \\
\text { She gave me a book this thick on } \\
\text { behaviour and different strategies to } \\
\text { deal with it. She's like "I'm here for } \\
\text { whatever you need.” Some got better } \\
\text { and I've had a couple situations where } \\
\text { one kid's been suspended like six times } \\
\text { this year. They feel like the student is } \\
\text { not going to do that. This is going to } \\
\text { get taken care of. He's going home. } \\
\text { They back you up if there is a problem } \\
\text { with parents. What happened? This is } \\
\text { what happened. Let's get it straightened } \\
\text { out. They are very strong in their } \\
\text { expectations with us and the children. }\end{array}$ \\
\hline & $\begin{array}{l}\text { They back you up if there is a } \\
\text { problem with the parents. What } \\
\text { happened? This is what } \\
\text { happened. Let's get it } \\
\text { straightened out }\end{array}$ & \\
\hline \multicolumn{3}{|l|}{ Handling difficult situations } \\
\hline Being flexible & $\begin{array}{l}\text { There are always opportunities } \\
\text { that we can kind of look towards } \\
\text { each other or go places, go to } \\
\text { meetings, share ideas with others. }\end{array}$ & $\begin{array}{l}\text { Ms. H is always giving us } \\
\text { opportunities. There is a meeting here. } \\
\text { Who would like to go? Myself, a } \\
\text { kindergarten teacher and two third } \\
\text { grade teachers just came back from (a } \\
\text { town) a couple of weeks ago. We went } \\
\text { to a dual language conference in (a } \\
\text { town). There are always opportunities } \\
\text { that we can kind of look towards each } \\
\text { other or go places, go to meetings, } \\
\text { share ideas with others. }\end{array}$ \\
\hline
\end{tabular}




\begin{tabular}{|c|c|c|}
\hline Antecedent and Element & Text Selected by Validator & Text Selected by Author \\
\hline \multicolumn{3}{|c|}{ Consistency and Reliability } \\
\hline \multirow[t]{7}{*}{ Having consistency } & $\begin{array}{l}\text { We turn our lesson plans in to her } \\
\text { on Monday. She reviews our } \\
\text { lesson plans. }\end{array}$ & $\begin{array}{l}\text { We turn our lesson plans in to her on } \\
\text { Monday. She reviews our lesson plans. }\end{array}$ \\
\hline & $\begin{array}{l}\text { She makes sure that we are } \\
\text { integrating everything that we } \\
\text { need to with technology, cultural } \\
\text { arts and global studies }\end{array}$ & $\begin{array}{l}\text { She makes sure that we are integrating } \\
\text { everything that we need to with } \\
\text { technology, cultural arts and global } \\
\text { studies. }\end{array}$ \\
\hline & & $\begin{array}{l}\text { She gives us feedback, that we are } \\
\text { doing a great job. }\end{array}$ \\
\hline & $\begin{array}{l}\text { Throughout the week, emails. } \\
\text { Little notes in our boxes. It was } \\
\text { like you have a great lesson plan. } \\
\text { Just things like that. She may not } \\
\text { say anything about your lesson } \\
\text { plans this week, but she may say } \\
\text { something next week. }\end{array}$ & $\begin{array}{l}\text { I: So you give it to her on Monday and } \\
\text { when do you get the feedback? } \\
\text { R: Throughout the week, e-mails. Little } \\
\text { notes in our boxes...she may not say } \\
\text { anything about your lesson plans this } \\
\text { week, but she may say something next } \\
\text { week. }\end{array}$ \\
\hline & & $\begin{array}{l}\text { They poke in regularly to check on the } \\
\text { children just to see what's going on, to } \\
\text { ask questions if they need to. They will } \\
\text { stay in. They may sit down and } \\
\text { observe a lesson or just sit down for a } \\
\text { few minutes. Probably at least once or } \\
\text { twice a week she is in and out of the } \\
\text { room for something. }\end{array}$ \\
\hline & & $\begin{array}{l}\text { I: Does your school have a specific } \\
\text { code? } \\
\text { R: Just positive behaviour } \\
\text { management... }\end{array}$ \\
\hline & & $\begin{array}{l}\text { I can write them up and then that is } \\
\text { when Ms. H and Ms. G will kind of } \\
\text { review what went on. Then if they get } \\
\text { suspended or get ISS or something like } \\
\text { that, then they will talk with them about } \\
\text { that or something more will come of it. } \\
\text { If it's a situation, where there is } \\
\text { harsher, a bigger deal than something I } \\
\text { can just kind of catch and stop. }\end{array}$ \\
\hline
\end{tabular}




\begin{tabular}{|c|c|c|}
\hline Antecedent and Element & Text Selected by Validator & Text Selected by Author \\
\hline \multirow[t]{2}{*}{ Being dependable } & & $\begin{array}{l}\text { Ms. H and Ms. G have very strong } \\
\text { beliefs and very high expectations on } \\
\text { what student behaviour is like. This } \\
\text { year, I've had quite a bit of behaviour } \\
\text { in my room that I haven't had to } \\
\text { address before. I'm with them on the } \\
\text { very first day and I'm like “Oh my } \\
\text { God. I had to call nine parents. I've not } \\
\text { had this in five years. What do I do?” } \\
\text { She gave me a book this thick on } \\
\text { behaviour and different strategies to } \\
\text { deal with it. She's like “I'm here for } \\
\text { whatever you need.” Some got better } \\
\text { and I've had a couple situations where } \\
\text { one kid's been suspended like six times } \\
\text { this year. They feel like the student is } \\
\text { not going to do that. This is going to } \\
\text { get taken care of. He's going home. } \\
\text { They are not going to have that. They } \\
\text { back you up if there is a problem with } \\
\text { the parents. What happened? This is } \\
\text { what happened. Let's get it straightened } \\
\text { out. } \\
\text { They are very strong in their } \\
\text { expectations with us and the children. }\end{array}$ \\
\hline & $\begin{array}{l}\text { They are very strong in their } \\
\text { expectations with us and the } \\
\text { children }\end{array}$ & $\begin{array}{l}\text { They are very strong in their } \\
\text { expectations with us and the children. }\end{array}$ \\
\hline \multicolumn{3}{|l|}{$\begin{array}{l}\text { Demonstrating commitment, } \\
\text { having dedication }\end{array}$} \\
\hline Being diligent & & $\begin{array}{l}\text { The other day just in talking with her } \\
\text { and she was talking about going to see } \\
\text { a special needs class. }\end{array}$ \\
\hline \multirow[t]{3}{*}{ Tools for uncertainty reduction } & & I: Has it influenced your lessons? \\
\hline & & $\begin{array}{l}\text { R: It has. A lot of times they come in } \\
\text { during reading workshop. They’ve got } \\
\text { our reading lessons and they’ve said } \\
\text { stuff like “I was in another first grade } \\
\text { class and I saw them do a guided } \\
\text { reading.” }\end{array}$ \\
\hline & & $\begin{array}{l}\text { They just check in to see if we have } \\
\text { any questions or if our team has any } \\
\text { questions. }\end{array}$ \\
\hline
\end{tabular}




\begin{tabular}{|c|c|c|}
\hline Antecedent and Element & Text Selected by Validator & Text Selected by Author \\
\hline \multicolumn{3}{|l|}{ Fairness } \\
\hline \multirow[t]{3}{*}{$\begin{array}{l}\text { Just procedures assure people that } \\
\text { a structure exists to protect their } \\
\text { material self-interests in the long- } \\
\text { run }\end{array}$} & & $\begin{array}{l}\text { I: Disciplinary school climate... } \\
\text { R: Very strong. Ms. H and Ms. G have } \\
\text { very strong beliefs and very high } \\
\text { expectations on what student behaviour } \\
\text { is like. } \\
\text { This year, I've had quite a bit of } \\
\text { behaviour in my room that I haven't } \\
\text { had to address before. I'm with them on } \\
\text { the very first day and I'm like “Oh my } \\
\text { God. I had to call nine parents. I've not } \\
\text { had this in five years. What do I do?” } \\
\text { She gave me a book this thick on } \\
\text { behaviour and different strategies to } \\
\text { deal with it. } \\
\text { She's like "I'm here for whatever you } \\
\text { need.” }\end{array}$ \\
\hline & & $\begin{array}{l}\text { Some got better and I've had a couple } \\
\text { situations where one kid's been } \\
\text { suspended like six times this year. } \\
\text { They feel like the student is not going } \\
\text { to do that. This is going to get taken } \\
\text { care of. He's going home. They are not } \\
\text { going to have that. }\end{array}$ \\
\hline & & $\begin{array}{l}\text { They back you up if there is a problem } \\
\text { with the parents. What happened? This } \\
\text { is what happened. Let's get it } \\
\text { straightened out. } \\
\text { They are very strong in their } \\
\text { expectations with us and the children. }\end{array}$ \\
\hline $\begin{array}{l}\text { Fair procedures thus help protect } \\
\text { and strengthen individuals } \\
\text { identification with the group or } \\
\text { organization }\end{array}$ & $\begin{array}{l}\text { I think my school is very good at just } \\
\text { taking care and loving the children } \\
\text { here. One of the things that we } \\
\text { provide the students with is } \\
\text { homework haven...It's just a little } \\
\text { something extra in the morning just } \\
\text { to kind of get their day going. }\end{array}$ & $\begin{array}{l}\text { I think my school is very good at just taking } \\
\text { care and loving the children here. One of } \\
\text { the things that we provide the students with } \\
\text { is homework haven...It's just a little } \\
\text { something extra in the morning just to kind } \\
\text { of get their day going. }\end{array}$ \\
\hline \multicolumn{3}{|l|}{$\begin{array}{l}\text { Intention to enact decisions } \\
\text { properly }\end{array}$} \\
\hline \multicolumn{3}{|l|}{$\begin{array}{l}\text { Very related to accepting an } \\
\text { unfavourable outcome; connected } \\
\text { to integrity }\end{array}$} \\
\hline \multicolumn{3}{|l|}{ Honesty } \\
\hline \multicolumn{3}{|l|}{ Telling the truth } \\
\hline \multicolumn{3}{|l|}{$\begin{array}{l}\text { Keeping promises, honoring } \\
\text { agreements }\end{array}$} \\
\hline \multicolumn{3}{|l|}{$\begin{array}{l}\text { Having authenticity, being real, } \\
\text { being true to oneself, having } \\
\text { integrity }\end{array}$} \\
\hline \multicolumn{3}{|l|}{ Accepting responsibility } \\
\hline Avoiding manipulation & & \\
\hline
\end{tabular}




\begin{tabular}{|c|c|c|}
\hline Antecedent and Element & Text Selected by Validator & Text Selected by Author \\
\hline \multicolumn{3}{|l|}{ Integrity } \\
\hline \multirow[t]{4}{*}{$\begin{array}{l}\text { Moral-ethical perspective guide's } \\
\text { one’s work - in schools: actions } \\
\text { are understood as advancing the } \\
\text { best interests of children }\end{array}$} & & $\begin{array}{l}\text { They poke in regularly to check on the } \\
\text { children just to see what's going on, to } \\
\text { ask questions if they need to. They will } \\
\text { stay in. They may sit down and observe } \\
\text { a lesson or just sit down for a few } \\
\text { minutes. Probably at least once or twice } \\
\text { a week she is in and out of the room for } \\
\text { something. }\end{array}$ \\
\hline & \multirow[t]{2}{*}{$\begin{array}{l}\text { If we are thinking of a particular } \\
\text { idea, as long as Ms. H. says, it's } \\
\text { in the best interests of children, } \\
\text { then she is very, that is her thing. } \\
\text { If you think that this is in the best } \\
\text { interests of your child, then she is } \\
\text { okay with it. As long as you can } \\
\text { make a case or prove that you } \\
\text { think this is the very best thing } \\
\text { for my children, then she will } \\
\text { take your suggestion or whatever. } \\
\text { She will really listen. }\end{array}$} & $\begin{array}{l}\text { If we are thinking of a particular idea, } \\
\text { as long as Ms. H. says, it’s in the best } \\
\text { interests of children, then she is very, } \\
\text { that is her thing. If you think that this is } \\
\text { in the best interests of your child, then } \\
\text { she is okay with it. As long as you can } \\
\text { make a case or prove that you think this } \\
\text { is the very best thing for my children, } \\
\text { then she will take your suggestion or } \\
\text { whatever. She will really listen. }\end{array}$ \\
\hline & & \\
\hline & & $\begin{array}{l}\text { I: Disciplinary school climate... } \\
\text { R: Very strong. Ms. H. and Ms. G. } \\
\text { have very strong beliefs and very high } \\
\text { expectations on what student behaviour } \\
\text { is like. This year, I've had quite a bit of } \\
\text { behaviour in my room that I haven't } \\
\text { had to address before. I'm with them on } \\
\text { the very first day and I'm like “Oh my } \\
\text { God. I had to call nine parents. I've not } \\
\text { had this in five years. What do I do?” } \\
\text { She gave me a book this thick on } \\
\text { behaviour and different strategies to } \\
\text { deal with it. She's like "I'm here for } \\
\text { whatever you need.” Some got better } \\
\text { and I've had a couple situations where } \\
\text { one kid's been suspended like six times } \\
\text { this year. They feel like the student is } \\
\text { not going to do that. This is going to } \\
\text { get taken care of. He's going home. } \\
\text { They are not going to have that. They } \\
\text { back you up if there is a problem with } \\
\text { the parents. What happened? This is } \\
\text { what happened. Let's get it straightened } \\
\text { out. They are very strong in their } \\
\text { expectations with us and the children. }\end{array}$ \\
\hline \multirow[t]{2}{*}{ Modelling } & & $\begin{array}{l}\text { We turn our lesson plans in to her on } \\
\text { Monday. She reviews our lesson plans. }\end{array}$ \\
\hline & & $\begin{array}{l}\text { She makes sure that we are integrating } \\
\text { everything that we need to with } \\
\text { technology, cultural arts and global } \\
\text { studies. She gives us feedback, that we } \\
\text { are doing a great job. }\end{array}$ \\
\hline
\end{tabular}




\begin{tabular}{|c|c|c|}
\hline Antecedent and Element & Text Selected by Validator & Text Selected by Author \\
\hline \multicolumn{3}{|l|}{$\begin{array}{l}\text { Intense staff watchfulness of } \\
\text { leader actions, match between } \\
\text { words and deeds }\end{array}$} \\
\hline \multicolumn{3}{|l|}{ Loyalty } \\
\hline \multicolumn{3}{|l|}{$\begin{array}{l}\text { Seems to encourage a more } \\
\text { complete exploration of ideas as } \\
\text { people can concentrate on the } \\
\text { content and cognitive meaning of } \\
\text { messages }\end{array}$} \\
\hline \multirow[t]{3}{*}{$\begin{array}{l}\text { Means people will be working } \\
\text { towards group goals }\end{array}$} & & $\begin{array}{l}\text { I: Is this environment collaborative? } \\
\text { R: Very. We all work well together. } \\
\text { R: I think it's a very good place to } \\
\text { work. } \\
\text { I: Do teachers feel valued here? } \\
\text { R: Yes. } \\
\text { I: What is it about the school that } \\
\text { makes you feel valued? } \\
\text { R: There is something about our } \\
\text { school. I've never heard anyone come } \\
\text { in and say something negative about } \\
\text { our school. I’ve always heard people } \\
\text { say that they went in our school and felt } \\
\text { so comfortable and so warm. } \\
\text { That is kind of what we want for the } \\
\text { children and for people to come in... }\end{array}$ \\
\hline & & $\begin{array}{l}\text { I did my student teaching in a } \\
\text { wonderful school but it just didn't have } \\
\text { this small kind of inviting feeling } \\
\text { where when you come in it takes you } \\
\text { thirty minutes to get to your room } \\
\text { because you see all these people that } \\
\text { you want to stop and talk to. We are } \\
\text { very much like that. }\end{array}$ \\
\hline & & $\begin{array}{l}\text { Our principal and vice-principal, you } \\
\text { can poke your head in their door all the } \\
\text { time. They are always asking what is } \\
\text { going on. } \\
\text { Everybody knows everybody and } \\
\text { everybody is all together. } \\
\text { I: Would you characterize this as a } \\
\text { trusting environment? } \\
\text { R: Yes. }\end{array}$ \\
\hline $\begin{array}{l}\text { Fears of reprisals or scapegoating } \\
\text { are mitigated }\end{array}$ & & \\
\hline \multicolumn{3}{|l|}{ Openness } \\
\hline $\begin{array}{l}\text { Give and get rapid and direct } \\
\text { disclosure of relevant } \\
\text { information; sharing important } \\
\text { information }\end{array}$ & & \\
\hline
\end{tabular}




\begin{tabular}{|c|c|c|}
\hline Antecedent and Element & Text Selected by Validator & Text Selected by Author \\
\hline \multirow[t]{3}{*}{$\begin{array}{l}\text { Sharing decision making, sharing } \\
\text { power }\end{array}$} & $\begin{array}{l}\text { We get to pretty much vote on } \\
\text { who our grade chairs are }\end{array}$ & \\
\hline & $\begin{array}{l}\text { Ms. } \mathrm{H} \text { is always giving us } \\
\text { opportunities. There is a meeting } \\
\text { here. Who would like to go?” }\end{array}$ & $\begin{array}{l}\text { Ms. } \mathrm{H} \text { is always giving us } \\
\text { opportunities. There is a meeting here. } \\
\text { Who would like to go? }\end{array}$ \\
\hline & $\begin{array}{l}\text { There are always opportunities } \\
\text { that we can kind of look towards } \\
\text { each other or go to places, go to } \\
\text { meetings, share ideas with others. }\end{array}$ & \\
\hline \multirow[t]{3}{*}{$\begin{array}{l}\text { Openness in information means } \\
\text { disclosure of facts, alternatives, } \\
\text { judgments, intentions and } \\
\text { feelings }\end{array}$} & $\begin{array}{l}\text { She might ask us to present } \\
\text { something at the next staff } \\
\text { meeting. You girls that went to } \\
\text { (a town) can tell us about going } \\
\text { to CA. What did they do there } \\
\text { that was different than what we } \\
\text { do here? So it may be something } \\
\text { that we share with the whole staff } \\
\text { during staff meeting. }\end{array}$ & \\
\hline & & $\begin{array}{l}\text { The other day just in talking with her } \\
\text { and she was talking about going to see } \\
\text { a special needs class. She said she had } \\
\text { thought of something that would be } \\
\text { really cool. She was saying that the } \\
\text { teacher had some number cards laid out } \\
\text { in number order. She said that the child } \\
\text { would stand on number three and they } \\
\text { had to do three plus three and they } \\
\text { would have to jump three spaces. She } \\
\text { said she thought that was a cool way of } \\
\text { physically getting them moving around. } \\
\text { I thought that was really good and } \\
\text { wanted it so I could use it for summer } \\
\text { school. So they are always giving } \\
\text { suggestions. I found a new one. I saw } \\
\text { this. That sounds like something you } \\
\text { would like. She is very helpful doing } \\
\text { that. }\end{array}$ \\
\hline & & $\begin{array}{l}\text { I: So the impact model - is the whole } \\
\text { school using the same theme of the } \\
\text { farm? } \\
\text { R:....Everybody is kind of doing their } \\
\text { own thing, but with the help of others. } \\
\text { I: Is this environment collaborative? } \\
\text { R: Very. We all work well together. I } \\
\text { think it's a very good place to } \\
\text { work...There is something about our } \\
\text { school. I've never heard anyone come } \\
\text { in and say something negative about } \\
\text { our school. I've always heard people } \\
\text { say that they went in our school and felt } \\
\text { so comfortable and so warm. That is } \\
\text { kind of what we want for the children } \\
\text { and for people to come in...I did my } \\
\text { student teaching in a wonderful school } \\
\text { but it just didn't have this small kind of }\end{array}$ \\
\hline
\end{tabular}




\begin{tabular}{|c|c|c|}
\hline & & $\begin{array}{l}\text { inviting feeling where when you come } \\
\text { in it takes you thirty minutes to get to } \\
\text { your room because you see all these } \\
\text { people that you want to stop and talk } \\
\text { to. We are very much like that. Our } \\
\text { principal and vice-principal, you can } \\
\text { poke your head in their door all the } \\
\text { time. They are always asking what is } \\
\text { going on. Everybody knows everybody } \\
\text { and everybody is all together. }\end{array}$ \\
\hline Antecedent and Element & Text Selected by Validator & Text Selected by Author \\
\hline $\begin{array}{l}\text { Openness in control accepts } \\
\text { dependence rooted in a } \\
\text { confidence in the reliability of } \\
\text { others and delegation of } \\
\text { important tasks to them }\end{array}$ & & $\begin{array}{l}\text { Ms. H is always giving us } \\
\text { opportunities. There is a meeting here. } \\
\text { Who would like to go? Myself, a } \\
\text { kindergarten teacher and two third } \\
\text { grade teachers just came back from (a } \\
\text { town) a couple of weeks ago. We went } \\
\text { to a dual language conference in (a } \\
\text { town). It was a chance for me...There } \\
\text { are always opportunities that we can } \\
\text { kind of look towards each other or go } \\
\text { places, go to meetings, share ideas with } \\
\text { others. }\end{array}$ \\
\hline $\begin{array}{l}\text { Openness in influence allows } \\
\text { others to initiate change to plans, } \\
\text { goals, concepts, criteria and } \\
\text { resource }\end{array}$ & $\begin{array}{l}\text { If we are thinking of a particular } \\
\text { idea, as long as Ms. H says, it's in } \\
\text { the best interests of the children, } \\
\text { then she is very, that is her thing. } \\
\text { If you think that this is in the best } \\
\text { interests of your child then she is } \\
\text { okay with it. As long as you can } \\
\text { make a case or prove that you } \\
\text { think this is the very thing for my } \\
\text { children, then she will take your } \\
\text { suggestion or whatever. She will } \\
\text { really listen. }\end{array}$ & $\begin{array}{l}\text { I: After you guys go to those } \\
\text { workshops, then how is that? } \\
\text { R: She might ask us to present } \\
\text { something at the next staff meeting. } \\
\text { You girls that went to (a town) can tell } \\
\text { us about going to CA. What did they do } \\
\text { there that was different than what we } \\
\text { do here? So it may be something that } \\
\text { we share with the whole staff during } \\
\text { staff meeting. } \\
\text { I: Can you talk about other ways you } \\
\text { share? } \\
\text { R: We may just go in her office or we } \\
\text { will come in here and say this is what } \\
\text { we've done. What do you think? It may } \\
\text { be something like that or e-mail. } \\
\text { I: How much influence do you have in } \\
\text { making decisions related to improving } \\
\text { student learning? } \\
\text { R: If we are thinking of a particular } \\
\text { idea, as long as Ms. Howard says, it's } \\
\text { in the best interests of children, then } \\
\text { she is very, that is her thing. If you } \\
\text { think that this is in the best interests of } \\
\text { your child, then she is okay with it. As } \\
\text { long as you can make a case or prove } \\
\text { that you think this is the very best thing } \\
\text { for my children, then she will take your } \\
\text { suggestion or whatever. She will really } \\
\text { listen. }\end{array}$ \\
\hline
\end{tabular}




\begin{tabular}{|c|c|c|}
\hline Antecedent and Element & Text Selected by Validator & Text Selected by Author \\
\hline \multicolumn{3}{|c|}{ Personal Regard for Others } \\
\hline \multirow{4}{*}{$\begin{array}{l}\text { Actions taken by a member of a } \\
\text { role set to reduce others sense of } \\
\text { vulnerability }\end{array}$} & & $\begin{array}{l}\text { R: She gives us feedback, that we are } \\
\text { doing a great job. }\end{array}$ \\
\hline & & $\begin{array}{l}\text { The technology kind of scares me a } \\
\text { little bit but she is very encouraging. } \\
\text { Oh try it. You'll get it. She's very } \\
\text { positive with that. }\end{array}$ \\
\hline & & $\begin{array}{l}\text { She is very affirming and she will tell } \\
\text { you that you are doing a great job on } \\
\text { the lesson. }\end{array}$ \\
\hline & & $\begin{array}{l}\text { She always seems to know what you } \\
\text { are doing...She always seems to know } \\
\text { what is going on with everybody. It's } \\
\text { wonderful. }\end{array}$ \\
\hline \multicolumn{3}{|l|}{$\begin{array}{l}\text { Positive expressions of care and } \\
\text { concern }\end{array}$} \\
\hline \multicolumn{3}{|l|}{ Respect } \\
\hline \multicolumn{3}{|l|}{$\begin{array}{l}\text { Involves recognition of the } \\
\text { important role each person plays } \\
\text { in a child's education }\end{array}$} \\
\hline \multirow[t]{3}{*}{$\begin{array}{l}\text { And the mutual dependencies that } \\
\text { exist among various parties } \\
\text { involved in this activity }\end{array}$} & & $\begin{array}{l}\text { I: What role does your principal play in } \\
\text { guiding and supporting your work in } \\
\text { the classroom? } \\
\text { R: She is absolutely fabulous. She is } \\
\text { very respected. } \\
\text { I: So the impact model - is the whole } \\
\text { school using the same theme of the } \\
\text { farm? } \\
\text { R: ...Everybody is kind of doing their } \\
\text { own thing, but with the help of others. }\end{array}$ \\
\hline & & $\begin{array}{l}\text { I: So the impact model - is the whole } \\
\text { school using the same theme of the } \\
\text { farm? } \\
\text { R: ... Everybody is kind of doing their } \\
\text { own thing, but with the help of others. }\end{array}$ \\
\hline & & $\begin{array}{l}\text { I wouldn't work anywhere else. This is } \\
\text { a good place. I wanted to work here } \\
\text { when I graduated from college. I } \\
\text { wanted to work here. That's what I did. } \\
\text { I had heard so many good things about } \\
\text { our principal and I wanted to interview } \\
\text { with her. I did and I've been here ever } \\
\text { since and I love it. I love the teachers } \\
\text { here and just everybody. It's a really } \\
\text { good place. It's everywhere - it's the } \\
\text { library, the cafeteria, everywhere. }\end{array}$ \\
\hline \multicolumn{3}{|l|}{ Vulnerability } \\
\hline $\begin{array}{l}\text { Related to the dependence on the } \\
\text { other person to act with good } \\
\text { intention }\end{array}$ & & \\
\hline
\end{tabular}

